\title{
AN INVESTIGATION OF FOREIGN EXCHANGE RISK MANAGEMENT BY \\ EXPORTING SMALL AND MEDIUM SIZED ENTERPRISES
}

by

Vu Hung Dang

\begin{abstract}
A thesis
submitted to Victoria University of Wellington in fulfilment of the requirements for the degree of Doctor of Philosophy
\end{abstract}

Victoria University of Wellington

2015 


\begin{abstract}
Previous studies on foreign exchange (forex) risk management have tended to focus on multinational enterprises; while how SMEs manage their forex risk is still largely unexplored. As small and medium sized enterprises (SMEs) are increasingly involved in international markets, they have become a new research setting on forex risk management. Given that SMEs have limited access to resources, skills and capabilities, internal hedging techniques could be favoured by SMEs. There is limited research on this matter, and the extant literature on forex management generally considers derivatives as major hedging techniques for large firms. This thesis primarily investigates how exporting SMEs manage forex risk. In addition, approaches to forex management could be changed as a firm becomes more experienced internationally. Following the basic principles of internationalisation theory, the thesis also examines the impact of the internationalisation degree of the firm on forex management decisions.

This thesis sheds new light on SMEs' hedging practices by providing a better understanding of SMEs' choices of forex risk management. Three research questions have been raised: (1) what determinants influence SMEs' choice to hedge as a way of managing forex risk; (2) what strategies do SMEs use when they choose hedging to manage forex exposure; and (3) how does the degree of internationalisation impact the choice of forex management.
\end{abstract}

The thesis draws on two theoretical perspectives to help address these overarching questions. It extends the use of the resource-based view (RBV), and combines this with internationalisation theory. The setting of SMEs is a context for using the RBV. New Zealand and Australian exporting SMEs provide the sample for testing the hypotheses.

The contributions of this thesis are twofold. Firstly, the thesis identifies four determinants of forex risk strategy by exporting SMEs, i.e. degree of internationalisation (specifically, export ratio), forex exposure, perceived forex risk, and resources. Secondly, it extends the use of the RBV and the internationalisation theory in forex risk management of SMEs. In addition, the thesis uses a research approach combining an exploratory qualitative study and a main quantitative study. 


\section{Acknowledgments}

Before I started my PhD degree five years ago, Professor Neil Quigley provided me tremendous and valuable help. It was Professor Neil Quigley who brought me to enjoy academic and social life in New Zealand. I am sincerely grateful for his generous support to start an amazing journey in this country.

This "marathon" journey would not have been possible without support of many people. First, I would like to express my deep gratitude to Professor Val Lindsay, Dr Hongzhi Gao and Dr Leigh Roberts for their patient guidance, enthusiastic encouragement and useful critiques of this research work. Val, Leigh, and Hongzhi, I appreciate very much your outstanding guidance and mentorship throughout the $\mathrm{PhD}$. Thank you for your inspiration. Thank you for understanding me. You made me grow as an academic person and taught me the fine art of academia.

My grateful thanks are also extended to all staff in School of Marketing and International Business. My thanks go to the Research Committee for the support in terms of conference attendance and field work. I would like to acknowledge useful and constructive recommendations on this project from Professor David Crick, Professor Kim Fam, Dr James E Richard, Dr Daniel Laufer, Dr Cheryl Rivers, and Dr Revti Raman. I would also like to thank Jessie Johnston and Asako Clear for administrative assistance.

To all fellow $\mathrm{PhD}$ students that I shared office with over the past few years: Janine, Suzana, Stephen, Lachie, Madnoor, Richa, Vũ Thị Anh Đào, Ainie, Lin, Fahana, Kim Thảo, Gloria, Hoàng Sinh, Honghong and Bo. It was a great time to exchange ideas and walk this path with you.

Special thanks should be given to Mr Nguyễn Thành Long, who is always with me on this journey as a brother, as a friend, and as a teacher. Thank you for accompanying me, encouraging me, and sharing all thoughts and feelings.

I would like to acknowledge all New Zealand and Australian companies which volunteered for this research by part taking in the interviews and the surveys. Without the fantastic response, this thesis would not have been possible. 
A big thank to all of my Facebook friends, who shared feelings and made me feel like I were in home country. Special thanks go to Facebooker Nguyễn Hữu Thư for valuable documents, information and kind thoughts.

I would like to express my great appreciation to my beloved students: Hoàng Anh_4KN2, Thanh Phong_4KN2, Bảo Thanh_6KD2, Phan Toàn_10QT, Lê Phong_10TH, Quốc Khang_11NH, Trường Nghĩa_11NH, Đăng Khoa_11NH, Phước Lợi_11NH, Minh Lý_11NH, Minh Hồ_11NH, Trung Nghĩa_11NH, Quỳnh Hoa_12TC, and Trần Thế Trung for your kind assistance, and especially for collecting business database. I would also like to extend my thanks to all of my students for keeping me going forward.

Finally, I would like to express my deep gratitude to all family members: grandparents, grandmother in law, parents, parents in laws, brothers and sisters, for their support and encouragement throughout my study. Thank you for your love, and for your sacrifices to support my education. Thank you for offering encouragement to embark on this journey. My warmest thanks go to Thái Bảo Trạng and Trần Minh Hiếu. None of you leaves me alone on my journey. My heartfelt thanks go to my wife Nguyễn Ngọc Thúy Sơn and my daughter Đặng Ngọc Minh Nguyệt. I am truly lucky to have both of you. Thank you for your patience and unconditional love. You kept me going forward. I am proud of you all. 


\section{TABLE OF CONTENTS}

ABSTRACT $\quad$.....................................................................................................................

TABLE OF CONTENTS.................................................................................................iv

LIST OF TABLES .....................................................................................................viii

LIST OF FIGURES .................................................................................................................... $\mathrm{x}$

CHAPTER 1. INTRODUCTION ............................................................................ 1

1.1. BACKGROUND TO THE RESEARCH....................................................

1.2. RESEARCH PROBLEMS AND QUESTIONS …………………................... 3

1.3. OVERVIEW OF THE LITERATURE AND RESEARCH GAPS ....................... 4

1.4. JUSTIFICATION FOR RESEARCH AND EXPECTED CONTRIBUTIONS ... 6

1.5. RESEARCH METHODOLOGY UTILISED ………………………................ 7

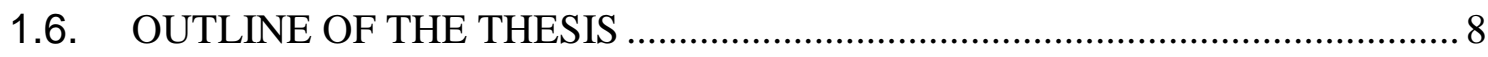

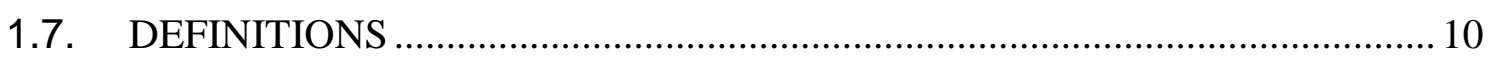

1.8. DELIMITATION OF SCOPE AND KEY ASSUMPTION ………………....... 12

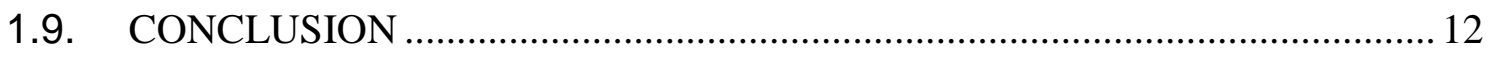

CHAPTER 2. LITERATURE REVIEW ............................................................... 13

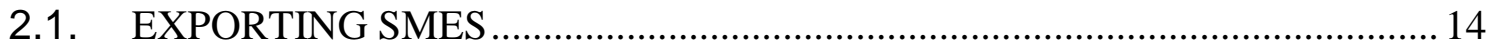

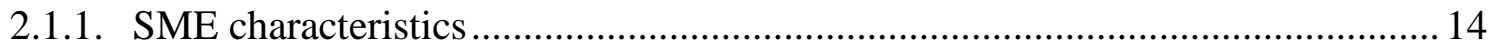

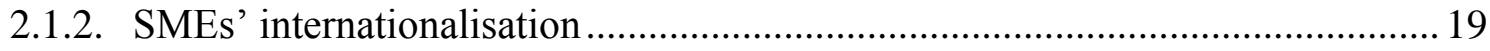

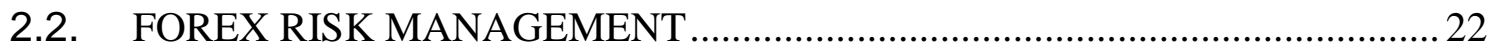

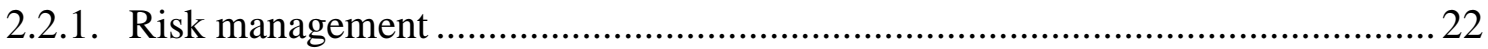

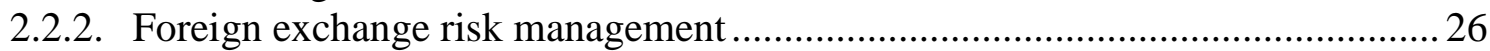

2.2.3. The importance of forex management in an international business setting .........34

2.2.4. Forex risk exposure: Does size matter?............................................................ 35

2.2.5. Are SMEs or large firms more likely to hedge? ................................................ 36

2.2.6. The importance of forex risk management for SMEs .......................................... 37

2.3. THE EXTANT LITERATURE ON HEDGING DETERMINANTS ...................38

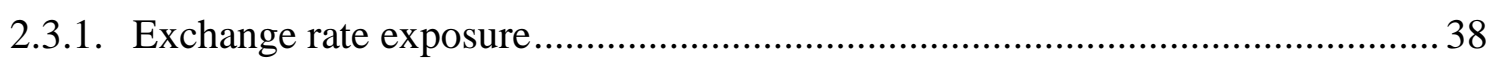

2.3.2. Determinants of firms' choice of hedging strategy ............................................. 40

2.4. NEW PERSPECTIVE ON HEDGING DETERMINANTS ................................ 48

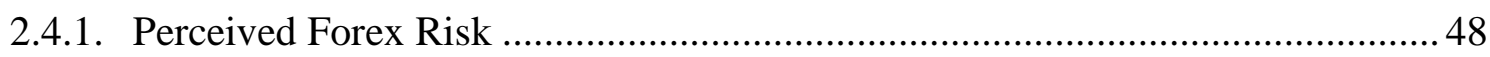

2.4.2. Resources associated with forex risk management ............................................ 49

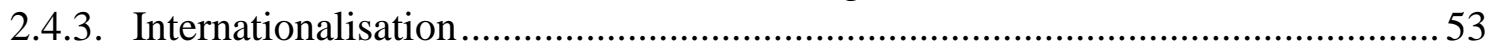




\section{CHAPTER 3. RESEARCH DESIGN AND EXPLORATORY QUALITATIVE STUDY 59}

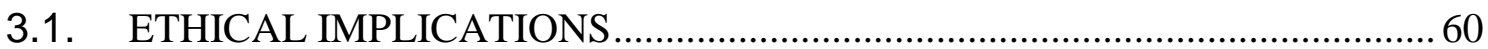

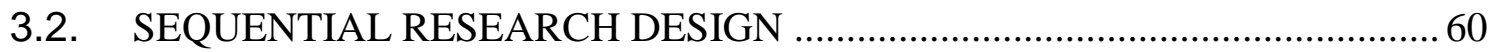

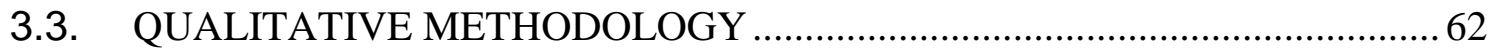

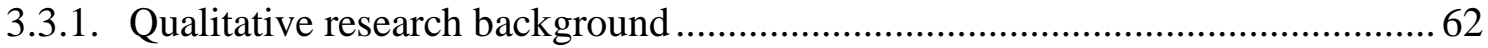

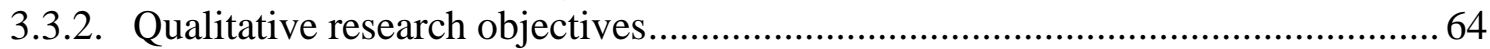

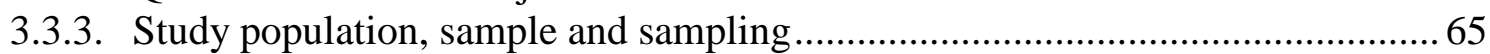

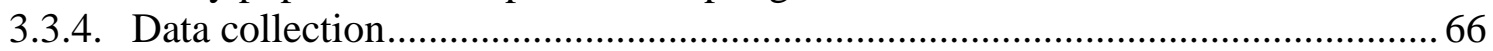

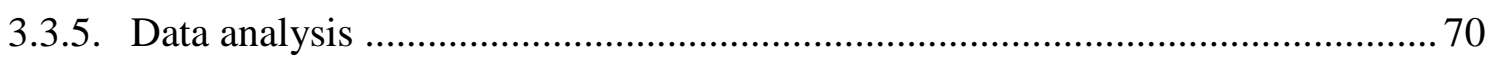

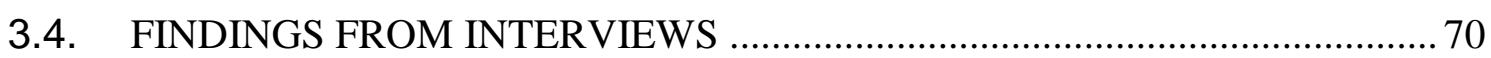

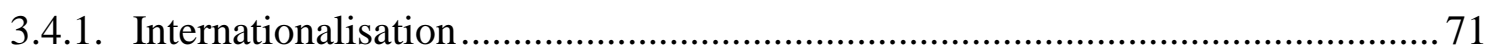

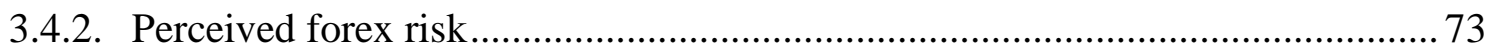

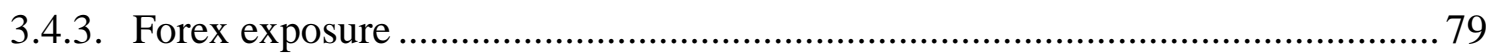

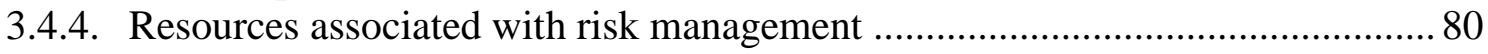

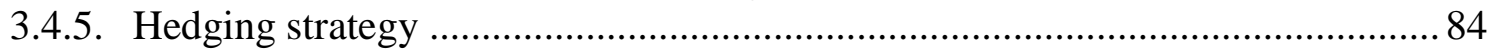

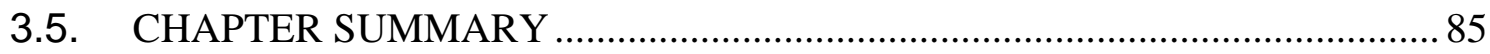

CHAPTER 4. CONCEPTUALIZATION AND HYPOTHESES ...........................88

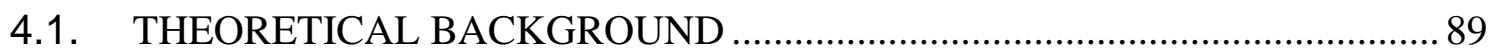

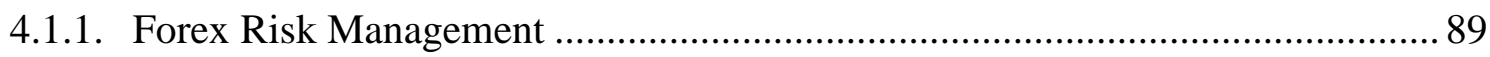

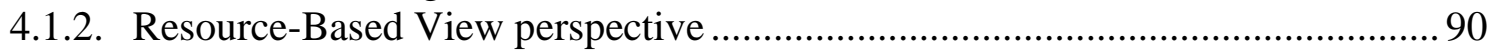

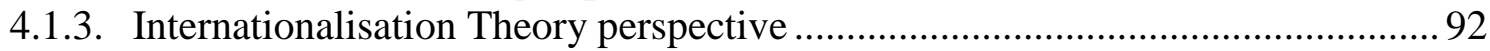

4.2. THE CONCEPTUAL MODEL AND HYPOTHESES ….................................... 93

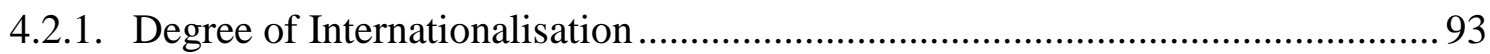

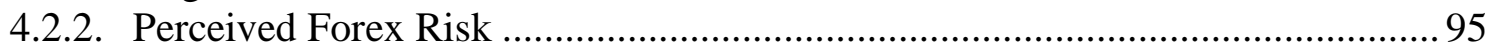

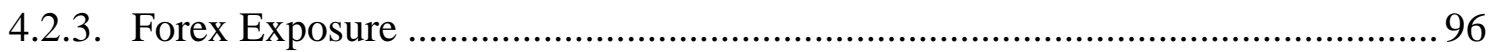

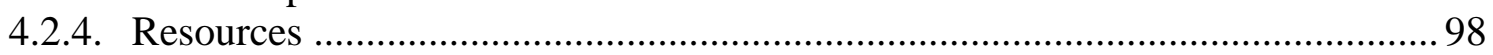

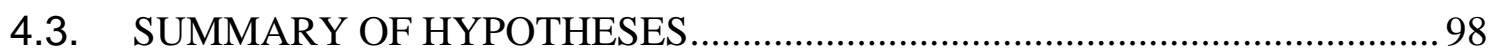

CHAPTER 5. QUANTITATIVE METHODOLOGY .....................................100

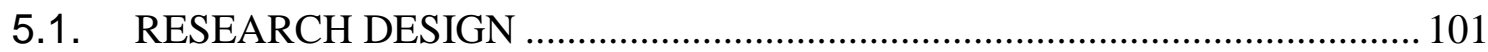

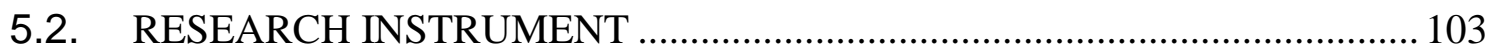

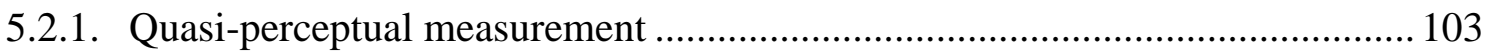

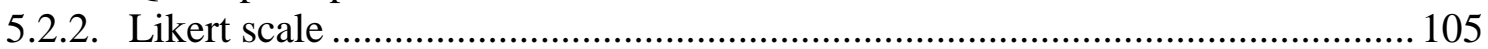

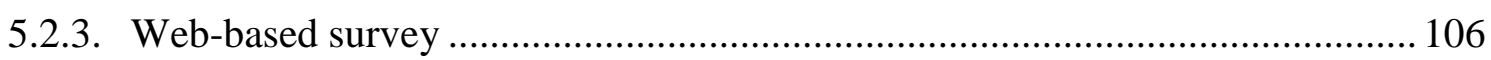

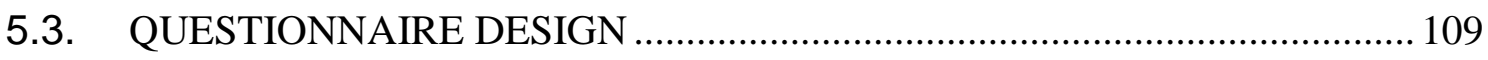

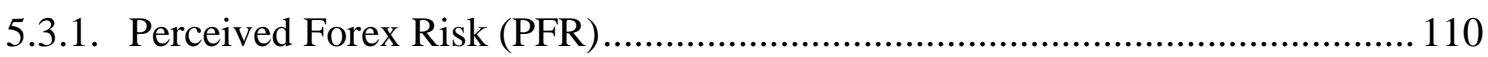

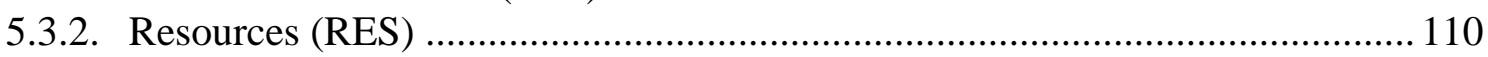




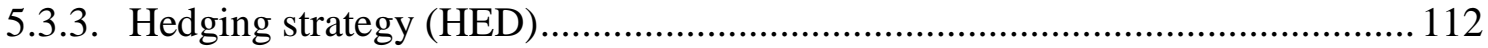

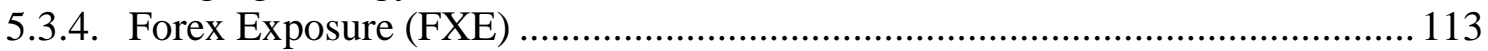

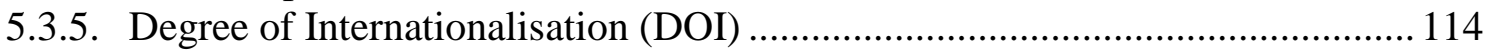

5.3.6. Measurement Model of Forex Risk Management .......................................... 115

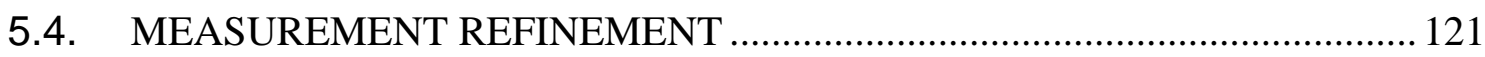

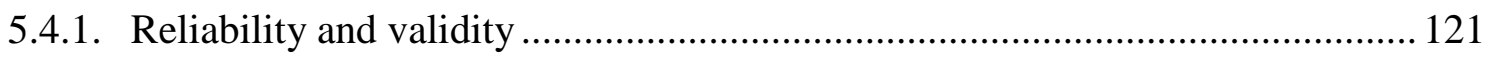

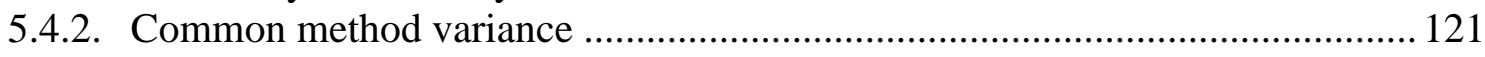

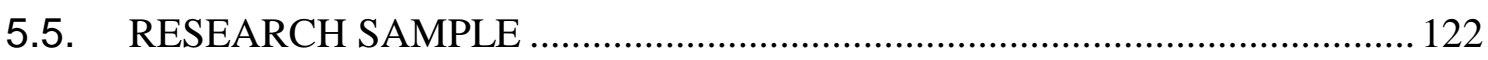

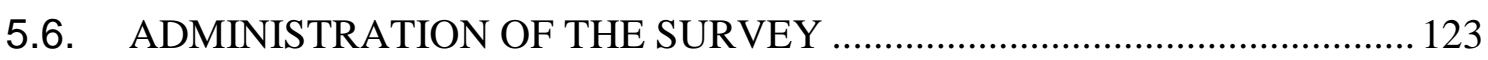

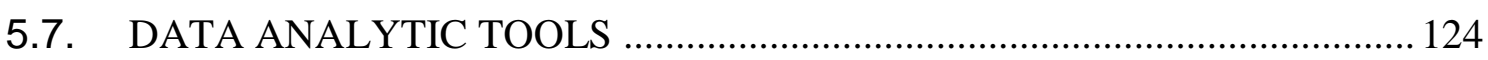

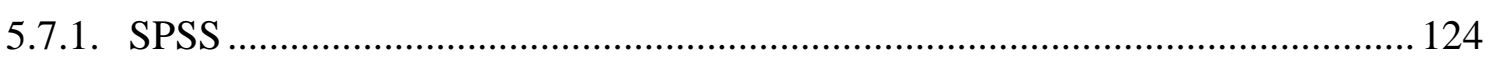

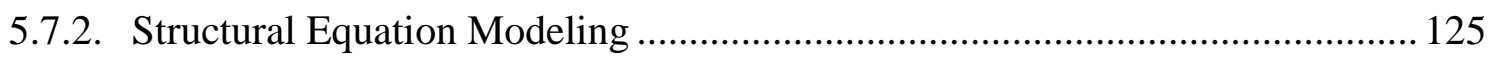

5.8. CRITICAL STATISTICAL VALUES APPLIED IN THE STUDY................ 126

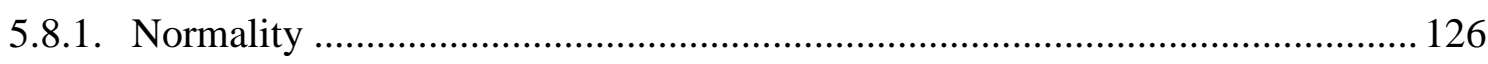

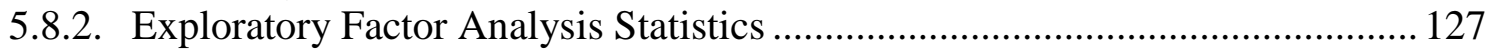

5.8.3. Confirmatory Factor Analysis and Goodness-of-Fit Statistics ........................ 128

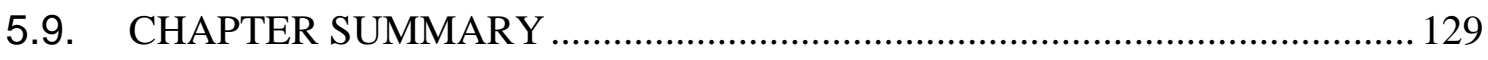

CHAPTER 6. QUANTITATIVE ANALYSIS.................................................130

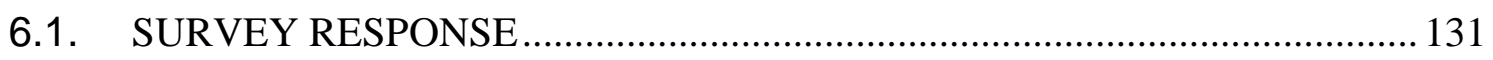

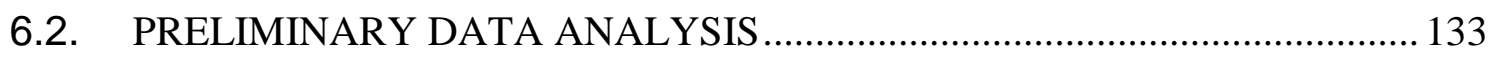

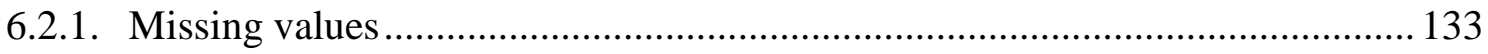

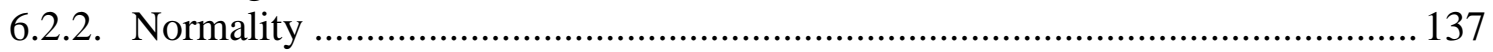

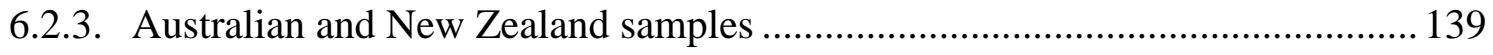

6.3. EXPLORATORY FACTOR ANALYSIS (EFA) ............................................. 140

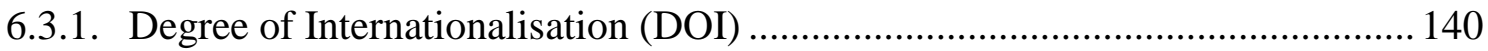

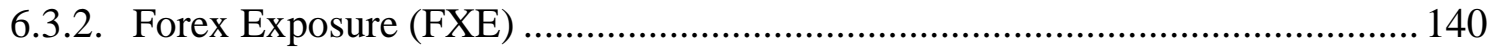

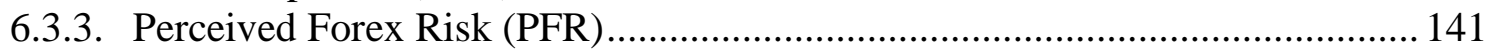

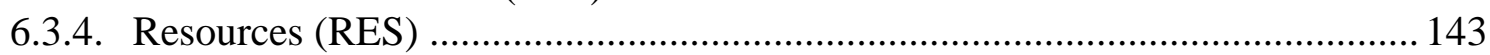

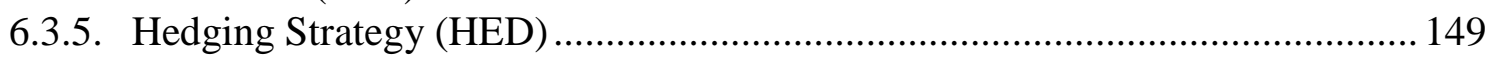

6.4. CONFIRMATORY FACTOR ANALYSIS (CFA) MODEL........................... 149

6.5. STRUCTURAL MODEL AND HYPOTHESIS TESTING ............................ 153

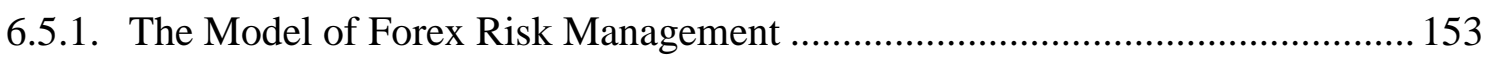

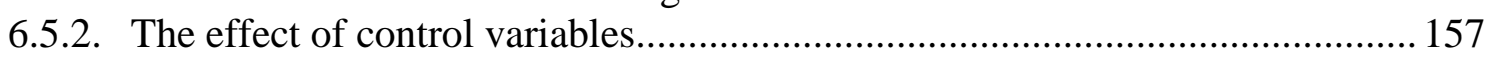

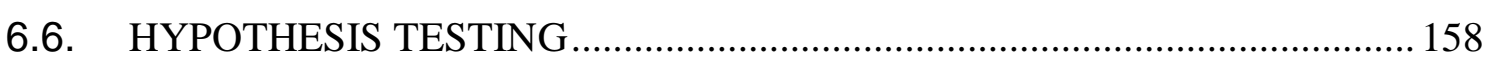

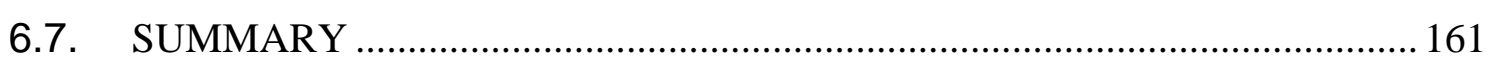

CHAPTER 7. DISCUSSION AND CONCLUSION ....................................... 162

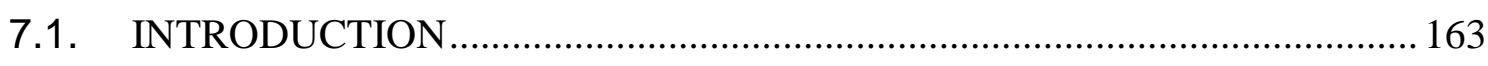




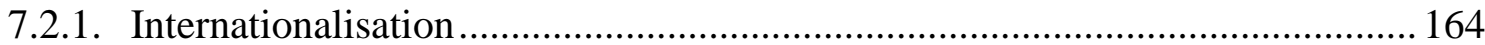

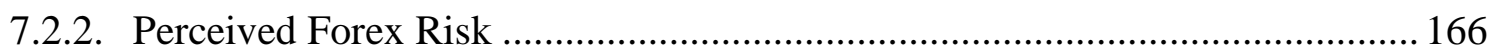

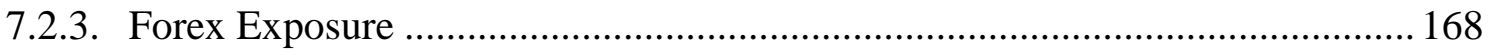

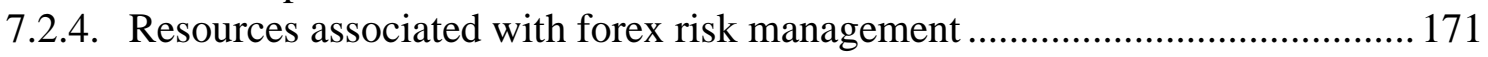

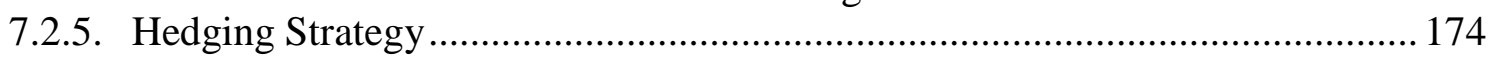

7.3. THE MODEL OF FOREX RISK MANAGEMENT ...................................... 177

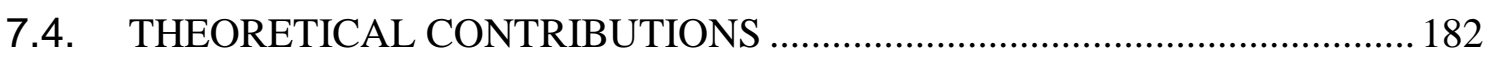

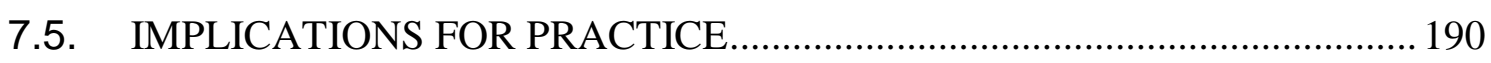

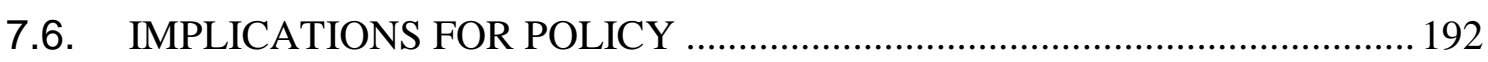

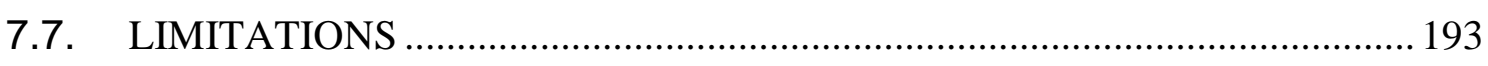

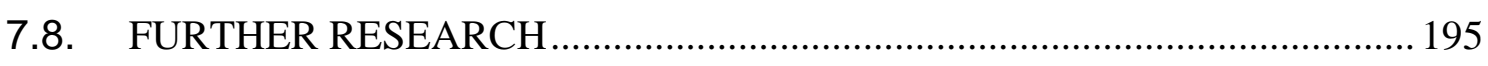

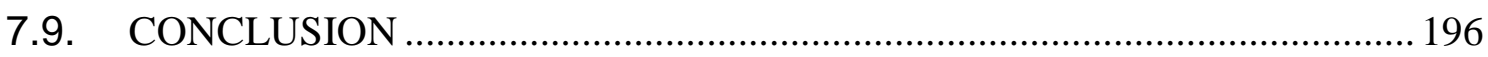

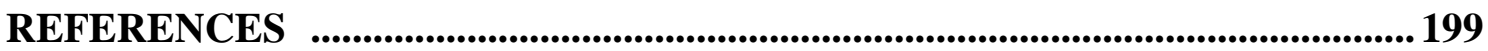

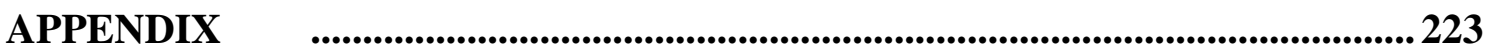

Appendix A: Research on Forex Risk Management: The Choice of Hedging

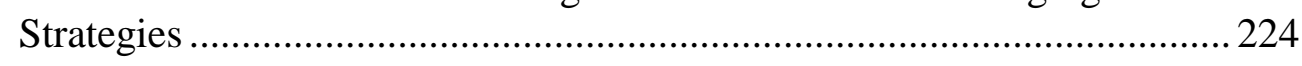

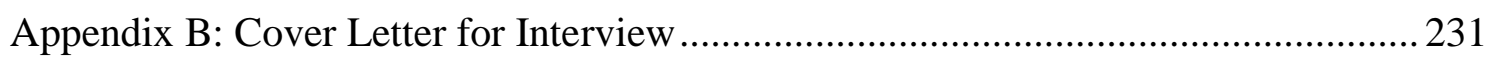

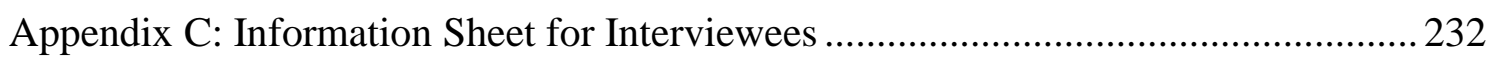

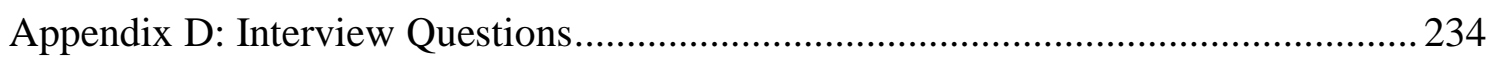

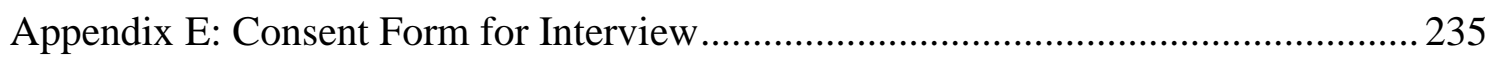

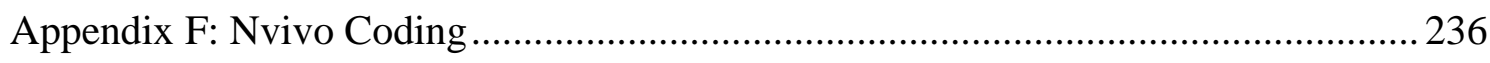

Appendix G: Cover Email for Survey Participants .................................................... 237

Appendix H: Reminder Email for Survey Participants ............................................ 238

Appendix I: Web-Based Survey Instrument ..........................................................239

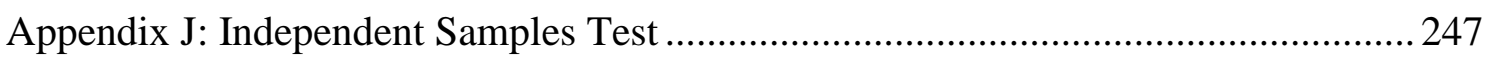

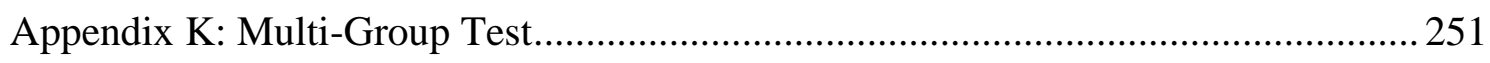




\section{LIST OF TABLES}

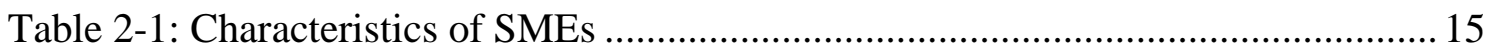

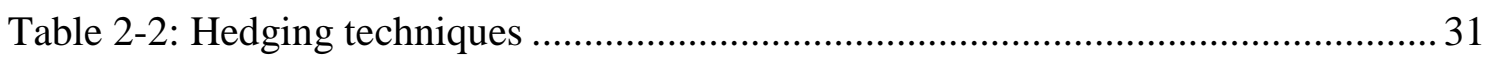

Table 2-3: Determinants of firms' choice of hedging techniques.................................. 45

Table 2-4: Operationalization of selected resources/capabilities ................................... 51

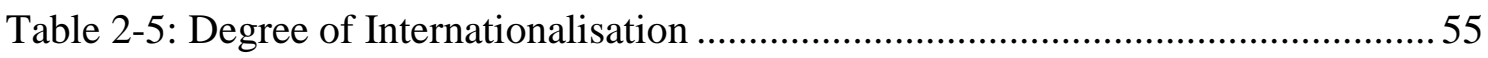

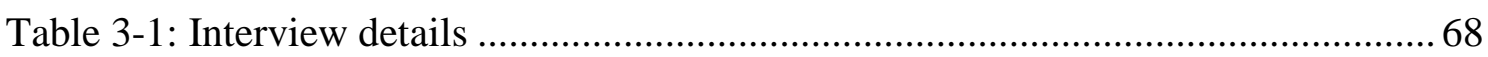

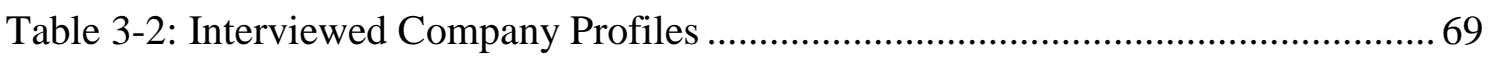

Table 3-3: Summary of Qualitative Findings Issues Relating to Forex Risk

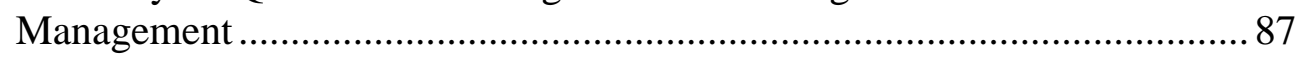

Table 4-1: Hypotheses for factors influencing forex hedging strategy by

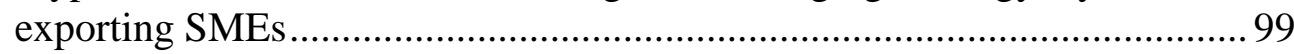

Table 5-1: The use of quasi-perceptual measures in the study .................................. 103

Table 5-2: Advantages and disadvantages of web-based surveys compared to mail questionnaires......................................................................... 106

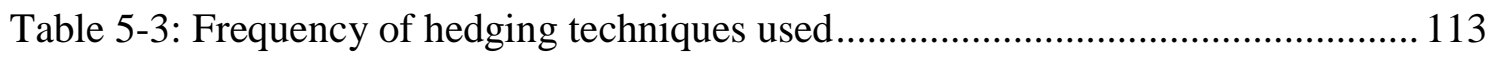

Table 5-4: The measure of 'Degree of Internationalisation' ....................................... 114

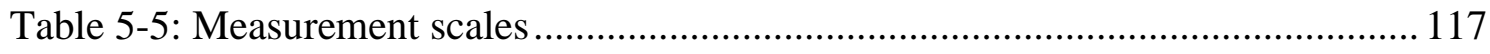

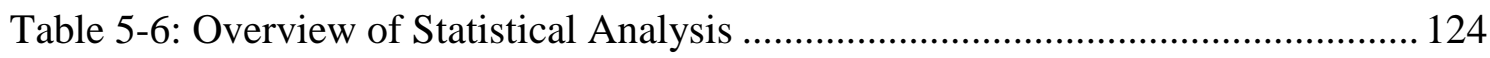

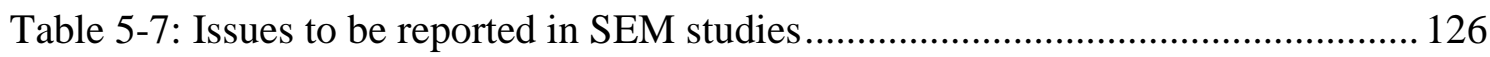

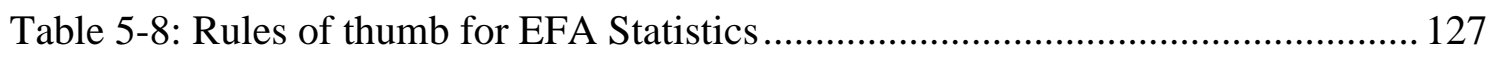

Table 5-9: Rules of thumb for CFA and Goodness-of-Fit Statistics............................ 128

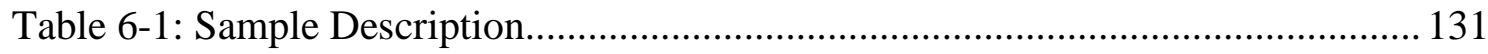

Table 6-2: Internationalisation of SMEs in the sample ............................................... 133

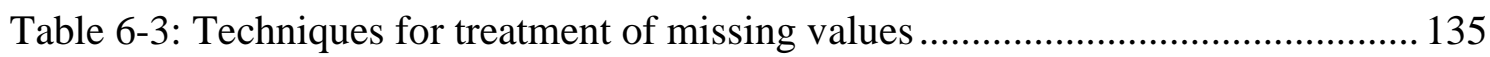

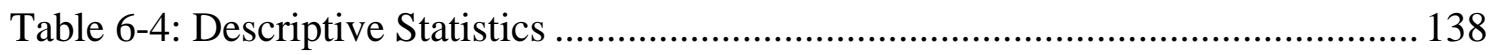

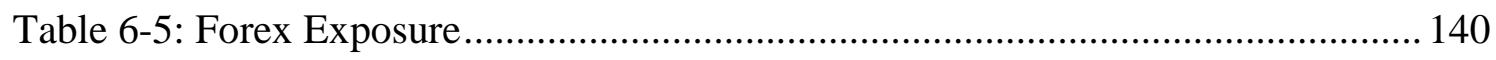

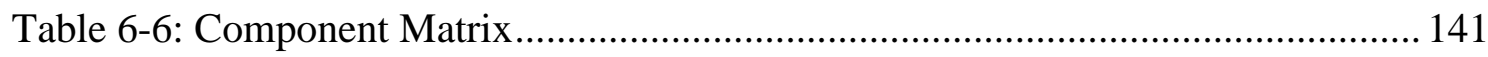

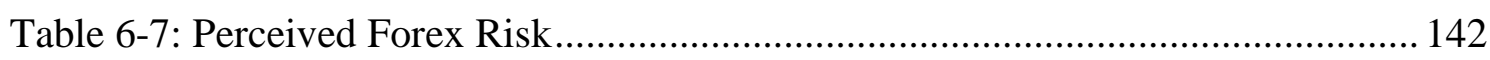

Table 6-8: Resources Component Matrix of the first factor analysis of 30

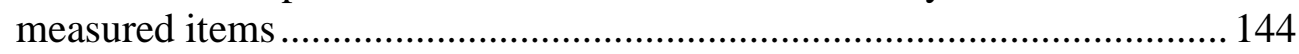

Table 6-9: Resources Component Matrix of the second factor analysis of 25

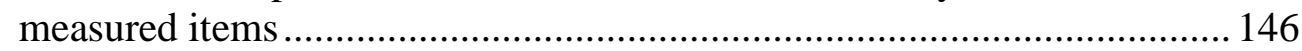

Table 6-10: Resources Component Matrix of the third factor analysis of 19

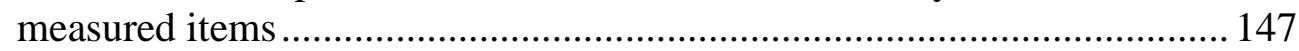

Table 6-11: Resources Associated with Forex Risk Management............................... 148 
Table 6-12: Confirmatory Factor Analysis

Table 6-13: Standardized Factor Loadings (SFL), Average Variance Extracted (AVE), and Construct Reliabilities (CR) 150

Table 6-14: Construct Correlation Estimate 151

Table 6-15: Regression Weights and P-value 155

Table 6-16: Description of Control Variables 157

Table 6-17: Moderation effect on the relationship between DOI and FXE 158

Table 6-18: Summary of Supported Hypotheses ..... 160

Table 7-1: Summary of Findings and Implications 180

Table 7-2: Contributions to the Literature on Forex Risk Management 183 


\section{LIST OF FIGURES}

Figure 2-1: Risk Management Process, adapted from McNamee (1997)...................... 25

Figure 3-1: Sequential Research Design (Creswell, 2003; Driscoll et al., 2007) ........... 61

Figure 4-1: The influence of a firm's resources on its hedging strategy ....................... 92

Figure 4-2: The impact of a firm's degree of internationalisation on forex risk............. 92

Figure 4-3: The Model of Forex Risk Management ................................................... 99

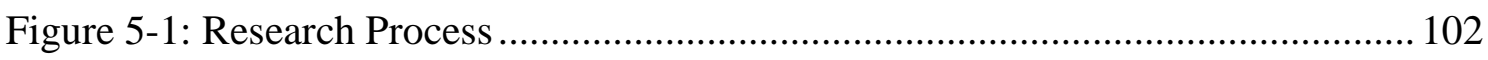

Figure 5-2: The Measurement Model of Forex Risk Management............................... 120

Figure 6-1: The Respecified Measurement Model of Forex Risk Management............ 152

Figure 6-2: The Structural Equation Modeling of Forex Risk Management ................ 154

Figure 6-3: Respecified Model of Forex Risk Management ....................................... 161 


\section{CHAPTER 1. INTRODUCTION}

This chapter aims to provide the study's foundations as follows:
(1) Presenting the background of this thesis;
(2) Setting research problems and questions;
(3) Providing an overview of the literature and research gaps;
(4) Justifying the research study;
(5) Describing briefly the methodology;
(6) Outlining the thesis;
(7) Providing key definitions;
(8) Setting out delimitations of this thesis. 


\subsection{BACKGROUND TO THE RESEARCH}

As a result of globalization, firms, whether they are multinational enterprises (MNEs) or small and medium sized enterprises (SMEs), have been increasingly involved in international business. Exporting firms might be particularly affected by fluctuations of exchange rates, for the fluctuation in currency markets impacts on the economy in general and firm production costs and revenues, in particular. It is also worth considering the fluctuations in the context of a floating exchange rate. Therefore, foreign exchange (forex) risk management is of interest to exporting firms.

However, a majority of research papers on this topic focus specifically on tackling problems in MNEs, while there is a scarcity of studies on managing forex risk for SMEs (Bartram, Brown, \& Minton, 2010; Jonuška \& Samėnaitė, 2003). Some research studies, such as those of Jonuška \& Samėnaitè (2003), Chan-Lau (2005) and Pramborg (2005), looked into hedging and managing forex risk in developing countries, where the majority of the companies are SMEs. These studies have addressed a variety of hedging determinants, but tended not to describe in detail how these determinants together impact hedging behaviours. This study investigates the interrelationships among hedging determinants, which are specific about exporting SMEs.

In the literature on forex risk management, there are a number of variables which have been seen as determinants of firms' choice to hedge forex risk. They include the cost of hedging versus benefits received, cost of using derivatives, managers' knowledge, trust in banks, accounting procedures (Jonuška \& Samėnaitè, 2003); hedging objectives (e.g., to reduce fluctuations in cash flows and fluctuations of accounting numbers), maturity of derivative markets (Pramborg, 2005); firm size, economies of scale, and international dependency (Berkman, Bradbury, \& Magan, 1997); accounting treatment, derivative market liquidity, exchange rate volatility, exposure volatility, and recent hedging outcomes (Brown, 2001).

In the light of all of these findings, firms might apply various hedging strategies and techniques to manage forex risk. They could use currency derivatives, foreign debt, and other external and internal methods, for example, leading and lagging, to hedge forex 
risk. But the usage of hedging techniques to manage their forex risk has not been thoroughly explored.

This thesis added to the current literature on forex risk management by focusing on how SMEs manage their forex risk, specifically identified factors that influence hedging strategy, and the relationships between these factors. The thesis extended the literature on forex risk management to a setting of exporting SMEs, examined the impact of factors with regard to firms' resources, and the degree of internationalisation (Gankema, Snuif, \& Zwart, 2000).

\subsection{RESEARCH PROBLEMS AND QUESTIONS}

National economies in recent years have grown closer together as a result of globalisation; firms are, therefore, influenced by global changes (Fard, Cheong, \& Yap, 2014; OECD, 1997). As a result, fluctuations in global forex markets impact all firms, but especially those which are directly involved in international business. Several findings question the value of firms hedging forex risk because the risk may not be a major impediment to international trade, and because difficulties, costs of hedging, and short-term exchange rate fluctuations are not considerable (Brookes, Hargreaves, Lucas, $\&$ White, 2000). However, a number of studies demonstrate that firms should be managed in anticipation of uncertainty of forex rates (Brookes et al., 2000; Dash, Babu, Kodagi, \& Vivekanand, 2008; Dhanani, 2003; Joseph, 2000; Loderer \& Pichler, 2000; e.g., Marshall, 2000; Moosa, 2004; Morey \& Simpson, 2001; Pramborg, 2005). On account of this, a question arises as to the extent to which firms should hedge their forex risk.

Firm size has been seen to be one of the determinants of hedging policies. Børsum \& Ødegaard (2005) examined Norwegian non-financial firms and showed that the larger firms were, the higher their usage of derivatives. Similarly, Chan-Lau (2005) found that in Chile a majority of demand for forex hedging was from large firms, mostly because of their possession of resources and skills to implement forex hedging programs. In another study by Culp \& Miller (1995), there were only $13 \%$ of firms with a market value of $\$ 50$ million or less using derivatives as a hedging vehicle, whereas the proportion of firms with a market value greater than $\$ 250$ million that used derivatives 
was $65 \%$. Thus, because of size differences, it is likely that SMEs could have their own strategies for managing forex risks. Such strategies for SMEs might be distinct from those of larger firms. In other words, there might be a model for SMEs' practices in responding to forex rate fluctuations. The determinants of forex risk strategy and the interactions between these determinants may also be different for SMEs.

In addition, SMEs might face higher risk as they increase their export sales/total sales ratio over time; gaining experience and resources, and enhancing market knowledge lead them to further commitment in more distant markets (Coviello \& McAuley, 1999). The degree of internationalisation of a firm is likely to impact the forex risk management by SMEs. It is worthwhile investigating this impact.

This thesis is mainly concerned with identifying the determinants of forex strategy in SMEs. It sheds new light on SMEs' hedging practice by providing a better understanding of determinants impacting the choice of hedging strategy for managing forex risk, including the degree to which firms hedge and the hedging techniques that the firms may use. To address this problem, the study is guided by the following research questions:

1. What factors influence exporting SMEs to choose hedging as a way of managing forex risk?

2. What factors influence decisions on the hedging degree and on (internal or external) hedging techniques when exporting SMEs choose hedging to manage forex exposure?

3. How does an SME's internationalisation degree impact its choice of forex strategy?

\subsection{OVERVIEW OF THE LITERATURE AND RESEARCH GAPS}

The literature on forex risk management shows that there are numerous reasons for a firm to hedge. Hedging determinants are objective factors that have hard measures, many of which are not relevant for smaller firms, for example, leverage (González, Búa, Lopez, \& Sandías, 2007), liquidity (González et al., 2007; Joseph, 2000; Schiozer \& Saito, 2009), tax charge on profit (Joseph, 2000), and foreign debt (W. B. Elliott, 
Huffman, \& Makar, 2003; González et al., 2007). In addition, perceived risk could predict behaviours associated with dimensions of risk (Cox \& Rich, 1964; Hemsworth, Brophey, \& Baregheh, 2013; Kaplan, Szybillo, \& Jacoby, 1974). This thesis takes a different approach by investigating the managerial perception of forex risk and managers' subsequent choices regarding forex risk management.

The current literature on forex management tends to consider derivatives as the major form of hedging instrument, especially for large firms (Albuquerque, 2007; González et al., 2007; Pramborg, 2005; Schiozer \& Saito, 2009). These studies have extensively investigated single determinants that influence the use of hedging instruments, mostly derivatives. Given that hedging determinants are examined in isolation from each other, there is a need for a conceptual/theoretical framework for hedging strategy that considers not only the determining factors themselves, but also the relationships between them.

In order to build such a conceptual framework, the constructs need to be viewed through relevant theoretical lenses. The literature on forex risk management indicates a lack of an appropriate theoretical base, particularly in the context of SMEs. This thesis applies the Resource-Based View (RBV) and internationalisation theory. The RBV literature offers grounds for explaining firms' allocation of resources associated with forex risk management. The internationalisation literature offers some relevant insights on internationalisation degree and forex risk management.

A number of contexts, such as region, country, industry, and firm were found in the literature on forex risk management; however, a large number of research studies were undertaken in multinational enterprises - usually large firms. Recently, as a result of rapid internationalisation, SMEs are increasingly involved in international markets, and thus they become an important setting for research on forex risk management. There is the scarcity of studies on forex management in SMEs at the firm level (Kula, 2005), thus providing an opportunity for further research in this context. This thesis fulfils a need for contextual relevance: exporting SMEs. 


\subsection{JUSTIFICATION FOR RESEARCH AND EXPECTED CONTRIBUTIONS}

Hedging practice has been shown to be influenced by a number of factors; however, there is a lack of empirical research on hedging behaviours of SMEs, relative to large firms. The existing hedging literature has examined a large number of rationales for firms to hedge (for example, González et al., 2007; Joseph, 2000; Pramborg, 2005; Smith \& Stulz, 1985), as well as detailed discussions about whether a firm should hedge or not. This thesis develops a framework for SMEs' hedging behaviours in responding to forex uncertainties. The framework suggests a distinct approach by SMEs to hedging, which is largely neglected in the current literature on forex risk management

From a perspective of modern finance, theory on forex risk management consists of two pillars, i.e. the concepts of efficient markets and diversification (Boatright, 2011). Market efficiency holds that risks should only be taken if the expected reward for so doing is sufficient. Therefore, diversification or the ultimate hedge, removing risk totally, makes no profit or loss. Despite the doctrine of market efficiency that freely accessible information is incorporated in prices with sufficient speed and accuracy, there remain a number of corporate executives who are convinced of their own ability to predict future interest rates, commodity prices and exchange rates (Stulz, 1996). This suggests that firms do hedge against forex risk in their own ways. Given the limited research on SMEs in this context, it is important to understand why and how such firms hedge their forex risk. Specifically, this thesis looks into forex risk management of exporting SMEs.

This thesis makes a theoretical contribution by extending the use of various theoretical perspectives in the new setting of forex risk management, thus providing a new theoretical framework for forex risk management in exporting SMEs. First, as regards the Resource Based View (RBV), the thesis explores how exporting SMEs allocate their resources for managing forex uncertainty. Second, a firm's international experiences influence how it invests in international markets, and how it may respond to forex fluctuations. Therefore, this study investigates the influence of a firm's degree of internationalisation on hedging behaviours of exporting SMEs. By taking this approach, 
the thesis aims to firstly, extend the forex risk management literature by providing a model relevant to SMEs, and, secondly, to enrich the RBV and internationalisation theoretical bases by applying them in a relatively important setting - that is, forex risk management.

In addition, new latent constructs are used in this thesis along with newly-addressed research issues. For example, perceived risk is used in the setting of forex risk management, reflecting a new variable relevant to the issue, termed 'perceived forex risk'. The study also examines issues regarding resource allocation by the firm in the setting of forex risk management. Currently, these theoretical lenses have not been applied in the context of forex risk management in SMEs.

The study also makes the following methodological contributions to the academic literature in the area of forex risk management in two ways. First, given the relatively nascent status of research on forex risk management in SMEs, it is worth conducting an exploratory qualitative study to support the theoretical propositions. Also, the use of structural equation modeling in the subsequent quantitative stage captures structural relationships among the constructs. Second, the study introduces different measures to those used traditionally in forex risk management in large firms. Previously, such studies on forex risk management have overwhelmingly adopted a purely quantitative method with simple regressions measuring the direct relationships between hedging determinants and hedging practices. The majority of these studies utilise objective data, mostly financial ratios, which have been used as proxies for concepts associated with hedging practice. In order to capture the subjective nature of managerial decisions on forex risk management, this thesis draws on managerial perceptions of the influences of a range of determinants on hedging practice. Thus subjective data are used to reflect the latent constructs from the viewpoints of SME managers.

\subsection{RESEARCH METHODOLOGY UTILISED}

As outlined above, the study adopts a sequential research design with an exploratory qualitative study and a subsequent quantitative study using a web-based survey. Initially, semi-structured, in depth face-to-face interviews were conducted with financial controllers/managers/owners of exporting SMEs. The interviews aimed (1) to refine 
theoretical propositions, (2) to seek initial confirmation and validation of the conceptual model, (3) to identify new insights on the topic, and (4) to contribute to the interpretation of the empirical data analysis providing in-depth analysis and findings relating to the 'how' and 'why' aspects of forex risk management in exporting SMEs..

The surveys were distributed to New Zealand and Australian exporting firms across a full range of industry sectors represented in the business database provided by Kompass. Statistical analyses, including exploratory factor analysis (EFA), confirmatory factor analysis (CFA), and multi-group analysis were conducted to test the measurement model, structural model, research hypotheses, and the effect of control variables.

As stated, the results of the interviews were also considered alongside the empirical findings, which are jointly discussed to provide a comprehensive and rigorous analysis and interpretation of hedging behaviours of exporting SMEs.

\subsection{OUTLINE OF THE THESIS}

This thesis comprises eight chapters. A brief description of each chapter is provided below.

\section{Chapter 1: Introduction}

The first chapter provides the background of the study. Research questions and problems and discussed. A brief overview of the literature is provided and research gaps are identified and followed by the research justification. The methodology utilised in the study is then briefly described. This chapter also outlines the thesis, provides key definitions used, and sets out delimitations of the thesis.

\section{Chapter 2: Literature Review}

This chapter reviews the relevant literature that provides the foundation for the study. The focus is on the hedging determinants and SMEs' forex risk management. An introduction to the research setting of SMEs includes an overview of SMEs' characteristics and internationalisation, followed by the literature on forex risk management across firms of all sizes. The chapter mainly discusses determinants of 
hedging, the use of resources associated with forex risk management and degree of internationalisation in the context of forex risk management. The chapter outlines research gaps in the literature on forex risk management by SMEs, and then develops the rationale for this thesis.

\section{Chapter 3: Research Design and Qualitative Methodology}

The chapter begins with the research paradigm and research design of this thesis, followed by the rationale for adopting a sequential research design. The exploratory qualitative component of the study covers the qualitative design, data collection, interview technique and analysis of the qualitative data. Finally, the findings are presented.

\section{Chapter 4: Conceptual Model and Hypotheses}

This chapter presents the conceptual model and hypotheses. Based on the resourcebased view of the firm (the RBV) and internationalisation theory, the conceptual model is developed and hypotheses described. A number of quantitative findings are used as first-hand evidence, which provides robustness for the conceptual model.

\section{Chapter 5: Quantitative Research Methodology}

This chapter presents the main quantitative component of the thesis, with the design and application of the web-based survey instrument being described. In addition, the chapter presents the statistical procedures and techniques used to test the hypotheses and answer the research questions of the thesis, i.e. exploratory factor analysis, confirmation factor analysis, and structural modeling with AMOS Graphic 20.

\section{Chapter 6: Quantitative Analysis}

This chapter presents the findings from the web-based survey instrument. Exploratory Factor Analysis (EFA) is conducted with SPSS Statistics 20 to seek reliability and validity before the performance of Confirmatory Factor Analysis (CFA) in AMOS Graphic 20 to test the measurement models. Analyses of Variance and Structural Equation Modeling (SEM) were carried out to test the research hypotheses. Multi-group tests were conducted to investigate the effect of control variables. The results of the hypotheses testing and other findings are presented in this Chapter. 


\section{Chapter 7: Discussion}

This chapter focuses on the interpretation of the findings of the study. Results relating to the hypotheses from the quantitative survey are discussed, along with relevant findings and interpretations supported by the qualitative findings. These are considered in the light of the extant literature. Contributions are also highlighted.

\section{Chapter 8: Conclusion and implication}

This chapter presents the conclusions of the study, focusing on the original research questions. Also, implications from the findings are proposed in relation to theory, policy and practice. In addition, limitations of the study are acknowledged and avenues for future research are suggested.

\subsection{DEFINITIONS}

\section{SME}

In keeping with OECD's (2007a, p. 770) definition, this thesis considered SMEs as those which have no more than 250 employees.

\section{Hedging}

In this thesis, the terms hedging and managing forex risk are used interchangeably; these refer to planning, organizing, directing, and controlling a firm's systems and resources for improving its ability to respond to forex rate changes (adapted from the definition of McNamee, 1997). Under this broad definition, hedging is a process of financial management rather than an action. This process entails the use of hedging techniques. The study is concerned with (1) hedging degree, the extent to which hedging techniques are used, and (2) hedging technique, the use of internal versus external techniques.

\section{Perceived forex risk}

Adapting the definition of risk and perceived risk by Beck (2007), Chow, Lee, and Solt (1997) and Holton (2004), this thesis defines perceived forex risk as managerial risk perception of uncertainty and exposure specifically associated with foreign exchange rates. The concept of perceived forex risk is a function of a number of hedging 
determinants, for example, managerial perceptions on the effects of forex changes on overall business risk, firms' losses and their proceeds. In addition, perceived forex risk is presented as a multidimensional construct, similar to perceived risk in consumer behaviour.

Perceived forex risk refers to the managerial perception of forex risk. Perceived forex risk is operationalized in the study as the subjective judgment that managers make about the characteristics and severity of forex uncertainty. In this regard, perceived forex risk is associated with (1) exchange rate fluctuations, (2) forex exposure and (3) managerial psychology, awareness and attitude toward forex changes.

\section{Resources}

Resources, or firm resources, include all assets, capabilities, organizational processes, firm attributes, information, and knowledge controlled by a firm that enable the firm to conceive of, and implement, strategy that improves its efficiency and effectiveness (Coltman, Devinney, \& Midgley, 2011). In this thesis, resources are concerned with those that are specifically used to improve firms' efficiency and effectiveness in forex risk management.

\section{Degree of internationalisation (DOI)}

The term "Degree of Internationalisation" refers to export intensity, which is measured by the firm's export sales/total sales ratio (Cavusgil, 1980; Gankema et al., 2000), herein after called export/sales ratio or export ratio. Exhibiting export intensity, this ratio is an appropriate measure of DOI in this study, which investigates the forex risk management of exporting SMEs.

\section{Forex exposure}

Forex exposure is the extent to which a firm's cash flows are susceptible to variations in foreign currency exchange rates. It is associated with the amounts of foreign currencies, presenting the sensitivity of the future, real value of any physical or financial asset to random variations of the future domestic purchasing powers of these foreign currencies (Adler \& Dumas, 1984). 


\subsection{DELIMITATION OF SCOPE AND KEY ASSUMPTION}

The scope of this thesis is exporting SMEs, rather than MNEs nor non-exporting firms. The survey sample is taken from New Zealand and Australia due to the similarity of the two countries (V. Marsh, 2004). The combination of samples aims to increase the sample size.

This thesis is concerned with the identification of hedging determinants of exporting SMEs. Most previous research studies on forex risk management adopted objective data, e.g. financial ratios, which are popular in large firms, but seldom used in SMEs. The thesis examines how SMEs' forex risk management is influenced by managerial perception of forex risk and resources associated with forex risk management. As a result, this thesis employed an extensive use of perceptual measures as suggested by a number of scholars (e.g. Anderson \& Paine, 1975; Boyd, Dess, \& Rasheed, 1993; Hambrick \& Snow, 1977; D. Miller, 1988).

Given that exporting SMEs might use internal or/and external hedging techniques, this thesis examines (1) hedging degree, the extent to which hedging techniques are used, and (2) hedging technique, firms' tendency to use internal versus external techniques. The thesis aims to identify which determinants influence the choice of internal or external hedging techniques. The study does not attempt to examine every single hedging technique. Nor does it examine the effectiveness, efficiencies or the benefits of the hedging techniques that a firm uses.

\subsection{CONCLUSION}

This chapter has laid the foundations for the thesis. The research problem, research questions and research gaps were introduced. Then the rationale for the research was provided. Also, the methodology was briefly outlined and key definitions were presented. The thesis chapters were outlined, and delimitations were set out. 


\section{CHAPTER 2. LITERATURE REVIEW}

This chapter reviews the literature pertinent to this thesis. First, it presents the background of exporting SMEs. The section provides a review of the literature on SMEs' characteristics and internationalisation, outlining the research context of this thesis; that is forex risk management of exporting SMEs. Then the second section describes relevant facets of forex risk management. The third section specifically discusses the determinants of forex risk management. This section reviews research studies on forex risk management across firms of all sizes. The fourth section discusses the established theoretical background of the study, i.e. resource-based view and internationalisation theory, in the context of forex risk management. The final section illustrates research gaps relevant to the study. 


\subsection{EXPORTING SMES}

\subsubsection{SME characteristics}

SME, which refers to small and medium sized enterprise, is not a uniquely-defined term. Basically, SMEs employ fewer than a given number of employees, which varies across countries (OECD, 2007a, p. 770). Additionally, financial measures are also used to define SMEs. In the European Union, for instance, SMEs are those which employ at least 10 persons but fewer than 250 persons, have an annual turnover not exceeding EUR 50 million, and/or an annual balance sheet total not exceeding EUR 43 million (European Union Commission, 2003). Since governments and organizations are unlikely to agree on a single given number of employees and amount of capital for their financial business support, there is no single definition for a SME, either nationally or internationally. For example, New Zealand Ministry of Economic Development considers SMEs with an employment threshold of 99 or fewer employees as SMEs (New Zealand Goverment, 2014) ${ }^{1}$, while an Australian $\mathrm{SME}^{2}$ is defined by its revenue being below $\$ 20 \mathrm{~m}$.

SMEs are characterised as having limited skills, experience, and capabilities, as well as limited finance, human, management, and information resources (Ciubotariu, 2013; Coviello \& Munro, 1997; Coviello \& Munro, 1995; Hashim \& Wafa, 2002; Holmlund \& Kock, 1998; Sirtaine, 2006), which influence SMEs' business management in general, and internationalisation in particular. Table 2-1 shows empirical research and the specialized literature on SMEs' characteristics. Due to limited financial and managerial resources, SMEs cannot control all the essential assets to exploit the opportunities for traditional growth, such as internal resources invested in new factories, new shops, new branches etc. (Berra, Piatti, \& Vitali, 1995). Berra et al. hold that, financial constraints, on the one hand, limit the use of acquisitions, while the rapid change of the competitive context, on the other hand, limits the adoption of traditional

\footnotetext{
${ }^{1}$ See http://www.mbie.govt.nz/what-we-do/business-growth-agenda/sectors-reports-series/pdf-documentlibrary/the-small-business-sector-report-2014.pdf

${ }^{2}$ See http://www.asmea.org.au/SMEFacts
} 
growth strategies. To go international, SMEs usually attempt to sell directly to their first market; however, they are often unable to invest the effort and time required for market development, due to their limited resources; thus many use an established distributor (Coviello \& Munro, 1997). Given that exporting SMEs face human and financial resource constraints, exporting is seen as a viable strategy for growth due to limited scope of domestic expansion (Zafarullah, Ali, \& Young, 1997). OECD (2007b) and OECD (2012) reported that SMEs in its member countries were not able to identify and pursue new international market opportunities, due to limits on the time, competency and financial resources available to the SMEs.

Table 2-1: Characteristics of SMEs

Assumed SMEs' characteristics

- Constrained resources;

- Weak in marketing skills and abilities;

- Depending on relationship with others for development;

- Limited capabilities and managerial resources;

- Conduct of international marketing impacted by network partners;

- Limited financial, managerial, human and information resources seen to restrict moves to foreign markets;

- Different management practices compared to large firms;

- Do not have adequate financial resources and access to commercial lending;

- Rely on one-person management, thus insufficient time and attentions to various managerial functions;

- SMEs are more entrepreneurial and pay more personal attention to details than large firms;

- SMEs are less risk-averse in terms of credit risk

\section{Country Author (Date)}

New Coviello \& Munro

Zealand (1995)

New Coviello \& Munro

Zealand (1997)

Finland Holmlund \& Kock (1998)

Malaysia Hashim and Wafa (2002)

US Knight and

Cavusgil (2004)

$\begin{array}{cl}\text { German } & \text { Dietsch and Petey } \\ \text { and } & (2004) \\ \text { French } & \end{array}$ 
- SMEs are different from large firms in terms of their structures, processes, resources and culture;

N/A

Deros, Yusof, and Salleh (2006)

- The large firms have access to the whole range of financial instruments available in Chile. The small

Chile Sirtaine (2006) firms face financing constraints;

- SMEs have limited absorptive capacity;

Barkema and Drogendijk (2007)

- SMEs adapt more quickly to changes in economic N/A Ciubotariu (2013) and social conditions, activating almost in all sectors of the economy;

- SMEs have a rapid system for internal communication, with personal contact between management and employees;

- SMEs have an external communication system highly responsive to the market, based on direct contact between management and customers;

- SMEs' management is personalized and centralized; usually the owner is the manager;

- SMEs have a hierarchical structure with fewer levels;

- SMEs follow less formal strategy, usually intuitive;

- SMEs reduce specialization of staff, employees often have multiple tasks;

- SMEs have small dimensions in terms of employment;

- SMEs lack a strong position to negotiate;

- SMEs face difficulties in obtaining capital;

- SMEs have s close relationship with the local community;

Because of limited absorptive capacity, SMEs, especially those with little international experience, may also have constrained potential benefits of global learning (Barkema \& Drogendijk, 2007). Similarly, Eriksson, Majkgård, and Sharma (2000) point out that firms could only exploit and explore foreign opportunities effectively when these opportunities are related to their accumulated knowledge. These arguments are consistent with the theory of bounded rationality, which suggests that one notices an opportunity or a problem when one is knowledgeable about a situation (Simon, 1997). 
SMEs are different from large firms for many reasons. Deros et al. (2006) hold that SMEs are different from large firms in terms of their structures, processes, resources and culture. SMEs are more entrepreneurial and pay more personal attention to details than large firms (Knight \& Cavusgil, 2004). As most SMEs have a simple structure, they are able to respond quickly to changes in economic conditions, and are also capable of meeting local customers' needs (Ciubotariu, 2013; OECD, 2002). Dietsch and Petey (2004) conclude that German and French SMEs are less risk-averse in terms of credit risk. In addition, SMEs typically manage their business in significantly different ways than large firms. In an influential document on small enterprises, John Bolton, the Chairman of the Committee of Inquiry on Small Firms in the United Kingdom (Bolton, 1971), highlight the personalised style of management in small firms, and their tendency to lack formal management structures with specialised staff. Also, SMEs often operate in international markets in a distinct way, in comparison with large firms. For example, according to United States International Trade Commission (Okun et al., 2010) it is estimated that United States SMEs were more export-intensive than large firms; 20 per cent of SMEs' total revenues were gained from exporting, while that of large firms was 15 per cent. The Commission also reported that United States SMEs primarily tended to directly export to serve their foreign customers, rather than selling through foreign affiliates. An estimated 73 per cent of foreign sales by SMEs were conducted through direct exports. On the other hand, large firms primarily sold to foreign customers via foreign affiliates, rather than through direct exports; an estimated 85 per cent of foreign sales by large firms in 2007 were conducted through foreign affiliates of United States firms. This suggests that SMEs are likely to be more exportintensive than large firms, and to prefer exporting directly than selling through affiliates when they are more involved in international markets.

In general, SMEs are also distinct from large firms in terms of management. A difference in SMEs' managerial styles relative to large firms is indicated in the literature on comparative management (Bouncken, 2004; Deros et al., 2006; Hall \& Hall, 1990; Lee, Roehl, \& Choe, 2000; Maltz \& Kohli, 1996; Mikhailitchenko \& Lundstrom, 2006; Nakata \& Sivakumar, 2001; Poon, Evangelista, \& Albaum, 2005). The managerial style differences documented in the literature suggest that they are associated with two country-level attributes, that is, national culture and level of development. In addition, 
the literature on management accounting in SMEs shows that SMEs have little awareness of management accounting and its benefits. Further, the learning style and lifestyle of the owner-managers dictates how SMEs are run and how, in turn, any management information is viewed (Turner, 1997). While starting, growing and/or sustaining a business, SMEs' owner-managers are responsible for balancing business goals and managerial priorities with ownership control tendencies and family values, as in the case of the family enterprise, so as to satisfy all business stakeholders (Wang \& Poutziouris, 2010). SMEs are likely to have an informal, organic, and unified culture (Varintorn, Islam, \& Kulkarni, 2009).

Despite their resources being constrained, SMEs are reasonably regarded as the backbone of many economies (Altman \& Sabato, 2007), due to a large proportion of SMEs and a huge number of jobs provided by SMEs. Altman and Sabato reveal that more than 97 per cent of firms in OECD member counties are small and medium sized. In addition, statistics by the United States Small Business Administration ${ }^{3}$ also reported that US SMEs provided approximately 75 per cent of the net jobs for the economy, employing around 50 per cent of the private workforce, and representing 99.7 per cent of all employers. In Australia and New Zealand, SMEs are dominant across the economies in some business sectors, such as the property and business services, accounting for more than $50 \%$ of all new net jobs (Collins, Dickie, \& Weber, 2009).

In summary, SMEs are found to be different from large firms in many facets, such as management, internationalisation mode, and contribution to employment. Although SMEs are characterised as having constrained human, financial and managerial resources (Coviello \& Munro, 1997; Fontes \& Coombs, 1997; Holmlund \& Kock, 1998; Zafarullah et al., 1997), they are regarded as the backbone of economies due to their valuable contributions in terms of providing products and jobs. SMEs are different from large firms in terms of their structures, processes, resources and culture (Deros et al., 2006). It is worth taking these features into account when developing a framework that fits SMEs.

\footnotetext{
${ }^{3}$ See http://www.sba.gov
} 


\subsubsection{SMEs' internationalisation}

SMEs have become more active in international markets, making increasing contributions to economic growth and prosperity (Reynolds, 1997). Academics and business practitioners have recently shown interest in the internationalisation of SMEs in emerging economies, such as China (Ahlstrom \& Bruton, 2001), India (Saini \& Budhwar, 2008), Taiwan and Singapore (Sim \& Pandian, 2003), and Vietnam (Thai \& Chong, 2008). SMEs have been increasingly internationalised since the 1980s (UNCTAD, 1993). An OECD study (1997) examines SMEs' globalization from 18 member countries, and suggests that SMEs have been internationalizing more rapidly than in the past. OECD also provides evidence of small firms which become involved in international business activities almost from inception. Most of these SMEs are generating earnings in global markets more than in their home countries. In addition, SMEs "behave differently in their analysis of, and interaction with, their environment" (Shuman \& Seeger, 1986, p. 8) in comparison with large firms.

The internationalisation pattern of SMEs is dependent on firm and founder characteristics (Tuppura, Saarenketo, Puumalainen, Jantunen, \& Kyläheiko, 2008), as well as on macroeconomic environmental factors such as institutional regulations (Meyer, Estrin, Bhaumik, \& Peng, 2009). Born regional and born global patterns are increasingly applied over time due to changes in the macroeconomic environment (Sui, Yu, \& Baum, 2012), such as maturation of home markets, reduction of trade barriers resulting from free trade agreements, shrinking transportation and communication costs, improvements of global telecommunications and transport networks, and increasingly liberalised global trading regimes (Fan \& Phan, 2007). Such changes account for rapid internationalisation, thus they are used as an explanation for the emergence of early internationalised firms (e.g. Rialp, Rialp, \& Knight, 2005).

Empirical evidence from around the world shows that an increasing number of small firms are becoming involved in various international business activities from a very early age, and while being relatively small (Cavusgil \& Knight, 2009; Freeman, Edwards, \& Schroder, 2006; Oviatt \& McDougall, 2005). SMEs have been penetrating international markets through exporting, licensing, and foreign direct investment at different rates and pace across nations (Estrin, Meyer, Wright, \& Foliano, 2008; 
Yamakawa, Peng, \& Deeds, 2008). Such differences are caused by both negative effects of national culture, and positive effects of entrepreneurially oriented cultures, as well as developed formal institutions as defined by policy makers, which provide better regulatory systems, proper law enforcement, reduced corruption, and so forth (Ketkar \& Acs, 2013). As a result, SMEs appear to be better situated to take advantage of promarket reforms and of internationalisation opportunities.

With regard to accessing finance for internationalisation, SMEs seeking to enter new markets can face financial difficulties, such as shortages of working capital, and foreign exchange risk. SMEs encounter difficulties in obtaining finance because funders tend to have a higher perception of risks caused by exchange rate volatility, differing regulatory environments in the target market, perceived cultural difficulties and, in some cases, political risks (OECD, 2007b). In international markets, impacts of the financial environment, especially exchange rate fluctuations, have been shown to have a significant impact on SMEs' export performance (Maurel, 2009). For example, the devaluation of the European currency has a positive influence on Italian SMEs and vice versa (Majocchi, Bacchiocchi, \& Mayrhofer, 2005). In this study, Italian products, sold in Euro, are less expensive in international markets than the same products sold in another currency. Maurel (2009) also holds that exchange rate fluctuations matter for SMEs due to the expense of tools necessary to manage exchange risk: most SMEs cannot afford these tools. When entering new markets, SMEs need financial and management skills, including the ability to assess financial risk and to understand the use of more sophisticated financial instruments (OECD, 2007b) in order to hedge the exchange risk.

SMEs tend to increase their foreign market commitment over time, gaining experience and enhancing market knowledge, which lead them to further commitment in more distant markets (Coviello \& McAuley, 1999). In fact, the Establishment Chain models (also called Stages models) of internationalisation (Johanson \& Vahlne, 1977, 1990; Johanson \& Wiedersheim-Paul, 1975) argue that increased market knowledge and commitment affects internationalisation, which is incremental. Also, when a firm becomes an experienced exporter to some psychologically close country, the firm begins adjusting its export ratio optimally to changes in exchange rates, tariffs, and so 
on (Bilkey \& Tesar, 1977). Forex risk is one of the major concerns when internationalizing, and thus many firms make increasing attempts to manage this risk (Broll \& Wahl, 1997).

In terms of risk management, SMEs are likely to have more difficulties in comparison with large firms due to their scarce skills and resources, such as limited capital, management, time, experience, and information (Buckley, 1989). Recent empirical research shows that access to finance is an important growth constraint for SMEs (Beck, 2007; Beck \& Demirguc-Kunt, 2006); financial resources are important for them to leverage performance (Maranto-Vargas \& Gómez-Tagle Rangel, 2007). For instance, the growth of the Indian SME sector faces a major bottleneck due to its lack of adequate access to finance (Thampy, 2010). Chan-Lau (2005) also points out that SMEs may be prevented from accessing the forward market due to counterparty credit risk and lack of sophistication. In fact, collateral is generally required when clients do not meet internal credit rating requirements. Additionally, underwriting a forward contract requires first extending a credit line to the end-user. Therefore, costs associated with collateral and credit lines are passed on to the end-user at less favourable forward rates. Further, SMEs' treasurers or finance managers often lack the needed training for the active management of currency risk (Chan-Lau, 2005).

In such challenging situations, SMEs' treasurers or finance managers might be influenced by advisors, employees, and other important people (e.g., bankers), who form the SME's decision-making unit (Pennings \& Garcia, 2004). The people surrounding decision-makers could have a significant impact on the decisions, according to the literature in organizational behaviour and decision sciences (e.g., Moriarty \& Bateson, 1982) and treasurers/finance managers often lack the needed training for their active management. In fact, in line with Dholakia, Johnson, Della Bitta, and Dholakia (1993), Pennings \& Garcia find that SMEs' hedging practices may be influenced by a variety of individuals, either internal or external to the firm. Accordingly, decision-making units, with respect to finance/forex management, could be external consultants, the firms' own management teams, or individuals who possess information about hedging techniques and derivative markets. 


\subsection{FOREX RISK MANAGEMENT}

\subsubsection{Risk management}

\section{Risk}

Due to a general lack of agreement on a definition, risk has been defined in a number of ways, including: chance of loss, possibility of loss, uncertainty, dispersion of actual from expected results, probability of any outcome different from the one expected (C. M. Elliott \& Vaughan, 1972; Vaughan \& Vaughan, 2007). In the context of achieving the organization's goals, "risk is the concept that describes uncertainty in achieving goals" (McNamee, 1997, p. 2). In the finance and statistics literature, risk is defined as the variation from the expected outcome over time (Kallman, 2005). On account of this, risk can be measured by the magnitude of variance and standard deviation. According to Slovic \& Peters (2006), risk could be perceived and enacted as feelings and as analysis. While the former refers to instinctive and intuitive reactions to danger, the latter refers to assessment and decision making with logic, reason, and deliberation. Hansson (2008) defines risk across five disciplines. Accordingly, risk could be labelled as one of: (1) an unwanted event which may or may not occur, (2) the cause of an unwanted event which may or may not occur, (3) the probability of an unwanted event which may or may not occur, (4) the statistical expected value of an unwanted event which may or may not occur, and (5) the fact that a decision is made under conditions of known probabilities.

No matter how risk is defined, risk entails two essential components: exposure and uncertainty (Holton, 2004). Seeking a general definition of risk, he proposed:

“... Situations may appear disparate, but they share common elements. First people care about the outcomes. If someone has a personal interest in what transpires, that person is exposed. Second, people don't know what will happen. In each situation, the outcome is uncertain. (...) Risk, then, is exposure to a proposition of which one is uncertain"'(Holton, 2004, p. 22)

Adapting this definition of Holton (2004), the term foreign exchange risk in this thesis refers to a firm's exposure to foreign exchange rate changes of which the firms are 
uncertain. In other words, firms are at risk of foreign exchange if they are uncertain of fluctuations in foreign exchange, and are exposed if they have an interest in situations that are influenced by foreign exchange rate.

\section{Management of risk}

Recently, firms' risk management practices have been changing in accordance with changes in objectives at the firm level. While firms' primary objectives of risk management were to insure against hazards and to minimise probable loss, risk managers today are seen to put assets at risk for set objectives (McNamee, 1997). Likewise, corporate risk managers might focus not on minimizing variance, but rather on mitigating downside risks while extending their search for a comparative advantage into financial markets, an advantage that derives from information acquired through normal business activities (Stulz, 1996). Whatever the objectives are, they could have significant impacts on the practice of risk management.

Likewise, the approach to risk management is not only developed for specific uncertainties, but also for interrelated uncertainties. Primarily, the particularist view from the finance and insurance literature puts a heavy emphasis on managing corporate exposure with hedging and insurance instruments. However, Oxelheim \& Wihlborg (1987) argue that from the integrated risk management perspective, the interrelation of unanticipated movements in interest rates, forex rates, inflation rates, and relative prices could jointly make up the context for managing macroeconomic risk. From the same perspective, a wide range of interrelated uncertainties is categorised into three main groups along with many subcategories: general environmental, industry and firm specific uncertainties (K. D. Miller, 1992) ${ }^{4}$. Accordingly, forex risk is one macroeconomic uncertainty, and macroeconomic uncertainties are included in a subcategory of the group of general environmental risks identified in Miller's (1992) framework.

\footnotetext{
${ }^{4}$ This thesis applies APA 6 reference style. When different authors with the same last name were cited, their first and middle initials were included, so that a reader can differentiate between them. Read more at: http://www.cws.illinois.edu/workshop/writers/citation/apa/intextcitation/\#samename
} 
Exposures to such uncertainties can be managed with two approaches, namely financial risk management and strategic management (K. D. Miller, 1992). First, Miller insists that exposures to forex rate movements could be hedged with derivative products such as forward contracts, future contracts, and options. Second, he also argues that risks could be potentially mitigated with five strategic responses: avoidance, control, cooperation, imitation, and flexibility.

\section{What is risk management?}

McNamee (1997) provides a useful view of risk management and proposes that risk is never managed since it is a conceptual property. It is the organization that is managed to anticipate the uncertainties characterised by risk. He also writes:

Managing risk is actually managing the organization: planning, organizing, directing, and controlling organization systems and resources to achieve objectives. Managing risk must come from within and act to change the organization and its response to change in environment. Rather than try to guess what risks will affect the organization, the organization should build in certain characteristic to improve its ability to respond to change. (McNamee, 1997, p. 4)

However, it is more common to view risk management as the process of determining whether or how much of the risk is acceptable and what action should be taken (McNamee, 1997). Accordingly, risk management includes risk assessment and risk treatment. Potential treatments are risk diversification or avoidance, risk sharing and contingency planning (McNamee, 1997).

Figure 2-1 presents a framework for integrated risk-management, which is adapted from McNamee's (1997) notion that the risk management process includes three major steps: (1) establishing firms objectives, (2) risk assessment and (3) risk treatment. This process is regularly influenced by risk communication between experts, from experts to management teams, and from management teams to the public in the whole process of risk analysis. A number of text books relating to risk management follow this framework and suggest a process of risk management, for example C. M. Elliott and Vaughan (1972), Vaughan and Vaughan (2007), Shapiro (2006). As the first step in the 
risk-management process, a firm would determine objectives by deciding precisely what is to be expected from its risk-management programme. It is common to be aware of risks before anything is undertaken. A number of tools can be used to identify risks, including insurance policy checklists, risk analysis questionnaires, flow process charts, analysis of financial statements, and inspection of firms' operations. After risk identification, risks must be evaluated by measuring the possible size of loss and the probability that it is likely to occur. Based on this evaluation, ranking of priorities is followed, known as risk prioritization. The next step is the consideration of alternative techniques and selection of risk treatment. Risk characteristics are considered as determinants of the treatment, such as whether a risk is to be transferred or to be retained.

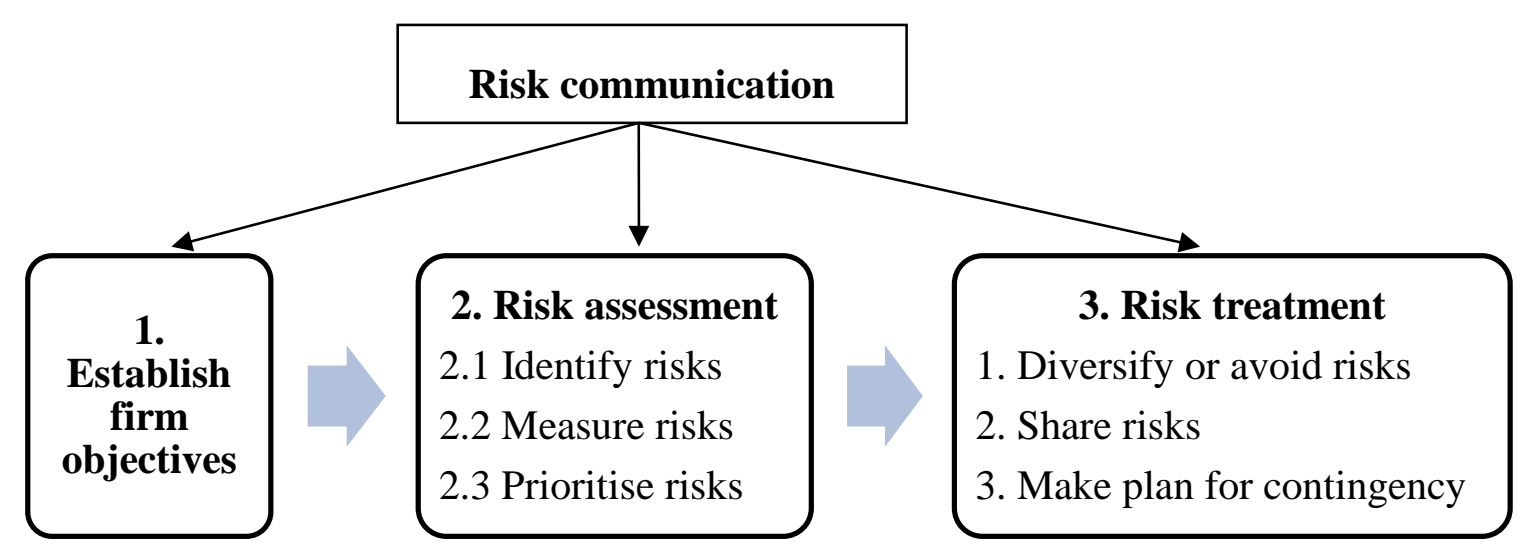

Figure 2-1: Risk Management Process, adapted from McNamee (1997)

Similarly, Finger (1999) conceives risk-management as

"the practice of assessing and identifying the different kinds of risks facing a person, an institution, or society because of its activities and environment, determining the likelihood of losses and other consequences from those risks, and taking appropriate actions, which include monitoring the risks and reducing the losses and other consequences from them". (Finger, 1999, p. 731)

Thus a firm's financial risk manager, who is part of a risk-management department or group, is firstly attempting to assess and measure the risks facing the firm as a result of 
its activities and the business environment; then to monitor the risks for any change; to determine whether the firm has the resources to deal with the risks; to alert senior managers and boards of directors about the risk information; and finally to suggest courses of action for the firm to take to deal with the risks (Finger, 1999). As discussed earlier, forex risk is categorised as one of the risks faced by firms; thus it is reasonable to adapt this risk-management framework for forex risk-management.

SMEs, similar to large firms, also face business risks, which can cause financial distress and bankruptcy in the worst case (Tan, 2014). However, the theme of risk management for SMEs has largely been neglected in the business management literature (Gao, Sung, \& Zhang, 2013; Henschel, 2009; Sharifi, 2014; Tan, 2014). The extant literature on SMEs' risk management shows that SMEs are incapable of employing formal structures and knowledge for risk management, and thus they tend to adopt informal processes of risk management (Henschel, 2009). Studying German SMEs, Gao et al. (2013) also find that SMEs lack formal methods for risk management. These findings imply that SMEs are more likely to use informal hedging techniques for managing forex risk; this will be discussed in the next sections.

\subsubsection{Foreign exchange risk management}

\section{Forex risk}

Although risk is perceived differently in a number of contexts, foreign exchange (forex) risks are those which arise from the changes in price of one currency against another. Forex risk, also called currency risk, forex rate risk, or simply exchange risk, is associated with unexpected changes in forex rates (Bartram, Dufey, \& Frenkel, 2005). For this reason, forex risk can be statistically measured by the variance or standard deviation of changes in forex rates. It is apparent that forex risk originates from fluctuations in currency prices, which might trigger exposures: economic exposure, transaction exposure and accounting exposure (Bodnár, 2007; Dominguez \& Tesar, 2008; Mooslechner \& Gnan, 2007; Shapiro, 2006).

\section{Management of forex risk}

The process of forex risk management, which is adapted from the process of managing risk (shown in Figure 2-1), includes three major steps. Firstly, firms start by the 
establishment of their hedging objectives, e.g., mitigating certain forex risk exposure, or reducing the volatility of cash flows. Secondly, assessment of forex risk is referred to as measuring forex exposure by estimating possible loss if forex rates changes and the probability of changes; and, thirdly, identifying, measuring and prioritizing factors that indeed influence firms' ability to respond to forex rate changes, e.g., tax liabilities, transaction cost, investment opportunities.

\section{To hedge or not to hedge}

The term hedging is defined differently in the literature. Broadly, Leland (1960, p. 140) holds that hedgers are those who seek insurance against the risk they may face. To analyse the hedging choice of managers, Smith \& Stulz (1985, p. 399) consider hedging as "the acquisition of financial assets that reduce the variance of the firm's payoffs". Leland's concept is widely used in the literature concerning forex management. Hedging can be carried out internally, known as internal hedging, when a firm tries to manage forex risk without the acquisition of financial instruments. On the other hand, external hedging entails the acquisition of financial instruments, e.g., currency derivatives, which are financial instruments whose characteristics and value depend upon the characteristics and value of a currency.

Considering that risk management is about "planning, organizing, directing, and controlling organization systems and resources to achieve objectives" (McNamee, 1997, p. 4), managing forex risk refers to planning, organizing, directing, and controlling a firm's systems and resources for improving its ability to respond to forex rate changes. Although hedging aims to seek insurance for forex risk, hedging is one way of managing forex risk, the other way is to do nothing. A decision whether to hedge or not to hedge is one step in the process of managing forex risk. To this end, "doing nothing" (no-hedge) is one of the hedging strategies. It might not necessary to hedge if SMEs could find benefits from favourable movements in the exchange rates, or if there might be no way they make a loss.

While some themes from the literature oppose hedging at a corporate level, others support corporate forex hedging strategies. For example, Dufey \& Srinivasulu (1983) made a case for corporate forex risk hedging. They point out that in a perfect world in 
which Purchasing Power Parity (PPP) theorem, Capital Asset Pricing Model (CAPM), Modigliani-Miller (MM) theorem, the Concept of Self-insurance, the Efficient Market Hypothesis, Hedging of Consumption Bundle and The Uncertainty of Forward Rates \& Spot Rates are all valid, there would be no need to hedge. Since we are not in an ideal world, however, it is evident that firms do need to hedge, as much of the literature suggests (Dufey \& Srinivasulu, 1983).

In line with the study of Dufey \& Srinivasulu (1983), a large number of studies provide empirical support for the performance of hedging strategies (Brookes et al., 2000; Dash et al., 2008; Dhanani, 2003; Joseph, 2000; Loderer \& Pichler, 2000; e.g., Marshall, 2000; Moosa, 2004; Morey \& Simpson, 2001; Pramborg, 2005). Short-term fluctuations in the exchange rate can be hedged with little difficulty and at little cost, while longterm movements are likely to be more serious (Brookes et al., 2000). In addition, it is thought to be imperative to hedge against adverse movements in exchange rates that may cause infrequent but large exposures (Moosa, 2004).

In practice, however, firms may choose not to hedge for various reasons, despite no evidence that hedgers outperform non-hedgers; for example, as a result of using derivatives (Allayannis, Brown, \& Klapper, 2001). For instance, because of difficulties for firms in measuring forex exposure, e.g., since they are unable to estimate future cash flows and presumably firm value (Loderer \& Pichler, 2000; Papaioannou, 2006; Pramborg, 2005), some might make the decision not to hedge. Other reasons for this decision could be insignificant forex exposure and the cost of setting up a hedging programme (Pramborg, 2005). To this end, due to high cost of establishing a hedging programme, and low magnitude of international involvement of SMEs in comparison with large MNEs, SMEs might choose not to hedge; however, once SMEs have a high percentage of their turnover denominated in a foreign currency, forex exposure would be potentially just as significant for SMEs as for large firms, and then SMEs might choose to hedge.

\section{Hedging strategies}

There are a number of hedging strategies noted in the literature concerning forex risk management; however, most hedging strategies refer to the use of currency derivatives 
as hedging instruments. For instance, firms under a no hedge strategy never purchase a forward foreign exchange contract to cover exchange rate risk. An alternative strategy is always-hedge, also referred to as hedged strategy. Selective hedging is a strategy under which firms will hedge if forward rates are at a premium. Large premia strategy is referred to as hedging when forward rates are at a historically large premium. This happens if spot exchange rates and future/forward exchange rates are quite different, when forward exchange rates and spot exchange rates move apart. On a relative purchasing power parity (ppp) exchange rate, firms will hedge whenever the current spot rate is above the ppp equilibrium, which is referred to as ppp down strategy. Under a hedge-no-hedge strategy, firms may hedge when the estimated exchange rate is higher than the forward rate offered for a short position, but lower than that offered for a long position. All of these hedging strategies (summarized in Eaker \& Grant, 1987; Moosa, 2004; Morey \& Simpson, 2001) are based on the use of currency derivatives.

The effectiveness of these strategies is extensively covered in the literature. For example, empirical data from Moosa (2004) study show no significant difference in the performance of the three strategies, namely no hedge, always hedge and hedge-nohedge, if foreign currency exposure is regular over a long period of time. This result implies that frequent forex exposure is not necessarily hedged because the unbiased efficiency hypothesis holds over a long period of time. According to this hypothesis, overestimation and underestimation of future spot prices in the short run would balance one another in the long run. Moreover, unbiasedness also implies that in the long run, negative errors would cancel out positive errors, since the estimation error is random rather than systematic (Moosa, 2004).

However, Morey \& Simpson (2001) find that in every time horizon, and for every sample of their study, an un-hedged strategy, also referred as to no hedge strategy, performs better than a hedged strategy, which is in line with the previously discussed notion that firms do not necessarily need to hedge. Additionally, Eaker \& Grant (1987) find that currency cross-hedging is likely to offer risk reduction opportunities, but unlikely to be as effective as using the same currency hedges. This result is consistent with logical predictions about the relationship between currencies. In other words, the true correlation between assets and currencies is one of the determinants of the 
measured effectiveness of cross hedging (Eaker \& Grant, 1987, p. 87). As a result, multiple hedges, which partially mitigate problems of inter-temporal instability of the exchange rate coefficients, are more effective than single currency cross-hedges. Eaker and Grant also add that the effectiveness of naive hedging strategies and more sophisticated ones is the same when portfolio positions are being hedged.

There are two initial inputs necessary for any hedging strategy, exchange rate forecast and exposure measurement (Jacque, 1981). These provide information for the assessment of risks in relation to exchange rate movements. However, not all firms have this capability, so SMEs' willingness and their ability to forecast exchange rates and measure exposure are also in doubt. Firms are unlikely to know how to quantify their risk profile as they are unable to figure out the percentage that their operating cash flows change if the forex rates change (Loderer \& Pichler, 2000). Similarly, Swedish and Korean nonfinancial firms have difficulties in estimating their forex exposure (Pramborg, 2005). It is the complexities to measure accurately current risk exposure that presents a challenge for firms in selecting the appropriate hedging strategy (Papaioannou, 2006). Also, daily exchange rates are extremely difficult to precisely forecast (Zhou, 1992). In the light of all of these results, SMEs might find difficulties in accessing these two key initial inputs for their forex risk management.

\section{Hedging techniques}

Basically, foreign currency risk may be hedged with internal and external techniques (Eaker \& Grant, 1987; Joseph, 2000). A wide range of hedging techniques is listed in Table 2.2. According to Mathur (1985), internal hedging refers primarily to the shifting of funds and commodities within a firm so as to maintain favourable balance sheet positions; on the other hand, external hedging generally involves contractual obligations with parties external to the firm. Similarly, this thesis defines external hedging as the use of contractual obligations with parties external to a firm, whereas internal hedging is defined as the use of a firm's systems and resources e.g., funds, goods within the firm. Both external and internal hedging can be used to improve the firm's ability to respond to forex rate changes. 
Table 2-2: Hedging techniques

\section{Category Techniques}

1. Pricing.

There are three options for currency invoicing, using:

- domestic currency of the country where firms are based.

- the currency in which the majority of the costs are incurred.

Internal

- the domestic currency of the main competitors in order to eliminate the effect of exchange rate variations on comparative prices.

2. Matching inflows and outflows with respect to timing of settlement.

3. Inter-company netting of foreign receivables and payables

4. Asset/liability management

5. Transfer pricing agreements

6. Leading and lagging

7. Adjustment clause in sales contracts

8. Cross hedging with futures.

9. Cross-currency interest rate swaps

10. Foreign currency swaps

11. Forward exchange contracts

12. Forex options

External 13. Forex futures

14. Foreign currency borrowing and lending

15. Factoring bills receivable

16. European currency unit

17. Special drawing rights

18. Other currency blocs

19. Government exchange risk guarantee

20. Insurance policies

Source: (Eaker \& Grant, 1987; Joseph (2000); Mathur, 1985) 
The selection of hedging techniques is significantly influenced by firm size (Block \& Gallagher, 1986; Booth, Smith, \& Stolz, 1984; Nance, Smith, \& Smithson, 1993; Warner, 1977). There are other ways to categorise hedging techniques e.g., natural and operational hedging. In a context of forex risk management, natural hedging refers to the matching of inflows and outflows, or the use of cash flows in different currencies so that the cash flows from each could cancel out forex risk. Operational hedging is another option for firms to manage forex risk, particularly for large firms. Pantzalis, Simkins, and Laux (2001) hold that operational hedging is best suited for managing forex rate risk, including various operational decisions related to marketing, production, sourcing, plant location, treasury, and so on. Boyabatli and Toktay (2004) argue that operational hedging may create a long term hedge, and it requires higher levels of capital investment compared to financial hedging. Therefore, an operational hedge would more likely be used by large firms due to their greater ability to design effective ways to manage forex risk in terms of the breadth and the depth of their subsidiaries' network structure. This result may lead us to consider that SMEs' approach to selecting their hedging strategies may be different from that of large firms.

Currency forward, which is a non-standardised contract between two parties calling for delivery of a specified amount of currency at a fixed future date and rate, is the most preferred hedging instrument amongst derivative instruments (Dash, 2009; Marshall, 2000; Papaioannou, 2006; Pramborg, 2005). These scholars find that forward is the most widely used method among currency derivatives in Asian countries such as Korea and India, as well as in developed financial markets like US, UK, Sweden; while Swaps, futures contracts, and options are less popular than forward contracts and other options are even less attractive than other instruments. This is in line with previous research (e.g., Bodnar \& Gebhardt, 1999; Marshall, 2000). Additionally, forward cover is favoured by firms that are absolutely risk-intolerant (Dash \& N.S., 2009), or in instances where there is a decreasing trend in exchange rates (Albuquerque, 2007; Dash et al., 2008). However, SMEs might be prevented from accessing the forward market because of counterparty credit risk and lack of sophistication, as noted in a study in Chile (Chan-Lau, 2005). 
Overall, the use of currency derivatives is extensively examined in the literature with the following broad findings. First, they are not popular in underdeveloped markets, for example, in Poland, because of the low liquidity of these instruments, and firms' lack of knowledge and reluctance to pay a premium (Central European, June 1999 cited by Jonuška \& Samėnaitè, 2003, pp. 9-10). Second, currency derivatives are mainly used to hedge transaction exposure (Loderer \& Pichler, 2000). Third, derivatives may be too costly for firms (Jonuška \& Samėnaitè, 2003). Fourth, firms are likely to place more emphasis on internal hedging techniques than currency derivatives (Hakkarainen, Joseph, Kasanen, \& Puttonen, 1998; McRae \& Walker, 1980), even though this is inconsistent with the results of Joseph's (2000) empirical study in UK industrial firms. Fifth, foreign-denominated debt could be used as a hedge, and may substitute for foreign currency derivatives (W. B. Elliott et al., 2003). Sixth, firms might use imports to match the forex exposure created by exports, thus there would be a strong, negative relationship between imports and the use of foreign exchange derivatives on the aggregate level.

Another important factor in firms' choice of hedging techniques is the extensive use of the US dollar for the invoicing of world trade. The use of the US dollar for invoicing is a popular internal hedging technique; even though the US dollar is subject to fluctuation. This trend could be explained by three reasons: (1) the fact that the US is an important consumption and production market in the world, (2) that a number of countries peg their currency to the US dollar, and (3) that goods involved in international trade transactions are still relatively homogeneous, which calls for worldwide pricing to be in a common vehicle currency (L. S. Goldberg \& Tille, 2008; Magee \& Rao, 1980). According to Goldberg \& Tille, it is likely that the use of the US dollar for invoicing will continue, since these three forces support the likelihood of the continuation of the USD role in international trade.

SMEs mainly resort to internal hedging tools and techniques. For example, SMEs in a study of Kula (2005) heavily used lagging for Turkish Lira payable with leading foreign currencies, borrowing in the same currency of sales, and using short maturity of foreign currency denominated loans. These firms are less likely to be familiar with contractual hedging techniques such as forwards, futures, swaps, and options. Kula stresses that 
these SMEs are "not even fully aware of the nature of these techniques". However, even when SMEs are aware of external hedging, they may prefer not to set up a costly hedging program using external techniques such as derivatives and foreign debt (Jonuška \& Samėnaite, 2003), due to their limited access to resources (Ciubotariu, 2013; Coviello \& Munro, 1997; Coviello \& Munro, 1995; Hashim \& Wafa, 2002; Holmlund \& Kock, 1998; Sirtaine, 2006).

\subsubsection{The importance of forex management in an international business setting}

Research on the effect of forex risk on internationalisation, both foreign direct investment (FDI) and exports, is ambiguous (Cushman, 1988a). An increase in bilateral exchange risk would probably reduce FDI, due to a lower desire among firms of holding foreign real assets (Branson \& Henderson, 1984); however, there could be a number of situations in which forex uncertainty could also theoretically increase FDI, for example, as a substitute for a decrease of exports (Cushman, 1985; Itagaki, 1981). At the firm level, Solakoglu (2010) find that an increase in exchange rate risk negatively impact real exports, whereas Kasman and Kasman (2005) report reverse findings, suggesting that there exists a long run and short run positive impact of real exchange volatility on exports, in line with the findings of Asseery and Peel (1991), Doyle (2001), and Bredin, Fountas, and Murphy (2003). Likewise, it is likely that forex rate risk would asymmetrically affect exports, negatively or positively, in periods of depreciation or appreciation, respectively (Cushman, 1988b; Fang, Lai, \& Miller, 2009; Fang, Lai, \& Thompson, 2007). In addition, Fang et al. (2009) suggest various sources of asymmetries such as exporter asymmetric risk perception, US-dollar invoicing, incomplete financial markets, fear of floating, fear of depreciation, and lack of active or improper forex intervention amongst others.

Firms involved in international operations under exchange rate uncertainty develop ways to protect themselves from forex rate risk (Broll \& Wahl, 1997), since forex risk management, either at a country level or at a firm level, might matter for export performance (Prater \& Ghosh, 2005; Sekkat \& Varoudakis, 2000). For instance, Sekkat and Varoudakis (2000) report that exchange rate mismanagement at a country level or an inappropriate exchange rate policy, might reduce the incentives for exporters to penetrate foreign markets. Therefore, an appropriate exchange rate policy itself has 
much to recommend it for promoting exports. Further, given the important effect of financing constraints on the sensitivity of exports to exchange rate fluctuations, Dekle and Ryoo (2007) suggest that firms would hedge against exchange rate fluctuations, since they might suffer from low cash flows due to depreciation. Additionally, crosshedging could increase the gains from international trade in transitional economies, which are characterised by missing and imperfect risk sharing markets for international trade (Broll, Mallick, \& Wong, 2001).

\subsubsection{Forex risk exposure: Does size matter?}

On the one hand, it is likely that SMEs might suffer greater forex exposure than large firms, because, as Ahmed and Omneya (2007) argue, larger firms might suffer lower forex exposure due to sufficient resources, in terms of personnel and knowledge, to hedge their risk in international transactions. Likewise, Yeo and Lai (2004) argue that SMEs venturing overseas would face greater risks and vulnerability than the large firms, which have more advantages of size to access global resources. This implies that SMEs may be well aware of forex exposure, but not have the resources to manage the risk when they penetrate, grow, and succeed in the global marketplace; they may suffer losses caused by forex fluctuations, or losing business opportunities (International Trade Administration, 2008).

On the other hand, Doidge, Griffin, and Williamson (2002) find that SMEs are actually less sensitive to exchange rate fluctuations than large firms due to two possible reasons. First, in terms od transaction exposure, SMEs tend to operate in markets with inelastic demand, while large firms compete in more price-sensitive markets. Second, in terms of translation exposure, it would take more time for exchange rate movements to affect the stock prices of listed SMEs than those of large firms, for fewer investors might understand the role of exchange rate exposure in a small firm compared to a large firm, possibly due to a lack of information. Further, not all SMEs are publicly listed, so SMEs' values are unlikely to be sensitive to exchange rate movements.

From these two points of view, it is likely that SMEs might face two major dangers if they fail to have a forex risk management program. First, they might suffer greater forex risk exposure. Second, they might be unable to compete in markets where demand is 
price-sensitive. Therefore, it is important to recognise the advantages and disadvantages for SMEs of managing forex risk, and the implications for SMEs venturing into the international marketplace.

\subsubsection{Are SMEs or large firms more likely to hedge?}

There are several arguments on how forex risk management would be affected by firm size, which is regarded as an endogenous variable, and a function of scale economies in organization and production (Nance et al., 1993). A number of scholars, for example, Block and Gallagher (1986), Booth et al. (1984) argue that larger firms are more likely to hedge because of informational scale economies of hedging programs. They also hold that large firms could afford to employ managers with the specialised information to manage a hedging program. In line with this argument, based on reported U.S. data, Papaioannou (2006) notes that the larger firms tend to use derivative instruments for hedging their exchange rate risk. Nance et al. (1993) also hold that large firms are more likely to hedge with instruments such as the swap, forward, and over-the-counter options markets due to significant scale economies in the structure of transactions costs.

The relation between hedging and firm size seems to be ambiguous, with controversial arguments in the literature. However, there is general support for the hypothesis that large firms are more likely to hedge with formal hedging programmes, because derivatives are major instruments that would be used in hedging programs of large firms, whereas they could be unaffordable for SMEs. In fact, given the informational scale economies of hedging programs, information-specialised managers and hedging instruments, large firms are more likely to hedge with derivatives, or other external hedging instruments, e.g., foreign debt. Likewise, Graham \& Rogers (2002) find that hedging increases with firm size; however, they also indicate that this result is not consistent with informational asymmetry leading to increase hedging. This result would be consistent with fixed costs limiting hedging by small firms, implying that SMEs fail to afford high fixed costs of establishing a hedging program. Hence, SMEs would be inclined to use less costly hedging instruments, e.g., internal hedging. In addition, SMEs are more likely, as previously discussed, to adopt informal processes to develop risk management capability (Henschel, 2009), and lack formal methods for risk management 
(Gao et al., 2013). These support the notion that SMEs are more likely to hedge with internal hedging techniques.

\subsubsection{The importance of forex risk management for SMEs}

Forex risk management is important for internationalised SMEs because forex risk is particularly severe for firms entering new foreign markets, and it might place the firms at a disadvantage (Nakos \& Brouthers, 2002). In fact, SMEs are becoming increasingly active in global markets (Bonaccorsi, 1992; Erramilli \& D'Souza, 1993; Haahti, Hall, \& Donckels, 1998). As a result, they may be confronted with various risks, including unstable political, economic and social environments (Ramcharran, 2000). However, managing foreign exchange risk is among the second tier of concerns for SMEs (Prater \& Ghosh, 2005), while, in a study of by Klassen and Whybark (1994), it ranks last for MNEs. Also, a study conducted by Price Waterhouse and Confederation of British Industry (Northern Ireland, 1995), reveals that currency fluctuation is the top export problem for small UK companies.

Forex risk management is also important for internationalised SMEs, as it is critical for smaller firms to manage short-term cash flow (Prater \& Ghosh, 2005); cash flow problems are the primary cause for SMEs' failures (Small Business Administration, U.S. 1994). SMEs are often limited in financial resources (Coviello \& Martin, 1999); therefore the fluctuations of exchange rates would have much more negative impact on the financial resources of SMEs in international markets (Prater \& Ghosh, 2005). Looking into a survey with 1,400 SMEs in Singapore, Hong Kong, Malaysia and the Philippines by the non-bank provider of cross-border payments in February 2014, Asaolu (2011) finds that SMEs in these four countries have become more sensitive to foreign exchange fluctuations. This study also reports that about 27 per cent of Singaporean SMEs regularly check foreign exchange rates each day, compared with 21 per cent of SMEs in Hong Kong, 19 per cent in the Philippines and 16 per cent in Malaysia. As a result, SMEs need to manage forex risk to ensure stability and availability of capital, which could improve their ability to export and physically expand into international markets (Westhead, Wright, \& Ucbasaran, 2001, p. 342). 


\subsection{THE EXTANT LITERATURE ON HEDGING DETERMINANTS}

This section reviews various determinants of forex risk management, which are identified in the current literature. A number of research papers relating to determinants of hedging strategies were summarized in Appendix A. The section begins with the basic factor that influences a firm to hedge forex risk, that is, forex risk exposure, also known as exchange rate exposure. Subsequently, a number of rationales for the use of hedging strategy are presented.

\subsubsection{Exchange rate exposure}

\section{Definition of exchange rate exposure}

Exchange rate exposure could be perceived in different ways. Broadly, exchange rate exposure, known as economic exposure of exchange rate, describes the extent to which firm value is influenced by exchange rate movement (Dominguez \& Tesar, 2008). In other words, exchange rate exposure is considered as currency mismatch (Mooslechner \& Gnan, 2007). Narrowly, different types of exchange rate exposures are measured by the effect of the exchange rate on specific components of a firm's balance sheet or on various types of transactions. The combination of these exposures forms the economic exposure. Following are various major types of exchange rate exposures identified in the literature (Dominguez \& Tesar, 2008; Mooslechner \& Gnan, 2007; Shapiro, 2006).

- translation exposure, also known as accounting exposure, refers to changes in accounting positions - the balance sheet or income statement - as a result of different denomination of assets, liabilities and/or income and expenditure. Translation exposure arises from the need, for purposes of reporting and consideration, to convert the financial statements of foreign operations from the local currency involved to the home currency.

- transaction exposure presents the changes of contractually binding future foreign currency denominated cash inflows or outflows from external contracts, foreign investment, and so on, as a result of exchange rate changes.

- operating exposure implies the changes of market position such as competition, relative prices, quantities of demand or supply and so forth due to the fluctuation of exchange rates. 
- contingency exposure concerns the potential revaluation of future possible liabilities, for instance, in the case where a firm submits an offer on a tender.

In general, forex exposure reflects the sensitivity of items exposed to exchange rate changes. It can be measured by the product of net value of these items and the sensitivity to exchange rate changes. On account of this, exchange rate exposure exists when there are changes in exchange rates. Consequently, forex risk is the product of exchange rate exposure and the probability of an exchange rate change (Douch, 1996 as cited in Mooslechner \& Gnan, 2007, p. 207).

\section{Evidence on exchange rate exposure}

Even though only about $10-25 \%$ of non-financial firms are likely to suffer significant forex rate exposures resulting from the impact of exchange rate risk on the stock returns, exchange rate exposure is constantly changing over time because of changes in corporate assets, liabilities, activities and developments in the competitive environment (Bartram, Dufey, \& Frenkel, 2005). Estimating the exchange rate exposure of publicly listed firms in eight non-US industrialised and emerging markets, Dominguez \& Tesar (2006), however, find a considerable amount of exposure to numerous exchange rates. On the one hand, the direction of exposure depends on the specific exchange rate and varies over time. On the other hand, exposure is correlated with firm size as well as multinational status, foreign sales, international assets, competiveness and trade at the industry level. Accordingly, the smaller firms are, the more likely they are to be exposed to exchange rate risk, because the larger firms might have more access to mechanisms for hedging exposure than smaller ones.

Also, although a large number of empirical studies reveal that very few firms have significant forex rate exposures (Bartov \& Bodnar, 1994; Bartov, Bodnar, \& Kaul, 1996; Dominguez \& Tesar, 2001; Griffin \& Stulz, 2001; He \& Ng, 1998; Jorion, 1990), it is, at the same time, found that the number of firms that have significant forex exposure depends on the type of forex rate index used to measure exposure (Fraser $\&$ Pantzalis, 2003). Moreover, by extending prior theoretical results to model a global firms' exchange rate exposure, Bartram, Brown, \& Minton (2010) show empirically that firms that pass through part of the currency changes to customers and utilise both 
operational and financial hedging may reduce their exposure. To illustrate, Bartram, Brown, \& Minton indicate that exposure may be reduced by about $10-15 \%$ by passthrough or operational hedging, about $40 \%$ by financial hedging with foreign debt, and to a lesser extent by forex derivatives.

In general, as a result of market imperfections and deviations from parity conditions, such as purchasing power parity and the international Fisher effect ${ }^{5}$, there exists the risk caused by unexpected changes of exchange rates (Bartram, et al., 2005). On account of this, it is important to understand how small, non-financial firms may better implement or improve their risk management systems ${ }^{6}$.

\subsubsection{Determinants of firms' choice of hedging strategy}

Given that most firms are exposed to forex rates due to the rapid globalization of the business environment, firms may implement an active policy of risk management, hedging more and using a variety of hedging techniques. Imperfections in financial markets are also responsible for exchange rate exposure (Bartram, et al., 2005), and thus for the existence of incentives to hedging in association with either the creation of value or a manager's aversion to risk (González, Búa, Lopez, \& Sandías, 2007). In spite of these incentives, which justify hedging activities, it is worth considering costs and benefits related to hedging strategies when ultimately evaluating the hedging decision (Géczy, Minton, \& Schrand, 1997; Muller \& Verschoor, 2005). Thus, this section presents key theoretical points of view on this aspect.

There are a number of determinants identified in the literature on the choice about hedging strategy for managing forex risk (see Table 2-3). Rationales for hedging noted in the table are as follows:

5 According to which the change of the current exchange rate between any two currencies is approximately equivalent to the difference between the two countries' nominal interest rates for that time.

${ }^{6}$ Non-financial firms are those which do not deal with financial or investment-related goods or service (see http://www.businessdictionary.com/definition/non-financial-industry.html ) 


\section{Degree of Internationalisation}

A firm's degree of internationalisation could significantly influence the firm's exposure to forex risk (Mathur, 1985; Reeb, Kwok, \& Baek, 1998), and thus diversification of its usage of hedging techniques. According to Mathur, when a firm has many foreign sales or manufacturing subsidiaries, it could better utilise internal hedging techniques, and become a "successful" firm. This author advises firms to put a considerable emphasis on various easily-implemented, zero or low cost hedging strategies, which are known as internal hedging. On the one hand, Joseph (2000) indicate that the greater use of internal techniques would imply a lower use of external techniques. On the other hand, a firm would be likely to hedge more, and to utilise more external techniques because of increasing forex exposure when it is more strongly involved in international markets. Whether a firm uses internal or external hedging instruments is also likely to depend on the ability of risk managers to use such instruments.

\section{Forex Exposure}

As discussed in the section above, forex risk exposure is a primary determinant for hedging. Firms incur forex exposure due to transactions in foreign currencies e.g., exports and imports (Aabo, Høg, \& Kuhn, 2010; Pramborg, 2005). Aabo, et al. (2010) find a strong negative relationship between importing and the use of currency derivatives on the aggregate level. Their findings support the notion that firms use importing to match the forex exposure created by foreign sales activities. Borrowings in foreign currency could also be a source of forex exposure, while foreign-denominated debts could substitute for foreign currency derivatives as a hedging tool (W. B. Elliott et al., 2003; González et al., 2007).

A number of studies show that types of exposure might also play a vital role in a firm's forex risk strategy. Joseph (2000) point out that the types of hedged exposure would impact the degree of utilization of hedging techniques, i.e. hedging degree, while the choice of a hedging technique might be affected by firms' characteristics. For example, firms could use intercompany netting and domestic invoicing to hedge transaction exposure, matching inflow and outflows for economic exposure, and asset/liability management for translation exposure. Joseph (2000) also states that UK MNEs focus more on transaction and economic exposures and less on translation exposures by using 
currency derivatives. On the other hand, Kula (2005) holds that Turkish SMEs are more concerned with managing transaction exposure than economic exposure, using internal hedging techniques.

The degree of utilisation of both internal and external techniques depends on the type of exposure that is hedged. Furthermore, the characteristics of the firms appear to explain the choice of hedging techniques but the use of certain hedging techniques appears to be associated with increases in the variability of some accounting measures.

\section{Managerial risk attitude}

Managerial attitude toward forex risk is likely to be determined by managerial perception of forex uncertainty. In fact, risk attitude is defined as "the chosen response to perception of significant uncertainty" (Hillson \& Murray-Webster, 2007, p. 3). In a context of forex risk management, the chosen response could be the choice of hedging techniques and strategies.

Risk aversion, for example, would be a choice of managers to treat forex risk. Managers, who are also shareholders, might implement terms of compensation that influence both the incentive to hedge and the choice of hedging techniques (Joseph, 2000). On account of this, managerial risk aversion, or, in other words, the risk attitude of managers toward forex risk, would influence the firms' resource allocation for forex risk management.

In addition, Smith \& Stulz (1985) also claim that risk managers dedicate all their human capital and often a significant portion of their financial capital to a hedge against the exchange risk exposed to protect their firms' profitability. The managers might be worried about possible losses and/or variations that impact their assets and their jobs as well. As a result, they are likely to allocate more resources, both human and financial, so as to adopt more hedging techniques and to hedge more, when they are exposed to a high forex risk, in order to protect the company's benefits.

\section{Under-investment problem}

In addition, a firm may prefer a hedging programme for its investment opportunities to lower potential risks rather than costly external finance support, which is known as the 
classical under-investment problem by S. C. Myers (1977). While Schiozer and Saito (2009) proxy investment opportunities with annual capital expenditure scaled by depreciation, González et al. (2007) and Pramborg (2005) use institutional ownership, market to book value and intangible assets as proxies for both information asymmetry and growth opportunities.

Under-investment problem is more relevant to strategies for reducing cost of capital by formal hedging programmes, which are mostly affordable to large firms. In contrast, SMEs' owners hedge to seek "peace of mind", that is, to fix their receivables, payables and cash flow, and to remain profitable regardless of the fluctuations of international forex markets (Tan, 2014). Hence, SMEs are unlikely to be concerned with underinvestment problem.

\section{Financial distress}

The cost of financial distress could be reduced as a result of risk management, and small firms are more likely to hedge, since the reduction of bankruptcy costs is greater for these firms (Smith \& Stulz, 1985, p. 398). In line with previous studies, Schiozer \& Saito (2009) use interest coverage, which is the average earnings before interest and taxes (EBIT) of the last three years divided by the interest expenses in the last three fiscal years, to measure financial distress. Accordingly, the greater interest coverage of a firm implies it has less financial distress, and thus the firm is less likely to hedge. Leverage, liquidity, profit per share, return on assets (ROA) could be used as various proxies for financial distress (González et al., 2007).

\section{Hedging costs}

Costs play an important role in a firm's hedging decision. The literature on forex risk management suggests that economies of scale are associated with high fixed costs of training employees and purchasing technical resources (González et al., 2007). As a result, firm size would likely be relevant to economies of scales, and also associated with the cost of hedging. In fact, there is a positive relationship between firm size and derivatives usage because of economies of scale (Fok, Carroll, \& Chiou, 1997; González et al., 2007; Nance et al., 1993; Shiu, Wang, Adams, \& Shin, 2012). The 
proxy for firm size is the natural logarithm of total asset (González et al., 2007) or the logarithm of total revenue (Pramborg, 2005).

\section{Tax benefit}

A firm could reduce the volatility of its earnings, and thus decrease its tax expenses if it is subject to a tax schedule that yields a convex function of earnings before tax (EBT) (Smith \& Stulz, 1985, p. 359). A dummy of tax convexity is used as a proxy to characterise whether or not a firm is subject to this convexity (Nance et al., 1993; Schiozer \& Saito, 2009).

\section{Information asymmetry}

A positive relationship between information asymmetry and hedging is expected, as the absence of disciplines imposed by capital markets could bring private benefits to managers (Schiozer \& Saito, 2009). Authors, like Mian (1996), Allayannis and Ofek (2001) also use a dummy to proxy information asymmetry. 
Table 2-3: Determinants of firms' choice of hedging techniques

\begin{tabular}{|c|c|c|c|}
\hline $\begin{array}{c}\text { Theoretical } \\
\text { rationales }\end{array}$ & Variable & Proxies and Measurement scale & Authors \\
\hline \multirow{4}{*}{$\begin{array}{c}\text { Degree of } \\
\text { internationalisation }\end{array}$} & \multirow[t]{4}{*}{$\begin{array}{l}\text { The degree of } \\
\text { internationalisation }\end{array}$} & $\begin{array}{l}\text { The number of foreign countries in } \\
\text { which the firm operates }\end{array}$ & (Joseph, 2000) \\
\hline & & The number of foreign subsidiaries & (Joseph, 2000) \\
\hline & & $\begin{array}{l}\text { The logarithm of the sum of number of } \\
\text { production subsidiaries plus one }\end{array}$ & $\begin{array}{l}\text { (Aabo et al., } \\
2010)\end{array}$ \\
\hline & & $\begin{array}{l}\text { The logarithm of the sum of number of } \\
\text { production sales plus one }\end{array}$ & $\begin{array}{l}\text { (Aabo et al., } \\
2010)\end{array}$ \\
\hline \multirow{5}{*}{ Risk exposure } & $\begin{array}{l}\text { Export in foreign } \\
\text { currency }\end{array}$ & Foreign sales/total sales & $\begin{array}{l}\text { (Aabo et al., } \\
\text { 2010; Pramborg, } \\
\text { 2005) }\end{array}$ \\
\hline & $\begin{array}{l}\text { Import in foreign } \\
\text { currency }\end{array}$ & $\begin{array}{l}\text { The percentage of the firm's } \\
\text { consolidated operating costs in foreign } \\
\text { currency }\end{array}$ & $\begin{array}{l}\text { (Aabo et al., } \\
\text { 2010; Pramborg, } \\
\text { 2005) }\end{array}$ \\
\hline & Foreign debt & Volume of foreign debt & $\begin{array}{l}\text { (W. B. Elliott et } \\
\text { al., 2003; } \\
\text { González et al., } \\
\text { 2007) }\end{array}$ \\
\hline & Types of exposure & $\begin{array}{l}\text { Economic, transaction, translation, } \\
\text { operating, contingency exposure }\end{array}$ & $\begin{array}{l}\text { (Joseph, 2000; } \\
\text { Kula, 2005; } \\
\text { Pramborg, 2005) }\end{array}$ \\
\hline & $\begin{array}{l}\text { Forex exposure } \\
\text { group }\end{array}$ & $\begin{array}{l}\text { Forex exposure groups: Import, Export } \\
\text { or Neutral }\end{array}$ & $\begin{array}{l}\text { (Joseph, 2000; } \\
\text { Kula, 2005) }\end{array}$ \\
\hline \multirow{3}{*}{$\begin{array}{l}\text { Managerial risk } \\
\text { attitude }\end{array}$} & $\begin{array}{l}\text { Exposure } \\
\text { perception }\end{array}$ & $\begin{array}{l}\text { Managerial assessments of forex } \\
\text { exposure }\end{array}$ & (Kula, 2005) \\
\hline & $\begin{array}{l}\text { Managerial risk } \\
\text { aversion }\end{array}$ & $\begin{array}{l}\text { - Managers' ownership measured by } \\
\text { the percentage of capital held by } \\
\text { managers }\end{array}$ & $\begin{array}{l}\text { (González et al., } \\
\text { 2007) }\end{array}$ \\
\hline & $\begin{array}{l}\text { Compensation } \\
\text { plans }\end{array}$ & $\begin{array}{l}\text { - Managers' remuneration to market } \\
\text { value } \\
\text { - Employees' remuneration to market } \\
\text { value } \\
\text { - } \text { Book value to market value } \\
\end{array}$ & $\begin{array}{l}\text { (Joseph, 2000) } \\
(\text { Joseph, 2000) } \\
\text { (Joseph, 2000) } \\
\end{array}$ \\
\hline \multirow{7}{*}{$\begin{array}{l}\text { Under-investment } \\
\text { problems }\end{array}$} & $\begin{array}{l}\text { Investment } \\
\text { opportunities }\end{array}$ & $\begin{array}{l}\text { - Annual capital expenditure scaled by } \\
\text { depreciation } \\
\text { - R\&D expenses in percent of the } \\
\text { turnover }\end{array}$ & $\begin{array}{l}\text { (Schiozer \& } \\
\text { Saito, 2009) } \\
\text { (Aabo et al., } \\
\text { 2010) }\end{array}$ \\
\hline & Firm size & The logarithm of total asset & $\begin{array}{l}\text { (González et al., } \\
\text { 2007) }\end{array}$ \\
\hline & Intangible asset & Intangible assets/total assets & $\begin{array}{l}\text { (González et al., } \\
\text { 2007) }\end{array}$ \\
\hline & Leverage & $\begin{array}{l}\text { - Debt-to-equity ratio } \\
\text { - Natural logarithum of the ratio } \\
\text { current assets/current liabilities }\end{array}$ & $\begin{array}{l}\text { (González et al., } \\
\text { 2007) } \\
\text { (Schiozer \& } \\
\text { Saito, 2009) }\end{array}$ \\
\hline & $\begin{array}{l}\text { Sales to market } \\
\text { value }\end{array}$ & Total sales/market value & (Joseph, 2000) \\
\hline & $\begin{array}{l}\text { Growth } \\
\text { opportunities }\end{array}$ & $\begin{array}{l}\text { - Market value of assets /Book value } \\
\text { of assets } \\
\text { - Book value to market value }\end{array}$ & $\begin{array}{l}\text { (González et al., } \\
\text { 2007) } \\
\text { (Joseph, 2000; } \\
\text { Pramborg, 2005) }\end{array}$ \\
\hline & Dividend yield & EPS/Share price & (Joseph, 2000) \\
\hline
\end{tabular}




\begin{tabular}{|c|c|c|c|}
\hline \multirow{4}{*}{ Financial distress } & Leverage $^{(*)}$ & $\begin{array}{l}\text { - Debt-to-equity ratio } \\
\text { - The equity divided by the total assets }\end{array}$ & $\begin{array}{l}\text { (González et al., } \\
\text { 2007; Pramborg, } \\
\text { 2005) } \\
\text { (Aabo et al., } \\
\text { 2010) }\end{array}$ \\
\hline & Liquidity & $\begin{array}{l}\text { - Current ratio: The ratio current } \\
\text { assets/current liabilities } \\
\\
\text { - Natural logarithum of the ratio } \\
\text { current assets/current liabilities } \\
\text { - Cash asset ratio } \\
\text { - Gross cash flow to market value } \\
\text { - Cash and marketable securities to } \\
\text { market value } \\
\text { - Quick asset ratio } \\
\text { - Working capital ratio } \\
\text { - Interest charges to operating and } \\
\text { non-operating income } \\
\text { - Preference capital and total } \\
\text { borrowing to total capital employed } \\
\text { - Total borrowing to ordinary } \\
\text { shareholders' equity plus reserves } \\
\text { - Long-term borrowing to market } \\
\text { value }\end{array}$ & $\begin{array}{l}\text { (González et al., } \\
\text { 2007; Pramborg, } \\
\text { 2005) } \\
\text { (Schiozer \& Saito, } \\
\text { 2009) } \\
\text { (Joseph, 2000) } \\
\text { (Joseph, 2000) } \\
\text { (Joseph, 2000) } \\
\text { (Joseph, 2000) } \\
\text { (Joseph, 2000) } \\
\text { (Joseph, 2000) } \\
\text { (Joseph, 2000) } \\
\text { (Joseph, 2000) } \\
\text { (Joseph, 2000) }\end{array}$ \\
\hline & EPS & Profit/number of shares & $\begin{array}{l}\text { (González et al., } \\
\text { 2007) }\end{array}$ \\
\hline & ROA & EBIT/Total assets & $\begin{array}{l}\text { (González et al., } \\
\text { 2007) }\end{array}$ \\
\hline Hedging costs & $\begin{array}{l}\text { Firm size }{ }^{(*)} \\
\text { (economies of } \\
\text { scale) }\end{array}$ & $\begin{array}{l}\text { - The logarithm of total revenues } \\
\text { - Total asset } \\
\text { - The logarithm of total asset } \\
\text { - The logarithm of sales }\end{array}$ & $\begin{array}{l}\text { (Pramborg, 2005) } \\
\text { (Aabo et al., } \\
2010 \text { ) } \\
\text { (Aabo et al., } \\
\text { 2010; González } \\
\text { et al., 2007; } \\
\text { Schiozer \& Saito, } \\
\text { 2009) } \\
\text { (Schiozer \& } \\
\text { Saito, 2009) }\end{array}$ \\
\hline \multirow[t]{5}{*}{ Tax Liabilities } & $\begin{array}{l}\text { Dummy of text } \\
\text { convexity }\end{array}$ & $\begin{array}{l}\text { It assumes a value of } 1 \text { if a tax credit } \\
\text { was transferred from one year to } \\
\text { another during the period in the } \\
\text { previous five years. Otherwise, it } \\
\text { assumes a value of } 0 .\end{array}$ & $\begin{array}{l}\text { (Nance et al., } \\
\text { 1993; Schiozer \& } \\
\text { Saito, 2009) }\end{array}$ \\
\hline & \multicolumn{2}{|c|}{ Tax charge on profit/loss to pre-tax profit/loss } & (Joseph, 2000) \\
\hline & \multicolumn{2}{|c|}{ Tax charge on profit/loss to market value } & (Joseph, 2000) \\
\hline & \multicolumn{2}{|c|}{ Operating profit to sales } & (Joseph, 2000) \\
\hline & \multicolumn{2}{|c|}{ Trading profit to sales } & (Joseph, 2000) \\
\hline \multirow{3}{*}{$\begin{array}{l}\text { Information } \\
\text { asymmetry }\end{array}$} & $\begin{array}{l}\text { Dummy of } \\
\text { information } \\
\text { asymmetry }\end{array}$ & $\begin{array}{l}\text { A value of } 1 \text { if a firm is from a } \\
\text { regulated industry and zero otherwise }\end{array}$ & $\begin{array}{l}\text { (Schiozer \& } \\
\text { Saito, 2009) }\end{array}$ \\
\hline & $\begin{array}{l}\text { Institutional } \\
\text { ownership }\end{array}$ & $\begin{array}{l}\text { Percentage of capital held by } \\
\text { institutions }\end{array}$ & $\begin{array}{l}\text { (González et al., } \\
\text { 2007) }\end{array}$ \\
\hline & $\begin{array}{l}\text { Market to book } \\
\text { value }\end{array}$ & & $\begin{array}{l}\text { (González et al., } \\
\text { 2007) }\end{array}$ \\
\hline
\end{tabular}

Note: * Variables might be related to several theoretical rationales. 
In summary, from the literature on determinants that influence a firm's choice about hedging strategy, there are eight fundamental reasons serving to account for a firm's hedging against forex risk and its utilization of hedging techniques, as shown in Table 2-3: (1) degree of internationalisation, (2) forex risk exposure, (3) managerial risk attitude, (4) under-investment problems, (5) financial distress, (6) hedging costs, (7) tax liabilities, and (8) information asymmetry.

However, recent research studies show a number of financial ratios, such as the number of shareholdings by the director, dividend pay-out ratio and debt to equity ratio (liquidity), which are not relevant to forex risk management (Shaari, Hasan, Palanimally, \& Mohamed, 2013). Although SMEs' managers might be affected by financial ratios when making hedging strategy, exporting SMEs might consider the forex exposure as a major drive to manage forex risk when they operate internationally. For example, New Zealand exporting SMEs may increasingly seek professional expertise for forex risk management due to the rise of New Zealand dollar (Pla, 2008). Also, SMEs tend to hedge transaction exposure, which is closely related to exporting revenues and cash flows (Kula, 2005). Given the literature, it could be argued that the degree of internationalisation, forex risk exposure, and perceived forex risk are major factors that influence exporting SMEs hedging strategy.

Many of the determinants, such as underdevelopment problem, financial distress and tax benefit, are more closely relevant to large firms. These determinants are mostly found in the literature on forex risk management in large firms (e.g., González et al., 2007; Joseph, 2000; Nance et al., 1993; Pramborg, 2005; Schiozer \& Saito, 2009). The literature on forex risk management in large firms has largely investigated the determinants of derivative usage. In addition, the current literature tends to regard these determinants in isolation of one another, and has, so far, overlooked the possible relationships between them in determining a firm's hedging strategy. This suggests a need to conceptualize major determinants relevant to exporting SMEs, such as degree of internationalisation and forex exposure, in a framework that could help to explain the forex risk management of these firms. 


\subsection{NEW PERSPECTIVE ON HEDGING DETERMINANTS}

\subsubsection{Perceived Forex Risk}

The concept of perceived risk is used in various research domains. Slovic (1987) states that perceived risk is a subjective evaluation. Perceived risk is primarily based on two core components: uncertainty and negative consequences (Beck, 2007; Chow et al., 1997). For example, in consumer behaviour research, perceived risk is considered as a multidimensional construct (March \& Shapira, 1987; Sarin \& Weber, 1993) and previous studies propose numerous dimensions of risk, illustrated in the case of shopping, e.g., finance, performance, physic, society, psychology, time/convenience, privacy, and source (Chang \& Tseng, 2013). These studies show that perceived risk is generally a subjective evaluation or perception of different dimensions of risk. In other words, it shows how one perceives various facets of uncertainty and consequences or exposure. As earlier mentioned, perceived forex risk is one of the determinants of managerial forex risk attitude, e.g., the chosen response to perception of forex exposure.

Perceived risk is an effect of a subjective evaluation that is influenced by numerous factors. These factors are likely to be distinct in various domains. Studying the effects on risk perception of telephone shopping behaviour, Chow et al. (1997), for instance, note that major determinants of risk perception level are cost and importance of the purchase, and individual subjective factors. Researchers in the domain of tourism consumer behaviour hold that perceived risk is impacted by the learning process, past behaviour/experience, tourist intra-personal characteristics, informational sources, and level of risk awareness (Fausti \& Gillespie, 2006). In biology "perceived risk is a function of information, knowledge, values and perception" (Dowling \& Staelin, 1994, p. 235). These studies show that there are various determinants which influence the perception of dimensions of risks. In this thesis, perceived forex risk refers to managerial risk perception of uncertainty and exposure specifically associated with foreign exchange rates. The perception is likely to be increased when firms operate internationally (Cavusgil, 1984).

Previous studies have shown that perceived risk could predict behaviours associated with dimensions of risk. For example, perceived risk is found to be predictive in the 
consumer behaviour domain. In this context, Cox and Rich (1964) find that perceived risk is one of the major behaviour determinants in the case of telephone shopping. Kaplan et al. (1974) reveal that buying behaviour is most influenced by performance risk associated with 12 different consumer products such as sports car, life insurance, colour television, and suits; but financial and psychological risk are found to be the most important risk factors for buying a sports car. In another domain, the decisionmakers' perceived risks and success metrics are found to influence a series of decisions in innovation processes (Hemsworth et al., 2013). In the domain of forex risk management, perceived forex risk is very likely to impact a firm's choice of responses to forex exposures. In this regard, perceived forex risk is concerned with managerial attitude toward forex risk.

\subsubsection{Resources associated with forex risk management}

This section will discuss the use and operationalization of the RBV in international business, as well as links with the forex risk management literature.

In 1991, a special research issue in the Journal of Management edited by Jay B. Barney was published, with articles by Barney (1991) and other scholars, e.g., Castanias and Helfat (1991), Conner (1991), Fiol (1991), and Harrison, Hitt, Hoskisson, and Ireland (1991) as cited in Barney, Ketchen, and Wright (2011, p. 1300) on the topic of the RBV. The RBV was introduced with the argument that firms are enabled to achieve competitive advantage, which leads to superior long term performance, with resources and capabilities that are valuable, rare and imperfectly imitable, and for which substitutes are uncommonly available (Barney, 1991; Robert M Grant, 1991; Penrose, 1995; Barney 1991; Grant 1991; Penrose 1959; Wernerfelt 1984 as cited in Wade \& Hulland, 2004, p. 108; Wernerfelt, 1984). The RBV has become an influential theoretical perspective in many management fields, such as strategy and marketing (Wade \& Hulland, 2004).

Over twenty years, the RBV has reached its maturity as a theory, referred as to resource-based theory (RBT), and it is widely acknowledged for its ability to describe, explain, and predict organizational relationships (Barney et al., 2011). Summarizing numerous selected papers over the past twenty years, Barney, et al. (2011) show that the 
RBV has developed and made remarkable contributions along five themes: interlinkages with other perspectives, processes of resource acquisition and development, the micro-foundation of RBT, RBT and sustainability, and method and measurement issues. They also affirm that the theory has contributed to significant conceptual and empirical innovations and needs to further innovate, both within these five themes and elsewhere, so that it can achieve revitalization and avoid decline.

In a global setting, the RBV has provided significant contributions to international business, with the identification of international knowledge and experience as valuable, unique, and hard-to-imitate resources of firms' success and failure in international competition (Peng, 2001, p. 820). Given that firms often face numerous uncertainties (K. D. Miller, 1992) when venturing into international markets, in order to manage risks from these uncertainties, firms need to use their resources to minimise, monitor, and control the impact of uncertain or unfortunate events (Hubbard, 2009).

However, as can be seen from the review of twenty-years research and application of the RBV recently conducted by Barney et al. (2011), it appears that very little discussion on the RBV has been conducted in the field of risk management, particularly in forex risk management. Thus, it seems necessary to enhance the usefulness of the RBV to the strategic management of risk, particularly forex risk. The application of the RBV to forex risk management could have the potential to provide, via a suitable framework, an overarching understanding of how resources might affect a firms' choice about hedging strategy.

Given that the RBV is one of the most useful theoretical perspectives in the strategic management field (Powell, 2001; Priem \& Butler, 2001; Rouse \& Daellenbach, 2002), scholars have examined a variety of resources, capabilities and core competencies under this theoretical base (Newbert, 2007). Reviewing 55 RBV-grounded empirical studies, Newbert found that only two of 26 resources, i.e. human capital and knowledge, and one of 32 capabilities, i.e. information technology, were examined in more than 5 per cent of the studies. Table 2-4 presents examples of how these resources/capabilities have been operationalized in the literature. 
Table 2-4: Operationalization of selected resources/capabilities

\begin{tabular}{|c|c|c|c|}
\hline Resources & Indicators & Field of study & $\begin{array}{l}\text { Supporting } \\
\text { research }\end{array}$ \\
\hline $\begin{array}{l}\text { Knowledge } \\
\quad \& \\
\text { Information } \\
\text { acquisition }\end{array}$ & $\begin{array}{l}\text { - } \text { Legal services } \\
\text { - } \text { Consulting services } \\
\text { - } \text { Courses in new business } \\
\text { - } \text { Management; } \\
\text { - } \text { Skills training programs } \\
\text { - } \text { Export assistance } \\
\text { - Plants/offices at reduced cost } \\
\text { - } \text { Business advisory service } \\
\text { - Tax-free trade zones/enterprise zones } \\
\text { - Low interest loans } \\
\text { - } \text { Operating subsidies } \\
\text { - } \text { Industry related grants } \\
\text { - Grants to assist in start/ups } \\
\text { - Loan guarantees } \\
\text { - Public venture capital } \\
\text { - Grants to support the development of } \\
\text { - } \text { new products and processes } \\
\text { - } \text { Locally based enterprise agency } \\
\text { Low cost accounting services }\end{array}$ & $\begin{array}{l}\text { Internationalisation of new } \\
\text { and small firms }\end{array}$ & $\begin{array}{l}\text { Westhead et al. } \\
\text { (2001) }\end{array}$ \\
\hline \multirow{3}{*}{ Human } & $\begin{array}{l}\text { Average number of advanced degrees } \\
\text { held by top management team } \\
\text { - Average number of advanced degrees } \\
\text { in science held by top management } \\
\text { team } \\
\text { - Average number of years' experience } \\
\text { in similar industries held by top } \\
\text { management team }\end{array}$ & $\begin{array}{l}\text { The effect of intellectual } \\
\text { capital on corporate } \\
\text { entrepreneurship }\end{array}$ & $\begin{array}{l}\text { Bantel and } \\
\text { Jackson (1989); } \\
\text { Beatty and } \\
\text { Zajac (1994); } \\
\text { McGee, } \\
\text { Dowling, and } \\
\text { Megginson } \\
\text { (1995); Hayton } \\
(2005)\end{array}$ \\
\hline & $\begin{array}{l}\text { - Gender } \\
\text { - Owners' age } \\
\text { - Level of education : undergraduate or } \\
\text { post graduate university degree } \\
\text { - Managerial or professional position for } \\
\text { last employer } \\
\text { - Previous business ownership } \\
\text { experience } \\
\text { - Presence of partners } \\
\text { - Number of employees } \\
\text { - Experience in the same industry as last } \\
\text { employer }\end{array}$ & $\begin{array}{l}\text { Internationalisation of new } \\
\text { and small firms }\end{array}$ & $\begin{array}{l}\text { Westhead et al. } \\
(2001)\end{array}$ \\
\hline & $\begin{array}{l}\text { - Average salary } \\
\text { - The percentage of full professors }\end{array}$ & $\begin{array}{l}\text { Resources affecting } \\
\text { strategic change and } \\
\text { performance in American } \\
\text { liberal arts colleges - a } \\
\text { turbulent environment }\end{array}$ & $\begin{array}{l}\text { Kraatz and } \\
\text { Zajac (2001) }\end{array}$ \\
\hline \multirow{2}{*}{ Financial } & $\begin{array}{l}\text { - Financial investment from banks or } \\
\text { financial institutions }\end{array}$ & $\begin{array}{l}\text { Internationalisation of new } \\
\text { and small firms }\end{array}$ & $\begin{array}{l}\text { Westhead et al. } \\
\text { (2001) }\end{array}$ \\
\hline & $\begin{array}{l}\text { - } \text { Market value } \\
\text { - Scale of operation, measured by the } \\
\text { size or enrolment }\end{array}$ & $\begin{array}{l}\text { Resources affecting } \\
\text { strategic change and } \\
\text { performance in American }\end{array}$ & $\begin{array}{l}\text { Kraatz and } \\
\text { Zajac (2001) }\end{array}$ \\
\hline
\end{tabular}




\begin{tabular}{|l|l|l|l|}
\hline & $\begin{array}{l}\text { - Scope of operation measured by total } \\
\text { number of fields in which a college } \\
\text { granted undergraduate majors. }\end{array}$ & $\begin{array}{l}\text { liberal arts colleges - a } \\
\text { turbulent environment }\end{array}$ & \\
\hline $\begin{array}{l}\text { Experience \& } \\
\text { Learning }\end{array}$ & - Firm age & $\begin{array}{l}\text { Resources affecting } \\
\text { strategic change and } \\
\text { performance in American } \\
\text { liberal arts colleges - a } \\
\text { turbulent environment }\end{array}$ & $\begin{array}{l}\text { Kraatz and } \\
\text { Zajac (2001) }\end{array}$ \\
\hline $\begin{array}{l}\text { Top } \\
\text { management } \\
\text { team }\end{array}$ & $\begin{array}{l}\text { - Team size } \\
\text { Number of previous industry } \\
\text { employers }\end{array}$ & $\begin{array}{l}\text { Strategic and social effects } \\
\text { in entrepreneurial firms }\end{array}$ & $\begin{array}{l}\text { Eisenhardt and } \\
\text { Schoonhoven } \\
(1996)\end{array}$ \\
\hline
\end{tabular}

Resources and capabilities, such as human resources, knowledge, experience, economies of scale, financial resources, top management team, learning, information acquisition, negotiation and pricing would be relevant for this thesis in forex risk management, and for establishing and adapting item measurements for the model development. The RBV primarily holds that resources and capabilities enable firms to generate profits and sustainable competitive advantages (Amit \& Schoemaker, 1993; Barney, 1986, 1991; Dierickx \& Cool, 1989; Mahoney \& Pandian, 1992; Wernerfelt, 1984). Drawing a strategy tripod, Peng (2006) regards resources as one of three legs of the strategy tripod. Physical, human, and organizational resources would directly determine a firm's formulation and implementation of strategy. The literature on firms' resources extensively examines business/marketing strategy (Molloy, Chadwick, Ployhart, \& Golden, 2011; Peng, 2001; Wernerfelt, 2011), and lacks investigation of hedging strategy (see Barney et al., 2011). Resources can be operationalized in a specific field of forex risk management, e.g., resources associated with forex risk management.

Recently, Lockett and Wild (2014) examined how Edith Penrose employed historical analysis in her work. The role of historical analysis was assessed in the development of the RBV, focusing on the work of Edith Penrose. History (path dependence) is said to be important in shaping the nature of a firm's resource base over time. Lockett and Wild hold that a historical perspective and analysis is entirely consistent with the central tenets of the RBV: that firms are heterogeneous and that the heterogeneity is driven by path dependency. Path dependency can be used to explain the process of resource accumulation over time, so it can also be used in a specific field of forex risk 
management, in order to understand firms' current resource status. It is important, therefore, to appreciate that SMEs' forex risk management practice may be dependent on their historical path of resource availability or accumulation and that their hedging practices may change over time.

\subsubsection{Internationalisation}

When a firm goes international, forex exposure may rise, thus increasing the level of systematic risk for the firm (Reeb et al., 1998). This section briefly reviews the extant literature on internationalisation, and discusses possible application of theoretical views in forex risk management.

There are various contemporary models of internationalisation of SMEs, e.g. “Innovation-Related Internationalisation" models (Bilkey \& Tesar, 1977), "Network Theory" (Johanson \& Vahlne, 1977; Sharma, 1992), and traditional economic theories such as Transaction Cost Theory (Zacharakis, 1997) and Resource Theory (Woodcock, Beamish, \& Makino, 1994; Yeoh \& Jeong, 1995). In addition, scholars also offer a number of integrated models of the internationalisation of SMEs (Bell, McNaughton, \& Young, 2001; Oviatt, Shrader, \& McDougall, 2004; Zahra \& George, 2002). The "born global" perspective, as outlined by (Oviatt \& McDougall, 1994), focuses on new ventures that internationalise from inception. In 1997, Madsen and Servais (1997) describe a process called a "leapfrog" process, which incorporates a process understanding of SMEs that are well established in their domestic markets but which suddenly, based on some critical triggering events, rapidly internationalise. The "leapfrog" process was then advanced by Bell et al. (2001), exploring the 'born-again' global phenomenon, and identifying a number of key triggers that encourage such firms to radically change their strategic directions and targeted markets. Bell, McNaughton, Young, and Crick (2003) propose a model of internationalisation that accommodates all three processes of internationalisation: incremental internationalisation, born global, and leapfrog. The scholars argue that an internationalisation pathway depends on firms' knowledge resources, the strategic posture, and the unique attributes of internal and external environments. 
Early process models of internationalisation describe two ways in which firms may internationalise: (1) Uppsala Internationalisation Model (U-Model), which form the basis of the 'stages' perspectives; and The Innovation-Related Internationalisation model (I-Model). The former explains the internationalisation across country markets through the hypothesis that firms' choice of models to enter a new market would vary across the degree of psychic distance (Andersen, 1993; Johanson \& Wiedersheim-Paul, 1975). The concept, psychic distance, includes factors that prevent and disturb the flow of information between markets and firms, such as differences in language, culture, political systems, level of education, or level of industrial development (Johanson \& Vahlne, 1977). According to Johanson and Wiedersheim-Paul (1975), there are four modes of entering an international market, which present degrees of internationalisation: (1) no regular export activities, (2) export via independent representatives, (3) establishment of an overseas sales subsidiary, and (4) overseas production/manufacturing units.

There are a number of I-Models (Bilkey \& Tesar, 1977; Cavusgil, 1980; Czinkota, 1982; Reid, 1981), with most of the relevant studies being restricted to manufacturing SMEs. Based on these I-Models, firms are categorised into various degrees of internationalisation, using one or a few characteristics of their international activities or involvement e.g., export ratio (Cavusgil, 1980), see Table 2-5. In criticizing the IModels, Andersen (1993) argue that the studies did not establish sound criteria for classifying firms according to different degrees; neither did they show how to discriminate across degrees by the use of dependent variables. Reviewing a number of models on the export development process, Leonidou and Katsikeas (1996) also consider models of internationalisation and suggest research guidelines for making contributions from marketing, business and other disciplines, such as economics, sociology and psychology. These scholars suggest possible research alternatives, for example, improving the analysis by taking a business policy perspective on exporting, investigating the export expansion process in relation to developments in domestic business, and constructing a model covering the whole spectrum of internationalisation mechanisms. 
Table 2-5: Degree of Internationalisation

\begin{tabular}{ll}
\hline Degree & Description \\
\hline Degree 1: Domestic Marketing & $\begin{array}{l}\text { Firms are not interested in or willing to } \\
\text { experiment with export, also incapable of handling } \\
\text { an export order. The export/sales ratio is 0 }\end{array}$ \\
Degree 2: Pre-export & $\begin{array}{l}\text { Firms are interested in exporting activities, } \\
\text { searching for relevant information about costs, } \\
\text { exchange risks, distribution, etc. The export/sales } \\
\text { ratio is 0 }\end{array}$ \\
Fegree 3: Experimental & $\begin{array}{l}\text { Firms start exporting on a small basis. The } \\
\text { Involvement }\end{array}$ \\
export/sales ratio varies from 0-9 per cent. \\
Firms have made a systematic effort to export to \\
multiple countries. The export/sales ratio varies \\
from 10-39 per cent
\end{tabular}

Source: Adapted from Gankema et al. (2000) and Cavusgil (1980)

In a context of forex risk management, the evidence shows that there is a scarcity of research on forex risk management using these, or other, models of internationalisation. The traditional stage models of internationalisation suggest that firms gradually move into increasingly more risky international transaction (Dickson, Weaver, \& Vozikis, 2013). In addition, the degree of a firm's internationalisation has been seen as a factor that influences the firm's hedging practice. For example, Joseph (2000) and Aabo et al. (2010) show that the degree of a firm's internationalisation impacts its selection of hedging strategy. They use various variables to measure the degree of a firm's internationalisation such as the number of foreign countries in which the firm operates, and the number of production/sales subsidiaries. As discussed in the previous section 2.3.2, the degree of internationalisation is suggested as one of the rationales for a firm's choice about hedging strategy. The next chapter of this thesis will discuss in detail the application of internationalisation theory to the study, and advance hypotheses in regards to the relationship between degree of internationalisation and hedging strategy in this context of forex risk management. 


\subsection{RESEARCH GAPS}

Earlier sections have discussed the literature on forex risk management along three major themes: (1) the choice about hedging strategy, (2) forex rate exposures and factors that influence a firm's hedging strategy, and (3) the relevance of the RBV, and internationalisation theory in the context of forex risk management. As SMEs are exposed to forex rate fluctuations due to market imperfections (Bartram, et al., 2005), the need to examine the factors that influence SMEs' approaches to forex risk has also been discussed. The literature on forex risk management has shown a number of rationales for forex risk management, such as (1) degree of internationalisation, (2) forex risk exposure, (3) managerial risk attitude, (4) under-investment problems, (5) financial distress, (6) hedging costs, (7) tax liabilities, and (8) information asymmetry. While large firms are more concerned with under-investment problems, financial distress, tax liabilities, and information asymmetry, exporting SMEs are closely affected, as discussed above, by the degree of internationalisation, forex exposure and managerial perception of forex risk. There are theoretical gaps relating to forex risk management by SMEs, specifically regarding the understanding of determinants that influence exporting SMEs' choice about hedging strategy. These gaps are discussed from three main perspectives as follows.

\section{The need for a conceptual /theoretical framework}

Given the characteristics of SMEs in the setting of international business, internal methods of hedging could be favoured by SMEs, for reasons mentioned earlier. The current literature on forex management, however, tends to consider derivatives as major hedging instruments, and these studies have been conducted mainly in large firms (see Albuquerque, 2007; González et al., 2007; Pramborg, 2005; Schiozer \& Saito, 2009). These studies have extensively tested the determinants that influence the use of hedging instruments, mostly derivatives. Because hedging determinants have been viewed in isolation from each other in the current literature on forex risk management, it is meaningful to incorporate, into a conceptual framework these isolated determinants, such as degree of internationalisation, forex exposure and managerial perception of forex risk, in order to show how they interact in a firm's decisions about hedging. Further, since little work has been conducted in the context of SMEs, the development 
and application of such a framework to exporting SMEs' decisions on forex risk management and hedging will address an important research gap.

\section{Lack of an appropriate theoretical base}

The determinants identified in the literature (as discussed above), tend to lack a theoretical framework, especially in regard to how they influence firms' decisionmaking behaviour in regard to forex risk. In order to build a conceptual framework, the constructs need to be viewed through relevant theoretical lenses. This chapter has outlined how the RBV and internationalisation theory can be helpful in explaining how firms manage forex risk, by providing new insight into firms' choice about hedging strategy. The RBV literature can offer grounds for explaining firms' allocation of resources associated with forex risk management. Since forex risk arises from a firm's exposure to foreign currencies, most commonly for SMEs in the context of exporting, the internationalisation literature offers some relevant insights into firm's management of forex risk. Thus, the literature on forex risk management indicates that there are theoretical gaps, particularly in the context of SMEs, which could be addressed by the application of the RBV and internationalisation theories to the issue.

\section{The need for contextual relevance: exporting SMEs}

The literature on forex risk management has been found in a number of contexts, such as region, country, industry, and firm. At the firm level, scholars have carried out much research on multinational enterprises - generally large firms. Recently, as a result of rapid internationalisation, SMEs are increasingly involved in international markets, and thus they become an important setting for research on forex risk management. There is the scarcity of studies on forex management in SMEs at the firm level (Kula, 2005), thus providing an opportunity for further research in this context.

In summary, the literature on forex risk management in SMEs appears to have three specified gaps: (1) conceptual and theoretical gaps relating to forex risk management, specifically regarding the understanding of how hedging determinants interact and are influential upon firms' choice about hedging strategy; (2) theoretical gaps relating to the use of the RBV literature, and internationalisation theory in a forex risk management 
context; and (3) contextual gaps relating to the SME literature, specifically regarding the management of forex risk in SMEs. 


\section{CHAPTER 3. RESEARCH DESIGN AND EXPLORATORY QUALITATIVE STUDY}

This chapter describes the research paradigm and research design of this thesis. The rationale for adopting a sequential research design is outlined. The exploratory qualitative study is described, along with findings. 


\subsection{ETHICAL IMPLICATIONS}

This thesis complied with the requirements of the Human Ethics Committee (HEC) of Victoria University of Wellington. The informants and survey respondents in this research participated in a voluntary fashion. Also, confidentiality and anonymity were ensured in the conduct of the interviews and survey, respectively, and in the production of the subsequent thesis. Full HEC approval for confidentiality of the interviews was granted on 21 July 2012, and full HEC approval for the anonymous online survey was granted on 21 April 2013. An information sheet was given to every informant; similarly an information sheet was incorporated in the email of the invitation sent to the targeted survey respondents. In doing so, informants were provided with sufficient information regarding the study before starting the interview or the survey. Subsequently, all informants were asked to sign the consent form. Copies of the information sheet and consent forms are available from the author upon request.

\subsection{SEQUENTIAL RESEARCH DESIGN}

This thesis used a sequential research design (Driscoll, Appiah-Yeboah, Salib, and Rupert (2007) including an exploratory qualitative study and a main quantitative study. A framework for the topic of interest, i.e. the conceptual model was proposed, based on the review of the literature on forex risk management, the RBV, and internationalisation theory. It is important to conduct an exploratory qualitative study to strengthen the conceptualization and provide initial confirmation of the conceptual model and hypotheses. It also assists in the interpretation of quantitative results. The use of qualitative research in this thesis was justified since qualitative findings were expected to provide the study with more robust theoretical underpinnings (Johnson, Onwuegbuzie, \& Turner, 2007). In light of the nature of the research questions (see section 1.2 in Chapter 1), which are concerned with exporting SMEs' decision making on hedging, the use of a qualitative exploratory component seeks for additional insights into the dynamics of firm decision making on hedging. 


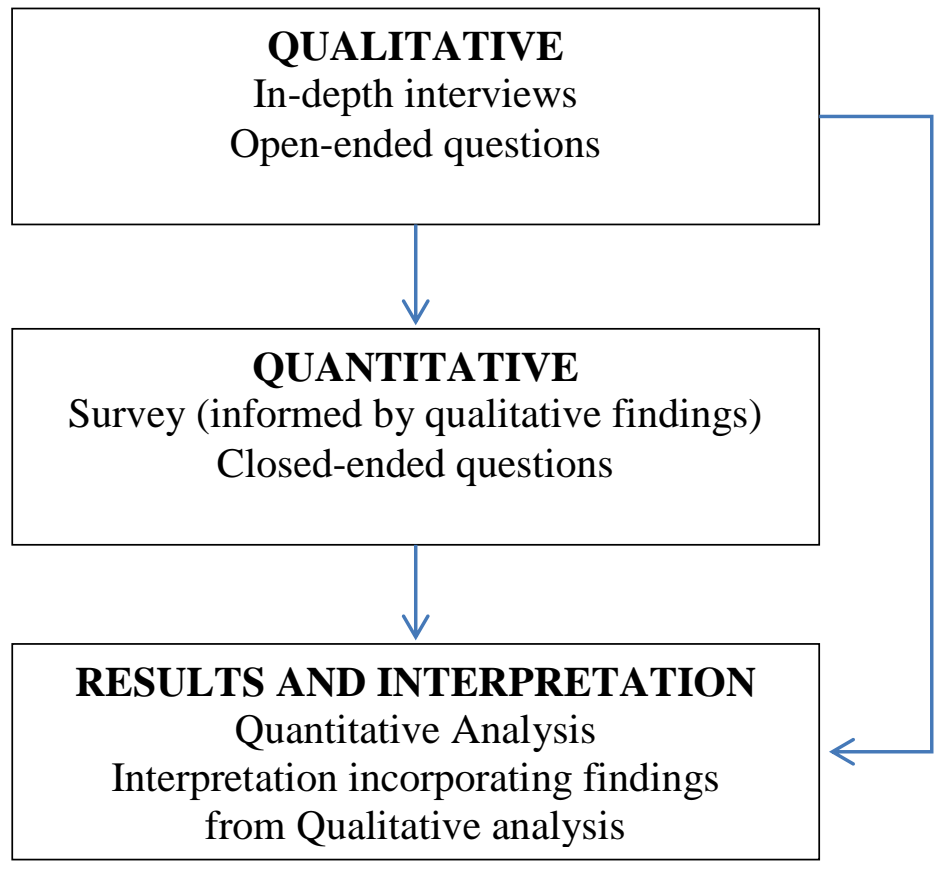

Figure 3-1: Sequential Research Design (Creswell, 2003; Driscoll et al., 2007)

A sequential research design adapted from Driscoll et al. (2007) and Creswell (2003) was applied in this thesis (see Figure 3-1). Primarily, this thesis seeks an innovative approach in the discovery of new perspectives or frameworks; the use of results from the exploratory qualitative element increased the breadth and depth of inquiry and the results and interpretations of the findings, in accordance with assertions by (Johnson et al., 2007). Secondly, the use of results from the exploratory study developed and informed the main quantitative study, helping to increase the validity of the constructs and interpretation of the results. Given that the literature on forex risk management showed determinants of a firm's choice about hedging strategy as pieces of a puzzle, the exploratory qualitative study was used in order to uncover unexpected results or unseen contextual factors (Jick, 1979). A quantitative survey is generally used to test the model in which unconsidered contextual factors are incorporated. Finally, both qualitative and quantitative data are jointly used for discussion and justification of the research question (Creswell, 2003).

Creswell (2003, p. 16) defines sequential procedures as an approach in which a researcher "seeks to elaborate on or expand the findings of one method with another 
method". A sequential approach, see Figure 3-1, may involve a qualitative method for exploratory purposes and a quantitative method with a large sample so as to generalise results to a population. This thesis began with a qualitative component, which was designed for exploratory purposes to understand decision making on hedging by SMEs. The qualitative findings aimed to inform the conceptual model. In addition, in-depth interviews from the qualitative component were used to ensure the validity of measures used in the quantitative component. It was followed by a quantitative component which aimed to test hypotheses. After this, the qualitative findings were jointly discussed with the quantitative findings (from structural equation modeling) during the interpretation stage. The qualitative data provide insights into the management of forex risk at a firm level, and the statistical analysis provides a detailed assessment of patterns emerging from the survey responses, as well as testing the conceptual model (Driscoll et al., 2007). These two methodologies are regarded as complementary, and offer a suitable approach to conducting this thesis.

The research design of this thesis provided a better understanding of how exporting SMEs manage forex risk, and also provides a fuller picture and deeper understanding of the issues, as well as enhancing description and overall understanding. Triangulation of the findings was enabled under the combination of both quantitative and qualitative methods, validating and explicating findings from either of the single-methods, and producing more comprehensive, internally consistent, and valid findings. This research design provided greater confidence in the research conclusions, handle threats to validity and gain a fuller and deeper understanding; and provide more meaningful answers to the research questions (Johnson et al., 2007).

\subsection{QUALITATIVE METHODOLOGY}

\subsubsection{Qualitative research background}

As described in the research design strategy, the qualitative study is an exploratory component. This part of the research was carried out to identify exporting SMEs' experiences concerning their approaches to forex risk management. This approach allowed for the exploration of how SMEs have worked to provide solutions to current problems relating to forex risk management by considering the firms in the context of 
their histories, an approach, which draws on a path dependency perspective (Lockett and Wild (2014). The qualitative research was based on descriptions of participants' approaches, provided by the firms' interview participants. This aimed to provide an understanding of the hedging practices of exporting SMEs. This part of the research sought for initial support for the conceptual model of forex risk management of exporting SMEs. A key purpose was to clarify the nature of forex risk management, which was studied in a traditional, normative and scientific sense. Current perspectives on this issue are not clear, as little is known about SMEs' management of forex risk, and there is weak empirical substantiation. In this situation, it is important to conduct theory extension from the interviews, which is similar to the approach of theory building, as suggested by Eisenhardt (1989), since the interviews provided fresh perspective of SMEs on this research topic, rather than the perspective of large firms.

On the one hand, the literature on exchange rate exposure and forex risk management, which have been studied extensively (e.g., Ahmed \& Omneya, 2007; Chan-Lau, 2005; Davies, Eckberg, \& Marshall, 2006; Jonuška \& Samėnaite, 2003; Kula, 2005; Mooslechner \& Gnan, 2007; Pramborg, 2005), was used to identify critical independent, dependent, and control variables. This approach is recommended by Edmondson and McManus (2007) and it helps to explain general mechanisms underlying how and why firms undertake hedging. On the other hand, a qualitative component is useful since qualitative research is most suitable for addressing "why" questions to understand and explain issues as well as "how" questions that describe processes and behaviours (Hennink, Hutter, \& Bailey, 2011). In this thesis, the qualitative component also enabled the contexts of SMEs and emerging markets to be considered within the findings. Basically, the qualitative element of this thesis sought to contribute to the robustness of the hypotheses relating to forex management by exporting SMEs. This enabled sensible connections to prior work (Edmondson \& McManus, 2007), before starting the quantitative stage.

This thesis adopted phenomenography, which was recently applied in international business research by Lamb, Sandberg, and Liesch (2011), and Lamb, Liesch, and Sandberg (2012). Phenomenography is an interpretive methodology, which is strongly rooted in phenomenological philosophy. Its notion of life-world indicates that the world 
is never a world of itself, but is always an "understood" world (Sandberg, 1994; Uljens, 1992). Similar to other interpretive methodologies, phenomenography is designed to capture how people understand a specific aspect of reality, and how the understanding forms the basis for their actions" (Lamb et al., 2012). On the other hand, unlike other interpretive methodologies, phenomenography is specifically designed to capture possible variation in the qualitatively different ways the same aspect of reality is understood (Marton, 1981, 1986; Marton \& Booth, 1997; Marton \& Pong, 2005; Sandberg, 2000).

This thesis extends the use of phenomenography in forex risk management research. Phenomenography was a well-established research method in a range of disciplines, e.g. education (Dall'Alba \& Hasselgren, 1996; Marton \& Booth, 1997; Wright, Murray, \& Geale, 2007), health science (Widäng, Fridlund, \& Mårtensson, 2008), and management (Sandberg \& Pinnington, 2009; Schembri \& Sandberg, 2002). Adapting a phenomenographic approach, this thesis investigated the hedging practices of SMEs, calling for a systematic identification and description of the qualitatively different ways in which SMEs' owners/financial managers understood forex risk management, and how these understandings translated into actions for forex risk management. Phenomenography was adopted to improve understanding of SMEs' forex risk management, examined empirically through analysing the hedging practices of exporting SMEs.

\subsubsection{Qualitative research objectives}

The qualitative component of this thesis looked in depth at the influences on firms' strategies for forex risk management. The qualitative research aimed to provide understanding on how forex exposure and managerial forex risk perception shaped hedging practices, and to explore the allocation of resources for managing forex risk. These avenues of enquiry were revealed from the literature review to be potentially important dimensions associated with forex risk management of exporting SMEs, and their internationalisation. This thesis aimed to develop a deeper insight into the influences on firms' hedging strategies and how they impact this outcome. 
In-depth interviews were conducted to provide data for the qualitative research on forex risk management by exporting SMEs, that is, the influences on firms' hedging strategy. Based on the preliminary theoretical framework of this research, developed from the literature review, key questions were addressed. These questions aimed to investigate how SMEs manage their forex risk, focusing on the influences on their choice of hedging techniques, as well as possible relationships between factors. To this end, informants were the firms' owners or financial controllers, as these informants were likely to be able to provide the most extensive and accurate information about their companies' hedging strategies and the influencing factors. The interviews primarily aimed to offer rich insights into the factors influencing the hedging strategies of exporting SMEs. As noted earlier, the interviews also assisted in informing the quantitative survey, e.g., refining measurement scales used in this thesis, and making sure of the content validity of the measures. Generally, the interviews searched for initial confirmation of the conceptualization and provide inputs into the development of the conceptual model.

\subsubsection{Study population, sample and sampling}

This thesis adopted a purposive sampling approach (M. B. Miles \& Huberman, 1994). In general, the sampling process of a qualitative research is theoretically, rather than statistically, driven (Eisenhardt, 1989; M. B. Miles \& Huberman, 1994). The interview sample was selected to provide a conceptual insight into SMEs' perceptions and management of forex risks. The interviews were analysed as multiple case studies or collective case studies, based on White's (1992) typologies of case studies (Stake, 2005). While Stake is more concerned with in-depth examination of a particular case, Eisenhardt (1989) is more interested in multiple cases, because multiple cases enable the elimination of an emergent finding that is simply idiosyncratic to a single case, rather than consistently replicated by several cases (Eisenhardt, 1991). Multiple cases also create more robust theory as the propositions are more deeply grounded, and constructs and relationships are more precisely delineated in varied empirical evidence (Eisenhardt \& Graebner, 2007). Such a level of understanding of these cases was expected to lead to better theorizing in terms of exporting SMEs as a whole. Purposive selection of cases for the interviews aimed to incorporate "fertile exemplar[s]" for the 
study (Polkinghorne, 2005, p. 140) so that the data collected were sufficiently rich to enable refinement and provide clarity to understanding SMEs' hedging practices. For this purpose, the chosen SMEs were those which were exporting at the time of the study, and thus, assumed to be exposed to forex risk.

Informants were managers of exporting SMEs in New Zealand. Firms were in various industry sectors, and of different sizes within the SME category, to provide variation for analysis (Eisenhardt, 1989). The OECD's (2007a) definition of SME was used for the study, whereby exporting firms were selected that had no more than 250 employees.

Determining the sample size for the qualitative part of the study conformed to various criteria introduced by Morse (2000). First, the scope of the research was considered to be not too broad; that is, it focused on firm's decision making regarding their choice about hedging strategy. Second, information was obtainable in the interviews, as the topic of hedging is obvious and clear. Third, data are on target (directly related to the topic) as participants were able to reflect on their hedging and express themselves accordingly in the interview. Importantly, the amount of usable data obtained from the interviews was likely to be high. On account of this, (as mentioned by Morse, 2000), the sample size for interviews in such a study ranges from 6 to 10. This is also in line with studies of a number of other researchers, e.g., Kuzel (1992) who recommended a sample size of 6 to 8, as well as Guest, Bunce, and Johnson (2006) who suggested 6 to 12 interviews for homogenous samples. Further, the study was guided by the important criterion of theoretical saturation (Yin, 2009), which indicates that the sample size is determined when additional interviews provide no further theoretical insights i.e. when theoretical saturation is reached. This qualitative study aimed to provide understanding on how exporting SMEs manage forex risk, and to strengthen the conceptualization and provide initial input into, and confirmation of, the conceptual model and hypotheses. On account of this, six interviews were undertaken with New Zealand exporting SMEs. Considerations of theoretical saturation were applied as the interviews progressed.

\subsubsection{Data collection}

There are several possible data sources for a qualitative research, such as interviews with participants, observations, documents and artefacts (Polkinghorne, 2005). 
However, the interview approach was the best fit for this thesis, because interviews could provide "a full and detailed account from an informant of the experience under study" (Polkinghorne, 2005, p. 142). Interviewing is also the most widely used approach for the production of qualitative data.

In this thesis, interviews were guided by an interview framework developed prior to the meetings with the managers concerned, i.e. the information sheet for interview. The interviews usually started with questions about the firms' internationalisation in general, and then followed with questions focusing on the topics of forex exposure, managerial perceptions on forex risk, resource allocation and hedging strategies of the firms. The interviews highlighted new dimensions and understanding of forex risk management to the extent that informants were interested in sharing information. To this end, openended and semi-structured questions were developed as part of the interview protocol, and a list of the main questions was given to informants in advance. This enabled better comparison across the cases, as well as ensuring that the qualitative data were consistent enough to categorise and analyse (Schendel \& Patton, 1978).

The semi-structured questions employed in the study helped to primarily explore the set topics following the interview protocol. Simultaneously, however, new leads could be developed at the researcher's discretion (Bernard, 2011) in order to disclose further information concerning the firms' hedging practice. Thus, additional open-ended questions were used as thought appropriate during the interviews.

In order to obtain rich insights into firms' hedging performance via in-depth interviews, emails explaining the purpose of the research were sent to a number of potential informants prior to confirming recruitment into the study (see cover letter, information sheet for informants and interview questions in Appendices B, C and D respectively). Details of the companies were found in the Kompass database, a business search engine that provides business users with comprehensive information about companies and their people, products and services. A number of firms potentially interested in participating in the research were introduced by other researchers known to the investigator. Once agreement was reached for the participants to be part of the study, meetings were arranged. The participants indicated their willingness to participate in the interviews by 
signing a consent form (see Appendix E). One of the interviews was conducted via Skype; the rest were held face-to-face.

The participants were CEOs/owners or financial controllers, who represented the views and decisions of their firm. In a study of technology policy formulation and enactment in SMEs and subsequent organizational impacts, e.g. export performance and financial performance, Lefebvre, Mason, and Lefebvre (1997) hold that the perceptions of CEOs are important in highlighting the key significant issues. Managerial perceptions have been shown to be more critical to organizational strategy than objective or archival measures (Anderson \& Paine, 1975; Frishammar, 2006; Lefebvre et al., 1997; Oswald, Mossholder, \& Harris, 1997). Therefore, the SME managers, i.e., CEOs/owners or financial controllers, are likely to be able to provide the most extensive and accurate information about the firms' forex risk management. The informants were all provided with consent forms and information sheets along with key interview questions before interviews. All details of respondents have been kept confidential in accordance with Victoria University's Human Ethics Policy.

\section{Table 3-1: Interview details}

Time frame

Between August and December 2012

Informants

CEOs/owners or financial officers who were in charge of managing forex risk

Number of interviews 6 (single informants) in 6 SMEs

Type of interviews Semi-structured, in-depth - including open-ended questions

- 1 Skype interview from the informant's home

- 5 face-to-face interviews +4 interviews at informants' offices

+1 interviews at cafe

Firms' location/Interview 6 in New Zealand/English

language

Duration of interviews $\quad 30-45$ minutes

Six semi-structured in-depth interviews were conducted by the investigator (see Table 3-1). Informants were CEOs/owners or financial controllers who were in charge of managing forex risk. As outlined, the sample size of six met the requirement of this thesis, and conformed to recommendations in the literature. Except for one interview conducted via Skype from the informant's home, the others were conducted face-to- 
face. Of the face-to-face interviews, four took place at interviewees' office; one was at cafés. Interviews lasting between 30 and 45 minutes maximum were audio-recorded; also, reflective notes were written by the investigator after the interviews.

Table 3-2 shows that six interviewed exporters dealt with a wide range of products. The main exporting products include software, garment, digital display solutions, toys, uniform \& logistical products. Of the six firms, Ship also has an office in Dubai. All firms were highly exposed to US dollars, which is in line with the trend of worldwide pricing in a common vehicle currency (L. S. Goldberg \& Tille, 2008; Magee \& Rao, 1980).

Table 3-2: Interviewed Company Profiles

\begin{tabular}{|c|c|c|c|c|c|}
\hline Company & Informants & $\begin{array}{l}\text { Number of } \\
\text { Employees }\end{array}$ & Industry & $\begin{array}{l}\text { Foreign } \\
\text { Currency }\end{array}$ & $\begin{array}{c}\text { Foreign } \\
\text { Branches }\end{array}$ \\
\hline $\begin{array}{l}\text { New Zealand } \\
\text { Software }\end{array}$ & & & & & \\
\hline $\begin{array}{l}\text { Software } \\
\text { Ship }\end{array}$ & $\begin{array}{l}\text { Single, Male } \\
\text { Single, Male }\end{array}$ & $\begin{array}{r}20 \\
5\end{array}$ & $\begin{array}{l}\text { Software } \\
\text { Services, }\end{array}$ & $\begin{array}{l}\text { USD } \\
\text { USD }\end{array}$ & $\begin{array}{l}\text { No } \\
\text { Yes, }\end{array}$ \\
\hline & & & $\begin{array}{l}\text { specialised ships } \\
\text { and underlined } \\
\text { water robots }\end{array}$ & & Dubai \\
\hline Garment & Two, Female & 2 & Garment & USD & No \\
\hline Digiso & Single, Male & 50 & $\begin{array}{l}\text { Digital display } \\
\text { solutions }\end{array}$ & USD & No \\
\hline Toy & Single, Male & 3 & Toy & $\begin{array}{l}\text { USD, } \\
\text { EUR }\end{array}$ & No \\
\hline Uniform & Single, Male & 3 & $\begin{array}{l}\text { Uniform and } \\
\text { logistical products }\end{array}$ & USD & No \\
\hline
\end{tabular}

Not only is the sample varied in terms of industry, but it is also diversified in terms of firm size. Table 3-2 shows the firm size ranges from 2 to 50 employees. The firms were in secondary and tertiary industries. Interviews were conducted with single informants, except for one which was undertaken with two co-owners. These two female informants in one firm were interviewed at the same time. The other five informants were male. Following a purposive approach (M. B. Miles \& Huberman, 1994), the sampling process of this thesis met the major criteria: exporting SMEs (including exporters also having overseas branches) in various industries, diversification of firm size within a predefined size category for SMEs, including both male and female informants. 


\subsubsection{Data analysis}

Qualitative data analysis essentially involves a process of immersion in the data (Hennink et al., 2011). The qualitative analysis in this thesis aimed to identify and interpret the experience of informants, forming an evidence-based understanding of the research issues. Generally, this analysis included three concurrent flows of activities: data reduction, data display, and conclusion drawing/verification (M. B. Miles \& Huberman, 1994). A continuous and iterative process was formed as the three activities are interactive and interrelated (M. B. Miles \& Huberman, 1994). The qualitative data analysis comprised a wide range of closely interlinked analytic tasks: developing codes, description, comparison, categorisation, conceptualization and theory development (Hennink et al., 2011).

Since detailed analysis of the data was required, NVivo 9 (Auld et al., 2007) was used to assist analysis of the interviews, see Appendix F. The audio-recorded interviews were transcribed, and then entered into NVivo 9. The data were coded, initially using open coding, in order to identify patterns and themes, as well as to draw conclusions. Coding was informed by the earlier conceptualization derived from the literature review; thus the analysis drew on some initial pre-conceptualization (M. B. Miles \& Huberman, 1994). Subsequent, more detailed coding was conducted in order to provide insights into interrelationships between themes identified and deeper description of the data (Sinkovics \& Ghauri, 2008). In essence, the data analysis utilised a combination of descriptive and pattern coding (M. B. Miles \& Huberman, 1994).

\subsection{FINDINGS FROM INTERVIEWS}

This section presents the results of the qualitative component of the study. It aims to present the findings from the semi-structured interviews of six New Zealand firms. The interviews explored how exporting SMEs manage forex risk, providing insights into the determinants of hedging strategy as well as the relationship among these factors. These in-depth interviews were carried out between August and December 2012.

From the literature review, the thesis focuses on five key themes. The themes refer to the hedging strategy of the interviewed firms, and five factors that potentially influence 
the firms' choice about hedging strategy, in order to minimise losses from the fluctuation of foreign exchange rates. The five key themes are:

- Internationalisation

- Perceived forex risk

- Forex exposure

- Resources associated with forex risk management

- Hedging strategy

The qualitative results are presented as they relate to each of these key themes. Additional insights are also provided.

\subsubsection{Internationalisation}

The data suggest that firms perceived more forex risk when they were in high degree of internationalisation. This conforms with a study of Cavusgil (1984, p. 196). The majority of informants stated that they used hedging techniques more extensively, especially external techniques, when they exported more. They perceived that their foreign revenue was more at risk from foreign exchange rates as they were more involved in international markets. An informant claimed:

Yeah, I would think, it's after a couple of years, probably after the first year or two that you'd start doing it. I think in our case, it's been four and a half years. And hedging is used more now than it was. So you're right, over time, you do start to use it more but you don't tend to think you will use it at the start. (Software)

This claim also indicates that the firm initially perceived less forex risk, and thus it was not interested in hedging activity until its perceived forex risk was high enough. In general, the majority of 6 interviewees also indicated that they tended not to hedge when the degree of their internationalisation of their business was low. There could be several reasons for this: for example, low perceived forex risk, as suggested by the manager's quote above. 
Another reason why many interviewed exporting SME managers were not concerned with forex risks in situations of a low degree of internationalisation was that they worried more about market risks than forex risk. One of the informants stated,

Yeah, at a grass roots level, I am more interested in turnover, obviously, and growing our business, than focusing our energy on optimising for exchange rates, and transactions through that. (Toy)

The evidence indicated that the firms prioritised their sales and profit generation, rather than hedging to protect the profits. However, Toy started protecting its profits from the risk of forex changes when revenues and profits reached a sustainable level.

Firms also suggested that forex risk was minor for small exporting orders, and the risk became more significant when orders grew larger. The following quote from Toy's CEO shows that firms perceived, and were more concerned about, currency risks, as they became more involved in international markets. He said,

Now one of the key things that we've done through that distribution model is over the last two years really when we saw the volatility, and all that exposure to different exchange rates, particularly the Euro as that's devalued - we've converted all of our FOB [Free On Board] customers so the people who are ordering bigger volumes, a full container at a time, we have payment terms now in USD. We've effectively eliminated the risk from that product by paying [manufacturing cost] in USD. We're not paying in Euro, we're paying in USD. So we have effectively mitigated any risks. (Toy)

As Toy was exporting to various countries, it was being exposed to risk caused by changes in exchange rates of currencies. The firm also recognised this exposure more clearly over time. In addition, it applied a diversity of natural hedging techniques. The data show that experience of doing international business helped firms, including Toy, to solve problems, including currency problems. For this reason, managerial perception about forex risk increased, and managers gradually became more skilful at managing this risk. In other words, managers underwent a learning process about managing forex risk. 
Internationalisation is likely to impact forex exposure, and perceived forex risk. The rationales for the impacts of internationalisation on perceived forex risk are three fold. First, the "real" forex exposure is likely to increase along with firms' involvement in international activity, for example, increasing export sales. Second, the recognition of forex issues is likely to be improved as firms have more opportunities and challenges that force them to learn, and to become trained in forex management. Third, when firms perceive the risk more clearly, they tend to seek knowledge and experience about forex risk in order to manage the risk. As the data indicate, firms hedged more when their degree of internationalisation as high, and applied more market instruments (e.g., derivative contracts) to protect their profit, since they knew more about how to use these tools.

In summary, exporting SMEs were more exposed to forex changes when they were more involved in international business. The firm, as a result, perceived higher forex risk. New Zealand firms were more concerned about economic forex exposure when their degree of internationalisation was high. For example, exporting SMEs in New Zealand became interested in forex risk as their business matured. Findings showed that New Zealand firms were likely to be active and well-prepared while seeking knowledge and experience about forex risk, in order to manage the risk. Firms tended to deal with the risk better when their experience increased.

Following are the main findings relating to internationalisation, as discussed in this section:

- When associated with experience and business maturity, a higher degree of internationalisation improved recognition of and knowledge about forex risk;

- High degree of internationalisation was associated with higher perceived forex risk.

\subsubsection{Perceived forex risk}

Fluctuation of exchange rates is one of the major factors that financial managers are concerned about while managing forex risk and deciding on hedging strategies. It is essential that firms whose business involves foreign currency denominated cost and/or revenue consider exchange rate changes. The uncertainty of exchange rate is likely to be 
a cause of loss as forex rate changes are against the value of currency denominated for payables and/or receivables. As previously discussed, a large number of scholars (e.g., Griffin and Stulz, 2001; Dominguez and Tesar, 2001; Bartram, 1999; He and Ng, 1998; Bartov et al., 1996; Bartov and Bodnar, 1994; Jorion, 1990 as cited in Bartram, et al., 2005 , p. 410) have concluded that forex risk exposure is not a major concern for firms regardless of their size. However, as the findings of this thesis show, firms were worried about exchange rate uncertainty in practice. Although actual exchange rate levels were not a big problem for firms in this study, managers were aware that exchange rate changes could have negative impacts on their firms' profit. The following quote illustrates this.

It's just that you don't know what's gonna happen with the global economics and how that will impact on the US currency and how that will impact on the New Zealand currency. So at the moment it is OK, and it's good but as to how much it will be like this next year we don't know (...) [We have] no plans to deal with that yet but we do want to get into the Asian markets, as well as into China so we will look at what the currency rate is.... if we were doing that, exporting direct to China and see if it has any impact. (Garment)

In practice, firms indicated that they keep an eye on the fluctuation of forex rates around the time when foreign revenues were converted into local currency, and especially when the fluctuation trends seem to be negative. Firms might not fully perceive forex risk in terms of its impact on their overall business and exporting activities, yet they were concerned about the impact of forex risk on their profits.

Perceived forex risk is likely to be different depending on the characteristics of a firm's business. For example, Ship perceived especially high forex risk due to its deep involvement in international markets. This firm has a branch in Dubai, United Arab Emirates, and a huge amount of its revenues are denominated in foreign currency (US dollar). Those firms which are intensely internationalised, and thus perceive high forex risk, are likely to worry about forex exchange rate fluctuation and forex risks. This firm affirmed, 
We do care because it affects the profit that we report back in New Zealand. We report our overall profits in NZD and it makes a big difference. A fluctuation of 8 cents or something, you know, would make 150,000 dollars a month difference, Kiwi, in our reporting, you know. So you're talking about a difference of 2 million dollars or something over a year on our bottom line. (Ship)

Evidence showed that perceived forex risk was different across firms. In the case of Ship, forex risk essentially comes from its foreign currency denominated sales. In the case of Digiso, however, foreign currency denominated cost primarily caused forex exposure as their exports were paid in local currency. This firm specified,

The companies that we're dealing with wanted us to provide a NZD fixed price even though the contract was going to last for two years and there was no certainty that we've been required to deliver those licenses. So we were going to have to carry the exchange rate risk for two years because they were insisting on NEW ZEALAND dollar pricing even though we have to buy in USD price but they didn't want USD pricing so we had to give NZD pricing. So, we had to think about... That sort of thing is becoming more and more prevalent... so as we expand away from Telecom and more into other companies as well, forex risk is very risky for us primarily because NZD is so volatile. It's a real risk for our business. (Digiso)

The above comments also suggest that perceived forex risk has several dimensions. For example, Ship perceived forex risk in terms of its impact on profit. Digiso perceived forex risk in terms of cost versus revenues; that is, in the sense that forex risk is likely to influence the firm's choice of denominated currency for export pricing.

Perceived forex risk conforms to firms' understanding of forex risk. Also, perceived forex risk depends on firms' prioritisation of risks, that is, managerial attitude to types of risks. Some of the firms revealed that they have not considered forex risk for two main reasons (1) they are small, and (2) forex rates did not change significantly. However, the firms tended to be concerned about the possibility of forex rates fluctuating dramatically. 
Not at this stage, I think, because we are so small and because what we're doing is a very specific task in terms of our currency, the way we're using it is very small, very specific in that it's just a payment to the factory we have a shipment of our units coming out to us. Currency fluctuation is quite minor to us at this stage but I think if it changes drastically until the USD goes a lot stronger again. (Garment)

With Garment, noting its small size, this suggested that it lacked the ability to recognise how forex risk impacted its business. The firm was reluctant to forecast exchange fluctuations, as forex forecasting seemed to be out of the manager's competence and expertise. Thus the firm allocated its limited resources for other activities, rather than for managing forex risk. It also worth mentioning that the firm's forex exposure was unlikely to be so strong and it would not have needed to place much effort and resource for managing its negative effects. However forex risk was not the firm's top priority.

There are various reasons for exporting SMEs not to consider forex risk as a top priority. As an exporter, product/service is one of core components for achieving success in terms of marketing. This conforms to the concept of the marketing mix (Borden, 1964). For example, Digiso considered its software sale as of key importance. Informants revealed,

Yeah, I think one of the reasons that we haven't spent more time looking at hedging is that we've also had more fundamental issues of just making sure that the revenue is [there, and we] focused on getting the revenue in. So, in some ways worrying about forex is a second-order issue for our business because the first-order issue is to make sure you have got the sales. (...) So, I do think the perception of forex risk relative to other risks, does play a role in resource allocation. We tend to discount it a little bit. We worry about it but we haven't worried about it [so much] that it's on top of the list. (Software)

We won't take the risk of exchange rate fluctuations, we also don't take the upside risk which that is the exchange rate fluctuations can make a lot of money for us, that's not our business. Our business is not to make money from exchange rate fluctuation, our business is to make money from selling software and selling 
product, so we try and enter into these contracts primarily for the purpose of providing certainty, not any foreign exchange rate gain or anything else. It just so happens with this particular contract, you know. That's not the reason for doing this. We did it to try to lock in our rates, so that we can go back to head office with some certainty and say that we are going to achieve our budget, because we know that we are not going to lose a lot of money from foreign exchange rate dealing. (Digiso)

The interview analysis suggests that managing forex risk was not a major concern of exporting SMEs. It was the firms' primary objective to yield good sales, and thus healthy profits. They made money from selling their products. This was essential for the exporting firm, as sales, rather than forex management, was of key interest. Where forex risk management was considered as important, it was simply to ensure firms' profits, rather than to make money by hedging. Managing forex risk was synonymous with avoiding forex exposure. One informant affirmed,

Thing, I guess is the cost, and probably a philosophical decision that I am not in the currency business. We are 'in the business' of providing services, with specialised ships and under-water robots and so I don't have enough expertise to guess the currency and if I purchase, one way or another, to me, it seems just like buying insurance, and it's at a cost to me. And If I can alter my fear so I don't need that, and if the only thing that affects me is how much profit I report in NZD, and partly I don't care about that because I am using profit from USD to reinvest in USD anyway, and there's just no need for me to spend that money on hedging (...) and philosophical decision that I am not in a currency business. (Ship)

As we can see, Ship focused effort and resources for its core businesses, providing products and services. The firm had low expectations for currency business. The firm aimed to seek certainty, not to make money out of hedging activity. Another informant expressed,

Certainty, so we are just after certainty, really. We're not trying to make money out of hedging. We're not a bank, and we shouldn't try to make money out of hedging activities. So the primary purpose for me for undertaking any formal 
hedging activity is to get certainty, is to get a price fixed so that we can plan. So if we are in negotiation, we agree a price with a client and it's a multi-million dollar contract, we will try to hedge that. So we try to get that certainty so that we know that's the price the client is going to pay us, we're not going to get caught out. (Digiso)

Forex fluctuation is not the only factor that influences managerial perception of forex risk. Despite operating in the same country, and having revenues in the same foreign currency, e.g., US dollar, firms perceived forex risk differently. Thus, there are several dimensions of the concept of perceived forex risk. This concept refers to managerial risk perception, not only about exchange rate volatility, but also about effects of exchange rate volatility on firms' business, for example, exporting, pricing, cost versus revenue, and thus profit. On the other hand, managerial ability to understand such effects varies dramatically. Small firms with less experience in both international markets as well as in forex markets are likely to be less concerned about forex uncertainty. Simply, what these firms are concerned about is the exchange rate fluctuation, which might act against their foreign currency denominated revenues. On account of this, perceived forex risk varies across firms.

Managers' thoughts and behaviours regarding forex risk, as evident from the interview data, show that perceived forex risk is of importance to decision making on hedging. As forex risk is not "the top of the game anyway" (Ship), firms tend to allocate effort and resources for core business, rather than for managing forex risk. As firms become more involved in international markets and perceive increasing forex risk, they attempt to mobilise more resources associated with forex risk management. This is rational, because risk perception is likely to influence risk attitude (Arkes, Herren, \& Isen, 1988), and thus decision making.

New Zealand exporting SMEs reported that they frequently suffered from significant fluctuations of the New Zealand Dollar. To this end, New Zealand exporting SMEs were more concerned about forex fluctuations and forex risk management strategies in the long term. Currency fluctuations are likely to impact a firms' choice of ways of managing forex risk. 
The main findings of this section are as follows:

- Forex fluctuations were a major concern in forex risk management;

- There were several dimensions to perceived forex risk in: overall business risk, profit, exporting, pricing;

- Perceived forex risk was subject to firms' knowledge about forex risk;

- Small firms lacked ability to recognise how forex risk impacted their business, and tended to consider forex risk as a secondary risk;

- Forex risk was not one of the major business concerns.

\subsubsection{Forex exposure}

As mentioned earlier, firms tend not to be too concerned about hedging until forex exposure is large enough. This notion is essential and practical. The literature concludes that tax reduction may be one of the reasons for firms to hedge; however, this seems truer for larger firms than small firms. As forex risk is of secondary interest to exporting SMEs, as the results of this thesis show, it is likely that these SMEs consider practical reasons, rather than theoretical rationale, to hedge. One of the practical reasons for managing forex risk is forex exposure; however, how much forex exposure is needed for it to matter is quite subjective. For example, Digiso noted (see below) that it was interested in hedging exposure of one million US\$ or above. When determining hedging strategy, firms considered "the amount of risk" (Digiso), i.e. contract values, foreign currency denominated revenue and cost. This firm stated,

OK, again, just the size, the amount of the risk, so, you know, we're buying parts from Japan, and they were only 4,000 dollars, then we've naturally just used the Japanese bank account. We operate bank accounts in several currencies: Australian dollars, Japanese yen, and American dollars for those small amounts of money. We just use natural hedging. For the large amounts of money, anything that exceeds a million dollars, then we will look at some formal hedging, hedging arrangement, that's for money that we're paying away. (Digiso)

Clearly, the size of exposure affected decision making on hedging. The firms tended to use internal/natural hedging as their first option. Only when exposure was large enough, did the firms use external hedging. Digiso added, 
We use natural hedging most of the time but the point of [making a] decision that we move to a more formal hedging thing would depend on the size of exposure. So, probably anything over a million dollars, we would look for some formal hedging. (Digiso)

Among determinants mentioned in the literature on hedging, forex exposure is the most frequently mentioned factor by the interviewees. It is clear that forex exposure is the most essential reason for firms to hedge, since a firm does not need to hedge if it is not exposed to forex risk. In addition, as already noted, forex risk is of secondary concern to firms, especially the small ones. Thus firms start using hedging techniques, especially external ones, as they face increasing forex exposure. How much forex exposure varies across firms is subject to firm size and managerial perception of forex risk. Evaluation of the size of exposure depends on financial capability, competence and expertise to understand how forex volatility affects firms' overall business risk, as well as exporting, pricing, and thus profit. To this end, managerial experience, competence and expertise are subject to mobilization and/or allocation of human resources associated with forex risk management, which are to be discussed in the next section. New Zealand firms understood their vulnerability to large amounts of forex exposure, and increased the use of hedging techniques in accordance with the growth of exposure.

In summary, this section discussed the following main findings:

- Forex exposure was a major concern with regard to the hedging decision;

- Size of forex exposure affected decisions on hedging;

- Evaluation of the size of exposure was subject to financial capability and human resources available for forex risk management.

\subsubsection{Resources associated with risk management}

Firms were concerned about physical resources (e.g., inputs and sources of supply), as these influenced their capability to deal with forex fluctuations, and then their choice about hedging strategy. For instance, a firm tried to find stable and competitive sources of supply in order to strengthen its financial capability; thus it felt more confident to cope with forex fluctuation. Alternatively, lower input prices might be able to 
compensate for losses caused by forex changes. Firms may try to find benefits from physical resources to make up for possible forex loss. A firm said,

And the thing for us is that once we start having to order more units, we can then actually bargain the price down on the actual unit price. So at the moment it's quite high because the units are so small but as soon as we start, fitting you know, hundreds of units through the factory, we have then got more of a bargaining strength, to try to get a lower cost which would then hopefully be able to cover the increase in the USD, you know, fluctuation. So, there will always be that to look at in the future as well. (Garment)

SMEs generally lack resources for managing forex risk. The literature shows that SMEs have limited resources, not only for forex risk management, but also for overall business. Interview data from this thesis also showed that SMEs consider forex risk as a secondary concern compared with other business risks. To this end, firms tend to give priority in the use of their resources to their core business. Firms are unlikely to allocate much human resources to hedging activities until forex exposure is large enough. An informant affirmed,

There is no way we would have a full time person on this. No way. Not in a small business. If you were a bigger business, you might have someone dedicated to it. But not, not in a business of this size, not in my opinion. No. (Software)

Again, firms are reluctant to spend resources on managing forex risk since they allocate most of their resources to the running of their business, at least until it is well developed. Another firms asserted,

As our business matures, we may look at that [forex risk management] more closely. (Toy)

Although firms may have insufficient resources for managing forex risk, they sometimes attempt to use external resources, for example, traders and brokers. No matter what firms do in response to forex exposure, they generally struggle to find resources associated with forex risk management. This makes sense in terms of the cost of resources. Depending on the size of forex exposure, firms should know which type of 
resources would be most effective, efficient and reasonable (in terms of cost) to apply to forex management. An informant noted,

I think the trick is, for a small business, to find a foreign exchange supplier like a trader, or a broker: that can work, which is good. I don't think it should be an internal skill. (...) Yeah, we used a currency trader before as our third party. (...) No, it would not be done internally. Yes, for a little bit of the time, mostly external resources. (Software)

Usually, small firms prefer natural hedging, due to limitations in available resources, especially human resources. In a small firm, the owner often has to manage all the business activities. Larger firms may have financial controllers to manage forex risk. Thus it is unlikely that SMEs are able to afford a formal hedging strategy, as they tend to be characterised as resource-poor. A firm manager said,

If I have got a small management team of about ten people, you know, if I get them to devote time to working out what our financial hedging strategy would be, they might do the other stuff, but they're not actually doing the business. I actually don't think that they're particularly skilled at this anyway. So they might as well do what they're good at, and we just naturally hedge. (Ship)

Natural hedging is relatively easy and practical for SMEs, as it does not require much knowledge of forex markets, nor commitment of many resources. Interviewed managers usually claimed that they had little knowledge about hedging and/or forex risk management, until the terms were explained to them. They might apply natural hedging techniques, but not know that they are hedging/managing forex risk in doing so. In addition, firms might be interested in natural hedging because of limited financial resources. One firm revealed,

One of the reasons that we haven't done more traditional hedging is that we haven't had the money. You've got to have money, you've actually got to have money to be able to purchase it, and be confident in your revenue streams that there's enough to pay the forex debt. So that's been one of the reasons that we've not used a formal hedging strategy. (Software) 
'Financial resources' was frequently mentioned as a constraint to forex management by interviewed managers. For example, Software said that it needed money to be confident of its revenue stream. One way that a firm might manage their forex risk is by postponing selling/buying of foreign currency until they can get good prices. For this, firms need financial resources. Regardless of a firm's efficiency, this is unlikely to be the best way because of the financial resource constraints.

In many cases, firms failed to postpone trading foreign currencies as they had a shortage of the currencies needed. No matter what hedging techniques are taken, the hedging story indicates that financial resources have a fundamental role in managing foreign currency in small exporting firms. Should firms have high perceived forex risk, they are likely to struggle for financial resources to access more effective hedging techniques, for example, external techniques.

Internal hedging techniques are available and relatively easy for SMEs; on other hand, external hedging techniques, such as derivatives, are generally costly (Jonuška \& Samènaite, 2003). Evidence in the literature suggests that small firms prefer internal hedging techniques to currency derivatives (Hakkarainen et al., 1998; McRae \& Walker, 1980).

The firm also explained that it applied internal hedging techniques rather than external hedging, due to its lack of ability to forecast forex fluctuations. In fact, a firm hedges because of the uncertainty of the forex market. To this end, the firm's explanation is likely inconsistent with normal practice. Obviously, firms do not need to hedge if they have already known the future forex rates, since there is no uncertainty, and thus no risk. This indicates that the interviewee was quite unclear about how and why to hedge.

Following are some main points of this section about issues relating to resources associated with forex risk management:

- SMEs lacked resources associated with forex risk management, especially knowledge about forex risk management;

- Most resources were allocated to core businesses as the top priority rather than for forex risk management as a secondary priority; 
- SMEs preferred internal hedging due to limited resources;

- Exporting SMEs lacked specific knowledge about forex risk management and tended to employ internal/natural hedging techniques;

- Internal hedging was preferable to external hedging due to the financial cost of external hedging;

- The availability and competence of human resources affected the firms' choice about hedging strategy.

\subsubsection{Hedging strategy}

As mentioned earlier, the interviewed SMEs indicated that they prefer natural hedging techniques. Many of the informants agreed that natural hedging techniques were more favourable. One New Zealand informant affirmed,

"Typically what we do is we try to manage it naturally as much as possible. So we try to get any debts that relate to our operation over there in USD and we try to get all the costs to operations over there in USD. (...) We just do everything we can to do it naturally. (...) I am using profit from USD to reinvest in USD anyway."(Ship)

It appears that natural hedging is the main method of managing forex for SMEs. Firms utilise these techniques, while devoting the majority of their time and effort to managing the business as a whole.

"No, we haven't changed our strategy. Well, I suppose, maybe in the very early days, I did do some [external] hedging. And then after looking at the results over 6 months or a year, I just decided it wasn't worth it. And actually it didn't make enough difference to us. The best thing for us was to naturally hedge. (...) Our strategy was, wherever we were operating, to get the costs in a currency we're paid in. So our strategy has moved: initially there was a [external] hedging strategy, very quickly we moved away from that, to a natural hedging strategy. It may be we're just not smart enough, you know, and probably part of it too, is that we've only got so much management expertise and time we can devote to things and the very best thing we can do with the heads above our shoulders is to devote them to run the best ships and robots." (Ship) 
If possible, firms were willing to apply internal hedging techniques. For example, Ship paid its costs in the same foreign currency, US dollar, as that in which its revenues were denominated. The informant explained,

"We're a growing company and some of the things that we want to buy are in USD. We are always building a new ship, we are buying a new ship at the moment, and a lot of that is transacted in US Dollars. We just devote the USD to that, and it kind of doesn't make any difference to us. If we weren't growing and we wanted to bring all our money home and give it to the shareholders to buy Porsches or something. Then, yeah, we'd care a whole lot more, but while we're still spending in USD and we have got the ability to take the foreign currency we earn and spend it in that currency for the value of our company, it doesn't seem to make too much difference to us." (Ship)

Decision making on hedging by exporting SMEs thus tended to be straight forward, and practical. Many managers felt that they lacked a reason/knowledge to hedge, and did not spend much time and effort to think about a hedging strategy based on external hedging techniques. Firms would hedge more and utilise more external hedging techniques when they were more exposed to exchange fluctuations, and thus more concerned about forex risk.

In summary, the main points addressed in this section are as follows:

- The choice of natural/internal hedging could be seen as the most common hedging strategy used by exporting SMEs

- Exporting SMEs made quick, practical and short term hedging strategy.

\subsection{CHAPTER SUMMARY}

This chapter consists of two main parts. First, it outlined the research design of this thesis, including the rationale for adopting a sequential research design including an exploratory qualitative study and a main quantitative study. Second, the qualitative methodology, protocol, analysis and findings were presented. 
For the exploratory qualitative study, semi structured, exploratory interviews were conducted with the financial controllers/CEOs of six exporting SMEs based in New Zealand. With prior conceptualization of the key themes from the literature review, the interviews aimed (1) to seek for initial input into, and validation of, the conceptual model, (2) to inform the quantitative survey instrument and (3) to provide detailed insights into factors that influence firms' choice of hedging techniques. A purposive sampling approach was adopted and companies were selected that differed in size and industry sector. The in-depth interviews lasted between 30 and 45 minutes, and were carried out face-to-face or via Skype, depending on the managers' availability. The interviews were analysed using NVivo 9. Findings of the qualitative research are presented in this chapter and summarised in Table 3-3.

This chapter provides breadth and depth of inquiry relating to the results and their interpretations, guiding the next phase (quantitative) of the study. Specifically, the findings are used to inform the development of the survey instrument, aiming to ensure the criterion validity. Finally, the findings will inform the interpretation and discussion of the quantitative results, as well as the conclusions and implication of the study, discussed in Chapter 7. 


\section{Table 3-3: Summary of Qualitative Findings Issues Relating to Forex Risk Management}

\section{Internationalisation}

- When associated with experience and business maturity, a higher degree of internationalisation improved recognition of and knowledge about forex risk;

- High degree of internationalisation was associated with higher perceived forex risk.

\section{Perceived forex risk}

- Forex fluctuations were a major concern in forex risk management;

- There were several dimensions to perceived forex risk in: overall business risk, profit, exporting, pricing;

- Perceived forex risk was subject to firms' knowledge about forex risk;

- Small firms lacked ability to recognise how forex risk impacted their business, and tended to consider forex risk as a secondary risk;

- Forex risk was not one of major business concerns.

\section{Forex exposure}

- Forex exposure was a major concern with regard to the hedging decision;

- Size of forex exposure affected decision making on hedging;

- Evaluation of the size of exposure was subject to financial capability and human resources available for forex risk management.

\section{Resources}

- SMEs lacked resources associated with forex risk management;

- Most resources were allocated to core businesses as the top priority rather than for forex risk management as a secondary priority;

- SMEs preferred internal hedging due to limited resources;

- Internal hedging was preferable to external hedging due to the financial cost of external hedging;

- The availability and competence of human resources affected the firms' choice about hedging strategy.

\section{Hedging strategy}

- The choice of natural/internal hedging could be seen as the most common hedging strategy used by exporting SMEs

- Exporting SMEs made quick, practical and short term hedging strategy. 


\section{CHAPTER 4. CONCEPTUALIZATION AND HYPOTHESES}

This chapter outlines the theoretical conceptualization for the study. It presents the conceptual model of the thesis, informed by a thorough review of the literature. Qualitative findings were incorporated to support the theoretical underpinnings. Then hypotheses are advanced on the basis of the conceptual model and the literature review. 


\subsection{THEORETICAL BACKGROUND}

This section sets a theoretical background for the study, discussing how the RBV and theory of internationalisation are relevant to forex risk management in SMEs. On these three theoretical perspectives, the framework of this research is drawn.

Literature has shown that there are a large number of determinants that could explain why a firm hedges its forex rate risks (e.g. Berkman et al., 1997; Brown, 2001; Jonuška \& Samènaitè, 2003; Pramborg, 2005). However, it is unlikely that all of the determinants play a role in every case, and also the magnitude of each determinant is likely to vary across firms. As discussed in previous chapters, SMEs own fewer resources and skills for operating in forex markets than large firms; thus they might manage forex risk in different ways. This suggests that there would be a distinctive approach for SMEs to deal with forex risk. The following section discusses possible determinants from the three mentioned theoretical perspectives, in the context of SMEs.

\subsubsection{Forex Risk Management}

One of the key elements of forex risk management is deciding on a hedging strategy(S. R. Goldberg \& Drogt, 2008; McNamee, 1997). Strategy can be seen as a pattern of resource allocation to achieve set performance outcomes. Formally, Cooper and Schendel (1971) define strategy as the basic goals and objectives of the business, the product-market matches chosen on which to compete, the major pattern of resources allocations, and the major operating policies used to relate the firm to its environment.

The strategy concept may refer to various levels of strategy, namely (1) the corporate level, (2) the business level and (3) the functional area level (Schendel \& Patton, 1978). Accordingly, corporate level strategy is relevant to a firm's choice of products and markets. Business level strategy shows a firm how to compete within a certain product or market area. Functional strategy refers to specific operational areas such as marketing, financial, manufacturing, and forex risk involved in implementation of the business strategy. To this end, hedging strategy form a part of functional strategy.

Schendel and Patton (1978) have also pointed out that at any strategy level, the concept of strategy refers to three essential aspects : (1) the goals, (2) means or resources and (3) 
the environmental constraints. In a context of forex management, forex strategy is related to (1) the goals of improving a firm's ability to respond to forex rate changes, (2) resources allocation for hedging and (3) environmental constraints e.g., forex policies and forex fluctuations.

The term 'hedging strategy' in this study is defined within a setting typical of forex risk management. Hedging strategies in financial research studies (e.g. Fonseca \& Rustem, 2012; Gobet \& Landon, 2014; Kroner \& Sultan, 1993; Leoni, Vandaele, \& Vanmaele, 2013) are referred to as various ways to hedge risk by using hedging techniques. For a setting typical of forex risk management, 'forex hedging strategy' is primarily concerned with a hedging perspective of financial scholars, and also relating to a strategy perspective of (Cooper \& Schendel, 1971). On account of this, a forex hedging strategy, hereafter named a 'hedging strategy' in this thesis, is a pattern of resource allocation for forex risk management, which aims to improve a firm's ability to respond to forex rate uncertainties. In such a pattern, the firm uses resources for managing its forex risk, deciding how much to be hedged, and selecting hedging techniques. This study looks into a number of hedging determinants that influence a firm's hedging strategy. Such a hedging strategy is composed of two decisions, namely (1) hedging degree, which refers to the extent to which a firm uses either or both internal and external hedging techniques to manage its forex risk, and (2) hedging technique, which refers to the firm's choice of internal versus external techniques.

\subsubsection{Resource-Based View perspective}

From the perspective of the RBV, Barney (1991) defines a firm's resources as assets, capabilities, organizational processes, information, and knowledge that are controlled by the firm. The resources enable the firm to conceive of and implement strategies for improvement of its efficiency and effectiveness (Draft, 1983 cited by Barney, 1991). Also, there are a variety of lists of resources generated by various authors, according to Barney. Resources are considered as capital, and classified into three categories: human resources, organizational resources, and physical resources.

Physical resources include physical technology used in a firm, a firm's plant and equipment, its geographic location, and its access to raw materials. Human 
resources include the training, experience, judgment, intelligence, relationships, and insight of individual managers and workers in a firm. Organizational resources include a firm's formal reporting structures, its formal and informal planning, controlling, and coordinating systems as well as informal relations among groups within a firm and those in its environment (Barney, 1991, p. 101).

Studying strategic management, Basu (1998, p. 145) suggested that a resource profile combines the following resources and capabilities: (1) Financial resources, e.g., cash flow, debt capacity, new equity availability; (2) Physical resources, e.g., plant \& equipment, inventories; (3) Human resources, e.g., scientists, production supervisors, sales personnel; (4) Organizational resources, e.g., quality control systems, corporate culture, relationships; (5) Technological capabilities, e.g., high quality production, low cost plants. Robert M. Grant (1991) suggested a sixth resource, intangible resources, e.g., reputation, brand recognition, goodwill. These types of resources have also been mentioned in other studies, e.g. Peng (2006).

As this thesis looks into forex risk management, financial resources could be argued as another important type of resource. Financial resources are strategically associated with financial decisions e.g., forex management. In this thesis, financial resources are regarded as both cash and non-cash funds, e.g., money and wealth, provided by different investors such as shareholders, lenders, and debt holders in exchange for remuneration, e.g., dividends, interests, capital gains. Basically, financial resources also include financial capabilities and liabilities. In fact, of eight rationales for a firm's hedging practice that have been discussed in the previous chapter, four rationales, namely (1) Under-investment problems, (2) Financial distress, (3) Hedging costs and (4) Tax liabilities, belong to financial resources. It follows that these four factors show that financial resources are also likely to impact a firm's selection of hedging strategy.

In summary, from the perspective of the RBV, it could be argued that the four resources, namely (1) human resources, (2) organizational resources, (3) physical resources and (4) financial resources, would directly influence a firm's choice about hedging strategy (see Figure 4-1). 


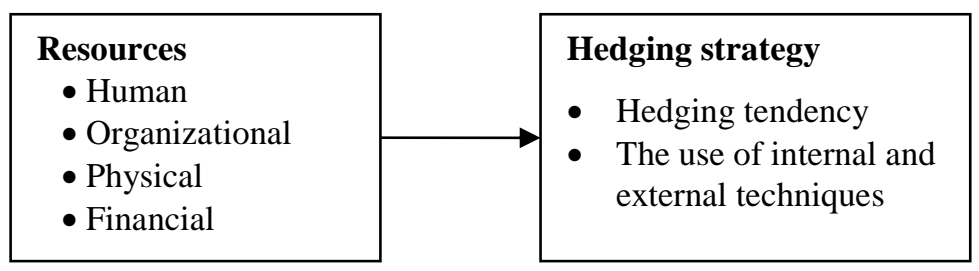

Figure 4-1: The influence of a firm's resources on its hedging strategy

\subsubsection{Internationalisation Theory perspective}

From the earlier discussion on SMEs' strategies in forex risk management, it follows that a firm's degree of internationalisation is likely to affect a firm's forex exposure and perceived forex risk. Internationalisation theory affirms the cyclical process by which firms increase their involvement in international operation (Cavusgil, 1984; Johanson \& Vahlne, 1977). These, and other, scholars recognise that firms, through this cyclical process, gain increased knowledge, experience, and reduction in uncertainty as well as reduction in perceived risk. In this regard, a firm's forex exposure and its perceived forex risk are likely to increase as it becomes more involved in international business. The following Figure 4-2 shows how a firm's degree of internationalisation might influence perceived forex risk and forex exposure.

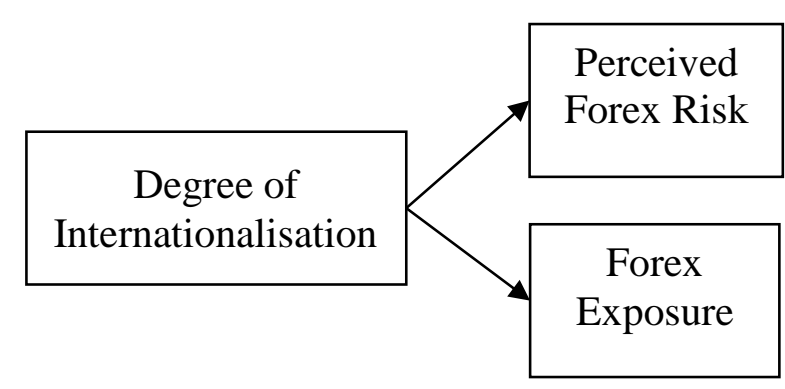

Figure 4-2: The impact of a firm's degree of internationalisation on forex risk

This section has conceptualized how an SME manages forex risk, extending the use of the RBV, and internationalisation theory in forex risk management. The section presents two major linkages, indicating (1) the impact of a firm's degree of internationalisation on forex risk management and (2) the relationships relating to resources associated with forex risk management. The next section will incorporate these linkages in a conceptual framework, and then develop relevant hypotheses. 


\subsection{THE CONCEPTUAL MODEL AND HYPOTHESES}

This section makes arguments and gives theoretical support for hypotheses in the conceptual model presented in Figure 4-3, showing constructs as determinants that affect two decisions regarding firms' forex risk hedging strategy: (1) how much they tend to hedge forex risk (hedging degree) and (2) their use of internal and/or external techniques (hedging technique).

\subsubsection{Degree of Internationalisation}

Cavusgil (1980) developed the Innovation-Related Internationalisation Models (Imodels), conceptualizing the internationalisation process in five stages: a domestic marketing, a pre-export, an experimental involvement, an active involvement, and a committed involvement. The I-models hold for SMEs (Cavusgil, 1980; Gankema et al., 2000) and SMEs are unlikely to pursue FDI (Coviello \& McAuley, 1999; Dalli, 1994). That is, a firm tends to export more as it is moving to higher degree of internationalisation (Gankema et al., 2000). Other process models of internationalisation (Johanson \& Vahlne, 1977) include the stages that firms follow as they progress into investment options, such as joint ventures and wholly-owned subsidiaries in the host market.

Interview data showed that exporting SMEs suffered higher forex exposure when they were more actively involved in international activities, and thus tended to perceive higher forex risk. This is because of firms' better understanding and wider experience of forex issues as the firm becomes more involved in the international market.

Internationalisation theory suggests that SMEs face higher risk as they increase their foreign market commitment over time; gaining experience and resources, and enhancing market knowledge lead them to further commitment in more distant markets (Coviello \& McAuley, 1999). Thus SMEs need to employ more effective strategies for managing risk when they enlarge their international markets. This implies that the degree of internationalisation of a firm is likely to impact the forex risk management decisions of SMEs, as well as their resource availability. 
Process models of internationalisation describe two main ways in which firms may internationalise: (1) Uppsala internationalisation model (U-Model) (Johanson \& Vahlne, 1977), and the Innovation-related internationalisation model (I-Model) (Cavusgil, 1984), both referred to as stages models. Although Joseph (2000) and Aabo et al. (2010) have shown that the degree of MNE internationalisation impacts the selection of hedging strategy, there is a scarcity of research on forex risk management using these models, at least in an SME context. As the internationalisation models indicate, risk increases as a firm increases its foreign market commitment and investment. It stands to reason that both forex exposure and peceived forex risk are associated with the degree of internationalisation. Even though a firm may have a better understanding of forex risk and forex exposure as it internationalises further, Cavusgil (1984, p. 196) indicates that "the sequential nature of the international process can contribute to greater perceived-risk associated with internationalisation business decisions, tentative nature of managerial expectations, and greater genuine uncertainty". Accordingly, when the firm becomes more involved in international markets, it will face more forex exposure and higher perceived forex risk.

H1: As a firm's degree of internationalisation increases, so too does its perceived forex risk.

H2: As a firm's degree of internationalisation increases, so too does its forex exposure.

As firms have overseas subsidiary/ies, overseas employees and foreign assets, they would be more exposed to exchange rate fluctuation due to the stronger demands on currency exchange. Given that Joseph (2000) pointed out that firms' characteristics associated with internationalisation influence the use of internal and external hedging techniques, this study tended to examine the effect of an overseas subsidiary, overseas employees and foreign assets on forex risk management ${ }^{7}$. These characteristics are associated with internationalisation, indicating the firm's involvement in international

\footnotetext{
${ }^{7}$ While the sudy focused on exporting SMEs, it was expected that some of them would also have international operations, and these control variables needed to be considered.
} 
markets; thus the study might shed light on the role of internationalisation in forex risk. As a result, this study investigated the effect of three control variable, i.e. overseas subsidiary, overseas employees and foreign assets.

\subsubsection{Perceived Forex Risk}

Peceived forex risk refers to the managerial perception of forex risk, i.e. the risk that managers are aware of. A number of factors, such as, managerial training, experience, judgment, intelligence, and the way in which problems are framed, tend to influence the perception of, and attitude toward, risk (March \& Shapira, 1987). This suggests that managerial perceptions of forex risk vary across individuals. In addition, March \& Shapira hold that managerial risk-taking propensity may also vary across context. Thus, some risk managers can be risk averse, while the others can be risk seeking. Perceived forex risk is likely to indicate managerial attitude toward forex risk.

Interview data showed that perceived forex risk is one of firms' major concerns regarding forex risk management. Firms tended to hedge more, and then made more use of external hedging techniques as they perceived themselves to be more exposed to forex risk. Consequently, firms attempted to invest more resources, for example, human resources, in forex risk management. Interviewed firms showed their interest in training and/or employment of experienced staff. In addition, training programs were thought to improve firms' understanding of forex risk management.

Managerial perception of forex risk had impacts on the incentive to hedge and the choice of hedging techniques (Joseph, 2000). Although internal hedging is generally preferable to external hedging for SMEs, for reasons already discussed, they may have a higher tendency to use external hedging when facing higher forex exposure; in this case, they would extend the use of various hedging techniques in an effort to manage exchange risk more effectively.

H3: When perceived forex risk increases, (i) the tendency to hedge and (ii) the likelihood of using external hedging techniques also increase.

In the context of SMEs, managers might have different levels of knowledge, training, and experience in regard to managing forex risk, depending on managerial capabilities 
and resource availability (Berra et al., 1995; Coviello \& Munro, 1997). Also, they might not know about hedging techniques, particularly external methods, which are likely to use complicated contractual mechanisms, such as buying and selling currency derivatives. As a consequence, some SME managers might have a low level of perceived forex risk, thus choosing to overlook the risk and not hedge. On the other hand, even though they may lack detailed knowledge, some managers might be risk averse, having a high level of perceived forex risk, and thus tending to hedge as much as they can. Moreover, a firm's choice of ways to deal with risk involves a trade-off between risk and return (March \& Shapira, 1987, p. 1406). Forex risk is just one extra risk among various types of risk that a firm may face. For SMEs, the overall perceived forex risk may be low because the return from exporting is considered to outweigh potential losses from exchange rate changes. In this case, an SME might focus on promoting export and/or other international activities while disregarding hegding techniques, particulary external techniques that require additional financial resources, such as the use of derivatives.

These arguments suggest that perceived forex risk serves a pivotal role in decisions about a firm's use of resources for its hedging strategy. Research shows that risk perception influences a firm's decision-making (Sitkin \& Pablo, 1992), and risk managers tend to choose responses according to their overall perception of forex uncertainty (Hillson \& Murray-Webster, 2007). In order to implement the responses, appropriate firm resources are necessary.

$H 4_{a, b, c, d}:$ The higher the perceived forex risk, the more likely the firm would be to invest in (a) physical, (b) organizational, (c) human, and (d) financial resources for hedging.

\subsubsection{Forex Exposure}

The forex exposure of a firm was defined by Bodnar and Marston (2000), as a measure of the sensitivity of its cash flows to changes in exchange rates. The future cash flows of a firm may arise from both domestic and foreign currency transactions, involving assets and liabilities, and generating revenues and expenses. Adler and Dumas (1984, p. 42) consider exposure to currency risk as "the amounts of foreign currencies which 
represent the sensitivity of the future, real value of any physical or financial asset to random variations in the future domestic purchasing powers of these foreign currencies, at some specific future date".

The extant literature on forex risk management indicates that a firm will need to manage its forex exposure due to market imperfection and deviations from parity conditions, especially when forex risk is perceived to be significant. The magnitude of forex exposure in SMEs is likely to vary, depending on, for example, their degree of internationalisation and nature of currency transactions. Evidence suggests that the higher the level of forex exposure a firm may face, the more likely the firm is to hedge (Bartram et al., 2010). Although internal hedging is generally preferable to external hedging for SMEs, for reasons already discussed, they may have a higher tendency to use external hedging when facing higher forex exposure; in this case, they would extend the use of various hedging techniques in an effort to manage exchange risk more effectively.

H5: When forex exposure increases (i) the tendency to hedge and (ii) the likelihood of using external hedging techniques also increase.

Given the critical role of resources in forex risk management already discussed, it is suggested that the impact of forex exposure on hedging strategy is mediated through resources. Considering that risk management is about "planning, organizing, directing, and controlling organization systems and resources to achieve objectives" (McNamee, 1997, p. 4), a firm would, when facing a risk, such as forex risk, attempt to mobilise its resources in order to execute an effective strategy (Learned, Christensen, Andrews, \& Guth, 1969; Porter, 1981). According to the RBV literature, resources are fundamental ingredients for a successful strategy (Barney, 1991). Therefore, when faced with high forex exposure, SMEs would devise a hedging strategy on the basis of their available resources to produce the desired outcomes.

$H 6_{a, b, c, d}$ : When a firm is more exposed to forex risk, it tends to use more (a) physical, (b) organizational, (c) human, and (d) financial resources to manage the risk. 


\subsubsection{Resources}

The effectiveness of a hedging strategy depends on the resources utilised. For example, research shows that the possession of physical and other resources (e.g., supplier relationship capabilities, customer relationship capabilities) tends to bring a firm cost advantages in international markets (Kaleka, 2002). In addition, organizational resources tend to be conducive to the achievement of satisfactory client service and employee performance (Salanova, Agut, \& Peiró, 2005). Therefore, availability of resources could act as an incentive for a firm to hedge, and to use a more costly external hedging technique. The firm, therefore, tends to hedge more and make more use of external hedging techniques.

$H 7_{a, b, c, d}$ : When a firm has (a) physical, (b) organizational, (c) human, and (d) financial resources available, or can invest in these resources, it will have (i) a greater tendency to hedge, and (ii) a greater likelihood of using external hedging techniques.

\subsection{SUMMARY OF HYPOTHESES}

This chapter developed seven hypotheses that show the relationship among five fundamental predictors, and specifically how these predictors impact a firm's hedging strategy, also called Forex Risk Management. The predictors include (1) Degree of Internationalisation, (2) Forex Exposure, (3) Perceived Forex Risk, and (4) Resources. A summary of hypotheses is presented in Table 4-1 and in the Conceptual Model of Forex Risk Management Figure 4-3. 
Table 4-1: Hypotheses for factors influencing forex hedging strategy by exporting SMEs

Number

Hypotheses

$\mathrm{H} 1 \quad$ As a firm's degree of internationalisation increases, so too does its perceived forex risk.

$\mathrm{H} 2$ As a firm's degree of internationalisation increases, so too does its forex exposure.

H3 When perceived forex risk increases, (i) the tendency to hedge and (ii) the likelihood of using external hedging techniques also increase.

$\mathrm{H} 4 \quad$ When a firm is more exposed to forex risk, it tends to use more (a) physical, (b) organizational, (c) human, and (d) financial resources to manage the risk.

H5 When forex exposure increases, (i) the tendency to hedge and (ii) the likelihood of using external hedging techniques also increase.

H6 The higher the perceived forex risk, the more likely the firm would be to invest in (a) physical, (b) organizational, (c) human, and (d) financial resources for hedging.

H7 When a firm has (a) physical, (b) organizational, (c) human, and (d) financial resources available, or can invest in these resources, it will have (i) a greater the tendency to hedge, and (ii) a greater likelihood of using external hedging techniques.

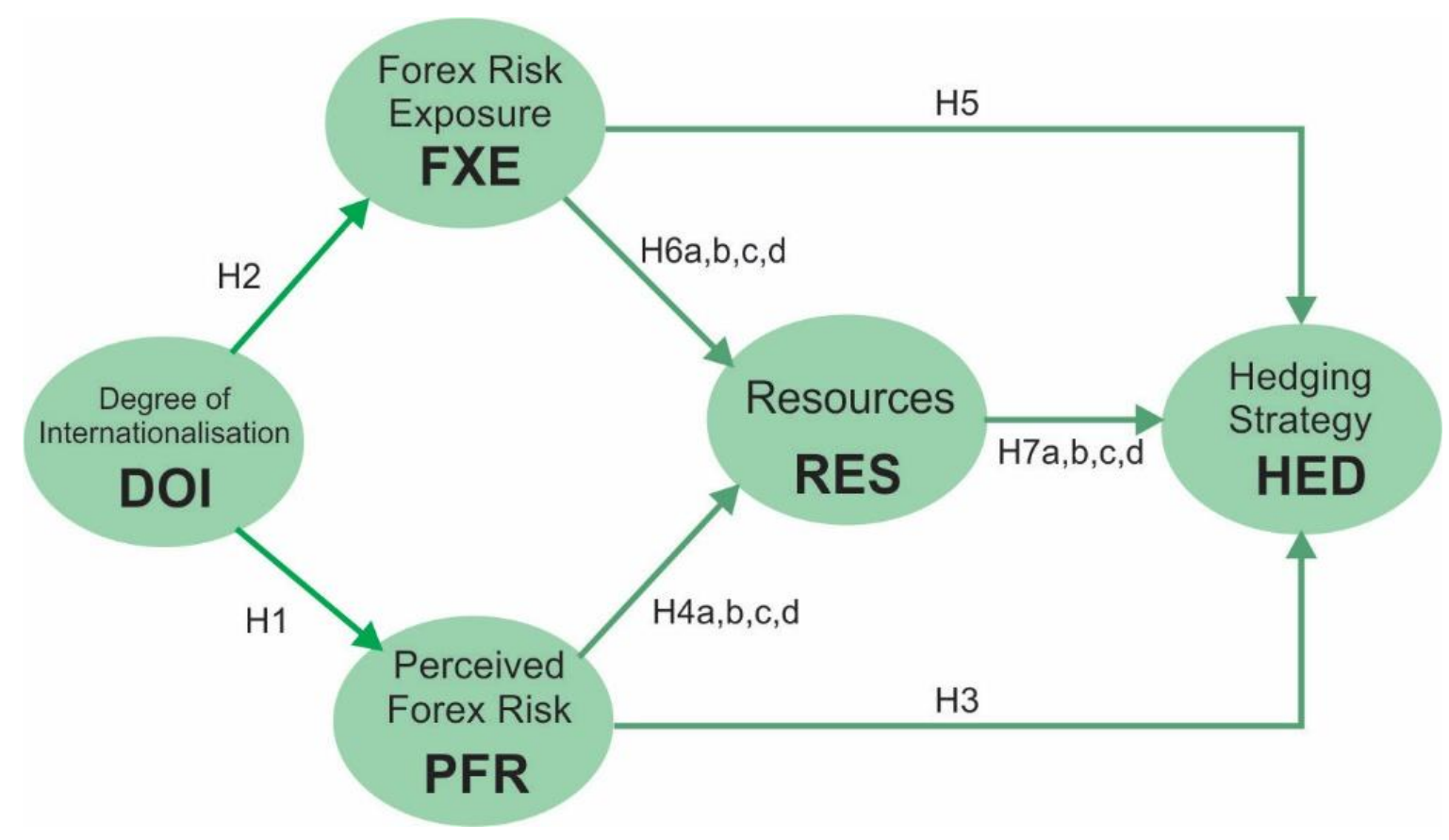

Figure 4-3: The Model of Forex Risk Management 


\section{CHAPTER 5. QUANTITATIVE METHODOLOGY}

This chapter covers the major quantitative study employed in this thesis, as the second phase of a sequential research design. The quantitative methodology utilised is outlined, including the research process, sample selection, data collection, and measurement of variables. Also, the statistical analysis tools used for testing the hypotheses are described. 


\subsection{RESEARCH DESIGN}

The research design of this thesis, which is adapted from the work of Hair, Black, Babin, and Anderson (2010) and Nguyen (2007), is aimed to refine the measurement model and to test hypotheses described in Chapter 4. Aiming to ensure that the survey questionnaire addresses all issues that are relevant to the research problem, this part of the study also refers to qualitative data from in-depth interviews undertaken with six managers in the qualitative component of this thesis (see Chapter 3). As most of the scales were adapted from a variety of previous studies, this step is important because of the difference between the research domains of forex risk management in this thesis and those of previous studies. A pre-testing survey was undertaken with the author's supervisory committee, two academics, and several $\mathrm{PhD}$ students in marketing, international business, and finance, as well as two interviewees, who took part in indepth interviews earlier. Figure 5-1 shows the research design of the study, which includes two stages: item generation and the main study.

Covariance-based Structural Equation Modeling (SEM) was an appropriate approach for this study. This is the "classical" SEM approach which utilizes software such as LISREL (Henseler, Ringle, \& Sinkovics, 2009) or AMOS (Hair et al., 2010). Another approach is Variance-based Structural Equation Modeling, also known in literature as partial least square (PLS) (Henseler et al., 2009) or component-based SEM (Tenenhaus, 2008). Variance-based Structural Equation Modeling is data driven in order to be predictive and to provide knowledge and new theoretical rationale about the researched phenomenon (Davcik, 2014); therefore Variance-based Structural Equation Modeling was not an appropriate approach for this study. The term SEM is usually referred to as covariance-based structural equation modeling in marketing and business (Chin, 1998), so this thesis simply names this approach as SEM. This SEM approach is based on the covariance matrices to explain the relationships between indicators and constructs, and to confirm the theoretical rationale that was specified by a model (Davcik, 2014). It is rationale to utilize SME approach in this study because this approach is considered a confirmatory method that is guided by theory, rather than by empirical results (Davcik, 2014). SEM approach was adopted to analyse how theory fits with observations and reality. Given that this study aimed to test a theoretical model of 
forex risk management by exporting SMEs, a theory-driven SEM approach was suitable, because of the exact construct specification in measurement and structural model as well as necessary modification of the models during the estimation procedure (Hair et al., 2010).

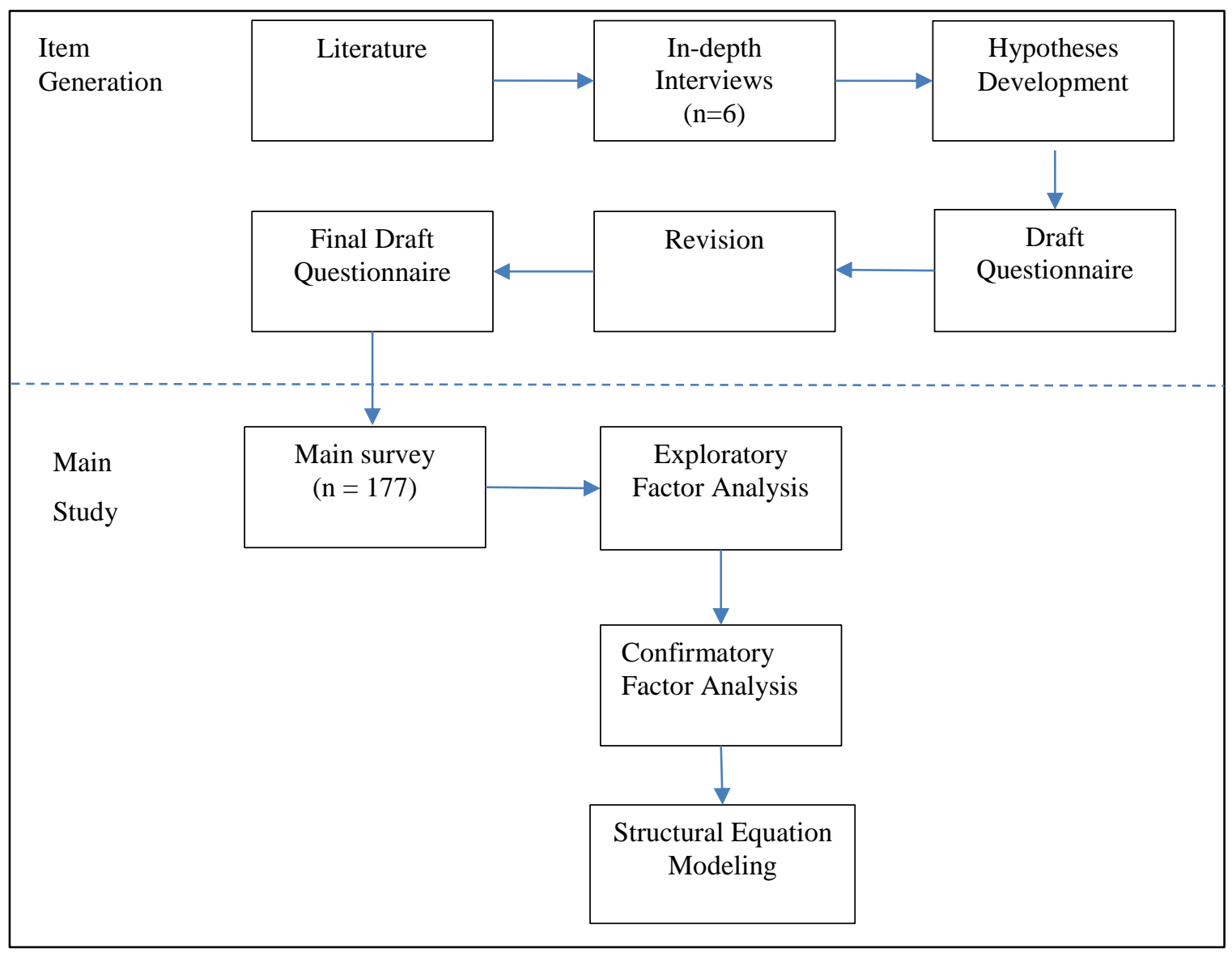

\section{Figure 5-1: Research Process}

Source: Adapted from the work of Churchill (1979), Steenkamp and Van Trijp (1991) and Nguyen (2007)

Two of the fundamental steps in Structural Equation Modeling (SEM), Exploratory Factor Analysis (EFA) and Confirmatory Factor Analysis (CFA), were conducted to test path models and hypotheses (Byrne, 2013; Hair et al., 2010). The use of SEM in this study aimed to seek fit-statistics assessing the matching of the conceptual model and data (Nachtigall, Kroehne, Funke, \& Steyer, 2003). Unlike the work of others (e.g. Géczy et al., 1997; González et al., 2007; Hagelin, 2003; Pramborg, 2005) that used a binomial logit model to investigate firms hedging behaviour, this thesis seeks an explanation for the relationships among hedging determinants and their effects on firms' 
hedging strategy, rather than just determining whether or not the firms hedge. In other words, it is reasonable to examine the structure of interrelationships (Hair et al., 2010).

\subsection{RESEARCH INSTRUMENT}

This section will justify the use of the measurements and scales, explaining why this thesis applies quasi-perceptual measurement and Likert scales.

\subsubsection{Quasi-perceptual measurement}

The measurement scales are adapted from the extant literature, except for those which are used for financial resources. The study made use of a hybrid between the operationally-defined and perceptual measures, that is, quasi-perceptual measures (Ketokivi \& Schroeder, 2004). Operationally-defined measurement is also known as the use of archival data or objective measurement (Boyd et al., 1993; Ketokivi \& Schroeder, 2004; Shortell \& Zajac, 1990). As can be seen in Table 5-1, this study employed an extensive use of perceptual measures.

\section{Table 5-1: The use of quasi-perceptual measures in the study}

$\begin{array}{ll}\text { Perceived forex risk } & \text { Perceptual } \\ \text { Resources } & \text { Perceptual } \\ \text { Hedging strategy } & \text { Perceptual } \\ \text { Forex exposure } & \text { Operationally-defined } \\ \text { Internationalisation } & \text { Operationally-defined }\end{array}$

For example, perceptual measures are utilised for describing managerial cognitions of forex risk and the extent to which hedging techniques have been employed. Operationally-defined measures are used to capture the extent to which exporting SMEs are exposed to forex fluctuation and the degree of internationalisation.

Boyd, Dess, \& Rasheed (1993) found that studies of firm actions, e.g., making decision on hedging forex risk, would benefit from the use of perceptual measurement. On the one hand, these authors recognised three major concerns regarding the use of perceptual measures, that is, (i) limitations regarding generalizability, (ii) reliability and validity problems, and (iii) sources of uncertainty. On the other hand, other authors (e.g., Anderson \& Paine, 1975; Hambrick \& Snow, 1977; D. Miller, 1988) have argued that managers' cognitions of the environment are more decisive than archival measures of 
the environment in terms of organizational strategy, structure, and process. Unlike indicators based on archival data, such as growth or profitability, perceptual measures capture a firm's environment from the perspective of organizational members or key informants. This approach, therefore, would enable researchers to look into a firm's financial behaviours, i.e. forex risk management. For instance, managers of exporting and importing SMEs tend to perceive the exposure of forex rate fluctuations adversely and would be likely to make decisions based on this perception. In addition, Boyd, Dess, \& Rasheed (1993) also hold that the current state of the firm's environment would likely affect managerial perception, while archival indicators reflect long term trends of hedging.

While most of the extant literature on forex risk management and hedging strategy has utilised operationally-defined measures, a number of studies support the use of perceptual measurement. Rumelt, Schendel, and Teece (1991) showed that objective data, such as Compustat and PIMS and archival indicators, have been widely used in the strategy literature. However, a number of scholars have raised serious doubts about the use of archival indicators, especially those used in large-sample empirical work that makes inferences to populations. For example, Ward, McCreery, Ritzman, \& Sharma (1998) argued that questions requiring absolute estimates of archival indicators would not necessarily yield more reliable results than perceptual measures. Bozarth and Edwards (1997) also conceded that archival indicators depend on the accounting system used and the capital structure, both of which vary from one industry to another, even varying within an industry. These authors also further predicted that aggregate financial measures are affected by an abundance of factors, and considered that finding significant relationships is difficult. Finally, Ward, Leong, and Boyer (1994) observed that informants would likely hesitate to disclose operationally-defined data relative to disclosing perceptual information. Ahmad and Mohamed Zabri (2013), citing Lybaert (1998), and Garg, Walters, and Priem (2003) also highlighted the difficulty of gaining objective data (especially financial data) from SME managers. Given these arguments, and notwithstanding the acknowledged limitations, the use of perceptual measures appears to be justified in this thesis. 
Since this study looks into SMEs' hedging strategy made by managers, which is partly and at times fully subjective, perceptual measures will be an appropriate method. As mentioned earlier, Ketokivi and Schroeder (2004) claim that objective measures are unlikely to be as appropriate as perceptual measures for those measures which concern the cognitions of individuals and organizations. Indeed, much of the risk management literature discusses outcomes that exist in the cognitions of individuals and organizations. Conceptualizing organizational strategy, scholars (e.g., Ginsberg, 1984; Ginsberg \& Venkatraman, 1985; Venkatraman \& Grant, 1986) are concerned about measurement reliability and validity. To assess the reliability and validity of perceptual measures developed by Miles, Snow, Meyer, \& Coleman Jr (1978), Shortell and Zajac (1990) have used both archival and perceptual data from two time periods and found that prediction using perceptual data is the same as prediction using archival data.

In summary, on the basis of studying an overarching model of a firm's forex risk management (specifically, influences on hedging strategy), the use of perceptual measures in this study is an appropriate approach. First, perceptual measures aim to capture firms' environment from the perspective of organizational members. Second, they are able to reflect the current state of the firm's environment. Third, perceptual indicators are preferred to financial ones as the latter is subject to accounting systems, the capital structure and a number of other factors. Fourth, informants are more likely to respond to perceptual questions than to disclose archival data. Fundamentally, this is a study about firms' financial behaviours that are largely influenced by individual cognitions; hence the use of perceptual measures is the most appropriate option. In order to address potential limitations on using perceptual measures, all of the measurement scales used in this thesis will be tested for reliability and validity, as outlined in Chapter 6.

\subsubsection{Likert scale}

The study aims to gather managerial cognitions about forex risk, resources, and hedging strategy. A five-point Likert scale enables the researcher to capture the best judgement of the respondents, and befits the purposes of the study. The use of five-point Likert scale for measuring perceived forex risk and resources is consistent with a number of previous studies from which item scales to measure these constructs are adapted. A 
corresponding verbal description was given to each response position in the scale, providing respondents a better understanding of the response options (Zikmund, 2003). A Likert scale was used for most of the variables in this study.

Zikmund (2003) stresses that the five-point Likert scale offers various response positions, which increases the sensitivity of the scale to the variability of the responses to questions (Zikmund, 2003). It not only gives respondents convenience, e.g., quick understanding on how to answer the survey questionnaire, but also enables researchers to aggregate and administer indicators (Boyd et al., 1993; Devlin, Dong, \& Brown, 1993; Lundstrom \& Lamont, 1976).

Moreover, the Likert scale, which is commonly used in social science and international business research, allows for the capture of interval-type data that permit advanced data analytical tools to be used (Cavana, Delahaye, \& Sekaran, 2001). Labelled response positions would likely increase the reliability and validity of the instrument since the meaning of each point is clarified (Krosnick, 1999). The labels further enhance the discriminatory and semantic properties of the response positions, thus establishing the scales' psychological interval (J. Myers \& Warner, 1968). Interviews with SME managers showed that many of the terms relating to forex risk management, for example forex risk, hedging, natural hedging, official hedging, and so on, have been understood slightly differently among the interviewed managers. Particularly, several SMEs' managers seemed not to know these terms well. On account of this, the Likert scale is useful in this study about forex risk management due to clear response positions.

\subsubsection{Web-based survey}

Table 5-2 is adapted from the $\mathrm{PhD}$ thesis of Gerschewski (2011), showing an overview of benefits and drawback of web-based surveys in comparison with mail questionnaires.

Table 5-2: Advantages and disadvantages of web-based surveys compared to mail questionnaires

\begin{tabular}{ccc}
\hline \multicolumn{1}{c}{ Advantages } & \multicolumn{2}{c}{ Disadvantages } \\
\hline Costs & & Visual appearance \\
$\bullet$ & Lower costs & - Possible different appearances \\
& $-\quad$ no printing of survey (Dixon \& & for respondents due to different
\end{tabular}




\begin{tabular}{cc}
\hline $\begin{array}{l}\text { Turner, 2007) } \\
\text { no costs for postage (Dixon \& } \\
\text { Turner, 2007) } \\
\text { overcome international } \\
\text { boundaries as barriers } \\
\text { (Dillman, 2000) }\end{array}$ & $\begin{array}{l}\text { monitor sizes, web browsers, } \\
\text { and operating systems (Dillman, } \\
\text { 2000) }\end{array}$ \\
Design \\
- More opportunities in terms of \\
layout (e.g., colour)
\end{tabular}

Source: Adapted from PhD thesis of Gerschewski (2011)

Recently, electronic-surveys have been increasingly important thanks to the advancement of the internet (Couper, 2000). The design and administration of selfadministered questionnaires are potentially efficient when electronic survey methods are employed (Dillman, 2000). Basically, there are two type of electronic-based surveys, that is, email and web-based survey (Sue \& Ritter, 2012). These authors define email surveys as those that convey the survey either in the body of the email or in the attachment. Email surveys are expected to have fast delivery and quick response with low costs. On the other hand, the response rate could be limited due to lack of anonymity as respondents' emails can be seen by the researchers.

Unlike email surveys, a web-based survey usually refers to a website on a network server, where the survey is stored. Despite having similar benefits as email surveys, anonymity is ensured because email address of respondents are not shown in a webbased approach (Jansen et al., 2007). 
A web-based survey has been shown to be advantageous in terms of cost, design, administration of survey and response. First, the cost of using a web-based surveys is lower than that for mail questionnaires as there is no printing and posting cost (Dixon $\&$ Turner, 2007). In addition, a web-based survey has easier access to a wide geographic sample, thus broadening international boundaries of the survey (Dillman, 2000). Regardless of geographic distance, delivery and response speed can be quicker in comparison with mail questions (Kwak \& Radler, 2002). Second, a web-based survey provides more opportunities with regard to survey design. For example, the layout of such a web-based survey can be more attractive to respondents, and thus provide better guides and generate enthusiasm to answer the questionnaire. Third, it is easier to administer a web-based survey, for instance, with tracking response rates, and sending reminders. Also data can be directly entered into the network server, thus reducing manual data entry errors (Sue \& Ritter, 2012).

On the other hand, web-based surveys have several drawbacks in terms of visual appearance, electronic spamming and technological problems. Due to various monitor sizes, web browsers, and operating systems a web-based survey may appear different to various respondents (Dillman, 2000). Survey emails which include the survey website might be seen as spam email (Dixon \& Turner, 2007). Besides, this approach might face technological problems, e.g., crash of the server storing surveys, interruptions caused by unstable internet connections (Jansen et al., 2007).

A web-based survey might also face a considerable drawback of low response rate. Although high response rate for web-based surveys could be found in some studies (Griffis et al., 2003), mail surveys are likely to have a higher response rate than webbased surveys (Kwak \& Radler, 2002; Shih \& Fan, 2008). Differences in response rates between web-based and mail survey can be explained by attributes of the target population type (Shih \& Fan, 2008). On the other hand, the survey nature, for example, mail versus web-based survey, has a critical impact on response rates; so too does the design and implementation procedures (Dillman, 2000).

Despite its possible drawbacks, this study adopted a web-based survey due to its benefits compared to mail surveys. To overcome the drawbacks mentioned above, a large sample was selected, as discussed below. The ease of access to business databases 
also encouraged the adoption of a web-based survey instrument. The network server of Victoria University of Wellington is available and trustworthy for academic staff to implement online surveys using the Qualtrics Survey Tool, which is commonly employed by a number of universities worldwide as well as by corporate and government organizations (Qualtrics, 2014)

\subsection{QUESTIONNAIRE DESIGN}

This section presents the operationalization of the constructs in the conceptual model, together with the discussion on questions and questionnaire design. Basically, constructs were operationalized in accordance with the literature on forex risk management which included influences on, and rationales for firms' choice about hedging strategy (hedging rationales). The constructs are summarised later in this chapter in Table 5-5 and modelled in Figure 5-2. In addition, relevant literature from the $\mathrm{RBV}$, and internationalisation theory was also applied in order to define and operationalize the constructs.

The survey questionnaire has five parts, corresponding to the constructs used in the model, as follows

Perceived forex risk

PFR

Resources

RES

Forex risk management HED

Forex exposure

FXE

Internationalisation $^{8}$

DOI

A final of version of the questionnaire is attached in Appendix I.

\footnotetext{
${ }^{8}$ This part includes questions to measure degree of internationalisation, control variables associated with internationalisation and description of firms' internationalisation. Only degree of internationalisation (export ratio) was tested directly in the model.
} 


\subsubsection{Perceived Forex Risk (PFR)}

Adapting scales proposed by Kula (2005), this study uses a 5-point Likert scale to measure perceived forex risk. This construct is operationalized by three items (Kula, 2005), which are managerial perceptions on (1) the ratio of forex risk to overall business risk, (2) the extent of losses a firm suffers due to changes in forex rates, and (3) the extent to which changes in forex rates affect a firm's proceeds ${ }^{9}$ (even if it does not have any forex obligation or proceeds).

The three-item measure of perceived forex risk in this thesis is justified in accordance with the study of Ganzach, Ellis, Pazy, and Ricci-Siag (2008). Ganzach and his colleagues compared a single-item measure of risk perception with a four-item instrument proposed by Sitkin and Weingart (1995) and found that the latter is a measure of perceived return rather than a measure of perceived risk. The construct validity of the former, which consists of a single question: "How risky is the prospect?" was supported by a number of studies (e.g., Coombs \& Lehner, 1981; Payne, 1975; Pollatsek \& Tversky, 1970; Weber, Blais, \& Betz, 2002). In line with these studies and the study of Kula (2005), this thesis used the single-item measure for three prospects of forex risk management in attempt to know how risky changes in forex rates are to (1) overall business risk, (2) firms' losses and (3) their proceeds. This three-item measure of perceived forex risk is shown to be appropriate for the purposes of this thesis.

\subsubsection{Resources (RES)}

Rather than using objective proxies, resources are measured using perceptual measures in the survey methodology. Capturing data about resources from respondents is said to be useful for getting direct assessments about particular resources (Armstrong \& Shimizu, 2007), and is relevant in the context of forex risk management. Further, a survey questionnaire which is developed and based on interviews with selected exporting SMEs should mitigate the construct measurement problems (c.f., Chen, Farh, \& MacMillan, 1993). Reviewing approaches to empirical research on the RBV,

\footnotetext{
${ }^{9}$ Money received through a sale or loan.
} 
Armstrong \& Shimizu revealed that 57 of 125 studies used this approach for measuring resources as independent variables.

By using this methodology, resources - including physical, human and organizational resources - are primarily operationalized in accordance with previously mentioned definitions of resources in Barney's (1991) study. In addition, the measures used are in line with previous empirical research outlined below in Table 5-5. In terms of financial resources, a number of factors e.g., under-investment problems, financial distress, hedging costs and tax liabilities, have been previously discussed in the literature review section and manifested in Table 2-3. The measures used for this thesis are also shown in Table 5-5 below. All of the measures are used in a context of forex risk management.

Physical resources are operationalized as (1) technology, (2) professional services, (3) professional equipment and (4) geographic location (Barney, 1991). Firms may access technological means, i.e. public media such as internet, television and newspaper as well as utilise professional services, e.g., consultancy and analysis, in an attempt to minimise possible losses caused by forex changes. They may also use professional equipment which includes the necessary items for managing currency transactions, e.g., software particularly for forecasting exchange rates, buying and selling foreign currencies. Additionally, they may take forex risk management into consideration when choosing locations and resources for overseas markets and/or branches.

Human resources are measured in six dimensions, i.e. the training, experience, judgment, intelligence, relationships, and insight of individual managers and workers in a firm (Barney, 1991). Firms may have been trained for and have had experience of forex risk management. Thus they are able to make considered decisions, as well as acquire and apply their knowledge and skills in an attempt to minimise possible losses caused by forex rate changes. Also they may have built a close relationship with those who are concerned with forex risk management, e.g., forex dealers and consultants. Finally, they may have capacity to gain accurate and deep understanding of forex markets and risk management.

Organizational resources have three components. They are (1) organizational training, (2) organizational autonomy, and (3) organizational supporting service (Salanova et al., 
2005; Westhead et al., 2001). Organizational resources are referred to as the organizational aspects of a job that are functional in achieving work goals, stimulating personal growth, learning, and development (Demerouti \& Bakker, 2011). On account of this, training, autonomy and supporting services are associated with personal growth, learning, and development in forex risk management. Measures of these three components, i.e. Organizational Training, Autonomy, and Supporting Services, were adapted from research studies of Salanova et al. (2005) and Westhead et al. (2001), as shown in Table 5-5 in the next sub-section 5.3.6.

Financial resources might play a pivotal role among the four types of resources in terms of forex risk management, as the forex risk decision is closely associated with the use of financial resources. In other words, risk managers tend to plan, organise, direct, and control a firm's financial resources in an attempt to improve its ability to respond to forex rate changes.

This study adopted perceptual measures of financial resources associated with forex risk management. As discussed in the literature on operationalization of financial resources, this thesis looks into firms' availability of financial resources to adapt to possible financial fluctuations by investigating (1) expenditure on forex risk management and (2) other financial resources available for forex risk management. Qualitative data appear not to show exporting SMEs as able to reduce the cost of hedging by achieving economies of scale, or taking advantage of being hedged so as to reduce tax due to tax convexity. In line with other studies on forex risk management, this study also added (3) internally generated fund, (4) bank loans/debts, and (5) equity to support forex risk management practice (specifically hedging strategy) to measure financial resources associated with forex risk management.

\subsubsection{Hedging strategy (HED)}

As defined earlier, this thesis operationalizes a firm's hedging strategy with (1) hedging degree, the extent to which hedging techniques are used, and (2) Hedging technique, the use of internal versus external techniques, in line with previous studies such as those of Mathur (1985), Eaker and Grant (1987), and (Eaker \& Grant, 1987; Joseph (2000); 
Mathur, 1985). Thus, informants are asked to indicate the extent to which they use a variety of hedging techniques.

Two variables were computed from ten items to measure hedging strategy: the frequency of hedging techniques used by SMEs (degree) and the ratio of internal to external hedging techniques used. Basically ten items (HED_1 to 10) indicate how frequently ten hedging techniques are used by SMEs. A five-point Likert scale is used for these items, meaning $1=$ Never; 2 = Rarely; 3 = Occasionally; $4=$ Frequently; $5=$ Very Frequently. Of these hedging techniques, five are considered as internal hedging and five as external hedging. An average of ten items is used to reflect hedging degree (HED_D), that is, the degree to which firms manage forex risk. In order to indicate if a firm is more likely to hedge with internal techniques, the Hedging technique (HED_T) was measure by the percentage of internal hedging degree relative to overall hedging degree. Table 5-3 illustrates an example of how these variables are computed. The lower row indicates a hypothetical response to the question asking the respondent the extent to which he/she uses the particular technique, following the Likert scale anchors noted above.

Table 5-3: Frequency of hedging techniques used

\begin{tabular}{|cccccccccc|}
\hline \multicolumn{4}{|c|}{ Internal Hedging } & \multicolumn{4}{c|}{ External Hedging } \\
\hline HED_1 & HED_2 & HED_3 & HED_4 & HED_5 & HED_6 & HED_7 & HED_8 & HED_9 & HED_10 \\
\hline 5 & 4 & 3 & 4 & 4 & 2 & 2 & 4 & 1 & 1 \\
\hline
\end{tabular}

HED_D $=\frac{\sum_{\mathrm{i}=1}^{10} \mathrm{HED}_{\mathrm{i}}}{10}=\frac{5+4+3+4+4+2+2+4+1+1}{10}=\frac{30}{10}=3.0$

$H_{-} \mathrm{T}_{-}=\frac{\sum_{\mathrm{i}=1}^{5} \mathrm{HED}_{\mathrm{i}}}{\sum_{\mathrm{i}=1}^{10} \mathrm{HED}_{\mathrm{i}}}=\frac{20}{30}=0.667=66.7 \%$

\subsubsection{Forex Exposure (FXE)}

There is a variety of typologies and ways for measuring forex exposure. Forex exposure can be classified into three groups, i.e. import, export and neutral groups (Joseph, 2000; Kula, 2005). In terms of measurement, forex exposure can be proxied by foreign currency denominated sales/total sales ratio (Aabo et al., 2010; Pramborg, 2005), the 
percentage of the firm's consolidated operating costs in foreign currency (Aabo et al., 2010; Pramborg, 2005), and volume of foreign currency denominated debt (W. B. Elliott et al., 2003; González et al., 2007). Of these measurements, foreign debt can be simultaneously used as a way to manage forex risk (W. B. Elliott et al., 2003).

Despite many ways for measuring forex exposure, foreign currency denominated sales/total sales ratio was utilised in this study. Since the study investigates exporting SMEs, foreign sales are likely to be important to such firms. This study is one of the first to use a three-item measure for Forex Risk Exposure, i.e. foreign currency denominated revenue, foreign currency denominated cost (Aabo et al., 2010; Pramborg, 2005) and foreign currency denominated debts (W. B. Elliott et al., 2003; González et al., 2007). This three-item measure aimed to combine many attributes of forex risk exposure. Given the importance of foreign sales, the other two items were considered supplementary, but still important to include in the study.

\subsubsection{Degree of Internationalisation (DOI)}

Similar to Gankema et al. (2000), this thesis utilises export involvement, which is operationalized by the firm's export sales/total sales ratio to measure the Degree of Internationalisation construct. Export sales as a percentage of total sales has frequently been used as the sole estimator of DOI in the literature on internationalisation (Cavusgil, 1980; Gankema et al., 2000). Exhibiting export intensity, this ratio is an appropriate measure of DOI in this study, which investigates the forex risk management of exporting SMEs. Ietto-Gillies (2009) argues that there is no unique "correct index" for the multifaceted concept 'DOI'. Given the theoretical framework behind the effect of internationalisation in forex risk management by exporting SMEs, it is rational for this study to define DOI as a firm's export intensity. In addition, the ratio was also used in the established I-model suggested by Cavusgil (1980), as found in the study of Gankema et al. (2000). The measures for the five degrees of internationalisation reflected in this thesis are shown in Table 5-4.

Table 5-4: The measure of 'Degree of Internationalisation'

\begin{tabular}{lcl}
\hline Degree & Likert scale & Export/sales ratio \\
\hline Domestic Marketing & 1 & $\begin{array}{l}0 \text { and incapable of handling an export } \\
\text { order }\end{array}$
\end{tabular}




\begin{tabular}{lll} 
Pre-export & 2 & 0 and interested in exporting activities, \\
& & $\begin{array}{l}\text { searching for relevant information about } \\
\text { costs, exchange risks, distribution) }\end{array}$ \\
Experimental Involvement & 3 & $\begin{array}{l}\text { Up to } 9 \% \\
10-39 \% \\
\text { Active Involvement }\end{array}$ \\
Committed Involvement & 4 & $40 \%$ or more \\
\hline
\end{tabular}

Source: Adapted from Gankema et al. (2000) and Cavusgil (1980)

Apart from the above mentioned item to measure degree of internationalisation, nine additional questions concerning internationalisation were included in the questionnaire. Given that the study examined the impact of internationalisation on forex strategy more generally, as outlined in the earlier chapters, these questions included items on entry modes, countries in which firms were doing business, exporting regions, years in international business, international marketing department, international strategic plan, overseas subsidiaries, overseas employees, and foreign assets (Gankema et al., 2000; Hadley \& Wilson, 2003; Joseph, 2000). Of these nine questions, the first six were used to describe how the sample was distributed in term of internationalisation.

The other three questions relating to overseas subsidiaries; overseas employees and foreign assets were used as control variables associated with internationalisation, as previously mentioned in Chapter 4 . The inclusion of these three control variables allowed for closer investigate of the influence of internationalisation on forex risk management, apart from the degree of internationalisation. In addition, the control variables referred to firms' allocation of resources in international markets. Given that this thesis also investigated thee of resources in forex risk management; it was worthwhile examining the role of these three items in the Model of Forex Risk Management.

\subsubsection{Measurement Model of Forex Risk Management}

The previous sub-sections provided the operationalization of the five constructs represented in the conceptual model. Operationalization and references are presented in Table 5-5. A final version of the questionnaire is attached in Appendix I. There are three single-item constructs (DOI, HGD, and HGT), and eight multi-item constructs (FXE, PFR and 6 components of RES). Notably, Forex Strategy comprises Hedging Degree (HGD) and Hedging Technique (HGT). Computation of two items measuring these two 
constructs was undertaken from 10 questions, as noted above. The questionnaire also included 9 questions (items) associated with internationalisation as mentioned. Totally, the questionnaire had 60 questions. 
Table 5-5: Measurement scales

\begin{tabular}{|c|c|c|c|}
\hline \multirow{2}{*}{$\frac{\text { Latent Variable }}{\text { Perceived Forex Risk }}$} & \multicolumn{2}{|l|}{ Observed Variables } & \multirow[t]{2}{*}{ References } \\
\hline & & & \\
\hline \multirow{7}{*}{$\frac{\pi}{2}$} & $\begin{array}{l}\text { Loss due to forex rate } \\
\text { fluctuation }\end{array}$ & PFR_1 & \multirow{7}{*}{ (Kula, 2005) } \\
\hline & Overall risk & PFR_2 & \\
\hline & Incomes & PFR_3 & \\
\hline & Export prices & PFR_4 & \\
\hline & Production volume & PFR_5 & \\
\hline & Domestic input & PFR_6 & \\
\hline & Decision to export & PFR_7 & \\
\hline \multicolumn{4}{|l|}{ RESOURCES } \\
\hline \multirow{8}{*}{ Physical } & Imported items & RES_P1 & \multirow{8}{*}{ (Kaleka, 2002) } \\
\hline & Sources of supply & RES_P2 & \\
\hline & Production Capacity & RES_P3 & \\
\hline & Hedging techniques & RES_P4 & \\
\hline & Financial consultants & RES_P5 & \\
\hline & Educators & RES_P6 & \\
\hline & Business books & RES_P7 & \\
\hline & Governmental bodies & RES_P8 & \\
\hline \multirow{6}{*}{ Human } & Experience of exporting & RES_H1 & \multirow{6}{*}{$\begin{array}{l}\text { (Eisenhardt \& } \\
\text { Schoonhoven, } \\
\text { 1996; Hayton, } \\
\text { 2005; Weinrauch, } \\
\text { Mann, Robinson, \& } \\
\text { Pharr, 1991; } \\
\text { Westhead et al., } \\
\text { 2001) }\end{array}$} \\
\hline & $\begin{array}{l}\text { Experience of forex risk } \\
\text { management }\end{array}$ & RES_H2 & \\
\hline & Advanced degrees & RES_H3 & \\
\hline & $\begin{array}{l}\text { Training in forex risk } \\
\text { management }\end{array}$ & RES_H4 & \\
\hline & $\begin{array}{l}\text { Personnel for forex risk } \\
\text { management }\end{array}$ & RES_H5 & \\
\hline & $\begin{array}{l}\text { Easy to perform our forex risk } \\
\text { management activities }\end{array}$ & RES_H6 & \\
\hline \multirow{6}{*}{ Organizational } & $\begin{array}{l}\text { Managers ask employees about } \\
\text { training }\end{array}$ & RES_OT1 & \multirow{6}{*}{$\begin{array}{l}\text { (Salanova et al., } \\
\text { 2005; Westhead et } \\
\text { al., 2001) }\end{array}$} \\
\hline & $\begin{array}{l}\text { Learning helps employees to } \\
\text { overcome obstacles }\end{array}$ & RES_OT2 & \\
\hline & $\begin{array}{l}\text { Training is practical for } \\
\text { employees }\end{array}$ & RES_OT3 & \\
\hline & $\begin{array}{l}\text { Sufficient training for forex risk } \\
\text { management }\end{array}$ & RES_OT4 & \\
\hline & $\begin{array}{l}\text { Autonomy to choose what } \\
\text { hedging techniques to perform }\end{array}$ & RES_OA1 & \\
\hline & $\begin{array}{l}\text { Autonomy to decide the extent } \\
\text { to which forex exposure is } \\
\text { hedged }\end{array}$ & RES_OA2 & \\
\hline
\end{tabular}




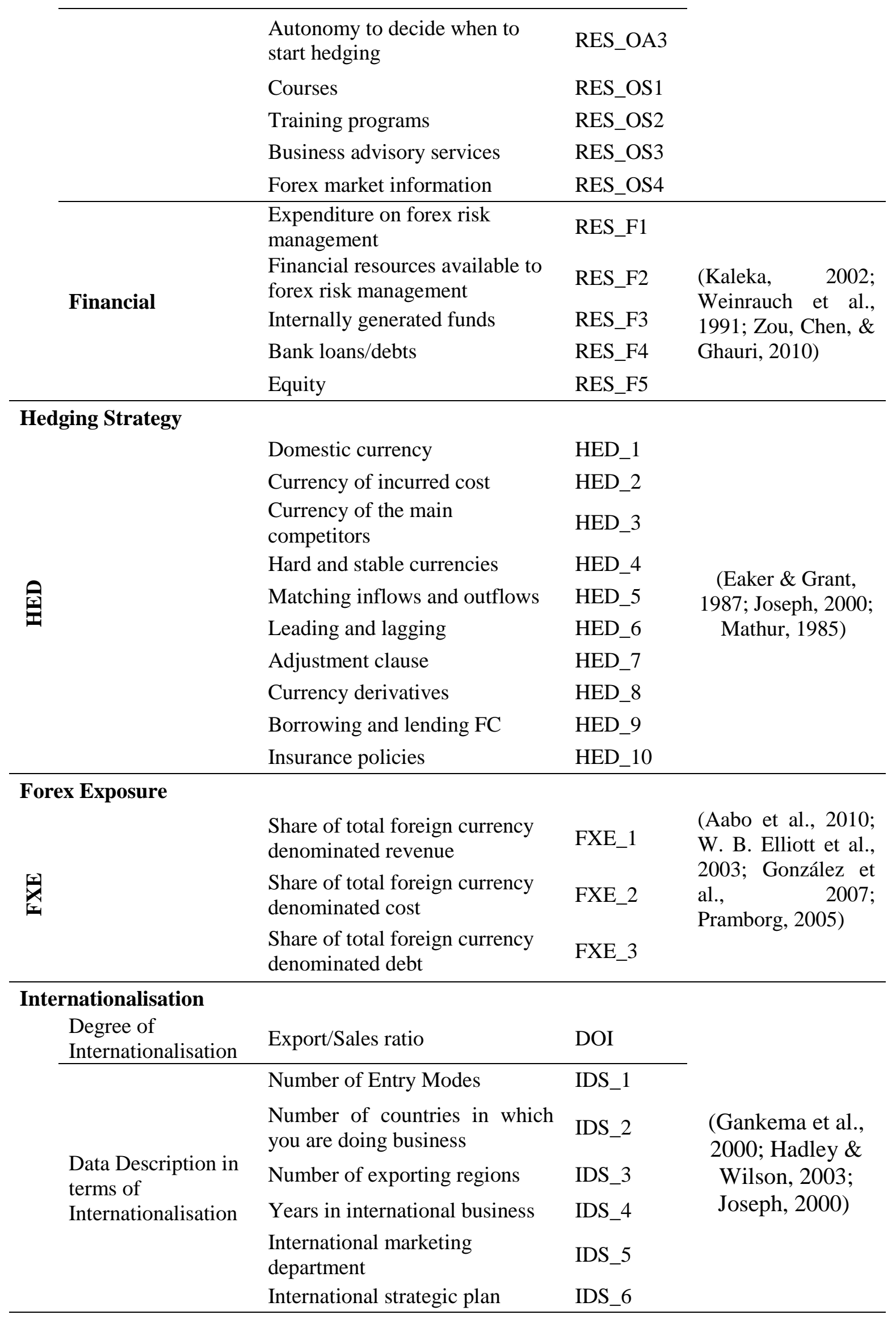


Control Variables associated with Internationalisation
Number of overseas subsidiaries CON_I1 Number of full-time equivalent overseas employees Foreign assets to total assets
CON_I2 CON_I3

The measures for the constructs associated with forex risk management were presented in Table 5-5, and were then modelled in Figure 5-2 called the Measurement Model of Forex Risk Management, or simply called 'measurement model'. Two constructs PFR and FXE were proxied by 7 items and 3 items, respectively. RES (Resources consists of six first-order constructs RES_P, RES_H, RES_OT, RES_OA, RES_OS and RES_F, which were measured by 8, 6, 4, 3, 4 and 5 items respectively. Hedging Strategy (HED) comprises two components: Hedging Degree (HGD) and Hedging technique (HGT). These two constructs and the Degree of Internationalisation construct (DOI) were single-item constructs. As can be seen, most of the latent variables were measured by at least 3 items as suggested by Hair et al. (2010). 


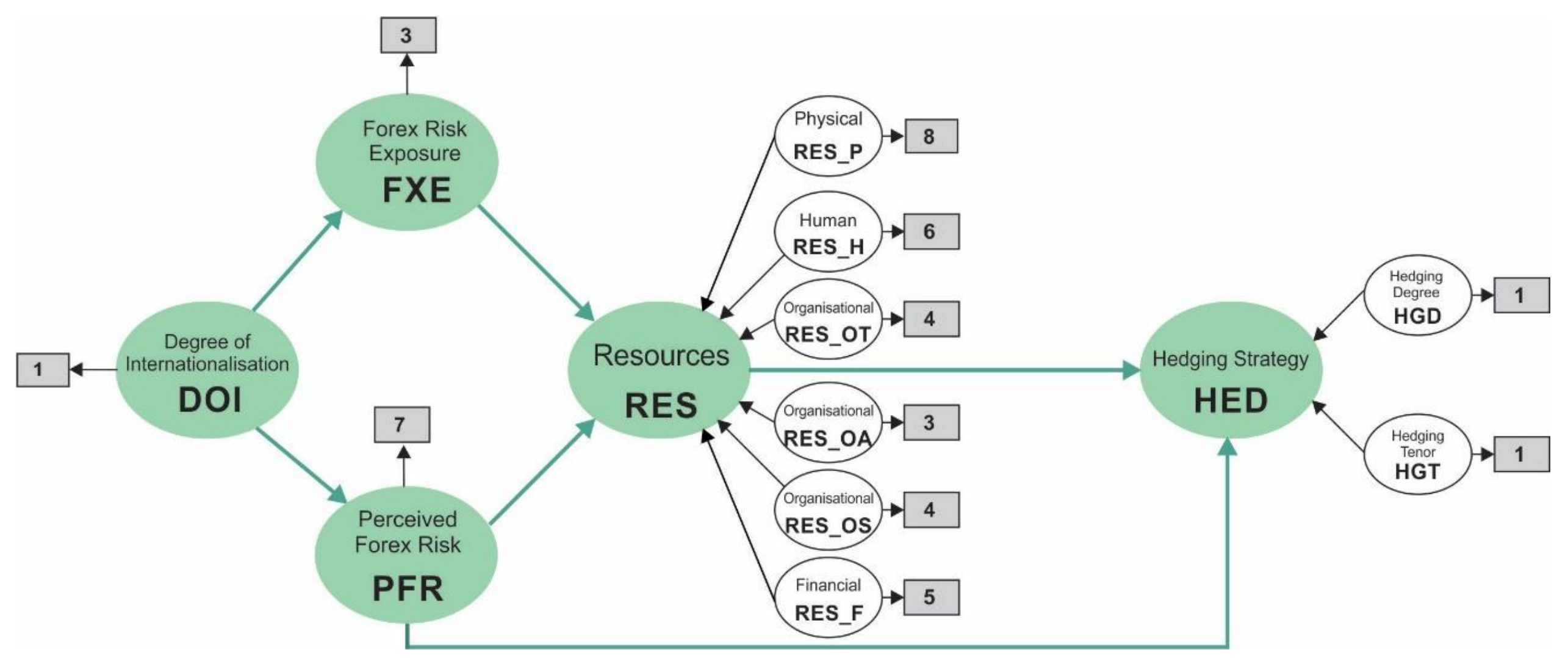

Figure 5-2: The Measurement Model of Forex Risk Management 


\subsection{MEASUREMENT REFINEMENT}

\subsubsection{Reliability and validity}

As shown in Figure 5-1, the research process aimed to ensure the measurement reliability and validity of the model. Primarily, the survey questionnaire was designed to address all issues of the research problem, since the qualitative data from the in-depth interviews were also employed for questionnaire design. This also aimed to ensure the content validity of the measurement items. Given that the research domain of forex risk management is different to the domains in which most of the scales have been used, this step is important.

Next, the degree of consistency between multiple measurements of constructs, i.e. reliability, was assessed with a series of diagnostic measures, as recommended by Hair et al. (2010). First, measures relating to each separate item were considered, including the correlation of the item to the summated scale score, and the correlation among items. Second, reliability coefficient, i.e. the consistency of the entire scale, was assessed with Cronbach's alpha. Third, exploratory factor analysis (EFA) was used to explore the survey data. The confirmed measurement model was then combined with structural theory to firmly establish an experimental SEM model (Hair et al., 2010).

EFA was conducted to provide information about the number of items required so as to ensure that the items being measured in the main survey properly represented the constructs or variables being measured. Similar to EFA, but philosophically different, CFA was used to provide a further confirmation of the measurement theory that specified how constructs are operationalized. This specification allows for confirmation of the measurement model through CFA. Unlike EFA, theory is required to derive items, and constructs are to be defined ahead of time in CFA. CFA was used to define one of two parts of an SEM: a measurement model and a structural model. In fact, CFA is a special case of an SEM, also known as the covariance structure (McDonald, 1978).

\subsubsection{Common method variance}

Common-method variance (CMV) is a potential issue with any survey-based study since it is the variance "attributable to the measurement method rather than to the constructs the measures represent" (Podsakoff, MacKenzie, Lee, \& Podsakoff, 2003). Primarily, proper controlling for CMV was taken from specific recommendations of 
Podsakoff et al. (2003), called a single-method-factors approach. Predictors and criterion variables were obtained from the same source, i.e. informants of the questionnaire. The questionnaire was designed under careful consideration for potential sources of common method bias as recommended by Podsakoff et al. (2003). Also, the measurement of predictors (i.e., Resources, Forex Exposure, and Perceived Forex Risk) and criterion variables, which manifested firms' hedging strategy, were psychologically separated. Additionally, interviews have been utilised for adjusting the questionnaire before the quantitative study. This single-method-factors approach was as used in line with studies of Carlson and Kacmar (2000), Elangovan and Xie (1999), MacKenzie, Podsakoff, and Fetter (1991), and MacKenzie, Podsakoff, and Fetter (1993), and Podsakoff, MacKenzie, Moorman, and Fetter (1990).

\subsection{RESEARCH SAMPLE}

The online survey was extended to Australia in order to increase the sample size. The Australian and New Zealand economies are very similar since the two countries are both strong in commodities - Australia with its large mining and agriculture sectors and New Zealand with dairy and forestry. The similarities between these economies is recognised in the Closer Economic Relations (CER) agreement between the two countries, whereby they have agreed to intensify efforts to integrate their economies but stopped short of advocating a common currency (V. Marsh, 2004). Given this context, it was, therefore, rational to have Australia as an additional part to New Zealand sample. The justification for the inclusion of the Australian and New Zealand samples will be provided in Chapter 6.

As with the qualitative study, survey participants were owners/financial controllers, or managing directors/CEOs of exporting SMEs. Participants were those who were responsible for managing the financial risks of the organization. An invitation including a link to the online survey was sent to exporting SMEs via email. Exporting SMEs' contact details were mainly obtained from Kompass database, and included additional firms whose details were obtained by web-based searches, magazines etc. SMEs were defined as having no more than 250 employees. 
Consolidating and summarizing of results in previous studies regarding sample size (n) and the ratio of indicators to latent variables (Boomsma, 1982; H. W. Marsh \& Bailey, 1991; H. W. Marsh, Balla, \& Hau, 1996; H. W. Marsh, Balla, \& McDonald, 1988; H. W. Marsh, Hau, Balla, \& Grayson, 1998), Westland (2010) suggest sample sizes:

$$
\begin{array}{ll}
n \geq 50 r^{2}-450 r+1,100 \\
\mathrm{r}=\mathrm{p} / \mathrm{k} & \\
\mathrm{n} & : \text { Sample sizes } \\
\mathrm{p} & : \text { Indicators (observed items) } \\
\mathrm{k} & : \text { Latent variables }
\end{array}
$$

Given that the conceptual model has 43 items $(\mathrm{p}=43)$, and 11 latent variables $(\mathrm{k}=11)$, sample size should be greater than 105 .

Firms were identified from the Kompass Business Database, as Kompass (2014) has comprehensive detailed and updated information, and claims to represent over $90 \%$ of firms in the business to business sector. This business database contain 4 million businesses from 60 countries (Kompass, 2014). This database does not allow users to access company email addresses, except for a desktop version applicable to New Zealand firms. Thus emails were found from company websites and/or online requests for participation in the survey.

\subsection{ADMINISTRATION OF THE SURVEY}

Australian and New Zealand firms were contacted three times via emails. An initial cover email (Appendix G) containing the link to access the web-based survey was sent to firms as an invitation to participate in the survey. The email described the purpose of the study and guaranteed anonymity and confidentiality of responses. A summary report of the findings was offered to respondents as an incentive to complete the survey. One week after the initial email, the first reminder email (Appendix $\mathrm{H}$ ) was sent, thanking those who had responded and reminding those who had not yet completed the surveys. By doing so, the response rate was expected to increase, since it was generally lower if no follow-up contact was carried out as suggested by Dillman (2000). Given that a number of email addresses were reported to be unreachable from the initial round of covering email, accounting for around $20 \%$, a second reminder was sent to find more responses. 
The web-based survey questionnaire, which is organised into 6 main parts as mentioned earlier, is presented in Appendix I.

\subsection{DATA ANALYTIC TOOLS}

Table 5-6 outlines the statistical analytic tools used in the quantitative stage of the research. SPSS Statistics 20 was used for normality test, exploratory factor analysis, and ANOVA test. This thesis also employed AMOS Graphic 20 to implement confirmatory factor analysis of the measurement model before testing the structural model and hypotheses. One-way analysis of variance (ANOVA) was used to test Hypotheses 1 and 2 , determining whether there exist any significant differences between the means of Perceived Forex Risk and Forex Exposure respectively, in two independent groups of internationalised firms in low and high degree of internationalisation. Structural equation modeling was conducted in AMOS Graphic 20 to test the rest of the hypotheses.

Table 5-6: Overview of Statistical Analysis

\begin{tabular}{ll}
\hline Issue & Analysis techniques \\
\hline Data cleaning & $\bullet$ Normality test with SPSS \\
$\begin{array}{l}\text { Exploratory test of } \\
\text { observable variables }\end{array}$ & $\begin{array}{l}\text { - Exploratory Factor Analysis (EFA) with } \\
\text { SPSS Statistics 20 }\end{array}$ \\
$\begin{array}{l}\text { Confirmatory test of } \\
\text { measurement theory }\end{array}$ & $\begin{array}{l}\text { - Confirmatory Factor Analysis (CFA) } \\
\text { westing of hypotheses }\end{array}$ \\
& $\begin{array}{l}\text { - Structural Equation Modeling (SEM) } \\
\text { with AMOS Graphic 20 }\end{array}$ \\
&
\end{tabular}

\subsubsection{SPSS}

The statistical software, SPSS Statistics 20, was employed for undertaking initial quantitative analyses in the study. Data were collected from the completed survey questionnaires on the network server, and then saved in Microsoft Excel. Initial data cleaning was carried out before data were copied to SPSS. First, descriptive analyses were effected in SPSS Statistics 20, for example, exploring means, standard deviations, Q-Q plots and histograms, aiming to describe and to clean data, and then to test normality to assure technical requirements of the subsequent analysis. Second, exploratory factor analyses were undertaken in SPSS Statistics 20 to seek reliability and 
validity before the performance of confirmatory factor analyses in AMOS Graphic 20 to test measurement models. Finally, analyses of variance were carried out to test the two hypotheses, as noted above.

\subsubsection{Structural Equation Modeling}

Structural Equation Modeling (henceforth referred to as SEM) has recently become one of the preferred data analysis methods for empirical research in operations management (Shah \& Goldstein, 2006). This progress can also be found in various fields of study, such as in psychology (Hershberger, 2003), marketing (Baumgartner \& Homburg, 1996), management information systems (Chin \& Todd, 1995; Gefen, Straub, \& Boudreau, 2000), strategic management (Shook, Ketchen, Hult, \& Kacmar, 2004), logistics (Garver \& Mentzer, 1999), and organizational research (Medsker, Williams, \& Holahan, 1994). According to these and other researchers, this methodology has numerous advantages that have led to its increased use in various research contexts. For instance, SEM enables the estimation of a measurement model that specifies relationships between observed (measured, manifest) variables and unobserved latent variables (factors). This feature of SEM made it useful for this thesis as all the major constructs of the model were latent variables that were measured by sets of observed variables. SEM also allowed for an estimation of a structural model that specifies relationships between the latent exogenous and endogenous variables and among the latent endogenous variables. SEM also accounts for biasing effects of random measurement errors. While previous studies about forex risk management applied multiple regressions to indicate the effect of the hedging determinants on hedging strategy, SEM was seen to be appropriate for this thesis as it allowed the investigation of relationships among hedging determinants.

Reviewing 92 strategic management studies published in nine prominent journals from 1984 to 2002, Shook et al. (2004) recommended various issues that should be reported in SEM studies: that is, sample, measurement, reproducibility, equivalent models and re-specification (see Table 5-7). 
Table 5-7: Issues to be reported in SEM studies

1. Sample issues
a. General description
b. Number of observations
c. Distribution of sample
d. Statistical power

2. Measurement issues
a. Reliability of measures
b. Measures of discriminant validity
c. Measures of convergent validity

\section{Reproducibility issues}
a. Input matrix
b. Name and version of software package used
c. Starting values
d. Computational options used
e. Analytical anomalies encountered

4. Equivalent models issues Potential existence acknowledged as a limitation

5. Re-specification issues

a. Changes cross-validated

b. Re-specified models not given status of hypothesized model

Source: Adapted from Shook et al. (2004)

These and other potential issues in the application of SEM were considered so as to ensure that this method is a valid one for examining the research question at hand.

\subsection{CRITICAL STATISTICAL VALUES APPLIED IN THE STUDY}

\subsubsection{Normality}

One of the fundamental assumptions for estimation methods in SEM is that all the univariate distributions are normal (Hair et al., 2010; Kline, 2005). Two other assumptions are (1) that the joint distribution of any pair of variables is bivariate normal, and (2) that all bivariate scatterplots are linear and homoscedastic. However, examination of all joint frequency distribution, according to Kline (2005), is commonly impractical, and multivariate normality is fortunately detectable in many instances through inspection of univariate distribution. It is worthwhile to inspect univariate normality of the sample data before employing estimation methods in SEM. 
A distribution can be non-normal if it demonstrates either skewness or kurtosis (Kline, 2005). This thesis adopted Kline's approach to inspect the normality of a distribution, using skew index and kurtosis index. A variable can be accepted as normally-distributed if the absolute value of the skew index is not greater than 3.0, and the absolute value of the kurtosis index does not exceed 10.

\subsubsection{Exploratory Factor Analysis Statistics}

This study adopted guides and critical statistics suggested by Hair et al. (2010). Table 58 shows such critical values relating to reliability and convergence validity of measurement in exploratory factor analysis.

Table 5-8: Rules of thumb for EFA Statistics

\begin{tabular}{ll}
\hline \multicolumn{1}{c}{ EFA Analysis } & Values \\
\hline $\begin{array}{l}\text { First-order construct } \\
\text { Reliability }\end{array}$ & \\
$\quad$ Item-total correlation & $\geq 0.30$ \\
$\quad$ Alpha & $\geq 0.70$ \\
Convergence & \\
$\quad$ Factor loading & $\geq 0.50$ \\
$\quad$ Total variance explained & $\geq 0.50$ \\
& \\
Second-order construct & \\
Requirements of first-order constructs & \\
Convergence and discrimination & \\
$\quad$ Extraction Sum of Square Loadings & $\geq 0.50$ \\
Loading difference & $\geq 0.30$ \\
\hline
\end{tabular}

Source: Adapted from Hair et al. (2010)

In line with a study of Robinson, Shaver, and Wrightsman (1991), Hair et al. (2010) agree that item-total correlations must be equal to, or exceed 0.50 and that the inter-item correlations must be equal to or exceed 0.30. These authors also support the use of Cronbach's alpha to test reliability, and agree on the lower limit for Cronbach's alpha of 0.70 (Hair et al., 2010).

First-order construct: (1) Reliability: an item is seen to be reliable if item-total correlation is greater than 0.3 and Alpha is greater than 0.7 ; (2) Convergence: Total variance explained via Principal Component Analysis (PCA) greater than 50\%, factor loading greater than 0.5 (Hair et al., 2010). 
Second-order construct: (1) First-order factor meets requirements of a first-order construct; (2) Convergence and discrimination via Principal Axis Factoring (PAF) extraction method and Promax rotation method with Kaiser normalisation: Extraction Sum of Square Loadings greater than $50 \%$, factor loadings greater than 0.5 ; difference between loadings of an item on two factors items is greater than 0.3 (Hair et al., 2010).

\subsubsection{Confirmatory Factor Analysis and Goodness-of-Fit Statistics}

Following EFA, measurements for the survey data were examined with confirmatory factor analysis (CFA). The measurements were assessed via (1) the goodness-of-fit of proposed measurement models, and (2) the construct validity in terms of convergent validity and discriminant validity.

Table 5-9 presents critical values for assessing the measurement model and structural model as suggested by Hair et al. (2010). Convergent validity is met if absolute standardised loading is greater than 0.5 , absolute standardised residuals lower than 0.4 , average variance extracted (AVE) greater than 0.5 , and construct reliability greater than 0.60. Discriminant validity is confirmed subject to no cross loading of an item on more than one factor and average variances extracted, which exceeds any squared interconstruct correlations associated with that factor. Ideal Competitive Fit Index (CFI) and Tucker-Levis Index (TLI) are expected to be greater than 0.92. Root Mean Square Error of Approximation (RMSEA) is expected to be lower than 0.08. Normed Chi-square is expected to be lower than 2.0. All these criteria for validity of modeling approach will be tested in Chapter 6.

Table 5-9: Rules of thumb for CFA and Goodness-of-Fit Statistics

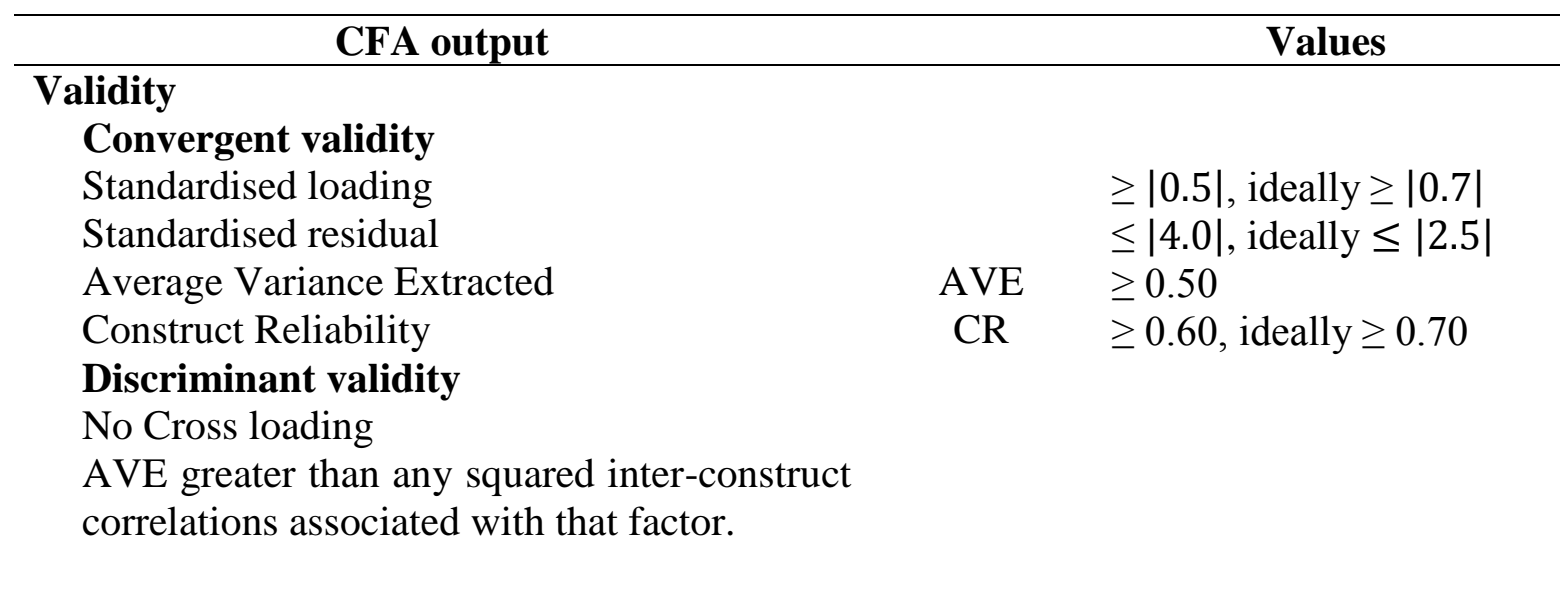




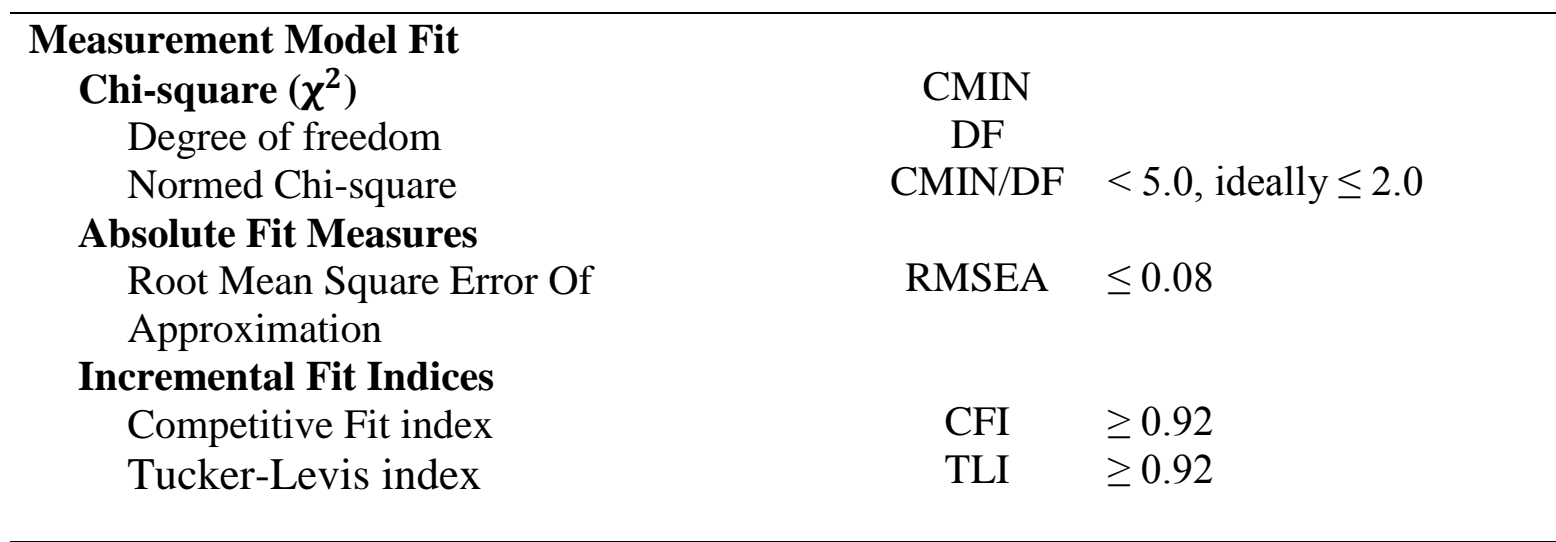

Source: Adapted from Hair et al. (2010)

Suggested by Hair, Black, Babin, Anderson, and Tatham (2006, p. 777), Average Variance Extracted (AVE) and Construct Reliability (CR) were calculated, as shown in equation 5.1 and 5.2 respectively, simply by using standardised loadings $(\lambda)$ and error variance terms $(\delta)$ :

$$
\begin{aligned}
& \mathrm{AVE}=\frac{\sum_{i=1}^{n} \lambda_{i}^{2}}{n} \\
& \mathrm{CR}=\frac{\left(\sum_{\mathrm{i}=1}^{\mathrm{n}} \lambda_{\mathrm{i}}\right)^{2}}{\left(\sum_{\mathrm{i}=1}^{\mathrm{n}} \lambda_{\mathrm{i}}\right)^{2}+\left(\sum_{\mathrm{i}=1}^{\mathrm{n}} \delta_{\mathrm{i}}\right)}
\end{aligned}
$$

\subsection{CHAPTER SUMMARY}

Chapter 5 has outlined the quantitative component of the sequential research design of this thesis. The quantitative analysis techniques used in the study were outlined, including EFA, CFA and SEM. Measurement scales deriving from the existing literature, coupled with the qualitative findings, were then described. The design of the questionnaire was described. The techniques for refinement of the measures to ensure reliability and validity, as well as techniques for controlling common method variance were discussed. The chapter also justified the use of the research instruments, that is, quasi-perceptual measurement, Likert scale and web-based survey. The sampling strategy along with administration of the survey were presented, which aimed to ensure a large enough sample for data analysis. Finally, the use of data analysis tools and critical statistical values were discussed. 


\section{CHAPTER 6. QUANTITATIVE ANALYSIS}

This chapter presents the result of the quantitative study. It introduces primary measurement refinement for five constructs (1) Degree of Internationalisation, (2) Forex Exposure, (3) Perceived Forex Risk, (4) Resources, and (5) Hedging Strategy. This section presents the analysis of 177 responses of Australian and New Zealand exporting SMEs from a web-based survey instrument. Quantitative results include (1) descriptive statistics, (2) exploratory factor analysis, (3) confirmatory factor analysis to investigate the measurement model and (4) tests for path models and hypotheses to examine relationships among hedging determinants and hedging strategy. The statistical analyses are outlined to answer the research question, ending up with a summary of the quantitative findings. 


\subsection{SURVEY RESPONSE}

Survey emails were sent to around 6,426 firms in the Kompass Business Database, including 2,934 Australian firms and 3,492 New Zealand firms. 190 responses were collected from $23^{\text {rd }}$ September to $14^{\text {th }}$ October, 2013. 177 of the responses were complete, and used for analysis. The sample size of 177 SMEs, presented in Table 6-1, is large enough for undertaking statistical analyses: EFA, CFA and SEM (Westland, 2010).

Table 6-1: Sample Description

\begin{tabular}{|c|c|c|c|c|c|c|c|}
\hline & & \multicolumn{2}{|c|}{ Australia } & \multicolumn{2}{|c|}{ New Zealand } & \multicolumn{2}{|c|}{ Both } \\
\hline & & $\mathrm{N}$ & $\%$ & $\mathrm{~N}$ & $\%$ & $\mathrm{~N}$ & $\%$ \\
\hline \multirow{5}{*}{ Employees } & $1-3$ & 4 & $11 \%$ & 14 & $10 \%$ & 18 & $10 \%$ \\
\hline & $4-10$ & 5 & $14 \%$ & 33 & $23 \%$ & 38 & $21 \%$ \\
\hline & $11-30$ & 8 & $23 \%$ & 53 & $37 \%$ & 61 & $34 \%$ \\
\hline & $31-90$ & 12 & $34 \%$ & 32 & $23 \%$ & 44 & $25 \%$ \\
\hline & $91-250$ & 6 & $17 \%$ & 10 & $7 \%$ & 16 & $9 \%$ \\
\hline \multirow{5}{*}{$\begin{array}{l}\text { Firm Age } \\
\text { (Years in } \\
\text { Business) }\end{array}$} & $4-10$ & 0 & $0 \%$ & 14 & $10 \%$ & 14 & $8 \%$ \\
\hline & $11-20$ & 5 & $14 \%$ & 35 & $25 \%$ & 40 & $23 \%$ \\
\hline & $21-30$ & 13 & $37 \%$ & 40 & $28 \%$ & 53 & $30 \%$ \\
\hline & $31-50$ & 12 & $34 \%$ & 33 & $23 \%$ & 45 & $25 \%$ \\
\hline & $51-120$ & 5 & $14 \%$ & 20 & $14 \%$ & 25 & $14 \%$ \\
\hline \multirow{2}{*}{$\begin{array}{c}\text { Main } \\
\text { Business }\end{array}$} & Manufacturing & 24 & $69 \%$ & 93 & $65 \%$ & 117 & $66 \%$ \\
\hline & Service & 11 & $31 \%$ & 49 & $35 \%$ & 60 & $34 \%$ \\
\hline \multirow{3}{*}{ Independence } & Independent Company & 34 & $97 \%$ & 124 & $87 \%$ & 158 & $89 \%$ \\
\hline & $\begin{array}{l}\text { Subsidiary of a } \\
\text { Foreign Company }\end{array}$ & 1 & $3 \%$ & 18 & $13 \%$ & 19 & $11 \%$ \\
\hline & Total & 35 & $20 \%$ & 142 & $80 \%$ & 177 & $100 \%$ \\
\hline
\end{tabular}

The distribution of categories in the sample appeared reasonable. The sample of 177 was suitable for this study, consistent with guidelines of Westland (2010), and this was also in line with other studies (Boomsma, 1982; H. W. Marsh \& Bailey, 1991; H. W. Marsh et al., 1996; H. W. Marsh et al., 1988; H. W. Marsh et al., 1998), Geographically, $80 \%$ of the sample was from New Zealand; the other $20 \%$ was from Australia. In terms of firms' age, $8 \%$ of sample was aged from 4 to 10 years, $23 \%$ from 11 to 20 years, $30 \%$ from 21 to 30 years, $25 \%$ from 31 to 50 years, and $14 \%$ older than 50 years. 
Manufacturing firms accounted for about two thirds of the sample; the other one third was service firms. A small portion (11\%) of SMEs responding was subsidiaries of foreign firms; a majority of responses were non-subsidiary, independent firms. The percentage in shaded columns showed that there was almost no difference in the distribution of categories across New Zealand and Australian samples. The section 6.2.4 will discuss more about the test of the group difference between these two samples.

In terms of internationalisation, there was not too much variation across the two samples, as shown in Table 6-2. Data showed that a majority (35\%) of firms operated in international business from 16 to 25 years. A small portion (16\%) of firms had less than nine years in international business, and $8 \%$ of firms had more than 40 years of experience in international markets. Firms which had from 10 to 15 years in international business accounted for $23 \%$, and as many as $18 \%$ of firms had 26 to 40 years in international business. This distribution appeared to be equitable in terms of firms' years in international business. With regard to entry mode, all of the firms were exporters. More than two-fifths of the firms (41\%) chose only one entry mode, i.e. exporting. More than half of the firms (59\%) have used one or more additional entry modes, apart from exporting, since starting business, e.g. franchising, joint venture, licencing, wholly-owned subsidiaries, strategic alliance, turnkey projects. A very small portion of firms used four $(8 \%)$ or more $(5 \%)$ entry modes when participating in international markets. While exporting to international markets, as many as $19 \%$ of firms sold their products to merely one region; a number of them, on the other hand, entered foreign markets in two to five regions. Not many SMEs exported to six (9\%) or more $(8 \%)$ regions. Two thirds of the firms in the sample had an international department; the other one third did not have such a department. Only 7\% of the firms exported to only one country; while most of them exported to three to five (28\%), six to ten $(30 \%)$, and eleven to twenty $(22 \%)$ countries. A number of the firms (14\%) export to more than 21 countries. Only one third of the firms were reported to have clear international strategic plan; the other two thirds said that they were reluctant to make such a strategic plan. In general, the data associated with internationalisation showed a variety of categories of exporting SMEs in the sample. 
Table 6-2: Internationalisation of SMEs in the sample

\begin{tabular}{|c|c|c|c|c|c|c|c|}
\hline & \multicolumn{2}{|c|}{ Australia } & \multicolumn{2}{|c|}{ New Zealand } & \multicolumn{2}{|c|}{ Both } \\
\hline & & $\mathrm{N}$ & $\%$ & $\mathrm{~N}$ & $\%$ & $\mathrm{~N}$ & $\%$ \\
\hline \multirow{5}{*}{$\begin{array}{l}\text { Years in } \\
\text { international } \\
\text { business }\end{array}$} & $1-9$ years & 2 & $6 \%$ & 26 & $18 \%$ & 28 & $16 \%$ \\
\hline & 10-15 years & 11 & $31 \%$ & 30 & $21 \%$ & 41 & $23 \%$ \\
\hline & $16-25$ years & 10 & $29 \%$ & 52 & $37 \%$ & 62 & $35 \%$ \\
\hline & $26-40$ years & 6 & $17 \%$ & 25 & $18 \%$ & 31 & $18 \%$ \\
\hline & Over 40 years & 6 & $17 \%$ & 9 & $6 \%$ & 15 & $8 \%$ \\
\hline \multirow{5}{*}{ Entry Modes } & One entry mode & 14 & $40 \%$ & 59 & $42 \%$ & 73 & $41 \%$ \\
\hline & 2 entry modes & 8 & $23 \%$ & 32 & $23 \%$ & 40 & $23 \%$ \\
\hline & 3 entry modes & 8 & $23 \%$ & 33 & $23 \%$ & 41 & $23 \%$ \\
\hline & 4 entry modes & 3 & $9 \%$ & 11 & $8 \%$ & 14 & $8 \%$ \\
\hline & 5-6 entry modes & 2 & $6 \%$ & 7 & $5 \%$ & 9 & $5 \%$ \\
\hline \multirow{5}{*}{ Exporting regions } & One region & 3 & $9 \%$ & 30 & $21 \%$ & 33 & $19 \%$ \\
\hline & $2-3$ regions & 13 & $23 \%$ & 40 & $19 \%$ & 53 & $20 \%$ \\
\hline & 4-5 regions & 15 & $28 \%$ & 35 & $16 \%$ & 50 & $19 \%$ \\
\hline & 6 regions & 1 & $3 \%$ & 20 & $11 \%$ & 21 & $9 \%$ \\
\hline & $7-8$ regions & 3 & $7 \%$ & 17 & $8 \%$ & 20 & $8 \%$ \\
\hline \multirow{2}{*}{$\begin{array}{l}\text { International } \\
\text { Marketing Dept. }\end{array}$} & No & 25 & $71 \%$ & 96 & $68 \%$ & 121 & $68 \%$ \\
\hline & Yes & 10 & $29 \%$ & 46 & $32 \%$ & 56 & $32 \%$ \\
\hline \multirow{5}{*}{$\begin{array}{l}\text { Number of } \\
\text { countries in which } \\
\text { firms are business }\end{array}$} & One country & 1 & $3 \%$ & 11 & $8 \%$ & 12 & $7 \%$ \\
\hline & 3-5 countries & 7 & $20 \%$ & 42 & $30 \%$ & 49 & $28 \%$ \\
\hline & $6-10$ countries & 16 & $46 \%$ & 37 & $26 \%$ & 53 & $30 \%$ \\
\hline & $11-20$ countries & 10 & $29 \%$ & 29 & $20 \%$ & 39 & $22 \%$ \\
\hline & $\begin{array}{l}\text { More than } 21 \\
\text { countries }\end{array}$ & 1 & $3 \%$ & 23 & $16 \%$ & 24 & $14 \%$ \\
\hline \multirow{2}{*}{$\begin{array}{l}\text { International } \\
\text { strategic plan }\end{array}$} & Unclear & 24 & $69 \%$ & 85 & $60 \%$ & 109 & $62 \%$ \\
\hline & Clear & 11 & $31 \%$ & 57 & $40 \%$ & 68 & $38 \%$ \\
\hline
\end{tabular}

\subsection{PRELIMINARY DATA ANALYSIS}

\subsubsection{Missing values}

Identification of missing data and remedies followed a four-step process. Primarily, missing data are not expected as part of the research design, but nevertheless, it is important to account for missing data. As suggested by Hair et al. (2010), 10\% is the cut-off value for considerable missing data. Thus, ten individual survey responses for which missing data exceed $10 \%$ were removed from sample, reducing the sample size to 177 observations. 
Table 6-3 shows that very few missing values were found in the data collected. There are 45 measured items that missed from 1 to 33 values. Thirty of these measured items (equal to two thirds of the measured items) missed between 1 and 3 values: eleven items that missed one value, eleven items missing 2, and eight items missing 3. Notably, financial measured items, i.e. RES_F4 and RES_F5, missed 15 and 14 values respectively. Especially, Importing Currency (DES_8) missed 33 values, and was not considered for data analysis. 
Table 6-3: Techniques for treatment of missing values

\begin{tabular}{|c|c|c|c|c|c|}
\hline No. & Name & Label & Scale & $\begin{array}{c}\text { Missing } \\
\text { Data }\end{array}$ & $\begin{array}{l}\text { Imputation } \\
\text { Techniques }\end{array}$ \\
\hline \multicolumn{6}{|c|}{ Perceived forex risk } \\
\hline 1 & PFR_1 & Loss due to forex rate fluctuation & Likert scale & 2 & $\mathrm{MC}$ \\
\hline 2 & PFR_2 & Overall risk & Likert scale & & \\
\hline 3 & PFR_3 & Incomes & Likert scale & 1 & $\mathrm{MC}$ \\
\hline 4 & PFR_4 & Export Prices & Likert scale & 1 & $\mathrm{MC}$ \\
\hline 5 & PFR_5 & Production Volume & Likert scale & & \\
\hline 6 & PFR_6 & Domestic Input & Likert scale & & \\
\hline 7 & PFR_7 & Decision to Export & Likert scale & & \\
\hline \multicolumn{6}{|c|}{ Resources } \\
\hline 1 & RES_P1 & Imported Items & Likert scale & 1 & $\mathrm{MC}$ \\
\hline 2 & RES_P2 & Sources of Supply & Likert scale & 2 & $\mathrm{MC}$ \\
\hline 3 & RES_P3 & Production Capacity & Likert scale & 1 & MC \\
\hline 4 & RES_P4 & Hedging Techniques & Likert scale & 1 & $\mathrm{MC}$ \\
\hline 5 & RES_P5 & Financial Consultants & Likert scale & & \\
\hline 6 & RES_P6 & Educators & Likert scale & & \\
\hline 7 & RES_P7 & Business Books & Likert scale & 4 & $\mathrm{MC}$ \\
\hline 8 & RES_P8 & Governmental Bodies & Likert scale & 1 & $\mathrm{MC}$ \\
\hline 9 & RES_H1 & Experience of Exporting & Likert scale & & \\
\hline 10 & RES_H2 & $\begin{array}{l}\text { Experience of Forex Risk } \\
\text { Management }\end{array}$ & Likert scale & & \\
\hline 11 & RES_H3 & Advanced Degrees & Likert scale & 1 & $\mathrm{MC}$ \\
\hline 12 & RES_H4 & $\begin{array}{l}\text { Training in Forex Risk } \\
\text { Management }\end{array}$ & Likert scale & & \\
\hline 13 & RES_H5 & $\begin{array}{l}\text { Personnel for forex risk } \\
\text { management }\end{array}$ & Likert scale & & \\
\hline 14 & RES_H6 & $\begin{array}{l}\text { Easy to perform our forex risk } \\
\text { management activities }\end{array}$ & Likert scale & 3 & $\mathrm{MC}$ \\
\hline 15 & RES_OT1 & $\begin{array}{l}\text { Managers ask employees about } \\
\text { training }\end{array}$ & Likert scale & 1 & $\mathrm{MC}$ \\
\hline 16 & RES_OT2 & $\begin{array}{l}\text { Learning helps employees to } \\
\text { overcome obstacles }\end{array}$ & Likert scale & 3 & $\mathrm{MC}$ \\
\hline 17 & RES_OT3 & Training is practical for employees & Likert scale & 3 & $\mathrm{MC}$ \\
\hline 18 & RES_OT4 & $\begin{array}{l}\text { Sufficient training for forex risk } \\
\text { management }\end{array}$ & Likert scale & 5 & $\mathrm{MC}$ \\
\hline 19 & RES_OA1 & $\begin{array}{l}\text { Autonomy to choose what hedging } \\
\text { techniques to perform }\end{array}$ & Likert scale & 2 & $\mathrm{MC}$ \\
\hline 20 & RES_OA2 & $\begin{array}{l}\text { Autonomy to decide the extent to } \\
\text { which forex exposure is hedged }\end{array}$ & Likert scale & 2 & $\mathrm{MC}$ \\
\hline 21 & RES_OA3 & $\begin{array}{l}\text { Autonomy to decide when to start } \\
\text { hedging }\end{array}$ & Likert scale & 3 & $\mathrm{MC}$ \\
\hline 22 & RES_OS1 & Courses & Likert scale & 2 & $\mathrm{MC}$ \\
\hline 23 & RES_OS2 & Training programs & Likert scale & 3 & $\mathrm{MC}$ \\
\hline 24 & RES_OS3 & Business advisory services & Likert scale & 2 & $\mathrm{MC}$ \\
\hline 25 & RES_OS4 & Forex market information & Likert scale & 4 & $\mathrm{MC}$ \\
\hline 26 & RES_F1 & $\begin{array}{l}\text { Expenditure on forex risk } \\
\text { management }\end{array}$ & Likert scale & 2 & $\mathrm{MC}$ \\
\hline
\end{tabular}




\begin{tabular}{|c|c|c|c|c|c|}
\hline 27 & RES_F2 & $\begin{array}{l}\text { Financial resources available to } \\
\text { forex risk management }\end{array}$ & Likert scale & 1 & $\mathrm{MC}$ \\
\hline 28 & RES_F3 & Internally generated funds & Likert scale & 11 & MC \\
\hline 29 & RES_F4 & Bank loans/debts & Likert scale & 15 & MC \\
\hline 30 & RES_F5 & Equity & Likert scale & 14 & MC \\
\hline \multicolumn{6}{|c|}{ Hedging } \\
\hline 1 & HED_1 & Domestic currency & Likert scale & 4 & MS \\
\hline 2 & HED_2 & Currency of incurred cost & Likert scale & 3 & MS \\
\hline 3 & HED_3 & Currency of the main competitors & Likert scale & 5 & MS \\
\hline 4 & HED_4 & Hard and stable currencies & Likert scale & 4 & MS \\
\hline 5 & HED_5 & Matching inflows and outflows & Likert scale & 2 & MS \\
\hline 6 & HED_6 & Leading and lagging & Likert scale & 2 & MS \\
\hline 7 & HED_7 & Adjustment clause & Likert scale & 4 & MS \\
\hline 8 & HED_8 & Currency derivatives & Likert scale & 4 & MS \\
\hline 9 & HED_9 & Borrowing and lending FC & Likert scale & 2 & MS \\
\hline 10 & HED_10 & Insurance policies & Likert scale & 3 & MS \\
\hline \multicolumn{6}{|c|}{ Forex Exposure } \\
\hline 1 & FXE_1 & $\begin{array}{l}\text { Share of total foreign currency } \\
\text { revenue }\end{array}$ & Likert scale & 1 & MS \\
\hline 2 & FXE_2 & Share of total foreign currency cost & Likert scale & 1 & MS \\
\hline 3 & FXE_3 & Share of total foreign currency debt & Likert scale & 5 & MS \\
\hline \multicolumn{6}{|c|}{ Internationalisation } \\
\hline 1 & DOI & Export/Sales ratio & Likert scale & & \\
\hline 2 & IDS_1 & Number of Entry Modes & Likert scale & 3 & MS \\
\hline 3 & IDS_2 & $\begin{array}{l}\text { Number of countries in which you } \\
\text { are doing business }\end{array}$ & Likert scale & & \\
\hline 4 & IDS_3 & Number of exporting regions & Likert scale & & \\
\hline 5 & IDS_4 & Years in international business & Likert scale & & \\
\hline 6 & IDS_5 & International Marketing Dept. & Nominal & & \\
\hline 7 & IDS_6 & International strategic plan & Likert scale & 2 & MS \\
\hline 8 & CON_I1 & Overseas Subsidiary & Nominal & & \\
\hline 9 & CON_I2 & Overseas Employees & Nominal & & \\
\hline 10 & CON_I3 & Foreign Assets & Nominal & & \\
\hline \multicolumn{6}{|c|}{ Other measured items } \\
\hline 1 & DES_1 & Firm Age & Likert scale & & \\
\hline 2 & DES_2 & Employees & Likert scale & & \\
\hline 3 & DES_4 & Main Business & Nominal & & \\
\hline 4 & DES_5 & Independence & Nominal & & \\
\hline 5 & DES_7 & Exporting Currency & Nominal & 10 & N/A \\
\hline 6 & DES_8 & Importing Currency & Nominal & 33 & N/A \\
\hline 7 & DES_9 & Home Country & Nominal & & \\
\hline
\end{tabular}

\section{Notes:}

MC Mean substitution with the mean value of available measured items in the same construct calculated from the same observation

MS Mean substitution with the mean value of that measured item calculated from all available responses

N/A No imputation used 
Subject to characteristics of measured items, imputation of missing data is either MC or MS. Both form of imputation, which are known as mean substitutions, involve replacing missing values with estimated values based on other information available in the sample (Hair et al., 2010). The former refers to the use of the mean value of available measured items in the same construct calculated from the same observation. The latter is concerned with the mean value of that measured item calculated from all available responses. MC was utilized for measured items that were related to other measured items of the same constructs. On the other hand, MS was used for those measured items that were independent of other measured items. MC was adopted for 28 measured items that had missing values, MS for 15 measured items. None of imputation methods were undertaken for two control variables, i.e. DES_7 and DES_8, as they are nominal items indicating exporting /importing currency mostly used by firms. These two measured items were not used for any analysis.

\subsubsection{Normality}

Referring to guidelines of Kline (2005) regarding critical statistics for normal distribution, the data used in this thesis were considered as normally-distributed (see Table 6-4). Values of skewness varied from -1.363 (RES_H1) to +1.921 (FXE_3). As many as $95 \%(72 / 76)$ of skewness values were close to the critical values from -1.0 to +1.0. Values for Kurtosis ranged from 1.127 (CON_I3) to 6.855 (RES_H1), and 74\% (56/76) kurtosis values were close to critical value of 3 (from 2.0 to 4.0 ). These values of skewness and kurtosis indicated that the measured items were not subject to skewness or kurtosis. The measured items may be taken to be normally distributed, and were thus retained for further multivariate analysis. 
Table 6-4: Descriptive Statistics

\begin{tabular}{|c|c|c|c|c|c|c|}
\hline $\begin{array}{c}\text { Measured } \\
\text { item }\end{array}$ & Minimum & Maximum & Mean & $\begin{array}{c}\text { Std. } \\
\text { Deviation }\end{array}$ & Skewness & Kurtosis \\
\hline PFR_1 & 1 & 5 & 3.503 & 1.122 & -0.732 & 2.761 \\
\hline PFR_2 & 1 & 5 & 3.616 & 0.971 & -1.039 & 3.866 \\
\hline PFR_3 & 1 & 5 & 3.607 & 1.042 & -1.017 & 3.492 \\
\hline PFR_4 & 1 & 5 & 3.290 & 1.186 & -0.328 & 2.170 \\
\hline PFR_5 & 1 & 5 & 2.774 & 1.014 & 0.070 & 2.344 \\
\hline PFR_6 & 1 & 5 & 2.966 & 1.092 & -0.143 & 2.172 \\
\hline PFR_7 & 1 & 5 & 2.678 & 1.013 & 0.085 & 2.260 \\
\hline RES_P1 & 1 & 5 & 3.801 & 1.294 & -1.068 & 3.029 \\
\hline RES_P2 & 1 & 5 & 3.653 & 1.115 & -0.800 & 2.996 \\
\hline RES_P3 & 1 & 5 & 3.824 & 1.006 & -0.929 & 3.560 \\
\hline RES_P4 & 1 & 5 & 3.378 & 0.948 & -0.738 & 3.196 \\
\hline RES_P5 & 1 & 5 & 3.599 & 1.046 & -0.757 & 2.993 \\
\hline RES_P6 & 1 & 5 & 2.780 & 0.912 & -0.138 & 2.872 \\
\hline RES_P7 & 1 & 5 & 3.107 & 0.909 & -0.485 & 2.985 \\
\hline RES_P8 & 1 & 5 & 2.229 & 0.959 & 0.384 & 2.544 \\
\hline RES_H1 & 1 & 5 & 4.153 & 0.757 & -1.363 & 6.855 \\
\hline RES_H2 & 1 & 5 & 3.729 & 0.968 & -0.868 & 3.604 \\
\hline RES_H3 & 1 & 5 & 3.319 & 1.134 & -0.393 & 2.338 \\
\hline RES_H4 & 1 & 5 & 2.746 & 1.122 & -0.021 & 1.980 \\
\hline RES_H5 & 1 & 5 & 3.650 & 0.966 & -0.656 & 3.155 \\
\hline RES_H6 & 1 & 5 & 3.187 & 1.009 & -0.280 & 2.413 \\
\hline RES_OT1 & 1 & 5 & 2.365 & 0.979 & 0.345 & 2.580 \\
\hline RES_OT2 & 1 & 5 & 3.342 & 0.999 & -0.795 & 3.288 \\
\hline RES_OT3 & 1 & 5 & 3.149 & 1.106 & -0.396 & 2.318 \\
\hline RES_OT4 & 1 & 5 & 2.840 & 0.964 & -0.060 & 2.651 \\
\hline RES_OA1 & 1 & 5 & 2.406 & 1.179 & 0.363 & 1.959 \\
\hline RES_OA2 & 1 & 5 & 2.479 & 1.234 & 0.303 & 1.838 \\
\hline RES_OA3 & 1 & 5 & 2.494 & 1.228 & 0.277 & 1.844 \\
\hline RES_OS1 & 1 & 5 & 2.343 & 1.182 & 0.471 & 2.035 \\
\hline RES_OS2 & 1 & 5 & 2.253 & 1.086 & 0.500 & 2.271 \\
\hline RES_OS3 & 1 & 5 & 3.383 & 1.154 & -0.850 & 2.726 \\
\hline RES_OS4 & 1 & 5 & 3.505 & 1.124 & -0.940 & 3.112 \\
\hline RES_F1 & 1 & 5 & 3.550 & 1.117 & -0.617 & 2.637 \\
\hline RES_F2 & 1 & 5 & 3.165 & 1.134 & -0.421 & 2.245 \\
\hline RES_F3 & 1 & 5 & 3.632 & 1.244 & -0.982 & 3.027 \\
\hline RES_F4 & 1 & 5 & 2.394 & 1.315 & 0.337 & 1.741 \\
\hline RES_F5 & 1 & 5 & 2.403 & 1.276 & 0.243 & 1.674 \\
\hline HED_1 & 1 & 5 & 2.827 & 1.383 & 0.081 & 1.678 \\
\hline HED_2 & 1 & 5 & 2.753 & 1.332 & 0.142 & 1.789 \\
\hline HED_3 & 1 & 5 & 2.477 & 1.254 & 0.495 & 2.186 \\
\hline HED_4 & 1 & 5 & 3.288 & 1.339 & -0.511 & 2.068 \\
\hline
\end{tabular}




\begin{tabular}{lrrrrrr}
\hline HED_5 & 1 & 5 & 2.869 & 1.301 & -0.065 & 1.804 \\
HED_6 & 1 & 5 & 2.468 & 1.127 & 0.198 & 1.990 \\
HED_7 & 1 & 5 & 2.162 & 1.224 & 0.751 & 2.413 \\
HED_8 & 1 & 5 & 2.521 & 1.321 & 0.252 & 1.691 \\
HED_9 & 1 & 5 & 1.886 & 1.022 & 1.032 & 3.313 \\
HED_10 & 1 & 5 & 1.713 & 0.940 & 1.304 & 4.110 \\
FXE_1 & 1 & 5 & 2.610 & 1.545 & 0.326 & 1.581 \\
FXE_2 & 1 & 5 & 2.074 & 1.252 & 0.852 & 2.456 \\
FXE_3 & 1 & 5 & 1.552 & 1.088 & 1.921 & 5.454 \\
DOI & 3 & 5 & 4.209 & 0.969 & -1.104 & 3.660 \\
IDS_1 & 1 & 5 & 2.133 & 1.187 & 0.763 & 2.654 \\
IDS_2 & 1 & 5 & 3.079 & 1.145 & 0.118 & 2.143 \\
IDS_3 & 1 & 5 & 2.672 & 1.232 & 0.405 & 2.289 \\
CON_I1 & 0 & 1 & 0.299 & 0.459 & 0.876 & 1.767 \\
IDS_4 & 1 & 5 & 2.797 & 1.160 & 0.117 & 2.297 \\
CON_I2 & 0 & 1 & 0.395 & 0.490 & 0.428 & 1.183 \\
IDS_5 & 0 & 1 & 0.316 & 0.466 & 0.790 & 1.624 \\
IDS_6 & 1 & 5 & 3.124 & 1.041 & -0.148 & 2.397 \\
CON_I3 & 0 & 1 & 0.412 & 0.494 & 0.356 & 1.127 \\
HED_D & 1.000 & 4.500 & 2.497 & 0.634 & -0.109 & 3.046 \\
HED_T & 0.294 & 0.766 & 0.572 & 0.088 & 0.354 & 3.401 \\
\hline
\end{tabular}

\subsubsection{Australian and New Zealand samples}

Although the literature reviewed in Section 5.5 shows that there are similarities between New Zealand and Australian economies, it is necessary to test for the similarity of firms in the two countries. Data description in Table 6-1 showed that sample was well distributed: Australian firms accounted about 20\%, New Zealand 80\%, of the data over most sub-groups of employees, firms' age, main business and independence. In addition, $\mathrm{t}$-tests were undertaken to validate the inclusion of firms in these two countries in the research sample, making sure that potential mean differences of measured items across the two sample groups do not exist.

Two samples T-test results (see Appendix J) show that the differences between the New Zealand and Australian firms are not significant. Australian firms have, on average, significantly different mean on only 12 among 62 measured items in comparison with New Zealand companies ( $\mathrm{p}<0.05$ ). This means that 50/62 measured items (equivalent to $81 \%$ ) have no significant mean differences between the two samples. Overall, these 
results suggest that New Zealand and Australian firms have similar characteristics, providing justification for analysing them together.

\subsection{EXPLORATORY FACTOR ANALYSIS (EFA)}

\subsubsection{Degree of Internationalisation (DOI)}

Given that the Degree of Internationalisation construct is a single-item construct, there was no EFA undertaken. The only item to measure this construct is export intensity, which was concerned with the export/total sales ratio.

\subsubsection{Forex Exposure (FXE)}

EFA results showed that a single-item measure was sufficient for the Forex Exposure construct. The first reason is that the three measured items associated with forex exposure were not significantly correlated, and thus the three-item measure for the Forex Exposure construct was not reliable. Share of total foreign currency cost (FXE_2) is not closely correlated with Share of total foreign currency revenue (FXE_1) and Share of total foreign currency debt (FXE_3). As shown in Table 6-5, correlation coefficients between FEX_2 and two other items were less than 0.3, i.e. FEX_1 (0.171) and FEX_3 (0.239). The Cronbach's alpha less than 0.5 would indicate the three-item measure of Forex Exposure was not reliable (Hair et al., 2010). In addition, the removal of either FXE_2 or FXE_3 was unable to improve considerably the Cronbach's alpha (0.474 and 0.377 respectively).

Table 6-5: Forex Exposure

\begin{tabular}{crrrrrr}
\hline & \multicolumn{2}{c}{ Correlation Matrix } & Factor & \multicolumn{2}{c}{ Reliability } \\
Measured item & FXE_1 & FXE_2 & FXE_3 & 1 & $\begin{array}{c}\text { Item-Total } \\
\text { Correlation }\end{array}$ & $\begin{array}{c}\text { Cronbach's } \\
\text { Alpha if } \\
\text { Item } \\
\text { Deleted }\end{array}$ \\
\hline FXE_1 & 1 & & & 0.722 & 0.311 & 0.383 \\
FXE_2 & 0.171 & 1 & & 0.617 & 0.242 & 0.474 \\
FXE_3 & 0.33 & 0.239 & 1 & 0.773 & 0.377 & 0.286 \\
\hline Eigenvalues & & & & 1.499 & & \\
Extraction Sum of & & & & $49.98 \%$ & & \\
Square Loadings & & & & & & \\
\hline
\end{tabular}


A single-item measure for the Forex Exposure construct was adopted because of content validity. Data show that investigated firms were not exposed to foreign currency revenues (FXE_1), costs (FXE_2), debts (FXE_3) at a similar degree, as the three measured items were not significantly correlated. In other words, firms might be considerably exposed to foreign currency revenues, but not to foreign currency cost and debt, and vice versa. This study, therefore, captured the exposure to foreign currency revenues (FEX_1) of exporting SMEs. The use of FEX_1 as a single-item measure for the Forex Exposure construct was also consistent with previous research studies (Aabo et al., 2010; W. B. Elliott et al., 2003; González et al., 2007; Pramborg, 2005).

\subsubsection{Perceived Forex Risk (PFR)}

Initial EFA results in Table 6-6 show that there are two components of perceived forex risk, i.e. perceived forex risk associated with decisions (Factor 1), and perceived forex risk associated with performance (Factor 2). The former refers to the perceived forex exposure to business decisions relating to exports, i.e. export prices (PFR_4), production volumes (PFR_5), domestic inputs (PFR_6) and decisions to export ratio (PFR_7). The latter refers to the perceived forex exposure to a firm's business performance in general, i.e. loss due to forex rate fluctuation (PFR_1), overall risk (PFR_2), and incomes (PFR_3).

Table 6-6: Component Matrix

\begin{tabular}{|ll|r|r|}
\hline \multirow{2}{*}{ Measured items } & \multicolumn{2}{|c|}{ Component $^{\mathrm{a}}$} \\
\cline { 3 - 4 } & \multicolumn{1}{|c|}{ Factor 1 } & \multicolumn{1}{|c|}{ Factor 2 } \\
\hline PFR_1 & Loss due to forex rate fluctuation & .449 & .382 \\
PFR_2 & Overall risk & .606 & .514 \\
PFR_3 & Incomes & .597 & .554 \\
PFR_4 & Export Prices & .691 & -.113 \\
PFR_5 & Production Volume & .794 & -.192 \\
PFR_6 & Domestic Input & .683 & -.423 \\
PFR_7 & Decision to Export & .635 & -.465 \\
\hline
\end{tabular}

Extraction Method: Principal Component Analysis.

a. 2 components extracted.

The shaded items that loaded on Factor 2 simultaneously loaded on Factor 1. The Component Matrix (Table 6-6) shows that the three measured items, i.e. PFR_1, PFR_2, and PFR_3, had high loadings on both factors. This is also evident from differences 
below 0.3 of loadings of the three items on Factor 1 and Factor 2 (Hair et al., 2010). For example, the loading of PFR_1 on Factor 1 is 0.449 , while the loading of this measured item on Factor 2 is 0.382 ; the difference between the two loadings is 0.117 , which is far less than 0.3, indicating the cross loading of PFR_1 on both factors. The evidence also means that the two factors were not discriminant. In addition, export prices (PFR_4), production volumes (PFR_5), domestic inputs (PFR_6) and decisions to export ratio (PFR_7) sufficiently represent attributes of managerial perception of exposure to most of the business decisions relating to exports. The content validity is ensured, therefore, as these four items are used to measure the Perceived Forex Risk construct. By doing so, PFR_1, PFR_2, and PFR_3 were removed from the measure of the Perceived Forex Risk construct, which is consistent with guidelines of Hair et al. (2010).

Table 6-7 exhibits the reliability and validity of the four-item measure of the Perceived Forex Risk construct. The correlation matrix shows that these four items were closely related, for correlation coefficients are greater than 0.3. In addition, factor loadings are greater than 0.5, item-total loadings were greater than 0.3 and Cronbach's alpha (0.758) is greater than 0.7. As suggested by Hair et al. (2010), these statistical values indicate the reliability and convergent validity of the measure of the Perceived Forex Risk construct, which include the four items, i.e.PFR_4, PFR_5, PFR_6 and PFR_7.

Table 6-7: Perceived Forex Risk

\begin{tabular}{|c|c|c|c|c|c|c|c|}
\hline \multirow[b]{2}{*}{ Measured item } & \multicolumn{4}{|c|}{ Correlation Matrix } & \multirow{2}{*}{$\begin{array}{c}\text { Factor } \\
1\end{array}$} & \multicolumn{2}{|c|}{ Reliability } \\
\hline & PFR_4 & PFR_5 & PFR_6 & PFR_7 & & $\begin{array}{l}\text { Item-Total } \\
\text { Correlation }\end{array}$ & Alpha \\
\hline PFR_4 & 1 & & & & 0.728 & 0.504 & \\
\hline PFR_5 & 0.639 & 1 & & & 0.837 & 0.670 & \\
\hline PFR_6 & 0.277 & 0.496 & 1 & & 0.762 & 0.545 & 0.158 \\
\hline PFR_7 & 0.316 & 0.382 & 0.555 & 1 & 0.727 & 0.518 & \\
\hline Eigenvalues & & & & & 2.339 & & \\
\hline $\begin{array}{r}\text { Extraction Sum of } \\
\text { Square Loadings } \\
\end{array}$ & & & & & $58.48 \%$ & & \\
\hline
\end{tabular}




\subsubsection{Resources (RES)}

Initial factor analysis was conducted with 30 measured items associated with the Resources construct. Results are shown in Table 6-8. Results showed that there were nine factors extracted. There are, however, merely 6 factors concerned with resources associated for forex risk management, as discussed in the literature review chapter of this thesis, i.e. (1) Physical, (2) Human, (3) Organizational Training, (4) Organizational Autonomy, (5) Organizational Supporting Service, and (6) Financial Resources. Reliability and validity of the measure of the Resources construct were examined.

Firstly, problematic items (in the shaded lines) had to be removed, following the guidelines of Hair et al. (2010). Measured items that loaded the least $(<0.30)$ on their respective factor, or that cross-loaded substantially across various factors, were identified and removed to ensure the convergent and discriminant validity. Content validity was also considered for removing an item. For example, Factor 9 consisted of two major measured items, information on how to find hedging solutions from governmental bodies (RES_P8) and advanced degrees of top management (RES_H3). The two measured items have highest loadings on Factor 9, i.e. RES_P8 (0.379) and RES_H3 (0.598); both are greater than 0.3. The former refers to physical resources; the latter is, however, associated with human resources. This factor was meaningless; in other words, its content validity was questionable. Hence, the two measured items, RES_P8 and RES_H3, were removed. As a result, Factor 9 no longer existed.

With the same approach, RES_F1, RES_F2 and RES_F3 were removed. Table 6-8 shows that Factor 7 included the most measured items associated with Financial Resources. RES_F1 had very low loading (0.131) on this factor, but quite high loading (0.311) on Factor 3. In addition, RES_F2 also had considerably low loading (-0.177) on Factor 7, and have cross loading on Factor 1 and Factor 4. Especially, RES_F3 loaded on a large number of factors, i.e. Factor 1, Factor 2, Factor 6 and Factor 7. RES_F3. These three items were removed to ensure the convergent and discriminant validity. On the one hand, this removal reduced the content validity of a measure of two remained items, i.e. bank loans/debts (RES_F4) and equity (RES_F5). On the other hand, these two items represent the two major financial sources. The measured items, therefore, remained, but were subsequently removed, as they cross-loaded on other factors, see 
Table 6-8. This means that the Financial Resources factor did not exist in the measure of the Resources construct. The study thus failed to capture the financial component of firms' resources.

Table 6-8: Resources Component Matrix of the first factor analysis of 30 measured items

\begin{tabular}{|c|c|c|c|c|c|c|c|c|c|}
\hline & \multicolumn{9}{|c|}{ Component } \\
\hline & 1 & 2 & 3 & 4 & 5 & 6 & 7 & 8 & 9 \\
\hline RES_P1 & 0.076 & 0.143 & 0.415 & -0.281 & 0.611 & 0.175 & -0.092 & 0.108 & 0.027 \\
\hline RES_P2 & 0.084 & 0.135 & 0.358 & -0.314 & 0.564 & 0.054 & 0.046 & 0.256 & -0.085 \\
\hline RES_P3 & 0.155 & 0.210 & 0.555 & -0.074 & 0.371 & 0.014 & -0.052 & 0.162 & 0.186 \\
\hline RES_P4 & 0.550 & 0.301 & 0.217 & 0.058 & -0.009 & -0.186 & -0.195 & 0.128 & -0.228 \\
\hline RES_P5 & 0.557 & 0.246 & 0.267 & -0.033 & 0.007 & 0.062 & 0.127 & -0.358 & 0.096 \\
\hline RES_P6 & 0.515 & 0.108 & 0.271 & -0.395 & -0.346 & -0.241 & 0.045 & -0.108 & 0.117 \\
\hline RES_P7 & 0.546 & -0.037 & 0.295 & -0.371 & -0.358 & 0.124 & 0.190 & -0.214 & 0.087 \\
\hline RES_P8 & 0.208 & -0.023 & 0.345 & -0.333 & -0.309 & -0.371 & 0.093 & -0.008 & 0.379 \\
\hline RES_H1 & 0.273 & 0.320 & -0.117 & 0.393 & 0.069 & 0.347 & 0.167 & -0.220 & 0.223 \\
\hline RES_H2 & 0.530 & 0.328 & -0.137 & 0.433 & -0.022 & 0.157 & 0.038 & 0.102 & -0.008 \\
\hline RES_H3 & 0.190 & 0.208 & -0.071 & 0.130 & -0.089 & 0.144 & 0.231 & 0.410 & 0.598 \\
\hline RES_H4 & 0.640 & 0.147 & -0.380 & 0.072 & 0.134 & -0.143 & -0.124 & 0.034 & 0.247 \\
\hline RES_H5 & 0.567 & 0.365 & 0.196 & 0.329 & 0.058 & -0.083 & -0.111 & 0.081 & -0.093 \\
\hline RES_H6 & 0.434 & 0.387 & 0.247 & 0.015 & -0.173 & -0.207 & -0.049 & -0.011 & -0.182 \\
\hline RES_OT1 & 0.523 & -0.342 & -0.311 & -0.066 & -0.139 & 0.151 & -0.081 & 0.336 & -0.079 \\
\hline RES_OT2 & 0.588 & -0.254 & -0.014 & -0.287 & -0.291 & 0.372 & -0.137 & 0.126 & -0.150 \\
\hline RES_OT3 & 0.539 & -0.270 & -0.011 & -0.275 & -0.133 & 0.395 & -0.196 & 0.231 & -0.115 \\
\hline RES_OT4 & 0.672 & 0.045 & -0.116 & -0.010 & -0.096 & -0.028 & -0.160 & 0.357 & 0.005 \\
\hline RES_OA1 & 0.355 & -0.782 & 0.284 & 0.303 & 0.087 & -0.095 & 0.006 & -0.047 & 0.031 \\
\hline RES_OA2 & 0.372 & -0.794 & 0.273 & 0.310 & 0.092 & -0.014 & 0.043 & -0.046 & 0.045 \\
\hline RES_OA3 & 0.378 & -0.769 & 0.292 & 0.326 & 0.090 & 0.004 & 0.030 & -0.064 & 0.084 \\
\hline RES_OS1 & 0.644 & -0.029 & -0.480 & -0.141 & 0.240 & -0.254 & -0.191 & -0.192 & 0.029 \\
\hline RES_OS2 & 0.615 & -0.046 & -0.444 & -0.197 & 0.248 & -0.303 & -0.177 & -0.179 & 0.058 \\
\hline RES_OS3 & 0.569 & -0.006 & -0.081 & -0.263 & 0.199 & 0.276 & 0.077 & -0.392 & -0.194 \\
\hline RES_OS4 & 0.574 & 0.116 & -0.172 & 0.100 & 0.269 & 0.231 & 0.271 & -0.221 & 0.085 \\
\hline RES_F1 & 0.005 & 0.192 & 0.311 & 0.204 & -0.173 & 0.066 & 0.131 & -0.111 & -0.321 \\
\hline RES_F2 & 0.443 & 0.263 & 0.220 & 0.514 & -0.097 & -0.281 & -0.177 & 0.052 & -0.170 \\
\hline RES_F3 & 0.307 & 0.274 & 0.000 & 0.114 & -0.192 & 0.244 & 0.361 & 0.103 & -0.120 \\
\hline RES_F4 & 0.161 & -0.077 & -0.202 & -0.225 & 0.138 & -0.223 & 0.606 & 0.226 & -0.294 \\
\hline RES_F5 & 0.292 & -0.193 & -0.144 & 0.032 & 0.135 & -0.359 & 0.563 & 0.171 & -0.130 \\
\hline
\end{tabular}

Extraction Method: Principal Component Analysis.

9 components extracted. 
The six shaded items in Table 6-9 were deleted from the measure of the Resources construct after the second round of EFA. Given the removal of both measured items of Factor 9 shown in the results of the first EFA of 30 measured items associated with Resources, it was necessary to run EFA again. Firstly, two measured items of Financial Resources were deleted, as RES_F4 loaded on Factor 5 (0.432) and Factor 8 (0.428), and RES_F5 loaded on Factor 5 (0.301), Factor 1 (0.301), and Factor 8 (0.288). Similarly, RES_P5 loaded on Factor 1 (0.543) and on Factor 7 (0.310); RES_H6 on Factor 1 (0.391), Factor 3 (0.203), and Factor 6 (0.245); RES_OS3 on Factor 1 (0.601) and on Factor 7 (0.461); RES_OS4 on Factor 1 (0.579) and on Factor 7 (0.385). The deletion of these six measured items was to ensure the convergent and discriminant validity of the measures of the Resources construct, as guided by Hair et al. (2010). There remained 19 measured items of the measure of the Resources construct. 
Table 6-9: Resources Component Matrix of the second factor analysis of 25 measured items

\begin{tabular}{|c|c|c|c|c|c|c|c|c|}
\hline & \multicolumn{8}{|c|}{ Component } \\
\hline & 1 & 2 & 3 & 4 & 5 & 6 & 7 & 8 \\
\hline RES_P1 & 0.087 & -0.185 & 0.590 & 0.025 & 0.468 & -0.283 & 0.002 & 0.083 \\
\hline RES_P2 & 0.086 & -0.172 & 0.511 & -0.051 & 0.543 & -0.129 & -0.019 & 0.241 \\
\hline RES_P3 & 0.135 & -0.198 & 0.635 & 0.153 & 0.205 & -0.095 & -0.175 & -0.019 \\
\hline RES_P4 & 0.521 & -0.305 & 0.218 & 0.041 & -0.098 & 0.134 & -0.390 & -0.068 \\
\hline RES_P5 & 0.534 & -0.259 & 0.296 & 0.060 & -0.123 & 0.130 & 0.310 & -0.234 \\
\hline RES_P6 & 0.504 & -0.160 & 0.231 & -0.422 & -0.182 & 0.360 & -0.028 & -0.218 \\
\hline RES_P7 & 0.545 & -0.006 & 0.283 & -0.419 & -0.272 & 0.210 & 0.319 & -0.057 \\
\hline RES_H1 & 0.253 & -0.297 & -0.101 & 0.495 & -0.250 & -0.166 & 0.392 & 0.198 \\
\hline RES_H2 & 0.499 & -0.306 & -0.134 & 0.421 & -0.290 & -0.033 & -0.015 & 0.297 \\
\hline RES_H4 & 0.636 & -0.205 & -0.348 & 0.186 & 0.133 & -0.112 & -0.149 & -0.138 \\
\hline RES_H5 & 0.524 & -0.342 & 0.184 & 0.349 & -0.194 & 0.061 & -0.211 & 0.123 \\
\hline RES_H6 & 0.391 & -0.375 & 0.203 & -0.025 & -0.198 & 0.245 & -0.204 & -0.087 \\
\hline RES_OT1 & 0.553 & 0.288 & -0.313 & -0.178 & -0.028 & -0.193 & -0.177 & 0.327 \\
\hline RES_OT2 & 0.611 & 0.200 & 0.002 & -0.458 & -0.200 & -0.268 & 0.047 & 0.190 \\
\hline RES_OT3 & 0.567 & 0.208 & 0.048 & -0.399 & -0.093 & -0.354 & -0.002 & 0.266 \\
\hline RES_OT4 & 0.668 & -0.087 & -0.097 & -0.062 & -0.099 & -0.037 & -0.366 & 0.193 \\
\hline RES_OA1 & 0.382 & 0.810 & 0.209 & 0.245 & -0.005 & 0.063 & -0.051 & -0.106 \\
\hline RES_OA2 & 0.403 & 0.822 & 0.217 & 0.263 & -0.028 & 0.043 & -0.015 & -0.076 \\
\hline RES_OA3 & 0.404 & 0.801 & 0.234 & 0.285 & -0.050 & 0.016 & 0.001 & -0.096 \\
\hline RES_OS1 & 0.668 & -0.082 & -0.422 & -0.009 & 0.363 & -0.089 & -0.059 & -0.351 \\
\hline RES_OS2 & 0.640 & -0.069 & -0.400 & -0.033 & 0.412 & -0.078 & -0.080 & -0.360 \\
\hline RES_OS3 & 0.601 & -0.089 & 0.034 & -0.125 & 0.155 & -0.122 & 0.461 & -0.080 \\
\hline RES_OS4 & 0.579 & -0.153 & -0.075 & 0.283 & 0.119 & -0.036 & 0.385 & 0.033 \\
\hline RES_F4 & 0.175 & 0.036 & -0.178 & -0.138 & 0.432 & 0.486 & 0.139 & 0.428 \\
\hline RES_F5 & 0.301 & 0.174 & -0.151 & 0.115 & 0.301 & 0.603 & 0.011 & 0.288 \\
\hline
\end{tabular}

Extraction Method: Principal Component Analysis.

8 components extracted.

Seven measured items of two factors were deleted after the third EFA of 19 measured items associated with Resources, as shown in Table 6-10. On the one hand, 3 measured items, i.e. RES_P4, RES_P6 and RES_P7, loaded on Factor 5, and four measured items. i.e. RES_H4, RES_OS1, RES_OS2, RES_OT4, loaded on Factor 2. On the other hand, these 7 measured items significantly loaded on other factors with high factor loading greater than 0.3. The discriminant validity of the measure of the Resources construct was strongly denied due to the cross-loadings. There remained four factors, i.e. Human Resources (Factor 4), Physical Resources (Factor 6), Organizational Training Resources 
(Factor 3), and Organizational Autonomy Resources, which was consistent with the literature on Resources associated with Forex Risk Management in previous sections. On account of this, the deletion of seven measured items of two factors ensured the content validity of the Resources construct. By doing so, the Organizational Supporting Service factor (Factor 2) was not analysed in the next sections, i.e. CFA and tests of path models, due to the bad measure of this factor. There remained 12 measured items of four factors associated with the Resources construct.

Table 6-10: Resources Component Matrix of the third factor analysis of 19 measured items

\begin{tabular}{|c|c|c|c|c|c|c|}
\hline \multirow{2}{*}{ Measured item } & \multicolumn{4}{|c|}{ Factor } & \multirow[b]{2}{*}{5} & \multirow[b]{2}{*}{6} \\
\hline & 1 & 2 & 3 & 4 & & \\
\hline RES_H1 & -0.043 & 0.124 & 0.051 & 0.450 & 0.027 & -0.014 \\
\hline RES_H2 & 0.026 & 0.284 & 0.277 & 0.819 & 0.153 & -0.019 \\
\hline RES_H5 & 0.068 & 0.269 & 0.215 & 0.671 & 0.317 & 0.246 \\
\hline RES_P1 & -0.011 & 0.001 & -0.011 & 0.044 & 0.097 & 0.752 \\
\hline RES_P2 & -0.026 & 0.008 & 0.013 & 0.017 & 0.089 & 0.616 \\
\hline RES_P3 & 0.040 & -0.038 & -0.025 & 0.151 & 0.181 & 0.571 \\
\hline RES_OT1 & 0.303 & 0.417 & 0.642 & 0.279 & 0.196 & -0.147 \\
\hline RES_OT2 & 0.275 & 0.307 & 0.821 & 0.253 & 0.432 & -0.005 \\
\hline RES_OT3 & 0.270 & 0.286 & 0.783 & 0.222 & 0.330 & 0.097 \\
\hline RES_OA1 & 0.930 & 0.141 & 0.329 & 0.025 & 0.107 & -0.006 \\
\hline RES_OA2 & 0.990 & 0.129 & 0.354 & 0.056 & 0.107 & -0.011 \\
\hline RES_OA3 & 0.974 & 0.124 & 0.342 & 0.078 & 0.112 & 0.002 \\
\hline RES_P4 & 0.055 & 0.303 & 0.260 & 0.507 & 0.403 & 0.261 \\
\hline RES_P6 & 0.059 & 0.272 & 0.339 & 0.243 & 0.926 & 0.154 \\
\hline RES_P7 & 0.179 & 0.164 & 0.473 & 0.236 & 0.680 & 0.115 \\
\hline RES_H4 & 0.078 & 0.681 & 0.365 & 0.568 & 0.219 & -0.002 \\
\hline RES_OS1 & 0.132 & 0.938 & 0.401 & 0.362 & 0.259 & -0.019 \\
\hline RES-OS2 & 0.132 & 0.938 & 0.379 & 0.303 & 0.243 & 0.019 \\
\hline RES_OT4 & 0.161 & 0.464 & 0.551 & 0.531 & 0.381 & 0.080 \\
\hline Eigenvalues & 3.15 & 3.20 & 3.33 & 2.75 & 2.35 & 1.48 \\
\hline$\%$ of Variance & $24.0 \%$ & $13.7 \%$ & $8.2 \%$ & $6.6 \%$ & $5.9 \%$ & $3.9 \%$ \\
\hline $\begin{array}{r}\text { Extraction Sum of } \\
\text { Square Loadings }\end{array}$ & & & 62.3 & & & \\
\hline
\end{tabular}

Reliability and validity tests were conducted for these 12 remaining items of four factors, shown in Table 6-11. Extraction Sum of Square Loadings (72.82\%) was greater than $50 \%$. Factor loadings (in shaded areas) were greater than 0.5 . Item-total correlation 
were greater than 0.3. Cronbach's alpha of Organizational Autonomy (0.975) and Organizational Training (0.776) were above critical value (0.7), while those of Human Resources (0.681) and of Physical Resources (0.674) were a slightly less than 0.7. These indicated the reliability and validity of Resources associated with forex risk management, consistent with guidelines of Hair et al. (2010).

Table 6-11: Resources Associated with Forex Risk Management

\begin{tabular}{|c|c|c|c|c|c|c|}
\hline \multirow[b]{2}{*}{ Measured item } & \multicolumn{4}{|c|}{ Factor } & \multicolumn{2}{|c|}{ Reliability } \\
\hline & 1 & 2 & 3 & 4 & $\begin{array}{l}\text { Item-Total } \\
\text { Correlation }\end{array}$ & Alpha \\
\hline RES_H1 & -0.046 & -0.025 & -0.036 & 0.765 & 0.450 & \\
\hline RES_H2 & 0.018 & 0.261 & -0.054 & 0.839 & 0.591 & 0.681 \\
\hline RES_H5 & 0.074 & 0.186 & 0.248 & 0.737 & 0.466 & \\
\hline RES_P1 & -0.015 & -0.03 & 0.822 & 0.015 & 0.567 & \\
\hline RES_P2 & -0.046 & 0.069 & 0.773 & -0.016 & 0.494 & 0.674 \\
\hline RES_P3 & 0.062 & -0.067 & 0.72 & 0.123 & 0.420 & \\
\hline RES_OT1 & 0.31 & 0.748 & -0.174 & 0.192 & 0.521 & \\
\hline RES_OT2 & 0.261 & 0.874 & -0.002 & 0.142 & 0.687 & 0.776 \\
\hline RES_OT3 & 0.255 & 0.857 & 0.111 & 0.108 & 0.641 & \\
\hline RES_OA1 & 0.962 & 0.308 & 0 & -0.008 & 0.920 & \\
\hline RES_OA2 & 0.984 & 0.323 & -0.007 & 0.016 & 0.965 & 0.975 \\
\hline RES_OA3 & 0.979 & 0.315 & 0.004 & 0.048 & 0.955 & \\
\hline Eigenvalues & 3.417 & 2.038 & 1.867 & 1.416 & & \\
\hline$\%$ of Variance & $28.47 \%$ & $16.99 \%$ & $15.56 \%$ & $11.80 \%$ & & \\
\hline $\begin{array}{r}\text { Extraction Sum of } \\
\text { Square Loadings } \\
\end{array}$ & & & $2 \%$ & & & \\
\hline
\end{tabular}

Factor analyses of items associated with the Resources construct showed that Resources had four factors. They are Human Resources, Physical Resources, Organizational Training Resources, and Organizational Autonomy Resources. Twelve measured items were used to measure these factors. Reliability and validity were ensured. Notably, measures of Organizational Supporting Service and Financial Resources were not well designed and unlikely to be useful for this thesis, as they were not statistically significant for the measurement model. This study failed to test the hypotheses relating to these two factors. Better measures are expected in future research studies. 


\subsubsection{Hedging Strategy (HED)}

This study used two single-item constructs, hedging degree (HGD) and hedging technique (HGT), to illustrate firms' hedging strategy. Hedging degree shows the degree to which firms use hedging techniques. On the other hand, hedging technique indicates if a firm is more likely to hedge with internal or external techniques. A test for collinearity was undertaken. Results show that there is no collinearity between the two measured items, because the VIF statistic is 1.000 .

\subsection{CONFIRMATORY FACTOR ANALYSIS (CFA) MODEL}

CFA of all multi-tem constructs in the so-called saturated model was carried out to assess the validity and the goodness-of-fit (GOF) of the measurement model. The measurement model includes 5 multi-item constructs, and 4 single-item constructs, see Table 6-12. Two of the single-item constructs, i.e. Hedging Technique and Hedging Degree, were used as dependent variables. As single-item constructs are likely problematic, which has been stated by Hair et al. (2010), this study did not attempt to conduct CFA of the four single-item constructs. By doing so, the saturated model was composed of five multi-item constructs, i.e. Perceived Forex Risk, Human Resources, Physical Resources, Organizational Autonomy Resources, and Organizational Training Resources.

Table 6-12: Confirmatory Factor Analysis

\begin{tabular}{cllc} 
Construct & & & No. of items \\
\hline \multirow{6}{*}{ Resources } & DOI & Degree of Internationalisation & 1 \\
& PFR & Perceived Forex Risk & 3 \\
& RES_H & Human & 3 \\
& RES_P & Physical & 3 \\
& RES_OA & Organizational Autonomy & 3 \\
& RES_OT & Organizational Training & 3 \\
& FXE & Forex Exposure & 1 \\
& HGD & Hedging Degree & 1 \\
\hline
\end{tabular}


The saturated model was tested for investigating how well measured items presented the constructs. Table 6-13 shows CFA output statistics. The overall model $\chi^{2}$ was 98.820 with 80 degrees of freedom, making an ideal CMIN/Df (1.235). Such a CMIN/Df below 2.0 indicated that the measurement model basically fitted. In addition, absolute fit measures were good, as RMSEA (0.037) is below the critical value of 0.080 , CFI (0.986) and TLI (0.982) are below critical value of 0.92 .

Table 6-13: Standardized Factor Loadings (SFL),

Average Variance Extracted (AVE), and Construct Reliabilities (CR)

\begin{tabular}{|c|c|c|c|c|c|}
\hline & & & SFL & AVE & $\mathrm{CR}$ \\
\hline RES_H5 & $<---$ & RES_H & 0.517 & & \\
\hline RES_H2 & $<---$ & RES_H & 0.935 & 0.467 & 0.759 \\
\hline RES_H1 & $<---$ & RES_H & 0.510 & & \\
\hline RES_P3 & $<---$ & RES_P & 0.504 & & \\
\hline RES_P2 & $<---$ & RES_P & 0.613 & 0.432 & 0.643 \\
\hline RES_P1 & $<---$ & RES_P & 0.817 & & \\
\hline RES_OT3 & $<--$ & RES_OT & 0.781 & & \\
\hline RES_OT2 & $<---$ & RES_OT & 0.824 & 0.557 & 0.781 \\
\hline RES_OT1 & $<---$ & RES_OT & 0.617 & & \\
\hline RES_OA3 & $<---$ & RES_OA & 0.973 & & \\
\hline RES_OA2 & $<---$ & RES_OA & 0.991 & 0.930 & 0.965 \\
\hline RES_OA1 & $<---$ & RES_OA & 0.928 & & \\
\hline PFR_6 & $<---$ & PFR & 0.519 & & \\
\hline PFR_5 & $<---$ & PFR & 0.935 & 0.536 & 0.724 \\
\hline PFR_4 & $<---$ & PFR & 0.682 & & \\
\hline CMIN & & 98.820 & & & \\
\hline Df & & 80 & & & \\
\hline $\mathrm{p}$ & & 0.000 & & & \\
\hline CMIN/Df & & 1.235 & & & \\
\hline TLI & & 0.982 & & & \\
\hline CFI & & 0.986 & & & \\
\hline RMSEA & & 0.037 & & & \\
\hline
\end{tabular}

The convergent validity of the measurement model was supported. The Standardised Factor Loading (SFL) of 15 measured items in Table 6-13 were mostly greater than 0.7, which indicated high convergent validity, as the size of factor loadings is an important consideration of convergent validity (Hair et al., 2006). Except for two constructs, i.e. RES_H (AVE $=0.467)$ and RES_P (AVE $=0.432)$, average variances extracted of the other three constructs were good, as they were greater than 0.5. In addition, Construct Reliability (CR) estimates exceeded 0.7, one of them (RES_P) is acceptable at 0.643. 
Statistics indicated that there were no problems with discriminant validity for the measurement model. Average variances extracted (AVE) of all five constructs, which were shown in Table 6-13, were greater than any squared inter-construct correlations associated with constructs presented in in Table 6-14, consistent with guidelines of Hair et al. (2010).

Table 6-14: Construct Correlation Estimate

\begin{tabular}{lllrr}
\hline & & & Estimate & $\begin{array}{r}\text { Square of } \\
\text { estimate }\end{array}$ \\
\hline RES_H & $<-->$ & RES_P & -0.047 & 0.002 \\
RES_H & $<-->$ & RES_OT & 0.257 & 0.066 \\
RES_H & $<-->$ & RES_OA & 0.026 & 0.001 \\
RES_H & $<-->$ & PFR & 0.195 & 0.038 \\
RES_P & $<-->$ & RES_OT & -0.007 & 0.000 \\
RES_P & $<-->$ & RES_OA & -0.007 & 0.000 \\
RES_P & $<-->$ & PFR & 0.076 & 0.006 \\
RES_OT & $<-->$ & RES_OA & 0.355 & 0.126 \\
RES_OT & $<-->$ & PFR & 0.514 & 0.264 \\
RES_OA & $<-->$ & PFR & 0.273 & 0.075 \\
\hline
\end{tabular}

Given the goodness-of-fit of the saturated model, the Respecified Measurement Model of Forex Risk Management is presented in Figure 6-1. The measurement model includes four single-item constructs, i.e. Degree of Internationalisation, Forex Exposure, Hedging Technique and Hedging Degree. There are five multi-item constructs, i.e. Perceived Forex Risk, Physical Resources, Human Resources, Organizational Training Resources, and Organizational Autonomy Resources. 


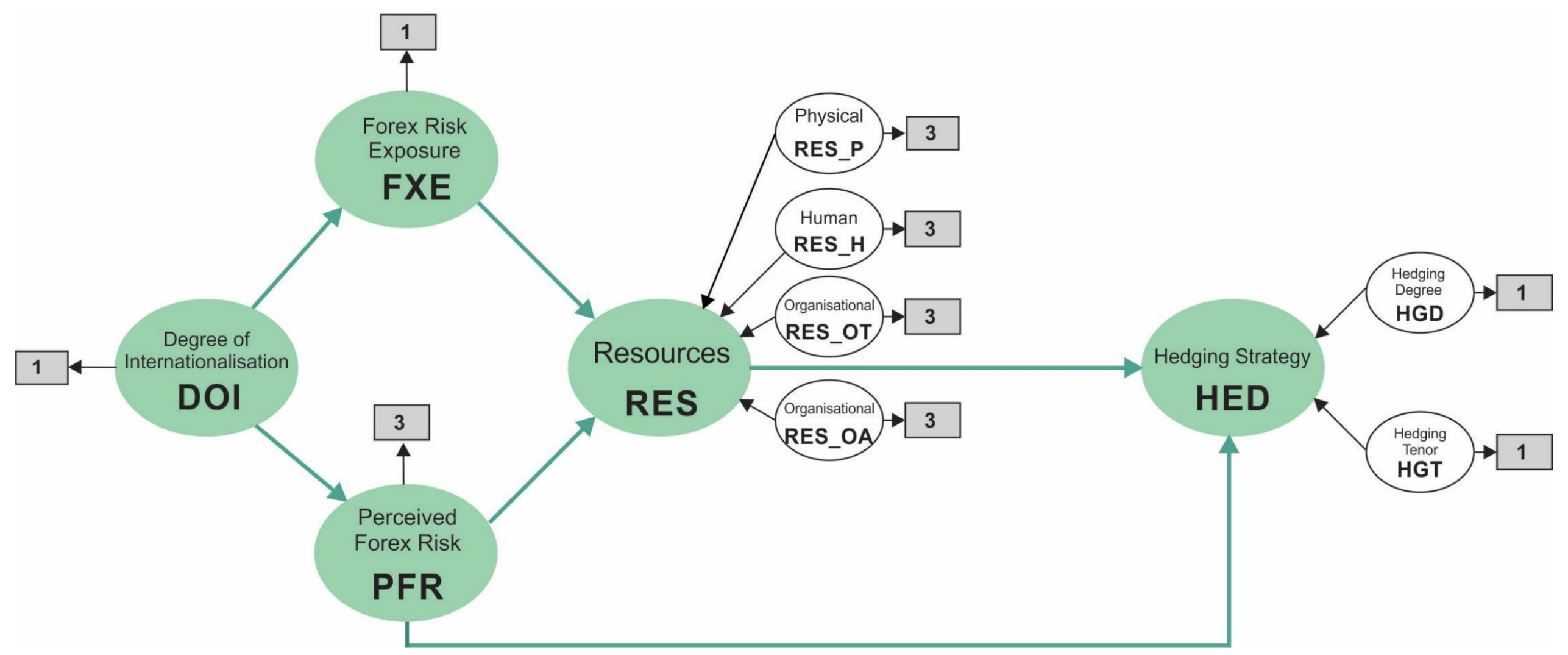

Figure 6-1: The Respecified Measurement Model of Forex Risk Management 


\subsection{STRUCTURAL MODEL AND HYPOTHESIS TESTING}

The tests of the structural model and hypotheses included two stages. Firstly, the Model of Forex Risk Management, also called "the structural model", was tested and respecified. And then, a number of tests were conducted to investigate the effect of the control variables in the structural model. After that, the final respecified model was established. Hypotheses were tested during the two stages.

\subsubsection{The Model of Forex Risk Management}

The structural model consists of seven factors that influence firms' hedging strategy. Based on previous CFA results, Resources has four components, which are considered as individual factors, i.e. RES_H, RES_P, RES_OT and RES_OA. Other three factors are Degree of Internationalisation (DOI), Forex Exposure (FXE), and Perceived Forex Risk (PFR). Two independent factors indicating firms' hedging strategy were Hedging Technique (HGT) and Hedging Degree (HGD).

Examination and respecification of the structural model was based on diagnostic measures in SEM and potential theoretical support as suggested by Hair et al. (2010). Physical Resources (RES_P) and Organizational Autonomy Resources (RES_OA) were removed from the structural model for absolute and incremental goodness of fit, as shown in Figure 6-2 and Table 6-15. Compared to the original structural model, there was a new significant relationship, i.e. the relationship between Organizational Training Resources (RES_OT) and Human Resources (RES_H). 


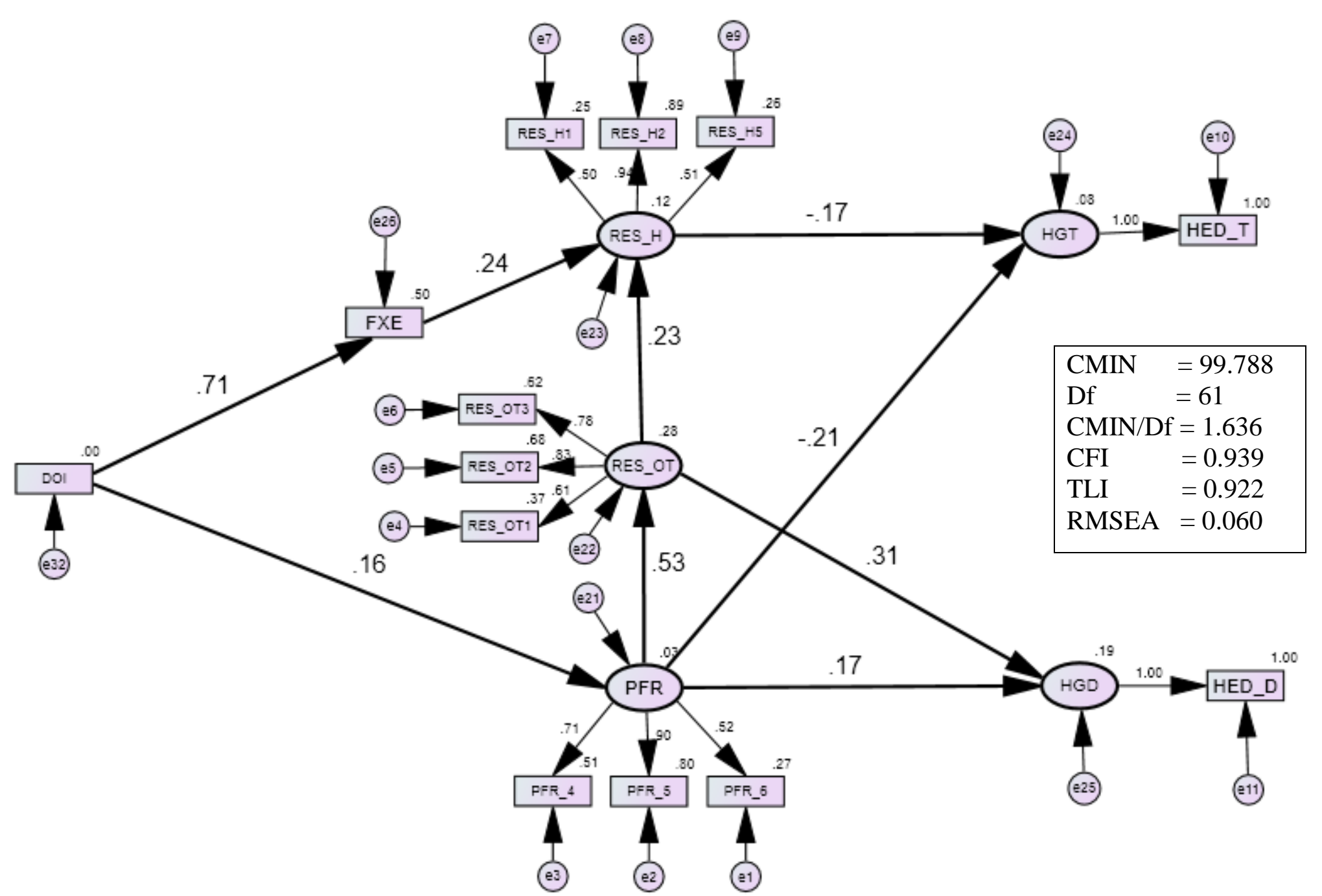

Figure 6-2: The Structural Equation Modeling of Forex Risk Management 
Table 6-15: Regression Weights and P-value

\begin{tabular}{lllrr}
\hline & & & Estimate & P \\
\hline PFR & $<---$ & DOI & 0.162 & 0.054 \\
RES_OT & $<---$ & PFR & 0.529 & $* * *$ \\
FXE_1 & $<---$ & DOI & 0.708 & $* * *$ \\
RES_H & $<---$ & RES_OT & 0.231 & 0.012 \\
RES_H & $<---$ & FXE_1 & 0.239 & 0.004 \\
HGT & $<---$ & RES_H & 0.172 & 0.033 \\
HGD & $<---$ & RES_OT & 0.315 & 0.002 \\
HGD & $<---$ & PFR & 0.172 & 0.077 \\
HGT & $<---$ & PFR & 0.210 & 0.013 \\
\hline RES_OT1 & $<---$ & RES_OT & 0.606 & \\
RES_OT2 & $<---$ & RES_OT & 0.826 & $* * *$ \\
RES_OT3 & $<---$ & RES_OT & 0.784 & $* * *$ \\
RES_H1 & $<---$ & RES_H & 0.504 & \\
RES_H2 & $<---$ & RES_H & 0.944 & $* * *$ \\
RES_H5 & $<---$ & RES_H & 0.510 & $* * *$ \\
PFR_6 & $<---$ & PFR & 0.519 & \\
PFR_5 & $<---$ & PFR & 0.896 & $* * *$ \\
PFR_4 & $<---$ & PFR & 0.713 & $* * *$ \\
HED_T & $<---$ & HGT & 1.000 & \\
HED_D & $<---$ & HGD & 1.000 & \\
\hline Notes: *** p-value $<0.01 ~$ & & & \\
& & & &
\end{tabular}

The Structural Equation Modeling of Forex Risk Management shown in Figure 6-2 fitted well, both absolutely and incrementally. This result was consistent with guidelines of Hair et al. (2010): CMIN/Df (1.636) below 2.0, RMSEA (0.060) less than 0.080, CFI (0.939) and TLI (0.922) greater than 0.920. In addition, regression weights and p-value in Table 6-15 shows that relationships were significant.

Following are the major findings regarding the Model of Forex Risk Management, which will be discussed in detail in Chapter 7 .

Degree of Internationalisation (DOI) set the background of Hedging Strategy. DOI was a primary determinant for firms to determine forex strategy. It had significant positive relationships with Perceived Forex Risk (PFR) $(0.16, \mathrm{p}=0.054)$ and Forex Exposure (FXE) $(0.71, \mathrm{p}=0.000)$, which supported Hypothesis 1 and Hypothesis 2.

Perceived Forex Risk (PFR) played a very important role in forex risk management. This construct had significant impacts on Resources and Hedging Strategy. Firstly, PFR 
had a significant positive impact $(0.17, \mathrm{p}=0.077)$ on Hedging Degree (HGD) and a significant negative impact $(-0.21, \mathrm{p}=0.013)$ on (internal) Hedging Technique (HGT), which supported both Hypothesis $\mathrm{H} 3_{\mathrm{i}}$ and $\mathrm{H} 3_{\mathrm{ii}}$. Secondly, PFR had a significant positive impact $(0.53, \mathrm{p}=0.000)$ on RES_OT, which supported Hypothesis H4 . The respecified model showed that RES_OT had a significant positive impact $(0.23, \mathrm{p}=0.012)$ on RES_H. This implied that PFR had positive impact on RES_H, as mentioned in Hypothesis $\mathrm{H} 4$; ; however, this relationship was fully mediated by RES_OT. It is noted that $\mathrm{H} 4_{\mathrm{a}, \mathrm{d}}$ associated with Physical and Financial were not supported.

As mentioned in the literature on hedging in Chapter 2, Forex Exposure (FXE) was one of the hedging determinants. This study argued that FXE affected the use of resources associated with forex risk management. It had a significant positive relationship $(0.24, \mathrm{p}$ $=0.004$ ) with Human Resources (RES_H), supporting Hypothesis 5c. It is noted that $\mathrm{H} 6_{\mathrm{a}, \mathrm{b}, \mathrm{d}}$ were not supported. These hypotheses were associated with Physical Resources $\left(\mathrm{H}_{\mathrm{a}}\right)$, Organizational Resources $\left(\mathrm{H}_{\mathrm{b}}\right)$, and Financial Resources (H6 $\mathrm{d}_{\mathrm{d}}$. Especially, the relationships between FXE and Hedging Strategy were fully mediated by Resources, as these relationships were not significant. In other words, both $\mathrm{H} 5_{\mathrm{i}}$ and $\mathrm{H} 5_{\mathrm{ii}}$ were not supported.

Human Resources (RES_H) and Organizational Training Resources (RES_OT) were substantial resources associated with forex risk management. The relations among Perceived Forex Risk, Resources, and Hedging Strategy showed how firms used their resources for determining their forex strategy. As previously mentioned, Perceived Forex Risk had positive impact on Organizational Training Resources (RES_OT) had a significant positive impact $(0.31, \mathrm{p}=0.002)$ on Hedging Degree (HGD), supporting $\mathrm{H} 7_{\mathrm{b}-\mathrm{i}}$, but not supporting $\mathrm{H} 7_{\mathrm{b}-\mathrm{ii}}$ concerned with Hedging Technique (HGT); and, Human Resources (RES_H) had a significant negative impact $(-0.17, \mathrm{p}=0.033)$ on HGT supporting $\mathrm{H} 7_{\mathrm{c}-\mathrm{ii}}$, but not supporting $\mathrm{H} 7_{\mathrm{c}-\mathrm{i}}$ concerned with HGD. RES_OT, and RES_H were important for firms to determine forex strategy; while Physical Resources (RES_P), and Organizational Resources (RES_OA), appeared to be not as important as the former two. Hypotheses H7a,d associated with RES_P and Financial Resources (RES_F) were not supported. 
This study did not investigate the role of Financial Resources (RES_F), Physical Resources (RES_P), and Organizational Autonomy Resources (RES_OA) in forex risk management. Factor analysis results showed that the measure of the Financial Resources construct was problematic; therefore hypotheses associated with RES_F were not tested. The measure of the Physical Resources construct was not well designed, because AVE (0.432) was less than 0.5 and CR below 0.7 . This could possibly be why hypotheses associated with RES_P were not supported. Factor analysis results show that Organizational Resources had two components, i.e. Organizational Training Resources (RES_OT) and RES_OA. The former was one of the hedging determinants, the latter was not.

\subsubsection{The effect of control variables}

This section investigates the effect of three variables, as described in Table 6-16. These variables, i.e. overseas subsidiaries (CON_I1), overseas employees (CON_I2), and foreign assets (CON_I3), were associated with internationalisation. Between 59\% and $70 \%$ of exporting firms in the sample had no overseas subsidiary, no overseas employee and no foreign assets. The variables indicated whether a firm had overseas subsidiaries/overseas employees/foreign assets or not.

Table 6-16: Description of Control Variables

\begin{tabular}{|l|l|r|r|}
\hline \multicolumn{2}{|c|}{} & N & $\%$ \\
\hline \multirow{2}{*}{ Overseas Subsidiary } & No & 124 & $70 \%$ \\
\cline { 2 - 4 } & Yes & 53 & $30 \%$ \\
\hline \multirow{2}{*}{ Overseas Employees } & No & 107 & $60 \%$ \\
\cline { 2 - 4 } & Yes & 70 & $40 \%$ \\
\hline \multirow{2}{*}{ Foreign Assets } & No & 104 & $59 \%$ \\
\cline { 2 - 4 } & Yes & 73 & $41 \%$ \\
\hline
\end{tabular}

Multiple-group tests were conducted in AMOS to investigate the effect of each control variable in the Structural Equation Modeling of Forex Risk Management in Figure 6-2. For each binary variable, the sample was classified into two groups, for example, whether a firm had an overseas subsidiary or not. Technically, the analyses were to compare the respecified Model of Forex Risk Management across two subgroups, as 
guided by Byrne (2013). The tests aimed to examine the effect of three control variables on nine relationships found in the respecified Model of Forex Risk Management.

Appendix K shows Z-score of tests for group differences. Statistical values indicated that there is no significant effect on eight of nine relationships. The only relationship between Degree of Internationalisation and Forex Exposure was positively affected by these three control variables, as shown in Table 6-17.

Table 6-17: Moderation effect on the relationship between DOI and FXE

\begin{tabular}{|l|l|r|r|c|}
\hline \multicolumn{2}{|c|}{} & Estimate & \multicolumn{1}{|c|}{ P } & \multirow{2}{*}{ Z-score } \\
\hline \multirow{2}{*}{ Overseas Subsidiary } & No & 1.022 & 0.000 & \multirow{2}{*}{$2.275^{* *}$} \\
\cline { 2 - 4 } & Yes & 1.469 & 0.000 & \\
\hline \multirow{2}{*}{ Overseas Employees } & No & 0.940 & 0.000 & \multirow{2}{*}{$3.19 * * *$} \\
\cline { 2 - 4 } & Yes & 1.543 & 0.000 & \\
\hline \multirow{2}{*}{ Foreign Assets } & No & 0.962 & 0.000 & \multirow{2}{*}{$2.737 * * *$} \\
\cline { 2 - 4 } & Yes & 1.457 & 0.000 & \\
\hline
\end{tabular}

Notes: $* * *$ p-value $<0.01 ; * *$ p-value $<0.05$

Table 6-17 shows statistical values of effect of the control variables on the relationship between Degree of Internationalisation (DOI) and Forex Exposure (FXE). Overseas subsidiary $(\mathrm{z}=2.275)$, overseas employees $(\mathrm{z}=3.19)$ and foreign assets $(\mathrm{z}=2.737)$ positively affected the impact of DOI on FXE. This relationship between DOI on FXE increased, since a firm would become more exposed to exchange rate fluctuations due to stronger demands on currency exchange, as it acquired an overseas subsidiary, overseas employees, and foreign assets. These results were consistent with previous discussion regarding these control variables in Chapter 4.

\subsection{HYPOTHESIS TESTING}

The results show that the majority of hypotheses were supported. Degree of Internationalisation had positive relationships with Perceived Forex Risk (H1) and Forex Risk Exposure (H2). The relationship between Perceived Forex Risk and Hedging Strategy $\left(\mathrm{H} 3_{\mathrm{i}}\right.$ and $\left.\mathrm{H} 3_{\mathrm{ii}}\right)$ were found significant and positive. These relationships were mediated by Human and Organizational Resources. Perceived Forex Risk had a positive relationship with Organizational Training Resources $\left(\mathrm{H} 4_{b}\right)$. In addition, there was a new positive relationship between Organizational Training Resources and Human 
Resources, named $\mathrm{H}^{\prime} 4_{\mathrm{c}}$. On the other hand, the relationship between Forex Exposure and Hedging Strategy (H5) was fully mediated by human and organizational resources $\left(\mathrm{H} 6_{\mathrm{b}, \mathrm{c}}\right.$ and $\mathrm{H} 7_{\mathrm{b}, \mathrm{c}}$ ), thus $\mathrm{H} 5$ was not supported. Two types of Resources had significant impacts on Hedging Strategy, i.e. a positive relationship between Organizational Resources and Hedging Degree $\left(\mathrm{H} 7_{\mathrm{b}-\mathrm{i}}\right)$ and a negative relationship between Human Resources and (internal) Hedging Technique ( $\left.\mathrm{H}_{\mathrm{c}-\mathrm{ii}}\right)$. Notably, $\mathrm{H} 1$ and $\mathrm{H} 3 \mathrm{i}$ were only signficant at the p-value $<0.1$ level, which is only weakly significant.

On the other hand, some of the hypotheses were rejected. Hypotheses relating to Physical Resources and Financial Resources $\left(\mathrm{H} 4_{\mathrm{a}, \mathrm{c}, \mathrm{d}}, \mathrm{H} 6_{\mathrm{a}, \mathrm{d}}, \mathrm{H} 7_{\mathrm{a}-\mathrm{i}}, 7_{\mathrm{a}-\mathrm{i} i}, \mathrm{H} 7_{\mathrm{d}-\mathrm{i}}\right.$, and $\left.\mathrm{H} 7_{\mathrm{d}-\mathrm{i} i}\right)$ were not supported. While $\mathrm{H} 7_{\mathrm{b}-\mathrm{i}}$ and $\mathrm{H} 7_{\mathrm{c}-\mathrm{ii}}$ ) were supported, the relationship between Organizational Resources and Hedging Technique $\left(\mathrm{H} 7_{\mathrm{b}-\mathrm{ii}}\right)$ and the relationship between Human Resources and Hedging Degree $\left(\mathrm{H}_{\mathrm{c}-\mathrm{i}}\right)$ were not supported.

Table 6-18 presents a summary of the results of hypothesis testing. 
Table 6-18: Summary of Supported Hypotheses

\begin{tabular}{|c|c|c|}
\hline \multicolumn{2}{|c|}{ Hypotheses } & \multirow{2}{*}{ 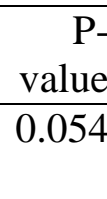 } \\
\hline H1 & $\begin{array}{l}\text { Degree of Internationalisation is positively related to Perceived } \\
\text { Forex Risk }\end{array}$ & \\
\hline $\mathrm{H} 2$ & $\begin{array}{l}\text { Degree of Internationalisation is positively related to Forex } \\
\text { Exposure }\end{array}$ & 0.000 \\
\hline $\mathrm{H} 3_{\mathrm{i}}$ & Perceived Forex Risk is positively related to Hedging Degree & 0.077 \\
\hline $\mathrm{H} 3_{\mathrm{ii}}$ & Perceived Forex Risk is negatively related to Hedging Technique & 0.013 \\
\hline $\mathrm{H} 4_{\mathrm{a}}$ & Perceived Forex Risk is positively related to Physical Resources & NS \\
\hline $\mathrm{H} 4_{b}$ & $\begin{array}{l}\text { Perceived Forex Risk is positively related to Organizational } \\
\text { Training Resources }\end{array}$ & 0.000 \\
\hline $\mathrm{H} 4_{\mathrm{c}}$ & Perceived Forex Risk is positively related to Human Resources & NS \\
\hline $\mathrm{H}^{\prime} 4_{\mathrm{c}}$ & $\begin{array}{l}\text { Organizational Training Resources is positively related to Human } \\
\text { Resources }\end{array}$ & 0.012 \\
\hline $\mathrm{H} 4_{\mathrm{d}}$ & Perceived Forex Risk is positively related to Financial Resources & NS \\
\hline $\mathrm{H} 5_{\mathrm{i}}$ & Forex Exposure is positively related to Hedging Degree & NS \\
\hline $\mathrm{H} 5_{\mathrm{ii}}$ & Forex Exposure is negatively related to Hedging Technique & NS \\
\hline $\mathrm{H6} 6_{\mathrm{a}}$ & Forex Exposure is positively related to Physical Resources & NS \\
\hline $\mathrm{H} 6_{\mathrm{b}}$ & Forex Exposure is positively related to Organizational Resources & NS \\
\hline $\mathrm{H} 6_{\mathrm{c}}$ & Forex Exposure is positively related to Human Resources & 0.004 \\
\hline $\mathrm{H} 6_{\mathrm{d}}$ & Forex Exposure is positively related to Financial Resources & NS \\
\hline $\mathrm{H} 7_{\mathrm{a}-\mathrm{i}}$ & Physical Resources is positively related to Hedging Degree & NS \\
\hline $\mathrm{H} 7_{\mathrm{a}-\mathrm{ii}}$ & Physical Resources is negatively related to Hedging Technique & NS \\
\hline $\mathrm{H} 7_{\mathrm{b}-\mathrm{i}}$ & $\begin{array}{l}\text { Organizational Training Resources is positively related to } \\
\text { Hedging Degree }\end{array}$ & 0.002 \\
\hline $\mathrm{H} 7_{\mathrm{b}-\mathrm{ii}}$ & $\begin{array}{l}\text { Organizational Training Resources is negatively related to } \\
\text { Hedging Technique }\end{array}$ & NS \\
\hline $\mathrm{H} 7_{\mathrm{c}-\mathrm{i}}$ & Human Resources is positively related to Hedging Degree & NS \\
\hline $\mathrm{H} 7_{\mathrm{c}-\mathrm{ii}}$ & Human Resources is negatively related to Hedging Technique & 0.033 \\
\hline $\mathrm{H} 7_{\mathrm{d}-\mathrm{i}}$ & Financial Resources is positively related to Hedging Degree & NS \\
\hline $\mathrm{H} 7_{\mathrm{d}-\mathrm{ii}}$ & Financial Resources is negatively related to Hedging Technique & NS \\
\hline
\end{tabular}

NS indicates that a hypothesis was not supported. 


\subsection{SUMMARY}

This chapter has presented the results of the quantitative study. Exploratory factor analysis and confirmatory factor analysis resulted in a measurement model which consisted of five multi-item constructs and four single-item constructs. Structural equation modeling was employed in the analysis, using AMOS 20. The Structural Model of Forex Risk Management was respecified as shown in Figure 6-3. Most of the hypotheses were supported; hypotheses associated with financial, organizational services, organizational autonomy, and physical resources were not. The Respecified Model of Forex Risk Management included two components of the Resources construct, i.e. Human Resources and Organizational Training Resources. One new relationship was found, the relationship between these two types of resources.

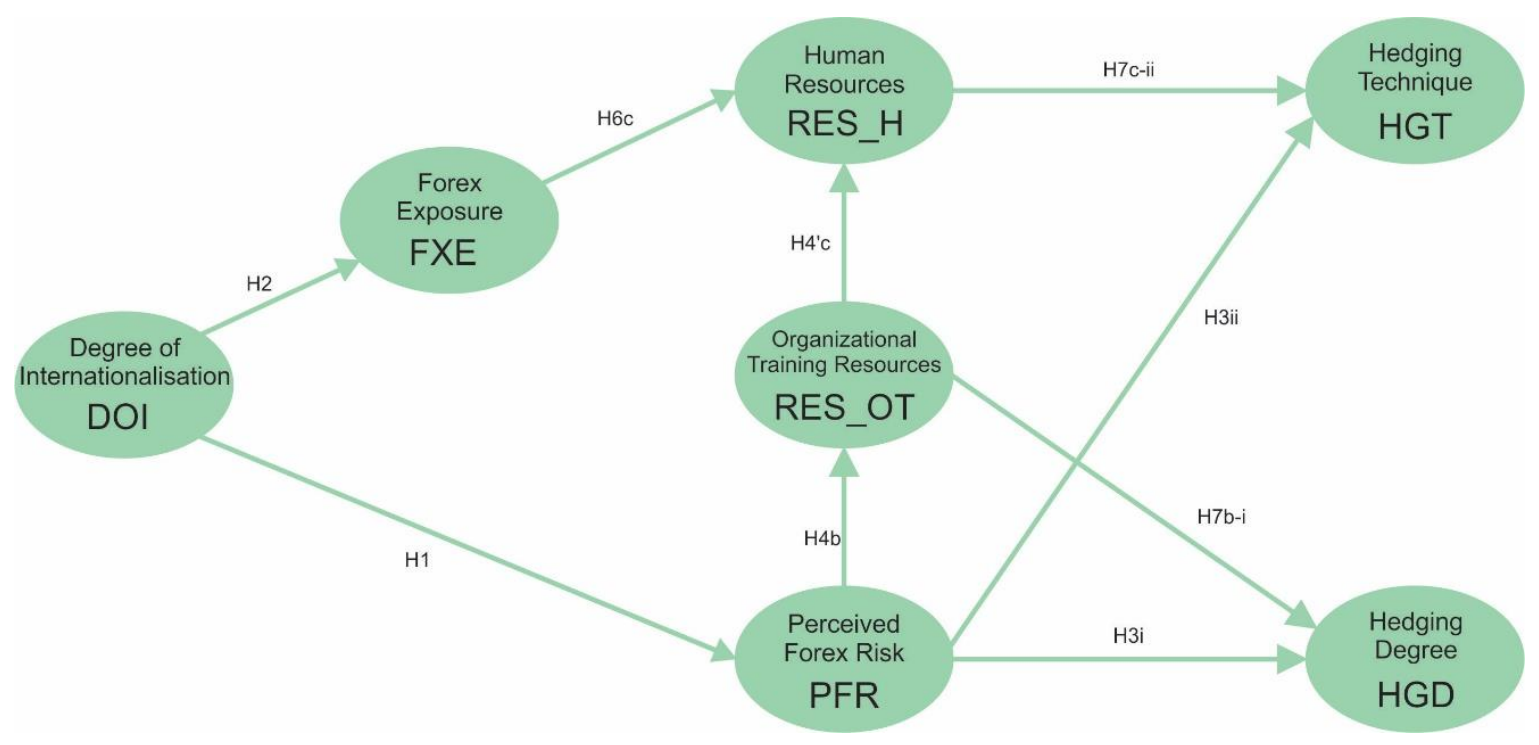

Figure 6-3: Respecified Model of Forex Risk Management

The next Chapter will discuss in detail the results outlined in this Chapter 6. Firstly, Chapter 7 discusses the supported hypotheses, new relationships and those hypotheses which were not supported. Secondly, it provides theoretical support for the respecified Model of Forex Risk Management. 


\section{CHAPTER 7. DISCUSSION AND CONCLUSION}

This chapter summarizes key findings of this thesis, and then discusses results of both qualitative and quantitative parts of the study. First, results from the exploratory qualitative interviews with New Zealand firms and quantitative survey instruments are considered together, in line with the sequential research design. Second, theoretical and methodological implications are discussed.

This chapter also highlights contributions to the literature on forex risk management, and implications for practice and policy. It then acknowledges limitations of this thesis, and suggests directions for future research. 


\subsection{INTRODUCTION}

This thesis investigated forex risk management of exporting SMEs. It specifically examined major determinants that impact the firms' choices of hedging strategy, i.e. the degree to which firms hedge forex risk, and the use of internal and external hedging techniques. A sequential research design was employed. A qualitative study was carried out to provide support for the conceptual model, which was developed based on the resource-based view of the firm (RBV) (Barney, 1991), and internationalisation theory (Cavusgil, 1984; Johanson \& Vahlne, 1977). An extensive literature review and exploratory interviews presented in Chapter 3 provided support for the conceptual model and operational construct definitions. In line with a sequential research design, a subsequent quantitative component was carried out for hypothesis testing.

As illustrated in Chapter 2, the extant literature on forex risk management is lacking understanding of SMEs' hedging practices, while an abundance of the literature on forex risk management by large firms was found. Based on the current literature on forex risk management and exploratory interviews, this study applied the resourcebased view and internationalisation theoretical lenses, which have not been used before in this context, to seek for new insights on exporting SMEs' hedging strategy. Given this gap identified in the literature, it is important to examine the factors most likely to impact SMEs' management of forex risk. In this study, the following factors were examined: firms' perception of forex risk, their resources allocation for forex risk management, and the influence of internationalisation on SMEs' hedging strategy. This chapter discusses how the findings align with the current literature to provide more informed perspectives of how SMEs manage foreign exchange risk.

This chapter integrates findings from both the qualitative and quantitative components of the study. Due to the social and economic similarities of Australia and New Zealand, quantitative findings from the surveys in these two countries are jointly discussed with the qualitative findings from interviews with New Zealand firms. The chapter aims to tie everything back to the original conceptualization, indicating how the constructs contribute to the model overall. 
In conclusion, contributions to the literature on forex risk management, and implications for practice and policy are highlighted. Limitations of the thesis and directions for future research are also addressed.

\subsection{DETERMINANTS OF HEDGING STRATEGY}

\subsubsection{Internationalisation}

Internationalisation is one of the four major determinants investigated in this thesis. The construct was operationalized by a single-item variable, Degree of Internationalisation, based on I-Model of Cavusgil (1980). Also, a number of variables accounting for firms' internationalisation were used as control variables to test for their effects on the relationships between the main constructs in the structural model. These were nominal variables associated with a firm's involvement in international markets, addressing the questions of whether the firm has overseas subsidiaries, overseas employees, and foreign assets.

This study found that degree of internationalisation was a primary determinant of SMEs' hedging strategy. First, it was positively related to forex exposure, i.e. the ratio of foreign currency denominated revenues to total revenues. Second, it had a positive impact on managerial perception of forex risk. The results showed that when a firm was more involved in exporting, it experienced higher levels of forex exposure, and also perceived more forex risk. Internationalisation sets a background to firms' decisions on hedging strategy.

For the example of "Toy" in the qualitative study, see Section 3.6.1, as Toy has been increased its involvement with exporting, it was (1) being exposed to currency risk caused by changes in exchange rates of various currencies, (2) understanding better about forex exposure, then (3) perceiving more forex risk, thus (4) employing a diversity of hedging techniques, and (5) gradually becoming more skilful at using external hedging techniques to manage this risk. The example illustrated the primary role of internationalisation in forex risk management.

In addition, empirical evidence also supported that three control variables associated with internationalisation strengthened the impact of internationalisation degree on 
hedging strategy. The positive relationship between internationalisation degree and forex exposure was increased by the more overseas subsidiaries, overseas employees, and foreign assets the firm had. It is evidenced that the relationship between degree of internationalisation and forex exposure was affected by these three control variables, while the relationship between degree of internationalisation and perceived forex risk was not.

Forex exposure was in the nature of an objective determinant of hedging, as it indicated the magnitude of exposure to forex risk. On the other hand, perceived forex risk was subjective, as it was concerned with managerial attitude toward forex risk. Empirical results showed that factors associated with internationalisation created impact on both magnitude of exposure to forex risk, and managerial attitude toward forex risk. Also, these factors tended to have more effect on magnitude of exposure to forex risk.

As mentioned in Chapter 3, Ship is one among six New Zealand interviewed SMEs having an overseas subsidiary. On the one hand, this firm was heavily exposed to forex fluctuations, as it had an overseas subsidiary. Despite the importance of forex exposure, the firm tended to be concerned about how to maximize its profit in New Zealand currency. The example showed that Ship's managerial attitude toward forex risk had a strong impact on the manager's perception of forex risk. It was managerial subjective concerns about profit/loss caused by forex fluctuations that influenced the managerial perception of forex risk. In other words, perceived forex risk was influenced by other factors, e.g. managerial attitude toward forex risk, as well as from degree of internationalisation. The firm (Ship) stated,

We do care because it [exposure] affects the profit that we report back in New Zealand. The report of overall profit is in NZD and it makes a big difference if there is a big fluctuation of 8 cents or something, you know, something [likely that] would make 150,000 dollars a month. It makes a difference in our Kiwi reporting, you know. So you're talking about the difference between 2 million dollars and something over a year. (Ship)

Overall, findings for the internationalisation construct fit well in the context of forex risk management. The extant literature on internationalisation theory holds that SMEs 
suffer higher risk as they become more involved in foreign markets over time, gaining experience and resources, enhancing market knowledge, and thus making further commitment in more distant markets (Coviello \& McAuley, 1999, p. 226). In the context of forex risk management, as SMEs export more, they are more exposed to forex fluctuations, and also perceive more forex risk. As a result, the SMEs in the study gained more training and resources associated with forex risk management, and tended to hedge more as well as utilized more external hedging techniques. This study emphasizes the primary role of internationalisation in forex risk management. Findings show that attributes of internationalisation in forex risk management include degree of internationalisation, and the presence of an overseas subsidiary, overseas employees, and foreign assets.

The following sub-sections will discuss more about findings relating to perceived forex risk, forex exposure, resources and hedging strategy. How a firm deals with forex fluctuation depends on availability and allocation of its resources for managing the risk associated with forex uncertainties, as discussed in Chapter 2. The following section 7.2.4 will discuss further the use of resources for managing forex risk.

\subsubsection{Perceived Forex Risk}

This study adapted the concept of perceived risk in a context of forex risk management, called perceived forex risk. Perceived risk has been widely studied in Psychometric theory (Slovic, 1992). Perception is also examined in various domains; for example, Sweeney, Soutar, and Johnson (1999) investigated perceived value for money along with perceived risk and perceived product and service quality. Given the subjectivity of perception, perceived forex risk refers to managerial risk perception of uncertainty and exposure specifically associated with foreign exchange rates. Also, this thesis considers perceived forex risk as managerial perception of a number of hedging determinants previously discussed in Section 2.3.2, for example, managerial risk attitude.

Factor analyses confirmed three variables for Perceived Forex Risk (PFR): managerial perception of the effect of forex changes on (1) the use of domestic inputs rather than overseas ones, (2) production volume, and (3) export prices. These three items are 
essential components of an exporting business. The measure of the perceived forex risk construct exhibits the perception of forex risk to firms' exporting operations, which was applicable in the context of forex risk management.

Perceived Forex Risk is an essential determinant of hedging strategy in the Model of Forex Risk Management. The Model is efficient in investigating the use of resources associated with forex risk management since perception has been proved to predict behaviours in various domains, for example, telephone shopping (Chow et al., 1997), buying behaviours associated with consumer products (Ackert \& Deaves, 2010), and decision making in innovation processes (Bodnar \& Marston, 2000). Empirical data also supported the effect of perceived forex risk on the allocation of resources associated with forex risk management, and especially directs impacts on hedging degree and the use of hedging techniques.

While forex exposure is a major objective factor that indirectly influences hedging strategy, perceived forex risk is a major subjective factor that directly influences such decisions. Both quantitative findings and qualitative exploratory interviews suggest that perceived forex risk is a major determinant of hedging, apart from forex exposure. Empirical quantitative data supported that firms tend to extend the use of external hedging techniques, and the use of resources associated with forex risk management, when the firms perceived more forex risk. Interviewees expressed their inclination to use more resources, to hedge more and to utilize more external hedging techniques as they realised stronger effects of forex changes. This finding enriches the extant literature on forex risk management. Forex exposure and managerial perception of forex risk are essential hedging determinants, in line with precious studies, e.g. (Bartram et al., 2010). In addition, mediating effect of resources is highlighted, which have not been mentioned specifically in forex risk management by SMEs.

Given that Human Resources is a complete mediator between Forex Exposure and Hedging Strategy, which will be discussed in detail in the next subsection, a direct relationship between Forex Exposure and Hedging Strategy does not exist. However, quantitative findings showed that Perceived Forex Risk had significant impacts on both Hedging Degree (Hypothesis $\mathrm{H}_{3}$ ) and Hedging Technique (Hypothesis $\mathrm{H} 3_{\mathrm{ii}}$ ). On account of this, perceived forex risk becomes a key determinant of hedging. This also 
implies that the use of the Perceived Forex Risk construct in this study fits well in the context of forex risk management by SMEs.

In addition, the use of perceived forex risk in this study provided advantages to research in forex risk management. While previous studies considered hedging determinants discussed in Section 2.3.2 as isolated variables, this study used Perceived Forex Risk as an aggregate latent variable to measure firms' perception of the effect of these individual determinants on the firms' exporting transactions. Apart from integrating isolated determinants, thus making a parsimonious conceptual model, this aggregate variable is practical, effective and feasible for research on SMEs due to its perceptual measurement. The use of a perceptual measure in this instance provides easier access to limited databases of SMEs despite a lack of consideration of individual determinants.

\subsubsection{Forex Exposure}

Forex Exposure can be understood from different perspectives. Bodnar and Marston (2000) defined Forex Exposure as a measure of the sensitivity of a firm's cash flows to changes in exchange rates. The future cash flows of a firm may arise from both domestic and foreign currency transactions, involving assets and liabilities, and generating revenues and expenses. To this end, a firm's cash flow consists of domestic and foreign currency components. While the former is unlikely to be sensitive to changes in forex risk, the latter is obviously subject to the exchange rates. Hence, a measure of Forex Exposure is composed of foreign currency cash flow and volatility of foreign currencies.

On the other hand, Adler and Dumas (1984) consider exposure to currency risk as "the amounts of foreign currencies which represent the sensitivity of the future, real value of any physical or financial asset to random variations in the future domestic purchasing powers of these foreign currencies, at some specific future date". In this definition, volatility of foreign currencies is not used to compute exposure. This thesis has adopted this definition, similarly not using volatility of foreign currencies. In line with previous studies (Aabo et al., 2010; González et al., 2007; Kula, 2005; Pramborg, 2005), the share of foreign currency denominated revenues to total revenues is used as a proxy for Forex Exposure. 
Given that this study examines forex risk management by exporting SMEs, it is rationale to use the definition of Forex Risk by Adler and Dumas (1984), which considers the volatility of foreign currencies as an economic environmental factor. Forex exposure arises from transactions in foreign currencies, e.g., exports and imports (Aabo et al., 2010; Pramborg, 2005). As firms export more to foreign markets, relative to their total sales, the firms are more exposed to the volatility of foreign currencies. In other words, forex exposure may be significantly increased, which makes firms utilising more human resources, hedge more and utilise more external hedging techniques. These arguments support the notion that internationalisation is a primary determinant of hedging, as discussed in previous Section 7.2.1, and that forex exposure is one of two major hedging determinants.

The study described in this thesis advances previous studies about forex exposure. Previous studies (Aabo et al., 2010; W. B. Elliott et al., 2003; González et al., 2007). Aabo, et al. (2010) found a strong negative relationship between importing and the use of currency derivatives on the aggregate level, supporting the notion that firms use imports to match the forex exposure created by foreign sales activities. González et al. (2007) and W. B. Elliott et al. (2003) found that borrowings in foreign currency caused forex exposure, but substituted for foreign currency derivatives as a hedging tool. These scholars demonstrated a relationship between forex exposure and the use of hedging techniques, but did not investigate the possible mediating role of other factors. Findings of this thesis indicate that there was not a direct relationship between Forex Exposure and Hedging Strategy; however the findings indicated a mediator, i.e. human resources, between the relationship between Forex Exposure and Hedging Strategy. The nonsignificant relationship between determinant variable Forex Exposure, and dependent variable Hedging Strategy demonstrated the full mediation (according to Baron and Kenny (1986)) of Human Resources. This study, as earlier discussed in Section 2.2.4, admitted the role of forex risk exposure as a primary determinant for hedging; on the other hand, it also advanced the fully mediating effect of human resources between forex exposure and hedging strategy.

Hypotheses $\mathrm{H} 5_{\mathrm{c}}$ and $\mathrm{H}_{\text {cii }}$ with regard to Forex Exposure - Human Resources Hedging Technique were strongly supported in this research. Findings from section 3.6 
showed that firms favoured internal hedging techniques due to their lack of resources. Empirical data supported Hypothesis $\mathrm{H} 5_{\mathrm{c}}$, which confirmed a highly significant, positive relationship $(\mathrm{p}=0.004)$ between Forex Exposure and Human Resources. Then Hypothesis $\mathrm{H6}_{\text {cii }}$ predicted that Human Resources are significantly and positively related to firms' use of external techniques. These findings are consistent across both qualitative and quantitative studies. In this study, human resources includes (1) experience of exporting (RES_H1), (2) experience of forex risk management (RES_H2) and personnel for forex risk management (RES_H5). With a low degree of internationalisation, firms allocate few resources associated with forex risk management, and mainly utilize internal hedging. As firms become more involved in international markets, the firms were more exposed to forex risk, gaining more experience in exporting in general and specific experience in forex risk management, also getting sufficient skilled personnel in forex risk management. As a result, firms have a greater incentive to "look for some formal hedging" (Digiso). When the exposure is large enough, the strong focus on Human Resources and the use of external hedging techniques is consistently evident in exploratory interviews presented in Section 3.6. A firm stated,

We use natural hedging most of the time but the point and position [at which] we move to formal hedging, thing would be depending on the size of exposure. So, probably anything with a million dollars, we look for some formal hedging. (Digiso)

In spite of controversial arguments as to whether firms are exposed to forex changes, findings of this study favoured the notion that there exists the risk caused by unexpected changes of exchange rates due to market imperfections (Bartram, et al., 2005). Both qualitative and quantitative findings showed that firms are more or less exposed to forex risk. The extent to which a firm hedges forex risk is subject to the size of exposure. In other words, exposure is a major incentive to firm's risk management, influencing firms' perceived forex risk, resources allocation and hedging decision making. 


\subsubsection{Resources associated with forex risk management}

Due to the limited resources of SMEs (Berra et al., 1995; Coviello \& Munro, 1997; Coviello \& Munro, 1995; Fontes \& Coombs, 1997; Holmlund \& Kock, 1998; Lau, 1992; Zafarullah et al., 1997), it is worthwhile to investigate firms' use of resources associated with forex risk management, since the firms might have distinct ways to manage their forex risk. For example, SMEs favour internal hedging techniques as they lack resources associated with forex risk management, especially human and training resources. This was found in both the qualitative and quantitative studies.

Qualitative exploratory interviews showed that firms allocated their resources for the main business activities, as forex risk is unlikely to be "the top of the world" (Software), or "the top of the game" (Ship). Almost all of the interviewees agree that they did not prioritize the use of resources associated with forex risk management until they perceived high forex risk. As a result, the firms preferred internal hedging techniques to external ones.

This study attempted to demonstrate the role of financial resources associated with forex risk management. A large number of previous studies in forex risk management extensively investigated financial factors that influence firm's hedging practices. Primarily, Smith \& Stulz (1985) indicated tax and financial distress as hedging determinants. The later studies examined cost of financial distress, tax liability (Joseph, 2000), financial leverage (Pramborg, 2005), bankruptcy costs, convex tax schedule (Albuquerque, 2007), bankruptcy costs, costs of setting up a hedging program (González et al., 2007), financial distress costs, tax benefits (Schiozer \& Saito, 2009), total assets, gross profit (Aabo et al., 2010). These studies confirmed the influences of these financial factors on hedging strategy. These financial factors are likely to relate to firms' fiscal characteristics, costs and benefits, rather than financial resources. On the other hand, this study investigated financial resources, which are assets and funding capabilities controlled by firms. This intention aimed to add a new component to the three components of resources defined by Barney (1991), making four components: Physical, Human, Organizational, and Financial Resources. While the three existing types of resources are suitable for studying sustainable competitiveness in marketing, this additional item is consistent with the domain of forex risk management as previous 
studies affirmed the important role of financial factors in forex risk management. In addition, qualitative interviews indicated the relationship between financial resources and hedging strategy.

Findings showed that firms favour internal hedging techniques due to lack of working capital. Specifically, firms were not concerned about forex risk as they were in urgent need of money for their business. However, the quantitative study did not demonstrate the role of financial resources associated with forex risk management. Factor analyses did not confirm a multi-item measure for this latent variable; thus a single item, i.e. ratio of debt to total assets, was used as a proxy for financial resources. Although ratio of debt to total assets is the most readily available proxy for the measure, this item was not suitable for capturing financial resources. In addition, quantitative results did not confirm the relationship of this item with hedging strategy either. These findings showed a limitation of the quantitative component while investigating the role of financial resources in this thesis.

Factor analyses of this study established that Physical Resources includes three variables: (1) imported inputs (RES_P1), sources of input supply (RES_P2), and (3) production capacity compare to market demand (RES_P3). It is hypothesized that firms are likely to be inclined to invest in physical resources, to hedge more, and to use more external hedging techniques as the firms incur higher forex risk. However, findings from both quantitative and qualitative analysis showed that this is not true. Quantitative analysis indicated a low but significant relationship between physical resources and perceived forex risk as well as hedging strategy. In addition, there was qualitative evidence that forex risk is not one of firms' top concerns, as physical resources are more likely to be associated with decisions on exporting activities rather than forex risk. Hence, interviewees expressed their inclination to organizational and human resources.

Similarly, whether firms tend to grant employees autonomy to manage forex risk is still inconsistent across firms. Qualitative interviews witnessed that forex risk is managed by firms' owners and/or the financial controller. This professional task is more likely to be assigned to specific staff, i.e. owners and financial controllers. Some employees might be asked to do more work relating to forex markets; however, owners and/or financial controllers are those who make hedging strategy. Neither did qualitative findings 
confirm the relationships between Autonomy Resources and Perceived Forex Risk as well as Hedging Degree, Hedging Technique. Both qualitative and quantitative analyses rejected the role of autonomy resources associated with forex risk management. The inclusion of employees' autonomy to manage forex risk in this study is a limitation in methodology, as there was not sound theoretical support for the inclusion. It was, therefore, chosen to remove this component of the multi-component construct, as the component was not really relevant in the research context.

Although employees are unlikely to be given autonomy to make hedging strategy, employees might be asked to perform hedging tasks. Hence, training and human resources are essential for managing forex risk.

Higher Perceived Forex Risk increase Organizational Training Resources. Factor analyses supported that the Organizational Training Resources construct is composed of three items: (1) managerial concerns to employees' desire for training (RES_OT1), (2) perceived learning benefits of overcoming obstacles (RES_OT2) and (3) practicability of training (RES_OT3). As firms incur higher perceived forex risk, the firms are more likely invest in training in forex risk management. This trend was found from qualitative exploratory interviews. Interviewees stated that they attempt to take part in training courses. Consequently, firms hedge more. The positive relationship between perceived forex risk and organizational training, advanced in Hypothesis H4b, is very highly significant. In addition, Organizational Training Resources has a highly significant positive relationship with Hedging Degree, presented in Hypothesis H6bi. Both qualitative and quantitative findings confirmed the mediating role of Organizational Training Resources.

'Human Resources' is essential for forex risk management. Interviewees were much concerned about their human resources as their firms perceived higher forex risk. Due to lack of experienced staff in forex risk management, firms choose not to hedge, or to hedge with natural hedging techniques. As discussed earlier, the firms tended to invest more in training, when perceiving higher forex risk, thus increasing skill and capability of employees who are in charge of forex risk management. This supported the hypothesis that Organizational Training Resources is positively related to Human Resources. Factor analyses demonstrated that Human Resources are composed of three 
variables: (1) experience of exporting (RES_H1), (2) experience of forex risk management, (3) personnel for forex risk management (RES_H5). Quantitative findings confirmed the positive relationship between Human Resources and Hedging Technique. Firms tended to practise external hedging techniques when human resources are sufficient.

Overall, training and human resources play an important role in forex risk management. When suffering higher forex risk, firms' managers attempt to take training courses, learning about forex risk management, and hedging more. As a result of training, human resources increase, and firms adopt more external hedging techniques. In addition to the decision not to examine the role of financial resources, this study rejected the role of physical resources in forex risk management, but strongly supported the role of organizational training and human resources.

\subsubsection{Hedging Strategy}

This thesis attempted to examine hedging degree, and the use of hedging techniques, as the dependent variables. A number of previous studies examined the use of currency derivatives to minimize loss caused by forex rate changes (Albuquerque, 2007; Eaker \& Grant, 1987; Schiozer \& Saito, 2009). Some of the studies investigated internal versus external hedging (Aabo et al., 2010; González et al., 2007; Joseph, 2000; Kula, 2005; Pramborg, 2005). For internal hedging, authors investigate the use of imports and foreign debt as major internal hedging techniques. This study investigated the use of a wide range of internal and external hedging techniques. Hedging Degree refers to the extent to which firms use all hedging techniques; and Hedging Technique compares the extent to which external hedging techniques are used with all of those techniques. High Hedging Degree means firms hedge more; and high Hedging Technique implies that firms adopt more internal compared to external hedging techniques.

Both qualitative and quantitative findings indicated that forex exposure and perceived forex risk are two major determinants of exporting SMEs' hedging strategy. While forex exposure indirectly affects hedging strategy via human resources, perceived forex risk has direct impacts on organizational training resources, human resources and hedging strategy. The effect of forex exposure on the use of hedging techniques is 
completely mediated by human resources, which was not mentioned in the extant literature on forex risk management. Forex exposure increased as firms exported more to international markets. However, most of the interviewed firms in New Zealand had limited resources associated with forex risk management, especially human resources, and thus they tended to utilise internal hedging techniques. Empirical data also showed that the firms tended not to consider forex exposure as the top priority, perceived lower risk of forex risk in comparison with business risks, and favoured internal hedging techniques. However, high degree of internationalisation and high perceived forex risk encouraged these firms to invest more resources for managing the risk. As a result, the firms hedged more, and adopted more external hedging techniques.

Although internal hedging is considered to be appropriate for exporting SMEs, qualitative evidence showed that firms had some difficulties executing these techniques. One respondent said that many places the firm dealt with were countries that are developing and have "interesting" processes. For dealing in the Middle East, for example, the time to get from tender to contract to delivery could be considerable, and in this time there could be significant US dollar rate changes. Due to the above, forward cover was not appropriate because no timings are guaranteed. The firm dealt with difficult countries like Iraq, where everything goes through a third party bank with huge fees; and the Iraqi banks often add errors into letters of credit, so that letter of credit fees become very expensive and slow. The firm's foreign currency planning is based on what various commentators were saying, watching international politics and events and trying to add a safety margin while not pricing themselves out of the business. The firm did hold foreign currency in US dollar accounts to manage when bringing the currency into New Zealand dollars. In addition, lack of banking facilities made long term hedging difficult and this carried its own risks as well.

Evidence also revealed that exporting SMEs had difficulties in practicing external hedging techniques, and thus training is likely to be essential for forex risk management in SMEs. It is likely to be difficult for firms to obtain specific staff or management training on currency derivatives, but it would be useful, according to interview respondents. For example, one respondent claimed that most of the information on alternative derivatives came from bankers, who sometimes offered products that did not 
necessarily suit the firm. Another respondent stated that the firm had contacts in banks' international services, and that banks are helpful. Banks offered some services but the services tended not to fit well with the firm's business. In these instances, bankers might not really understand the firm's business and requirements, or the firm might be incapable of taking bankers' advice due to lack of knowledge about currency derivatives. Respondents admitted that typical SMEs are likely to lack trained staff and much of the organizational learning relies on guidance from those who have had suitable training.

On the whole, exporting SMEs favoured internal hedging techniques. This finding was in line with previous studies about SMEs' choice of hedging techniques, i.e. the favourite option of informal hedging (Henschel, 2009), and the lack of formal methods for risk management (Gao et al., 2013). The survey data also revealed that $77.4 \%$ of firms in the survey sample utilise more internal hedging techniques than external ones. In addition, the mean of the Hedging Technique variable (HED_T) was 0.572 (see Table 6-4), which is greater than 0.5. In addition, most of the interviewed firms in New Zealand looked for information on the internet, and usually monitor exchange rate graphs daily looking at trends. The offshore directors, or more often, the CEOs of these firms get involved with forex management. Business size can change, so the main focus of these managers tended to be on larger contracts.

Due to lack of resources (Coviello \& McAuley, 1999), exporting SMEs' hedging practice is distinct from that of MNEs. This study demonstrated that Australian and New Zealand exporting SMEs favoured internal hedging techniques, while Joseph (2000) found that UK industrial MNEs focused on a very narrow set of hedging techniques, and made greater use of derivatives than internal hedging techniques. The degree of hedging by SMEs depended on size of exposure (Joseph, 2000); in contrast, MNEs relied on the type of exposure.

Overall, findings for forex risk management were consistent with previous studies about SMEs' hedging practice. SMEs perceive forex exposure as economic and transaction exposure, and attempt to hedge transactions (Kula, 2005). The firms rely heavily on internal hedging, and are unlikely to be aware of external hedging techniques (Kula, 
2005). Hedging degree is mainly determined by the size of the exchange exposure (González et al., 2007).

Findings from qualitative exploratory interviews demonstrated that many hedging determinants (mentioned in the hedging literature) lack recognition from interviewed SMEs. These firms are unlikely to clearly acknowledge that their hedging strategies were affected by economies of scale, financial distress costs, informational asymmetry, and growth opportunities (Schiozer \& Saito, 2009), market to book ratio, and liquidity (González et al., 2007). The firms do not hedge because of potential tax benefits (Smith \& Stulz, 1985). As previously mentioned, exporting SMEs are unlikely to consider forex risk as top priority, and they know little about forex risk management in many instances. Hence, the firms do not, and/or are unable to, recognize advantages and disadvantages of these factors. As a result, the firms are unlikely to be affected by these factors.

\subsection{THE MODEL OF FOREX RISK MANAGEMENT}

The Model of Forex Risk Management by SMEs has five determinants and two key decisions of hedging strategy. Internationalisation is a primary determinant of hedging strategy. While forex exposure indirectly affects the use of hedging techniques via human resources, perceived forex risk has direct impacts on organizational training resources, human resources and hedging strategy. As an objective factor referring to the magnitude of forex risk, forex exposure influenced the firms' allocation of human resources associated with forex risk management. Human resources are also influence by perceived forex risk via organizational training resources. On the other hand, perceived forex risk, as the subjective perception of managers of forex risk, has a direct positive relationship with hedging degree and the use of hedging techniques. As can be seen, human resources and organizational training resources are two important resources associated with forex risk management by exporting SMEs. These resources have a mediating effect on the relationship between forex exposure and hedging strategy, and that of perceived forex risk and hedging strategy. These findings are consistent with RBV, because resources, as one of three legs of the strategy tripod, determine a firm's formulation and implementation of strategy (Peng, 2006). The Model of Forex Risk Management presents not only the determining factors themselves, but 
also the relationships between them, and describing in detail how these determinants together impact hedging strategy.

Although SMEs managers are concerned about the exposure of forex rate changes, findings imply that managerial perception of forex risk plays a decisive role in an SME's hedging strategy, i.e. hedging degree and the choice of hedging techniques. Forex risk management is subject to perceived forex risk. When managerial perception of forex risk is high, firms tend to allocate more resources associated with forex risk management, tend to hedge more and tend to utilise more external hedging techniques. However, it is worthwhile noting that the relationship between perceived forex risk and hedging degree was just weak, while there was strong relationship between perceived forex risk and the use of external hedging techniques.

Human resources and organizational training resources are of vital importance to forex risk management by SMEs, and firms must consider investing in training and personnel for their hedging strategy. Unlike large firms, SMEs are less concerned about some financially specific facets, for example, tax reduction when they decide to hedge forex risk. This might be because SMEs lack sufficient human resources to understand or respond to the issues. When managers perceived high forex risk, they tended to invest in training programmes: managers ask employees about forex training programmes, letting employees attend the training programme which are practical for the employees. As a result, firms would have personnel who have experience in exporting and forex risk management. Human resources and organizational training resources become substantial for forex risk management.

In contrast, other resources, e.g. organizational autonomy resources, are inadequate for the Model of Forex Risk Management. Firstly, this study failed to measure financial resources, which could be important for this study. Secondly, the measures of physical resources were not well validated; thus the physical resources variable was removed from this study. The organizational autonomy resources variable was also dropped from the Model of Forex Risk Management, as there was not sound theoretical and empirical support for this type of resources in the Model. 
While the theoretical model shows a number of relationships among six major constructs, the respecified Model of Forex Risk Management had the most significant relationships. The direct relationship between Forex Exposure and Hedging Strategy was rejected; Human Resources fully mediated the relationship between Forex Exposure and Hedging Degree. Hypotheses relating to Financial Resources, Physical Resources and Organizational Autonomy Resources were not confirmed. Findings show that Human Resources and Organizational Training Resources were important for forex risk management. While Human Resources were closely related to the use of hedging techniques, Organizational Training Resources were concerned with hedging degree.

Essential relationships were retained in the respecified Model of Forex Risk Management. Adopting internationalisation theory in a new research setting of forex risk management, this study developed hypotheses regarding two positive relationships between the degree of internationalisation and (1) forex exposure, and (2) perceived forex risk. Empirical data supported these hypotheses, consistent with the extant literature on forex risk management, e.g. research studies by Joseph (2000) and Aabo et al. (2010), and also in line with the literature on internationalisation, e.g. study of Cavusgil (1984). It is, however, worthwhile noting that the relationship between degree of internationalisation and perceived forex risk was quite weak, while empirical data showed a close relationship between degree of internationalisation and forex exposure. On the RBV, this study hypothesised a number of relationships associated with various types of resources. Empirical data showed that human resources and organizational resources were two essential resources associated with forex risk management. In line with the RBV, these two types of resources played a key role in formulation and implementation of strategy (Peng, 2006). The resources were mediators for three relationships associated with hedging strategy: (1) between forex exposure and the use of hedging techniques, (2) between perceived forex risk and the use of hedging techniques, and (3) between perceived forex risk and hedging degree. Specifically, the first relationship was completely mediated by human resources. These findings showed that perceived forex risk was an important hedging determinant, as it has direct impact on both hedging degree and the use of hedging techniques.

Table 7-1 summarises the major findings and implications. 
Table 7-1: Summary of Findings and Implications

\begin{tabular}{|c|c|c|c|}
\hline Constructs & Qualitative interview findings & Quantitative survey results & Implications \\
\hline 1. Internationalisation & $\begin{array}{l}\text { Strong support } \\
\text { Yeah, I would say... after a couple of years... probably } \\
\text { after the first year of starting doing business, I think in our } \\
\text { case, it's four and a half years. And hedging is used more } \\
\text { now than it was. You're right, over time, you do start using } \\
\text { them more but you don't think you will use it at the start. } \\
\text { (Software) } \\
\text { Yeah, at a cross level, I am more interested in turnover } \\
\text { and on our own business than focusing energy on } \\
\text { optimising exchange rate, exchanging, you know, on } \\
\text { transactions like that. I think when our business is mature } \\
\text { we may look at that closely. (Toy) }\end{array}$ & $\begin{array}{l}\text { H1: Degree of } \\
\text { internationalisation is positively } \\
\text { related to Perceived Forex Risk. } \\
(\mathrm{p}=0.054) \\
\text { H2: Degree of } \\
\text { internationalisation is positively } \\
\text { related to Forex Exposure. } \\
(\mathrm{p}=0.000)\end{array}$ & $\begin{array}{l}\text { Firms incur and perceive higher } \\
\text { forex risk as they export more to } \\
\text { international markets. }\end{array}$ \\
\hline $\begin{array}{l}\text { 2. Perceived Forex } \\
\text { Risk }\end{array}$ & $\begin{array}{l}\text { Support } \\
\text { The companies that we're dealing with want us to provide } \\
\text { NZD fixed prices even when the contract lasts for two } \\
\text { years. There's certainty that we've been required those } \\
\text { licensees. Some bills have to carry the exchange risk for } \\
\text { two years cause it's... to NZ dollar pricing even though we } \\
\text { have to buy in USD price but what you have to price is... } \\
\text { to give NZD pricing. So, we have to think about. That's } \\
\text { sort of things coming more and more significant. So, as } \\
\text { we spent widely on Telecom and more into electronic } \\
\text { companies as well, it's far riskier for us primarily because } \\
\text { NZD is quite volatile. It's a real risk for our business. } \\
\text { (Digiso) }\end{array}$ & $\begin{array}{l}\text { H3i: Perceived Forex Risk is } \\
\text { positively related to Hedging } \\
\text { Degree. (weak significance } \\
\text { level: } p=0.077 \text { ) } \\
\text { H3ii: Perceived Forex Risk is } \\
\text { negatively related to Hedging } \\
\text { Technique. ( }=0.013 \text { ) } \\
\text { H4b: Perceived Forex Risk is } \\
\text { positively related to } \\
\text { Organizational Training } \\
\text { Resources. }(p=0.000)\end{array}$ & $\begin{array}{l}\text { Perceived Forex Risk plays an } \\
\text { important role in hedging strategy. } \\
\text { The positive relationship between } \\
\text { Perceived Forex Risk and Hedging } \\
\text { Degree is partially mediated by } \\
\text { Organizational Training Resources, } \\
\text { suggesting that when managers } \\
\text { perceive high forex risk, they } \\
\text { mobilise their organizational } \\
\text { training resources in order to } \\
\text { determine the degree of hedging } \\
\text { required. }\end{array}$ \\
\hline
\end{tabular}




\begin{tabular}{|c|c|c|c|}
\hline 3. Forex Exposure & $\begin{array}{l}\text { Support } \\
\text { OK, again, just the size, the amount of the risk, so, you } \\
\text { know, we bought parts and pens, and they were only } \\
4,000 \text { dollars, we've just naturally used our bank account. } \\
\text { We're operating bank accounts in several currencies. We } \\
\text { have a lot of Japanese yen, and USD so we just fill out a } \\
\text { small amount of money. We just use natural hedging. For } \\
\text { a large amount of money, anything that exceeds a million } \\
\text { dollars, then we will look at some formal hedging, } \\
\text { hedging arrangement, that's for the money we pay away. } \\
\text { (Digiso) }\end{array}$ & $\begin{array}{l}\text { H5i: Forex Exposure is } \\
\text { positively related to Hedging } \\
\text { Degree. (NS) } \\
\text { H5ii: Forex Exposure is } \\
\text { negatively related to Hedging } \\
\text { Technique. (NS) } \\
\text { H6c: Forex Exposure is } \\
\text { positively related to Human } \\
\text { Resources. }(\mathrm{p}=0.004)\end{array}$ & $\begin{array}{l}\text { Forex exposure affects hedging } \\
\text { strategy via the mediator human } \\
\text { resources. Forex Exposure does not } \\
\text { have direct impacts on Hedging } \\
\text { Strategy, which suggests a full } \\
\text { mediation effect for each of these } \\
\text { variables. }\end{array}$ \\
\hline 4. Resources & $\begin{array}{l}\text { Support } \\
\text { "It's no way that we will have full time personnel for that. } \\
\text { No way. Not for a small business. If you are a bigger } \\
\text { business you may have someone dedicated to it. But not, } \\
\text { not in my business, it's my opinion. No."(Software) }\end{array}$ & $\begin{array}{l}\text { H'4c: Organizational Training } \\
\text { Resources is positively related } \\
\text { to Human Resources. }(\mathrm{p}=0.012) \\
\text { H7bi: Organizational Training } \\
\text { Resources is positively related } \\
\text { to Hedging Degree. }(\mathrm{p}=0.002) \\
\text { H7cii: Human Resources is } \\
\text { positively related to Hedging } \\
\text { Technique. }(\mathrm{p}=0.033)\end{array}$ & $\begin{array}{l}\text { Human Resources and } \\
\text { Organizational Training Resources } \\
\text { are essential for forex risk } \\
\text { management, thus firms have more } \\
\text { inclination to invest in these } \\
\text { resources to help determine } \\
\text { hedging strategy as the firms } \\
\text { perceived higher forex risk. } \\
\text { Human Resources and } \\
\text { Organizational Training Resources } \\
\text { partly mediate the relationship } \\
\text { between Perceived Forex Risk and } \\
\text { Hedging Strategy. }\end{array}$ \\
\hline
\end{tabular}

NS: Not significant 


\subsection{THEORETICAL CONTRIBUTIONS}

The main research objectives of this study were to develop a framework of forex risk management in SMEs, by looking at hedging strategy. The framework describes how and why exporting SMEs hedge forex risk. As indicated in Chapters 1 and 2, previous studies about hedging forex risk were mainly conducted with large firms, multinational enterprises, and financial institutions. Several studies, like Schiozer \& Saito Schiozer and Saito (2009), and González et al. (2007), compared hedging practices across firm sizes. However, there is a lack of research that specifically investigates hedging of small and medium enterprises. The contributions of this study to theory/literature are exhibited in Table 7-2. 
Table 7-2: Contributions to the Literature on Forex Risk Management

\begin{tabular}{|c|c|c|c|c|}
\hline Research findings & $\begin{array}{l}\text { Supports previous } \\
\text { research findings }\end{array}$ & $\begin{array}{l}\text { Contradicts } \\
\text { previous } \\
\text { research } \\
\text { findings }\end{array}$ & Extends previous knowledge & $\begin{array}{l}\text { Contribution to the } \\
\text { literature on Forex } \\
\text { Risk Management }\end{array}$ \\
\hline $\begin{array}{l}\text { Internationalisation has positive } \\
\text { relationship with forex exposure } \\
\text { and perceived forex risk }\end{array}$ & $\begin{array}{l}\text { Coviello and } \\
\text { McAuley (1999) }\end{array}$ & & $\begin{array}{l}\text { This study provides new insights and } \\
\text { knowledge into firms' internationalisation, } \\
\text { extending conceptualization of } \\
\text { Internationalisation Theory in forex risk } \\
\text { management. Forex risk is relatively } \\
\text { unexplored from the perspective of this } \\
\text { theory. }\end{array}$ & $\begin{array}{l}\text { Internationalisation } \\
\text { Theory perspective was } \\
\text { adopted in forex risk } \\
\text { management of } \\
\text { exporting SMEs. }\end{array}$ \\
\hline $\begin{array}{l}\text { Forex exposure does not directly } \\
\text { impact hedging decision making, } \\
\text { but has indirect impact via human } \\
\text { resources. }\end{array}$ & $\begin{array}{l}\text { Kula (2005) } \\
\text { González, et al. } \\
(2007)\end{array}$ & $\begin{array}{l}\text { Kula (2005) } \\
\text { González, et al. } \\
(2007)\end{array}$ & $\begin{array}{l}\text { Previous studies, e.g., Kula (2005) and } \\
\text { González, et al. (2007) found the } \\
\text { relationships between forex exposure and } \\
\text { hedging strategy; this study demonstrates } \\
\text { that the relationships are indirect, and } \\
\text { indicates the complete mediating effect of } \\
\text { human resources. }\end{array}$ & $\begin{array}{l}\text { Forex exposure may } \\
\text { affect the choice of } \\
\text { hedging techniques, but } \\
\text { the effect is indirect via } \\
\text { human resources in the } \\
\text { context of SMEs. }\end{array}$ \\
\hline $\begin{array}{l}\text { This study adopted a newly- } \\
\text { advanced construct "perceived } \\
\text { forex risk". Perceived forex risk is } \\
\text { a key hedging determinant that } \\
\text { influences hedging strategy and the } \\
\text { inclination to use resources } \\
\text { associated with forex risk } \\
\text { management. }\end{array}$ & Slovic (1987) & & $\begin{array}{l}\text { This study extends the conceptualization of } \\
\text { perceived risk in forex risk management. } \\
\text { Using a new concept "perceived forex } \\
\text { risk", this study provides new insights into } \\
\text { hedging determinants, especially important } \\
\text { to SMEs. }\end{array}$ & $\begin{array}{l}\text { New hedging } \\
\text { determinant, i.e. } \\
\text { perceived forex risk, } \\
\text { which is an important } \\
\text { determinant of hedging } \\
\text { strategy of SMEs. }\end{array}$ \\
\hline
\end{tabular}


Chapter 7 - Discussion and Conclusion

\begin{tabular}{|c|c|c|c|}
\hline $\begin{array}{l}\text { Organizational training resources } \\
\text { and human resources play a } \\
\text { mediating role between perceived } \\
\text { forex risk and hedging strategy } \\
\text { Human resources fully mediate the } \\
\text { relationship between forex } \\
\text { exposure and the use of hedging } \\
\text { techniques }\end{array}$ & Barney (1991) & $\begin{array}{l}\text { This study also advanced two additional } \\
\text { hedging determinants: organizational } \\
\text { training resources and human resources, } \\
\text { extending the conceptualization of RBV } \\
\text { perspective in forex risk management. }\end{array}$ & $\begin{array}{l}\text { RBV perspective on } \\
\text { forex risk management } \\
\text { by exporting SMEs. }\end{array}$ \\
\hline
\end{tabular}


This study enriches the literature on forex risk management, adding an empirical research on SMEs' hedging behaviours. A large number of rationales to hedge (for example, González et al., 2007; Joseph, 2000; Pramborg, 2005; Smith \& Stulz, 1985) have been examined in the extant hedging literature. However, SMEs' hedging decisions are conspicuously neglected in the current literature on forex risk management. Although whether a firm should hedge or not is still controversial, this study primarily assumes that firms hedge in practice due to market imperfections and deviations from parity conditions (Bartram, et al., 2005). In the event of this happening, this study provides a specific framework of hedging by SMEs, which illustrates a distinct way that SMEs make hedging strategy. This is called the Model of Forex Risk Management by SMEs, or referred to as the Model of Forex Risk Management, and shown in Figure 6-3.

The Model of Forex Risk Management exhibits the relationships between seven constructs, describing how exporting SMEs hedge as a way of managing forex risk. Degree of Internationalisation is a primary influence on hedging. Forex exposure is one of the key influences on hedging; however, the exposure does not directly affect hedging strategy. The most important influence on a firm's choice of hedging techniques is the firm's perceived forex risk. Perceived forex risk has significant impacts on both hedging degree, referred to as the extent to which hedging techniques are used, and hedging technique, pertaining to the choice of external versus internal hedging techniques used. Perceived forex risk also increases the inclination for organizational training resources and human resources associated with forex risk management to be committed or utilized. To this end, Resources have a mediating effect on the relationship between perceived forex risk and hedging strategy.

Notably, the objective determinant 'forex exposure' had no direct impact on hedging strategy. The share of revenues denominated in foreign currencies was appointed as a proxy for this objective determinant. A higher share of revenues denominated in foreign currencies suggested more need of human resources, i.e. skilled manager and employees, to implement hedging techniques. As firms had more skilled people in forex risk management, the firm displayed higher tendency to use external hedging techniques. 
On the other hand, a subjective determinant, i.e. perceived forex risk, had a strong impact on hedging strategy, both directly and via resources as mediators. Perceived forex risk was featured by three items associated with managerial perception of how considerably forex fluctuations affect (1) export price, (2) production volume, and (3) domestic input. This determinant exhibited subjective perception of forex risk, and thus directly affected organizational perception of training regarding forex risk management. Higher perception on forex risk improved organizational perception of forex training, that is, managers asked employees about forex training to choose practical programmes aiming to help employees overcome obstacles associated with forex risk management. Higher organizational training resources increased the degree of hedging, as firms recognise the importance of hedging programmes and attendance at training events for forex risk management. At the same time, a higher perception of training for forex risk management increased human resources and the use of external hedging techniques. On the other hand, perceived forex risk also directly affected both hedging degree and the use of hedging techniques. Empirical data showed the above mentioned relationships among perceived forex risk, organizational training resources, human resources, hedging degree and the use of hedging techniques. These findings show that perceived forex risk is an essential hedging determinant.

While human resources were associated with the use of hedging techniques, organizational training resources were relevant to the degree of hedging. This finding shows that managerial experience in forex risk management, i.e. human resources, enables firms to deploy a variety of hedging techniques, especially external ones; however, more experience does not encourage the firms to hedge more, as how much to hedge forex risk was subject to firms' perception of forex risk and the importance of hedging training. Higher organizational perception of training for forex risk management, i.e. organizational training resources, on the one hand, increased the human resources and the use of external hedging techniques. On the other hand, more organizational resources increase the degree of hedging. As managers and employees found that it was time to hedge forex risk and to attend trainings for forex risk management, they hedged more. 
This study found that firms' internationalisation sets environmental conditions for forex risk management. When a firm's export sales ratio is high, the firm may incur more forex exposure and perceive higher forex risk. The firm also has more opportunities and incentives to adopt a variety of hedging techniques, as the firm becomes more experienced.

In addition, this study expresses a practical view on hedging behaviours of exporting SMEs. Modern finance is composed of two pillars, i.e. efficient market and diversification. Market efficiency is likely to curb firms' exposures to financial market risks, and diversification eliminates the need for financial hedging (Stulz, 1996). Due to market efficiency, freely accessible information is incorporated in prices with sufficient speed and accuracy, yet a number of corporate executives are convinced of their own ability to predict future interest rates, commodity prices and exchange rates (Stulz, 1996). Fitting well with this notion, findings from both qualitative and quantitative components of this thesis showed that firms do hedge forex risk in practice. Since forex risk is not regarded as the top priority by firms in this study, most likely because of their small size, they tend to adopt internal hedging techniques. As high forex risk is perceived, these firms tend to invest more resources in forex risk management, and thus they hedge more and extend the use of external hedging techniques.

In addition, this study extends the use of various theoretical views in the new setting of forex risk management. First, on the resource based view, this study explores how exporting SMEs allocate their own resources for managing forex uncertainty. The literature on RBV regards resources and capabilities as predictors of superior long term performance. Following this notion, this study assumes that firms need resources for their hedging strategies. Qualitative exploratory interviews support the view that firms need training and human resources to manage forex risk. Empirical data from webbased surveys in Australia and New Zealand showed the mediating effect of these resources on the relationships (1) between forex exposure and the use of hedging techniques, (2) between perceived forex risk and the use of hedging techniques, and (3) between perceived forex risk and hedging degree. To this end, this study enriches the current RBV by providing evidence that resources and capabilities can be regarded as key infuences on hedging strategy. 
As previously discussed, firms' internationalisation sets the environmental conditions for forex risk management. This study utilises the I-Model suggested by Cavusgil (1980) to investigate differences of forex exposure and perceived forex risk in relation to the firms' stages of internationalisation. Empirical data showed that internationalisation is a primary determinant of hedging strategy of exporting SMEs.

This study also aims to contribute to academic literature through a sequential research design, examining resource allocation in a new setting of forex risk management. As the literature on RBV was limited in the context of forex risk management, it was justified to use an initial qualitative approach to support the conceptualization and theoretical development. Also, the use of structural equation modeling as a quantitative technique attempted to better capture the structural relationships among constructs. In sum, the sequential research design in this study, along with the use of structural equation modeling provides a contribution to the academic literature in terms of methodology. Previous studies on forex risk management have usually adopted purely quantitative methods with simple regressions. By using structural equation modeling, this study was able to indicate not only relationships between individual determinants and hedging strategy, but also demonstrate the relationships among determinants. Hence, by using this technique, this study provides a better understanding of hedging practices.

In addition, this study used perceptual, multi-item measurements for the latent constructs. Previous studies in forex risk management have been largely based on objective data, e.g., financial ratios. The use of multi-item measures aimed to better reflect the latent constructs. Also managerial perceptions are likely to be more suitable for defining hedging strategy, especially in the context of SMEs, as discussed earlier in this thesis. This thesis favoured the use of latent constructs, for example, perceived forex risk, and resources. In light of the findings, this study was successful in advancing these constructs in a new domain of forex risk management. Perceived forex risk is regarded as a key infuence on hedging strategy. Similarly, organizational training and human resources are operationalized in the new domain of forex risk management.

To conclude, a key theoretical contribution has been made in this study by developing and testing an integrated hedging model for exporting SMEs. Within this model, specific theoretical contributions include: 
- Extending the theoretical domains of internationalisation and the RBV to incorporate their roles in forex risk management

- Highlighting the primary role of DOI in forex risk management

- Advancing latent constructs relevant in forex risk management in SMEs, e.g., perceived forex risk; also, highlighting the key role of forex risk perception in determining hedging strategies by SMEs

- Highlighting the mediating role of resources associated with forex risk management; also, identifying measures of the Resources construct relevant in the context of SMEs' forex risk management;

- Indicating the indirect influence of forex exposure on hedging degree via human resources

- Defining and investigating "hedging strategy" within a setting typical of forex risk management, which includes (1) hedging degree and (2) the use of internal versus external hedging techniques.

Contextually, the study makes a contribution by extending the existing literature on forex risk management to the context of SMEs. Little has been published to date on forex risk management and hedging strategy in the SME sector. For example, a recent study of Naylor and Greenwood (2008) examined hedging practices and compared these to firm characteristics, via a comparisons of New Zealand firms with US, Asian, and European firms. Naylor and Greenwood (2008) investigated hedging practice of firms in New Zealand, as a small country; on the other hand, their study was not specific about SMEs.

The study also makes a methodological contribution by applying a sequential research design, which included an exploratory qualitative approach, followed by the main quantitative study, which utilised structural equation modelling to define the relationships between hedging determinants. Prior research, predominantly with large firms, has tended to investigate isolated relationships between determinants of hedging, and not consider the complexities of their relationships. 


\subsection{IMPLICATIONS FOR PRACTICE}

The thesis also makes a contribution to practice by presenting a practical perspective on hedging, relevant for SMEs; this highlights the major determinants of forex hedging strategy that SME managers can consider.

Exporting SMEs need to be aware of the importance of forex exposure. Research findings from the study showed that forex exposure matters to exporting firms which are more involved in international markets. According to the managers interviewed, forex rate changes might impact firms' performance, especially for large orders. Transaction exposure is the most usual impact of forex fluctuations. As exporting firms attempt to increase their export ratio, transaction exposure becomes an essential concern for the firms. As a result, firms should be on the alert for forex fluctuations. Forex rate changes may bring unexpected profits, but also cause unexpected loss. As forex gains are not what exporting firms expect, it is not worthwhile to take a loss caused by forex uncertainties.

In order to manage effectively forex risk, exporting SMEs need to allocate enough resources associated with forex risk management. Resources play an important role in forex risk management for SMEs in this study. Among resources, those relating to human resources, such as training, skills and experiences regarding forex risk management are essential for developing and implementing a hedging strategy. The results also suggest that exporting firms should consider their organizational training and investment in human resources associated with forex risk management. To this end, firms need to increase managerial concerns to employees' desires for forex training, including encouraging employees and building their skills. It will be beneficial for firms to develop an organizational culture in which employees readily perceive learning benefits associated with forex management, which can help overcome obstacles. Practical application of training can increase the success of training programmes. As a result of good training programmes, exporting firms may become skilled hedgers.

\section{Exporting SMEs need to acquire sufficient understanding of forex risk management} while increasing exports. Qualitative interviews and survey responses showed that not many exporting firms have a proper understanding of forex risk management and 
hedging techniques. For example, they might not recognise natural hedging techniques as serious ways to manage forex risk, while thinking that using currency derivatives is too complicated for them. If these firms understand better the use of internal hedging, they may have an effective hedging strategy, in spite of not knowing about the use of external hedging techniques. Of course, it will be much better if the firms can also use external hedging techniques, when the need arises. It is also suggested that business managers read books relating to forex risk management, for example the books of Kenyon (1991) and Oxelheim (2012). Business managers need to seek the whole range of issues concerning currency risk management for the non-financial specialist. The books provide the business managers with a vital tool to understand the relationship between currency issues and commercial management. Business managers need to find a clear and accessible insight into the financial markets in which currencies are traded. The books also explain the management principles and classification of risks and link them with the organizations and its control.

Overall, it is very necessary for exporting SMEs to perceive clearly forex risk. Finding showed that perceived forex risk is the key hedging determinant, so it is important for managers to understand forex exposure well. Not only are managers required to understand forex risk in general, but they are also required to realize how forex fluctuations impact their business. Like perceived risk in other domains, such as biology (Dowling \& Staelin, 1994), tourism (Fausti \& Gillespie, 2006) and business (Chang \& Tseng, 2013; Cox \& Rich, 1964; Crespo, del Bosque, \& de los Salmones Sanchez, 2009; Hemsworth et al., 2013; Kaplan et al., 1974; Mitchell \& Harris, 2005; Sweeney et al., 1999), perceived forex risk is a function of information, knowledge, values, and perception (in this case, of forex uncertainties and exposure). Hence, managerial knowledge about forex risk management is essential for forex risk to be perceived and act as a hedging determinant.

Practical advice for exporting SMEs is outlined below:

- “Watch out for forex risk!" As earlier mentioned, although forex risk was not considered as a top priority by firms in this study, exporting firms should pay more attention to this risk, since forex risk can be a serious matter due to unexpected fluctuations of forex rates. 
- "Work out the best training plan, and become skilled hedgers". This emphasizes firms' knowledge about forex risk and ways to manage forex risk, i.e. both internal and external hedging techniques. Although forex risk is not the top of the game, and not always hedged, firms should become skilled hedgers to know when to hedge and which techniques to use.

- "Be aware of forex risk". In general, forex exposure matters to exporting firms, so managers should be aware of forex uncertainty, exposure, hedging techniques and management skills.

\subsection{IMPLICATIONS FOR POLICY}

Governmental support in terms of forex risk management is essential for exporting SMEs. Empirical results from the study demonstrate that governmental support presented an important mechanism for exporting firms to increase their inclination to invest in human resources associated with forex risk management. Exporting SMEs are seen to lack resources in general, and this study also highlighted the firms' scarcity of resources associated with forex risk management, in particular. On account of this, governmental support is helpful for the firms, especially new exporting SMEs. Particularly in developing economies, governmental support is essential for exporting SMEs, due to poor socio-economic conditions compared to those of developed countries. Support can be provided through banking systems as businesses mostly rely on banking forex services.

\section{Clear and well-communicated policies relating to foreign exchange are fundamental}

to promote exports. Empirical results also indicate that exporting SMEs need policies to develop hedging activities. For example, it is crucial to have clear policies relating to the supply of banking forex services. The policies provide orientation for banking operations, ensuring efficient and qualified services. Other policies, such as monetary policy, should be considered in ways that can benefit exporting SMEs, due to the important contributions of these firms in general, and their exports in particular, to most countries' economies. Overall, policies must be clear and communicated clearly to firms. 
It is crucial to help exporting SMEs gain widespread perception on forex risk. The study sheds new light on national policies and approaches for increasing export earnings from the SME sector. Given the substantial impact of perceived forex risk on the allocation of resources associated with forex risk management, the use of hedging techniques and hedging degree, perceived forex risk plays a crucial role in forex risk performance. In order to increase a country's export, government or the banking industry should build awareness and knowledge of forex risk among SMEs' mangers/owners. For example, training programmes on forex risk management should be included in international trade promotion.

\subsection{LIMITATIONS}

Like all empirical studies, this thesis has several limitations. Qualitative exploratory interviews could provide some longitudinal data about forex risk management by exporting SMEs. However, both the exploratory qualitative and the quantitative phase of this study were cross sectional in nature. Although the qualitative gathered some historical information, the quantitative study demonstrates merely a snapshot of forex risk management at a point in time. A longitudinal research design can provide additional and rich insights into the complexities and dynamics of hedging decisions by these firms. In terms of internationalisation, it would be interesting to investigate differences across different stages of internationalisation that extend beyond the measures used in this study.

In addition, this study adopted perceptual measurement, which is said to have some limitations in terms of generalizability, reliability and source of variation (Boyd et al., 1993). Findings from this study are limited by the variables used in the measure of key constructs. Perceptual scales of measurement may lack reliability and validity, although the study uses qualitative data from in-depth interviews to ensure the content validity, as well as applying EFA and CFA to mitigate erroneous empirical results. Earlier sections of the thesis have discussed the advantages and disadvantages of using perceptual measures in detail.

Further, some SEM scholars suggest that the use of single item measures, i.e. DOI (export intensity), FXE (Forex Exposure), HGD (Hedging Degree) and HGT (Hedging 
Technique), may be technically problematic e.g. Hair et al. (2010). However, a single item measure would provide researchers with a simple, short, and reliable measure, with both face and construct validity, for example a single item measure of social identification (Reysen, Katzarska - Miller, Nesbit, \& Pierce, 2013). Although the above mentioned single item measures actually presented the theoretical constructs: DOI, FXE, HGD and HGT, further research is recommended to develop these constructs further and apply more robust measures to measure the relationships identified in the conceptual model.

Another limitation of the study relates to hedging determinants in this study, which may not be exhaustive and absolute. An extensive examination of the current literature on forex risk management in Chapter 2 and exploratory interviews in Chapter 3 provided the rationale for incorporating new constructs for this study. In order to focus on investigating managerial characteristics of firms, this study excludes many financial indicators. Although these financial indicators, e.g., tax benefits were proved to be unimportant to interviewed SMEs, removal of many financial variables may be an over simplification. Since the study failed to find a valid measure of financial resources and that the measures of physical resources were also not well validated, this study is unable to provide insight into the role of financial and physical resources associated with forex risk management.

Moreover, geographic location of the sample firms is limited to the two largest economies in the Oceania region, Australia and New Zealand. These two isolated countries are relatively small in terms of their population. In particular, New Zealand is said to be a nation of SMEs. While the New Zealand Ministry of Economic Development considers SMEs with an employment threshold of 19 or fewer employess (MED, July 2010), this study defined SMEs as those which have no more than 250 employees in keeping with the OECD's (2007a, p. 770) definition, and consistent with other studies which widely use this definition. Although this study's definition of SMEs was used to identify the survey respondents, applications of this study's findings may not be totally correct in geographic contexts that differ in size and proximity from New Zealand and Australia, e.g., USA or Europe. 


\subsection{FURTHER RESEARCH}

As outlined in Chapters 1 and 2, research on hedging by SMEs is still not fully developed. Therefore, a number of open research questions and much potential for future research are found.

One worthwhile future research question relates to the efficiency of hedging by SMEs. Findings of this study showed that forex exposure matters to exporting SMEs, and thus these SMEs do hedge. External hedging techniques become more favourable as firms perceive more forex risk, and are inclined to invest more resources in forex risk management. However, whether the use of hedging techniques is efficient at managing forex risk by SMEs is not fully studied. In addition, it is questionable as to whether the use of more external hedging techniques brings more benefits than drawbacks for SMEs.

In addition, the investigation of hedging strategy from longitudinal data is a promising area for future research. As outlined earlier, the use of longitudinal data may provide a better understanding of the changes in forex exposure, perceived forex risk, allocation of resources associated with forex risk management and hedging strategy over time.

As already noted, this study failed to confirm the role of financial resources associated with forex risk management. Further studies should be undertaken to provide more insight into this type of resource. Extant literature and exploratory analysis both suggest that financial resources play an important role in forex risk management, although this was not evident in the quantitative part of the study. Hence, a thorough study about financial resources may result in a modification of this study's hedging model for SMEs, describing more clearly SMEs' hedging behaviours over time.

Another potential future research area relates to investigating SMEs in different contexts. Given that this study examines hedging in exporting SMEs, future studies may extend the sample to on-selling SMEs that export products which have been purchased to a second buyer. In addition, replication of this study in different countries and crosscountry comparisons may provide a useful means to advance the generalizability of the findings. For example, empirical data in both developing and developed countries may 
provide comparative results about hedging decisions across different institutional environments.

Further research on SMEs' forex risk management could be conducted from the perspective of the recent decision making literature. On the one hand, this thesis sheds new light on SMEs' hedging practices by taking into account managerial perceptions of forex risk. On the other hand, perceived forex risk does not fully take into account the characteristics of risk managers, e.g. traits, abilities, knowledge corridors, networks etc., and their impact on decision making relating to forex risk management. The literature on causation and effectuation implies that decision makers take account of several factors, e.g. considering affordable losses, taking advantage of relationships of managers, exploiting contingencies as they arise and trying to act on controllable aspects of an unpredictable future (Sarasvathy, 2001). Therefore, consideration of decision making process from the perspective of the decision making literature, i.e. the process of causation and effectuation (Andersson, 2011; Sarasvathy, 2001), would provide a better understanding of decision making process (Andersson, 2011; Fisher, 2012) in terms of forex risk management.

\subsection{CONCLUSION}

This study contributes to the relatively small literature on forex risk management by exporting SMEs. In particular, it provides insights by applying perspectives that are relatively novel in this area, albeit from established theoretical streams - namely, the resource-based view, and internationalisation theory. Drawing on these theoretical lenses, the study examines the determinants of forex risk management by exporting SMEs.

As outlined in Chapters 1 and 2, SMEs have been increasingly internationalized since the 1980s (OECD, 1997; UNCTAD, 1993), becoming more active in international markets, and making increasing contributions to economic growth and prosperity (Reynolds, 1997). In addition, SMEs incur higher risk when increasing their foreign market commitment over time; and gaining experience and enhancing market knowledge lead them to further commitment in more distant markets (Coviello \& McAuley, 1999, p. 226). This study aimed to address the need for more research on 
forex management of SMEs, given the scarcity of studies in this area (Kula, 2005). The study adopted a sequential research design suggested by Driscoll et al. (2007). The study attempted to develop a framework of hedging by SMEs.

Key findings of this study are summarized as follows. First, internationalisation is a primary determinant of hedging activities. Degree of internationalisation has positive impacts on forex exposure and perceived forex risk. Second, perceived forex risk is a major determinant of hedging strategy. Third, forex exposure affects the use of hedging techniques, but this effect is completely mediated by human resources. Fourth, affected by perceived forex risk, resources, e.g., organizational training resources and human resources, have mediating effects on the relationships between perceived forex risk and hedging strategy. Overall, SMEs favour internal hedging techniques. When firms export more, they incur more forex exposure and perceive more forex risk, mobilizing and allocating more training and human resources to hedging, and then extending their use of external hedging techniques.

From these findings, a number of conclusions and implications have been drawn. One of the major implications is that perceived forex risk is an important determinant of hedging strategy. When forex exposure is not considered as a top priority, exporting SMEs tend to disregard other financial facets of hedging, for example, tax benefits and under-investment problems. These firms are more concerned about the size of exposure, and then finding solutions for hedging, for example, by mobilizing hedging resources and selecting techniques.

Overall, in considering the results of this study in the light of the current literature, the findings suggests that SMEs have a distinct approach to managing forex risk, and that different determinants are at play, when compared with large firms. A major reason for this is likely to be the relative lack of resources in SMEs. For example, SMEs lack human resources for managing forex risk. Owners and/or financial controllers, who are concurrently managing forex risk, are usually using their experiences and common sense to determine their hedging strategies. Thus managerial perception of forex risk is the key hedging determinant. 
International business is growing due to a decline in trade barriers, increasing numbers of free trade agreements, and technological advances in communications and logistics. SMEs have become more active in international markets, making greater contributions to economic growth and prosperity (Reynolds, 1997). As a result, the field of SMEs' forex risk management is a dynamic and current topic. This should identify an exciting research area for future research, and one which would also be of value to policy makers and managers as SMEs continue to play such critical roles in their economies. 


\section{REFERENCES}

Aabo, T., Høg, E., \& Kuhn, J. (2010). Integrated foreign exchange risk management: The role of import in medium-sized manufacturing firms. Journal of Multinational Financial Management, 20(4-5), 235-250.

Ackert, L. F., \& Deaves, R. (2010). Behavioral Finance: Psychology, Decision-Making and Markets. Mason: South-Western Cengage Learning.

Adler, M., \& Dumas, B. (1984). Exposure to Currency Risk: Definition and Measurement. Financial Management, 13(2), 41-50.

Administration, I. T. (2008). Trade Finace Guide, 2008 Edition. Washington, DC 20230.

Ahlstrom, D., \& Bruton, G. D. (2001). Learning from successful local private firms in China: Establishing legitimacy. The Academy of Management Executive, 15(4), 72-83.

Ahmad, K., \& Mohamed Zabri, S. (2013). The relationship between the use of management accounting practices and the performance of Malaysian mediumsized enterprises.

Ahmed, E.-M., \& Omneya, A.-S. (2007). Exchange rate exposure: Do size and foreign operations matter? Managerial Finance, 33(9), 26. doi: 10.1108/03074350710776262

Albuquerque, R. (2007). Optimal currency hedging. Global Finance Journal, 18(1), 1633.

Allayannis, G., Brown, G. W., \& Klapper, L. F. (2001). Exchange Rate Risk Management: Evidence from East Asia. World Bank Policy Research Working Paper(No. 2606).

Allayannis, G., \& Ofek, E. (2001). Exchange rate exposure, hedging, and the use of foreign currency derivatives. Journal of International Money and Finance, 20(2), 273-296.

Altman, E. I., \& Sabato, G. (2007). Modelling Credit Risk for SMEs: Evidence from the U.S. Market. Abacus, 43(3), 332-357. doi: 10.1111/j.1467-6281.2007.00234.x

Amit, R., \& Schoemaker, P. J. H. (1993). Strategic Assets and Organizational Rent. Strategic Management Journal, 14(1), 33-46.

Andersen, O. (1993). On the Internationalization Process of Firms: A Critical Analysis. Journal of International Business Studies, 24(2), 209-231.

Anderson, C. R., \& Paine, F. T. (1975). Managerial perceptions and strategic behavior. Academy of Management Journal, 18(4), 811-823.

Andersson, S. (2011). International entrepreneurship, born globals and the theory of effectuation. Journal of Small Business and Enterprise Development, 18(3), 627643.

Arkes, H. R., Herren, L. T., \& Isen, A. M. (1988). The role of potential loss in the influence of affect on risk-taking behavior. Organizational Behavior and Human 
Decision Processes, 42(2), 181-193. doi: http://dx.doi.org/10.1016/0749$\underline{\text { 5978(88)90011-8 }}$

Armstrong, C. E., \& Shimizu, K. (2007). A Review of Approaches to Empirical Research on the Resource-Based View of the Firm†. Journal of Management, 33(6), 959-986. doi: 10.1177/0149206307307645

Asaolu, T. O. (2011). Exchange Rate Risk Exposure of Nigerian Listed Firms: An Empirical Examination. International Business Research, 4(2), 219-225.

Asseery, A., \& Peel, D. A. (1991). The effects of exchange rate volatility on exports: some new estimates. Economics Letters, 37(2), 173-177.

Auld, G. W., Diker, A., Bock, M. A., Boushey, C. J., Bruhn, C. M., Cluskey, M., . . Zaghloul, S. (2007). Development of a Decision Tree to Determine Appropriateness of NVivo in Analyzing Qualitative Data Sets. Journal of Nutrition Education and Behavior, 39(1), 37-47.

Bantel, K. A., \& Jackson, S. E. (1989). Top management and innovations in banking: does the composition of the top team make a difference? Strategic Management Journal, 10(S1), 107-124.

Barkema, H. G., \& Drogendijk, R. (2007). Internationalising in small, incremental or larger steps? Journal of International Business Studies, 38(7), 1132-1148.

Barney, J. B. (1986). Strategic factor markets: Expectations, luck, and business strategy. Management Science, 32(10), 1231-1241.

Barney, J. B. (1991). Firm Resources and Sustained Competitive Advantage. Journal of Management, 17(1), 99-120.

Barney, J. B., Ketchen, D. J., \& Wright, M. (2011). The Future of Resource-Based Theory. Journal of Management, 37(5), 1299-1315. doi: $10.1177 / 0149206310391805$

Baron, R. M., \& Kenny, D. A. (1986). The moderator-mediator variable distinction in social psychological research: Conceptual, strategic, and statistical considerations. Journal of Personality and Social Psychology, 51(6), 1173-1182. doi: 10.1037/0022-3514.51.6.1173

Bartov, E., \& Bodnar, G. M. (1994). Firm valuation, earnings expectations, and the exchange - rate exposure effect. The Journal of Finance, 49(5), 1755-1785.

Bartov, E., Bodnar, G. M., \& Kaul, A. (1996). Exchange rate variability and the riskiness of US multinational firms: evidence from the breakdown of the Bretton Woods system. Journal of Financial Economics, 42(1), 105-132.

Bartram, S. M., Brown, G. W., \& Minton, B. A. (2010). Resolving the exposure puzzle: The many facets of exchange rate exposure. Journal of Financial Economics, 95(2), 148-173.

Bartram, S. M., Dufey, G., \& Frenkel, M. R. (2005). A primer on the exposure of nonfinancial corporations to foreign exchange rate risk. Journal of Multinational Financial Management, 15(4-5), 394-413.

Basu, A. (1998). The role of institutional support in Asian entrepreneurial expansion in Britain. Journal of Small Business and Enterprise Development, 5(4), 317-326. 
Beatty, R. P., \& Zajac, E. J. (1994). Managerial Incentives, Monitoring, and Risk Bearing: A Study of Executive Compensation, Ownership, and Board Structure in Initial Public Offerings. Administrative Science Quarterly, 39(2).

Beck, T. (2007). Financing constraints of SMEs in developing countries: Evidence, determinants and solutions: Tilburg University.

Beck, T., \& Demirguc-Kunt, A. (2006). Small and medium-size enterprises: Access to finance as a growth constraint. Journal of Banking \& Finance, 30(11), 29312943.

Bell, J., McNaughton, R., \& Young, S. (2001). 'Born-again global'firms: An extension to the 'born global'phenomenon. Journal of International Management, 7(3), 173-189.

Bell, J., McNaughton, R., Young, S., \& Crick, D. (2003). Towards an integrative model of small firm internationalisation. Journal of International Entrepreneurship, 1(4), 339-362.

Berkman, H., Bradbury, M. E., \& Magan, S. (1997). An International Comparison of Derivatives Use. Financial Management, 26(4), 69-73.

Bernard, H. R. (2011). Research methods in anthropology: Qualitative and quantitative approaches: Altamira press.

Berra, L., Piatti, L., \& Vitali, G. (1995). The internationalization process in the small and medium sized firms: A case study on the Italian clothing industry. Small Business Economics, 7(1), 67-75. doi: 10.1007/bf01074317

Bilkey, W. J., \& Tesar, G. (1977). The Export Behavior of Smaller-Sized Wisconsin Manufacturing Firms. Journal of International Business Studies, 8(1), 93-98.

Block, S. B., \& Gallagher, T. J. (1986). The use of interest rate futures and options by corporate financial managers. Financial Management, 73-78.

Boatright, J. R. (2011). Risk management and the responsible corporation: How sweeping the invisible hand? Business and Society Review, 116(1), 145-170.

Bodnar, G. M., \& Gebhardt, G. (1999). Derivatives Usage in Risk Management by US and German Non-Financial Firms: A Comparative Survey. Journal of International Financial Management \& Accounting, 10(3), 153-187. doi: 10.1111/1467-646x.00049

Bodnar, G. M., \& Marston, R. C. (2000). A Simple Model of Foreign Exchange Exposure. from http://finance.wharton.upenn.edu/weiss/wpapers/00-3.pdf

Bodnár, K. (2007). Survey evidence on the exchange rate exposure of Hungarian SMEs. Emerging Markets: Any Lessons for Southeastern Europe? Bank Magyar Nemzeti, 205.

Bonaccorsi, A. (1992). On the relationship between firm size and export intensity. Journal of International Business Studies, 605-635.

Boomsma, A. (1982). The robustness of LISREL against small sample sizes in factor analysis models. Systems under indirect observation: Causality, structure, prediction, 1, 149-173. 
Booth, J. R., Smith, R. L., \& Stolz, R. W. (1984). Use of interest rate futures by financial institutions. Journal of Bank Research, 15(1), 15-20.

Borden, N. H. (1964). The concept of the marketing mix. Journal of advertising research, 4(2), 2-7.

Børsum, Ø. G., \& Ødegaard, B. A. (2005). Currency hedging in Norwegian nonfinancial firms. In S. Gjedrem (Ed.), Economic Bulletin (Vol. L X X V I). Oslo: Norges Bank.

Bouncken, R. B. (2004). Cultural diversity in entrepreneurial teams: findings of new ventures in Germany. Creativity and Innovation Management, 13(4), 240-253.

Boyabatli, O., \& Toktay, B. (2004). Operational hedging: A review with discussion. . Working Paper, INSEAD.

Boyd, B. K., Dess, G. G., \& Rasheed, A. M. A. (1993). Divergence between Archival and Perceptual Measures of the Environment: Causes and Consequences. The Academy of Management Review, 18(2), 204-226.

Bozarth, C., \& Edwards, S. (1997). The impact of market requirements focus and manufacturing characteristics focus on plant performance. Journal of Operations Management, 15(3), 161-180.

Branson, W. H., \& Henderson, D. (1984). The specification and influence of asset markets: National Bureau of Economic Research Cambridge, Mass., USA.

Bredin, D., Fountas, S., \& Murphy, E. (2003). An Empirical Analysis of Short-run and Long-run Irish Export Functions: does exchange rate volatility matter? International Review of Applied Economics, 17(2), 193-208.

Broll, U., Mallick, R., \& Wong, K. P. (2001). International trade and hedging in economies in transition. Economic Systems, 25(2), 149-159.

Broll, U., \& Wahl, J. E. (1997). Export flexibility and hedging. Bulletin of Economic Research, 49(3), 205.

Brookes, A., Hargreaves, D., Lucas, C., \& White, B. (2000). Can hedging insulate firms from exchange rate risk. Reserve Bank of New Zealand Bulletin, 63.

Brown, G. W. (2001). Managing foreign exchange risk with derivatives. Journal of Financial Economics, 60(2-3), 401-448.

Buckley, P. J. (1989). Foreign direct investment by small and medium sized enterprises: The theoretical background. Small Business Economics, 1(2), 89-100. doi: $10.1007 / \mathrm{bf} 00398627$

Byrne, B. M. (2013). Structural equation modeling with AMOS: Basic concepts, applications, and programming: Routledge.

Carlson, D. S., \& Kacmar, K. M. (2000). Work-family conflict in the organization: do life role values make a difference? Journal of Management, 26(5), 1031-1054.

Castanias, R. P., \& Helfat, C. E. (1991). Managerial resources and rents. Journal of Management, 17(1), 155-171.

Cavana, R. Y., Delahaye, B. L., \& Sekaran, U. (2001). Applied business research. Qualitative and Quantitative Methods. 
Cavusgil, S. T. (1980). On the internationalization process of firms. European Research, 8(6), 273-281.

Cavusgil, S. T. (1984). Differences among exporting firms based on their degree of internationalization. Journal of Business Research, 12(2), 195-208.

Cavusgil, S. T., \& Knight, G. (2009). Born global firms: A new international enterprise: Business Expert Press.

Chan-Lau, J. A. (2005). Hedging Foreign Exchange Risk in Chile: Markets and Instruments. International Monetary Fund, IMF Working Paper(WP/05/37).

Chang, E.-C., \& Tseng, Y.-F. (2013). Research note: E-store image, perceived value and perceived risk. Journal of Business Research, 66(7), 864-870. doi: http://dx.doi.org/10.1016/j.jbusres.2011.06.012

Chen, M.-J., Farh, J.-L., \& MacMillan, I. C. (1993). An Exploration of the Expertness of outside Informants. The Academy of Management Journal, 36(6), 1614-1632.

Chin, W. W. (1998). The partial least squares approach to structural equation modeling. Modern methods for business research, 295(2), 295-336.

Chow, E. H., Lee, W. Y., \& Solt, M. E. (1997). The Exchange-Rate Risk Exposure of Asset Returns. The Journal of Business, 70(1), 105-123.

Churchill, J. G. A. (1979). A paradigm for developing better measures of marketing constructs. Journal of Marketing Research, 64-73.

Ciubotariu, M. S. (2013). The role of small and medium enterprises in the modern economy and the importance of IFRS application for SMEs. The USV Annals of Economics and Public Administration, $13(1$ (17)), 201-210.

Collins, E., Dickie, C., \& Weber, P. (2009). A New Zealand and Australian overview of ethics and sustainability in SMEs. African Journal of Business Ethics, 4(2), 4855 .

Coltman, T., Devinney, T., \& Midgley, D. (2011). Customer relationship management and firm performance. Journal of Information Technology, 26, 205-219.

Conner, K. R. (1991). A historical comparison of resource-based theory and five schools of thought within industrial organization economics: do we have a new theory of the firm? Journal of Management, 17(1), 121-154.

Coombs, C. H., \& Lehner, P. E. (1981). Evaluation of two alternative models for a theory of risk: I. Are moments of distributions useful in assessing risk? Journal of Experimental Psychology: Human Perception and Performance, 7(5), 1110.

Cooper, A. C., \& Schendel, D. E. (1971). Strategy Determination in Manufacturing Firms: Concepts and Research Findings. Paper presented at the Proc. Amer. Marketing Assoc., Fall Conference, Minneapolis.

Couper, M. P. (2000). Review: Web surveys: A review of issues and approaches. Public opinion quarterly, 464-494.

Coviello, N. E., \& Martin, K. A. M. (1999). Internationalization of Service SMEs: An Integrated Perspective from the Engineering Consulting Sector. Journal of International Marketing, 7(4), 42-66. 
Coviello, N. E., \& McAuley, A. (1999). Internationalisation and the smaller firm: A review of contemporary empirical research. Business And Economics-Management, 39(3), 223-256.

Coviello, N. E., \& Munro, H. (1997). Network relationships and the internationalisation process of small software firms. International Business Review, 6(4), 361-386.

Coviello, N. E., \& Munro, H. J. (1995). Growing the entrepreneurial firm: networking for international market development. European journal of marketing, 29(7), 4949-61. doi: 10.1108/03090569510095008

Cox, D. F., \& Rich, S. U. (1964). Perceived risk and consumer decision-making: The case of telephone shopping. Journal of Marketing Research, 32-39.

Crespo, A. H., del Bosque, I. R., \& de los Salmones Sanchez, M. G. (2009). The influence of perceived risk on Internet shopping behavior: a multidimensional perspective. Journal of Risk Research, 12(2), 259-277.

Creswell, J. W. (2003). Research design: Qualitative, quantitative, and mixed methods approaches: Sage publications Thousand Oaks, CA.

Culp, C. L., \& Miller, M. H. (1995). Hedging in the Theory of Corporate Fiannce: A reply to our critics. Journal of Applied Corporate Finance, 8(1), 121-128. doi: 10.1111/j.1745-6622.1995.tb00280.x

Cushman, D. O. (1985). Real exchange rate risk, expectations, and the level of direct investment. The Review of Economics and Statistics, 67(2), 297-308.

Cushman, D. O. (1988a). Exchange-Rate Uncertainty and Foreign Direct Investment in the United States. Weltwirtschaftliches Archiv, 124(2), 322-336.

Cushman, D. O. (1988b). U.S. bilateral trade flows and exchange risk during the floating period. Journal of International Economics, 24(3-4), 317-330.

Czinkota, M. R. (1982). Export development strategies. US. promotion policy

. New York: Praeger.

Dall'Alba, G., \& Hasselgren, B. (1996). Reflections on phenomenography: Toward a methodology? : Acta Universitatis Gothoburgensis Gothenburg.

Dalli, D. (1994). The exporting process: the evolution of small and medium sized firms toward internationalization. Advances in International Marketing, 6(8), 85-110.

Dash, M. (2009). Forex Risk Management Strategies for Indian IT Companies. SSRN eLibrary.

Dash, M., Babu, N., Kodagi, M., \& Vivekanand, B. Y. (2008). An Empirical Study of Forex Risk Management Strategies. Indian Journal of Finance, Vol. II, No. 8, December 2008.

Dash, M., \& N.S., A. K. (2009). Exchange Rate Dynamics and Forex Hedging Strategies. SSRN eLibrary.

Davcik, N. S. (2014). The use and misuse of structural equation modeling in management research: A review and critique. Journal of Advances in Management Research, 11(1), 47-81. 
Davies, D., Eckberg, C., \& Marshall, A. (2006). The determinants of Norwegian exporters' foreign exchange risk management. The European Journal of Finance, 12(3), 217-240.

Dekle, R., \& Ryoo, H. H. (2007). Exchange rate fluctuations, financing constraints, hedging, and exports: Evidence from firm level data. Journal of International Financial Markets, Institutions and Money, 17(5), 437-451.

Demerouti, E., \& Bakker, A. B. (2011). The job demands-resources model: challenges for future research. SA Journal of Industrial Psychology, 37(2), 01-09.

Deros, B. M., Yusof, S. r. M., \& Salleh, A. M. (2006). A benchmarking implementation framework for automotive manufacturing SMEs. Benchmarking: An International Journal, 13(4), 396-430.

Devlin, S. J., Dong, H., \& Brown, M. (1993). Selecting a scale for measuring quality. Marketing Research, 5, 12-12.

Dhanani, A. (2003). Foreign exchange risk management: a case in the mining industry. The British Accounting Review, 35(1), 35-63.

Dholakia, R., Johnson, J., Della Bitta, A., \& Dholakia, N. (1993). Decision-making time in organizational buying behavior: An investigation of its antecedents. Journal of the Academy of Marketing Science, 21(4), 281-292. doi: 10.1007/bf02894521

Dickson, P. H., Weaver, K. M., \& Vozikis, G. S. (2013). The Impact of the Institutional Environment on SME Internationalization: An Assessment of the Environmental Assumptions of Emerging Integrated Models of Internationalization. Journal of Applied Business \& Economics, 15(3).

Dierickx, I., \& Cool, K. (1989). Asset stock accumulation and sustainability of competitive advantage. Management Science, 35(12), 1504-1511.

Dietsch, M., \& Petey, J. (2004). Should SME exposures be treated as retail or corporate exposures? A comparative analysis of default probabilities and asset correlations in French and German SMEs. Journal of Banking \& Finance, 28(4), 773-788.

Dillman, D. A. (2000). Mail and internet surveys: The tailored design method (Vol. 2): Wiley New York.

Dixon, R., \& Turner, R. (2007). Electronic vs. conventional surveys. Handbook of research on electronic surveys and measurements, 105-111.

Doidge, C., Griffin, J. M., \& Williamson, R. G. (2002). Does Exchange Rate Exposure Matter? SSRN eLibrary. doi: 10.2139/ssrn.313060

Dominguez, K. M. E., \& Tesar, L. L. (2001). Trade and exposure: National Bureau of Economic Research.

Dominguez, K. M. E., \& Tesar, L. L. (2006). Exchange rate exposure. Journal of International Economics, 68(1), 188-218.

Dominguez, K. M. E., \& Tesar, L. L. (2008). Exchange rate exposure. In S. N. Durlauf \& L. E. Blume (Eds.), The new Palgrave dictionary of economics. Basingstoke: Palgrave Macmillan. 
Dowling, G. R., \& Staelin, R. (1994). A Model of Perceived Risk and Intended RiskHandling Activity. Journal of Consumer Research, 21(1), 119-134.

Doyle, E. (2001). Exchange rate volatility and Irish-UK trade, 1979-1992. Applied Economics, 33(2), 249-265.

Driscoll, D., Appiah-Yeboah, A., Salib, P., \& Rupert, D. J. (2007). Merging Qualitative and Quantitative Data in Mixed Methods Research: How To and Why Not.

Dufey, G., \& Srinivasulu, S. L. (1983). The Case for Corporate Management of Foreign Exchange Risk. Financial Management, 12(4), 54-62.

Eaker, M. R., \& Grant, D. M. (1987). Cross-hedging foreign currency risk. Journal of International Money and Finance, 6(1), 85-105.

Edmondson, A. C., \& McManus, S. E. (2007). METHODOLOGICAL FIT IN MANAGEMENT FIELD RESEARCH. Academy of Management Review, 32(4), 1155-1179.

Eisenhardt, K. M. (1989). Building Theories from Case Study Research. The Academy of Management Review, 14(4), 532-550.

Eisenhardt, K. M. (1991). Better Stories and Better Constructs: The Case for Rigor and Comparative Logic. The Academy of Management Review, 16(3), 620-627. doi: $10.2307 / 258921$

Eisenhardt, K. M., \& Graebner, M. E. (2007). THEORY BUILDING FROM CASES: OPPORTUNITIES AND CHALLENGES. Academy of Management Journal, 50(1), 25-32. doi: 10.5465/amj.2007.24160888

Eisenhardt, K. M., \& Schoonhoven, C. B. (1996). Resource-Based View of Strategic Alliance Formation: Strategic and Social Effects in Entrepreneurial Firms. Organization Science, 7(2), 136-150.

Elangovan, A., \& Xie, J. L. (1999). Effects of perceived power of supervisor on subordinate stress and motivation: The moderating role of subordinate characteristics. Journal of Organizational Behavior, 20(3), 359-373.

Elliott, C. M., \& Vaughan, E. J. (1972). Fundamentals of risk and insurance (Vol. 5): Wiley.

Elliott, W. B., Huffman, S. P., \& Makar, S. D. (2003). Foreign-denominated debt and foreign currency derivatives: complements or substitutes in hedging foreign currency risk? Journal of Multinational Financial Management, 13(2), 123-139.

Eriksson, K., Majkgård, A., \& Sharma, D. D. (2000). Path dependence and knowledge development in the internationalization process. MIR: Management International Review, 307-328.

Erramilli, M. K., \& D'Souza, D. E. (1993). Venturing into foreign markets: The case of the small service firm. Entrepreneurship theory and practice, 17, 29-29.

Estrin, S., Meyer, K. E., Wright, M., \& Foliano, F. (2008). Export propensity and intensity of subsidiaries in emerging economies. International Business Review, 17(5), 574-586. 
European Union Commission. (2003). Commission recommendation of 6 may 2003 concerning the definition of micro, small and medium-sized enterprises. Official Journal of the European Union, L, 124, 36-41.

Fan, T., \& Phan, P. (2007). International new ventures: revisiting the influences behind the 'born-global'firm. Journal of International Business Studies, 38(7), 11131131.

Fang, W., Lai, Y., \& Miller, S. M. (2009). Does exchange rate risk affect exports asymmetrically? Asian evidence. Journal of International Money and Finance, 28(2), 215-239.

Fang, W., Lai, Y., \& Thompson, H. (2007). Exchange rates, exchange risk, and Asian export revenue. International Review of Economics \& Finance, 16(2), 237.

Fard, M. S., Cheong, K.-C., \& Yap, S.-F. (2014). Reopening the Debate on Globalisation and Economic Growth Through Technology Transfer. Malaysian Journal of Economic Studies, 51(2), 231-247.

Fausti, S., \& Gillespie, J. (2006). Measuring risk attitude of agricultural producers using a mail survey: how consistent are the methods? Australian Journal of Agricultural and Resource Economics, 50(2), 171-188. doi: 10.1111/j.14678489.2006.00328.x

Finger, K. M. (1999). Trade, finance and financial crises / K. Michael Finger and Ludger Schuknecht. Geneva :: WTO.

Fiol, C. M. (1991). Managing culture as a competitive resource: An identity-based view of sustainable competitive advantage. Journal of Management, 17(1), 191-211.

Fisher, G. (2012). Effectuation, causation, and bricolage: a behavioral comparison of emerging theories in entrepreneurship research. Entrepreneurship theory and practice, 36(5), 1019-1051.

Fok, R. C., Carroll, C., \& Chiou, M. C. (1997). Determinants of corporate hedging and derivatives: a revisit. Journal of Economics and Business, 49(6), 569-585.

Fonseca, R. J., \& Rustem, B. (2012). Robust hedging strategies. Computers \& Operations Research, 39(11), 2528-2536. doi: http://dx.doi.org/10.1016/j.cor.2011.12.021

Fontes, M., \& Coombs, R. (1997). The coincidence of technology and market objectives in the internationalisation of new technology-based firms. International Small Business Journal, v15(n4), p14(22).

Fraser, S. P., \& Pantzalis, C. (2003). Foreign exchange rate exposure of US multinational corporations: a firm-specific approach. Journal of Multinational Finanical Management, 14(2004), 261-281. doi: 10.1016/j.mulfin.2003.07.008

Freeman, S., Edwards, R., \& Schroder, B. (2006). How smaller born-global firms use networks and alliances to overcome constraints to rapid internationalization. Journal of International Marketing, 14(3), 33-63.

Frishammar, J. (2006). Organizational environment revisited: a conceptual review and integration. International Studies of Management and Organization, 36(3), 2249. 
Gankema, H. G. J., Snuif, H. R., \& Zwart, P. S. (2000). The Internationalization Process of Small and Medium-sized Enterprises: An Evaluation of Stage Theory. Journal of Small Business Management, 38(4), 15-27.

Ganzach, Y., Ellis, S., Pazy, A., \& Ricci-Siag, T. (2008). On the perception and operationalization of risk perception. Judgment and Decision Making, 3(4), 317.

Gao, S. S., Sung, M. C., \& Zhang, J. (2013). Risk management capability building in SMEs: A social capital perspective. International Small Business Journal, 31(6), 677-700.

Garg, V. K., Walters, B. A., \& Priem, R. L. (2003). Chief executive scanning emphases, environmental dynamism, and manufacturing firm performance. Strategic Management Journal, 24(8), 725-744.

Géczy, C., Minton, B. A., \& Schrand, C. (1997). Why Firms Use Currency Derivatives. The Journal of Finance, 52(4), 1323-1354.

Gerschewski, S. (2011). Born Global Firms: An Integrated Analysis of the Determinants and Measurement of International Performance. (PhD), Victoria University of Wellington, New Zealand.

Ginsberg, A. (1984). Operationalizing organizational strategy: toward an integrative framework. Academy of Management Review, 548-557.

Ginsberg, A., \& Venkatraman, N. (1985). Contingency perspectives of organizational strategy: A critical review of the empirical research. Academy of Management Review, 421-434.

Gobet, E., \& Landon, N. (2014). Almost sure optimal hedging strategy. The Annals of Applied Probability, 24(4), 1652-1690.

Goldberg, L. S., \& Tille, C. (2008). Vehicle currency use in international trade. Journal of International Economics, 76(2), 177-192.

Goldberg, S. R., \& Drogt, E. L. (2008). Managing Foreign Exchange Risk. Journal of Corporate Accounting \& Finance, 19(2), 49-57. doi: 10.1002/jcaf.20373

González, L. O., Búa, M. V., Lopez, S. F., \& Sandías, A. R. (2007). Why Spanish Firms Hedge with Derivatives: An Examination of Transaction Exposure. SSRN eLibrary.

Graham, J. R., \& Rogers, D. A. (2002). Do Firms Hedge in Response to Tax Incentives? The Journal of Finance, 57(2), 815-839.

Grant, R. M. (1991). Contemporary strategy analysis: Concepts, techniques, applications (Vol. 25). Basil Blackwell: Cambridge, MA.

Grant, R. M. (1991). The resource-based theory of competitive advantage: implications for strategy formulation: California Management Review, University of California.

Griffin, J. M., \& Stulz, R. M. (2001). International competition and exchange rate shocks: a cross-country industry analysis of stock returns. Review of Financial Studies, 14(1), 215-241. 
Griffis, S. E., Goldsby, T. J., \& Cooper, M. (2003). WEB - BASED AND MAIL SURVEYS: A COMPARISON OF RESPONSE, DATA, AND COST. Journal of Business Logistics, 24(2), 237-258.

Guest, G., Bunce, A., \& Johnson, L. (2006). How many interviews are enough? An experiment with data saturation and variability. Field methods, 18(1), 59-82.

Haahti, A., Hall, G., \& Donckels, R. (1998). The Internationalization of SMEs: The Interstratos Project: London: Routledge.

Hadley, R. D., \& Wilson, H. I. M. (2003). The network model of internationalisation and experiential knowledge. International Business Review, 12(6), 697-717.

Hagelin, N. (2003). Why Firms Hedge with Currency Derivatives: An Examination of Transaction and Translation Exposure. SSRN eLibrary.

Hair, J. F., Black, W. C., Babin, B. J., \& Anderson, R. E. (2010). Multivariate Data Analysis: A Global Perspective: Pear Prentice Hall.

Hair, J. F., Black, W. C., Babin, B. J., Anderson, R. E., \& Tatham, R. (2006). Multivariate Data Analysis: Upper Saddle River, NJ: Prentice Hall.

Hakkarainen, A., Joseph, N., Kasanen, E., \& Puttonen, V. (1998). The foreign exchange exposure management practices of Finnish industrial firms. Journal of International Financial Management \& Accounting, 9(1), 34-57.

Hall, E. T., \& Hall, M. R. (1990). Understanding cultural differences (Vol. 12): Intercultural press Yarmouth, ME.

Hambrick, D. C., \& Snow, C. C. (1977). A Contextual Model of Strategic Decision Making in Organizations. Paper presented at the Academy of Management Proceedings.

Hansson, S. O. (2008). Risk. The Stanford Encyclopedia of Philosophy. http://plato.stanford.edu/archives/win2008/entries/risk/

Harrison, J. S., Hitt, M. A., Hoskisson, R. E., \& Ireland, R. D. (1991). Synergies and post-acquisition performance: Differences versus similarities in resource allocations. Journal of Management, 17(1), 173-190.

Hashim, M. K., \& Wafa, S. A. (2002). Small \& Medium-Sized Enterprises in Malaysia: Development Issues: Pearson Malaysia.

Hayton, J. C. (2005). Competing in the new economy: the effect of intellectual capital on corporate entrepreneurship in high-technology new ventures. $R \& D$ Management, 35(2), 137-155. doi: 10.1111/j.1467-9310.2005.00379.x

He, J., \& Ng, L. K. (1998). The Foreign Exchange Exposure of Japanese Multinational Corporations. The Journal of Finance, 53(2), 733-753.

Hemsworth, D., Brophey, G., \& Baregheh, A. (2013). INNOVATION PROCESS, DECISION-MAKING, PERCEIVED RISKS AND METRICS: A DYNAMICS TEST. International Journal of Innovation Management, 17(03), 1340014. doi: doi:10.1142/S1363919613400148

Hennink, M., Hutter, I., \& Bailey, A. (2011). Qualitative research methods: Sage. 
Henschel, T. (2009, 2009). Implementing a holistic risk management in Small and Medium Sized Enterprises (SMEs), Washington.

Henseler, J., Ringle, C. M., \& Sinkovics, R. R. (2009). The use of partial least squares path modeling in international marketing. Advances in International Marketing (AIM), 20, 277-320.

Hillson, D., \& Murray-Webster, R. (2007). Understanding and managing risk attitude (Second ed., pp. 165). Hants: Gower Publishing Limited.

Holmlund, M., \& Kock, S. (1998). Relationships and the Internationalisation of Finnish Small and Medium-Sized Companies. International Small Business Journal, 16(4), 46-63. doi: 10.1177/0266242698164003

Holton, G. A. (2004). Defining Risk. Financial Analysts Journal, 60(6).

Hubbard, D. W. (Ed.). (2009). The Failure of Risk Management: Why It's Broken and How to Fix It. . New Jersey: John Wiley \& Sons.

Ietto-Gillies, G. (2009). Conceptual issues behind the assessment of the degree of internationalization. Transnational Corporations, 18(3), 59-83.

Itagaki, T. (1981). The theory of the multinational firm under exchange rate uncertainty. Canadian Journal of Economics, 14(2), 276-297.

Jacque, L. L. (1981). Management of Foreign Exchange Risk: A Review Article. Journal of International Business Studies, 12(1), 81-101.

Jansen, K. J., Corley, K. G., \& Jansen, B. J. (2007). E-survey methodology. Handbook of research on electronic surveys and measurements, 416-425.

Jick, T. D. (1979). Mixing Qualitative and Quantitative Methods: Triangulation in Action. Administrative Science Quarterly, 24(4), 602-611.

Johanson, J., \& Vahlne, J.-E. (1977). The Internationalization Process of the Firm-A Model of Knowledge Development and Increasing Foreign Market Commitments. Journal of International Business Studies, 8(1), 23-32.

Johanson, J., \& Vahlne, J.-E. (1990). The mechanism of internationalisation. International Marketing Review, 7(4).

Johanson, J., \& Wiedersheim-Paul, F. (1975). THE INTERNATIONALIZATION OF THE FIRM - FOUR SWEDISH CASES 1. Journal of Management Studies, 12(3), 305-323. doi: 10.1111/j.1467-6486.1975.tb00514.x

Johnson, R. B., Onwuegbuzie, A. J., \& Turner, L. A. (2007). Toward a definition of mixed methods research. Journal of Mixed Methods Research, 1(2), 112-133.

Jonuška, M., \& Samėnaitè, I. è. (2003). Foreign Exchange Risk Management in Lithuanian Companies: The use of currency derivatives SSE Riga Working Papers: The Stockholm School of Economics in Riga.

Jorion, P. (1990). The exchange-rate exposure of US multinationals. The Journal of Business, 63(3), 331-345.

Joseph, N. L. (2000). The choice of hedging techniques and the characteristics of UK industrial firms. Journal of Multinational Financial Management, 10(2), 161184. 
Kaleka, A. (2002). Resources and capabilities driving competitive advantage in export markets: guidelines for industrial exporters. Industrial Marketing Management, 31(3), 273-283.

Kallman, J. (2005). What is risk? Risk Management Magazine, 52(10).

Kaplan, L. B., Szybillo, G. J., \& Jacoby, J. (1974). Components of perceived risk in product purchase: A cross-validation. Journal of Applied Psychology, 59(3), 287.

Kasman, A., \& Kasman, S. (2005). Exchange rate uncertainty in Turkey and its impact on export volume. METU Studies in Development, 32(1), 41.

Kenyon, A. (1991). Currency risk and business management. Oxford, UK ;Cambridge, Mass., USA: Blackwell.

Ketkar, S., \& Acs, Z. J. (2013). Where Angels Fear to Tread: Internationalization of Emerging Country SMEs. Journal of International Entrepreneurship, 11(3), 201-219.

Ketokivi, M. A., \& Schroeder, R. G. (2004). Perceptual measures of performance: fact or fiction? Journal of Operations Management, 22(3), 247-264.

Klassen, R. D., \& Whybark, D. C. (1994). Barriers to the management of international operations. Journal of Operations Management, 11(4), 385-396.

Kline, R. B. (2005). Principles and practice of structural equation modeling (2nd ed.). New York: Guilford press.

Knight, G. A., \& Cavusgil, S. T. (2004). Innovation, organizational capabilities, and the born-global firm. Journal of International Business Studies, 35(2), 124-141.

Kompass. (2014). Kompass Business Database. Retrieved 19 February, 2014, from http://www.kompass.co.nz/

Kraatz, M. S., \& Zajac, E. J. (2001). How Organizational Resources Affect Strategic Change and Performance in Turbulent Environments: Theory and Evidence. Organization Science, 12(5), 632-657.

Kroner, K. F., \& Sultan, J. (1993). Time-varying distributions and dynamic hedging with foreign currency futures. Journal of Financial and quantitative Analysis, 28(04), 535-551.

Krosnick, J. (1999). Survey Research. Annual Review of Psychology, 50(1), 537-567.

Kula, V. (2005). Foreign exchange exposure perception and management of Turkish SMEs. Journal of Small Business and Entrepreneurship, 18(4), 437(416).

Kuzel, A. J. (1992). Sampling in qualitative inquiry.

Kwak, N., \& Radler, B. (2002). A comparison between mail and web surveys: Response pattern, respondent profile, and data quality. JOURNAL OF OFFICIAL STATISTICS-STOCKHOLM-, 18(2), 257-274.

Lamb, P., Liesch, P. W., \& Sandberg, J. (2012). Small firm internationalisation competence. Paper presented at the Australia and New Zealand International Business Academy (ANZIBA) Annual Conference 2012. 
Lamb, P., Sandberg, J., \& Liesch, P. W. (2011). Small firm internationalisation unveiled through phenomenography. Journal of International Business Studies, 42(5), 672-693.

Lau, H.-F. (1992). Internationalization, Internalization, or a New Theory for Small, Low-technology Multinational Enterprise? European journal of marketing, 26(10), 17-17-31. doi: 10.1108/eum0000000000648

Learned, E., Christensen, R., Andrews, K., \& Guth, W. (1969). Business policy: Text and cases. Irwin: Homewood.

Lee, J., Roehl, T. W., \& Choe, S. (2000). What makes management style similar and distinct across borders? Growth, experience and culture in Korean and Japanese firms. Journal of International Business Studies, 631-652.

Lefebvre, L. A., Mason, R., \& Lefebvre, E. (1997). The influence prism in SMEs: the power of CEOs' perceptions on technology policy and its organizational impacts. Management Science, 43(6), 856-878.

Leland, L. J. (1960). The Theory of Hedging and Speculation in Commodity Futures. The Review of Economic Studies, 27(3), 139-151.

Leoni, P., Vandaele, N., \& Vanmaele, M. (2013). Hedging strategies for energy derivatives. Quantitative Finance, 14(10), 1725-1737. doi: 10.1080/14697688.2013.836294

Leonidou, L. C., \& Katsikeas, C. S. (1996). The Export Development Process: An Integrative Review of Empirical Models. Journal of International Business Studies, 27(3), 517-551.

Lockett, A., \& Wild, A. (2014). Bringing history (back) into the resource-based view. Business History, 56(3), 372-390.

Loderer, C. F., \& Pichler, K. (2000). Firms, Do You Know Your Currency Risk Exposure? Survey Results. SSRN eLibrary. doi: 10.2139/ssrn.203151

Lundstrom, W. J., \& Lamont, L. M. (1976). The development of a scale to measure consumer discontent. Journal of Marketing Research, 373-381.

Lybaert, N. (1998). The information use in a SME: its importance and some elements of influence. Small Business Economics, 10(2), 171-191.

MacKenzie, S. B., Podsakoff, P. M., \& Fetter, R. (1991). Organizational citizenship behavior and objective productivity as determinants of managerial evaluations of salespersons' performance. Organizational Behavior and Human Decision Processes, 50(1), 123-150.

MacKenzie, S. B., Podsakoff, P. M., \& Fetter, R. (1993). The impact of organizational citizenship behavior on evaluations of salesperson performance. The Journal of Marketing, 70-80.

Madsen, T. K., \& Servais, P. (1997). The internationalization of born globals: an evolutionary process? International Business Review, 6(6), 561-583.

Magee, S. P., \& Rao, R. K. S. (1980). Vehicle and Nonvehicle Currencies in International Trade. The American Economic Review, 70(2), 368-373. 
Mahoney, J. T., \& Pandian, J. R. (1992). The Resource-Based View Within the Conversation of Strategic Management. Strategic Management Journal, 13(5), 363-380.

Majocchi, A., Bacchiocchi, E., \& Mayrhofer, U. (2005). Firm size, business experience and export intensity in SMEs: A longitudinal approach to complex relationships. International Business Review, 14(6), 719-738.

Maltz, E., \& Kohli, A. K. (1996). Market intelligence dissemination across functional boundaries. Journal of Marketing Research, 47-61.

Maranto-Vargas, D., \& Gómez-Tagle Rangel, R. (2007). Development of internal resources and capabilities as sources of differentiation of SME under increased global competition: A field study in Mexico. Technological Forecasting and Social Change, 74(1), 90-99.

March, J. G., \& Shapira, Z. (1987). Managerial Perspectives on Risk and Risk Taking. Management Science, 33(11), 1404-1418.

Marsh, H. W., \& Bailey, M. (1991). Confirmatory factor analyses of multitraitmultimethod data: A comparison of alternative models. Applied psychological measurement, 15(1), 47-70.

Marsh, H. W., Balla, J. R., \& Hau, K.-T. (1996). An evaluation of incremental fit indices: A clarification of mathematical and empirical properties. Advanced structural equation modeling: Issues and techniques, 315-353.

Marsh, H. W., Balla, J. R., \& McDonald, R. P. (1988). Goodness-of-fit indexes in confirmatory factor analysis: The effect of sample size. Psychological Bulletin, 103(3), 391.

Marsh, H. W., Hau, K.-T., Balla, J. R., \& Grayson, D. (1998). Is more ever too much? The number of indicators per factor in confirmatory factor analysis. Multivariate behavioral research, 33(2), 181-220.

Marsh, V. (2004). New Zealand economy: Australia and New Zealand forge closer ties. New York: The Economist Intelligence Unit.

Marshall, A. (2000). Foreign exchange risk management in UK, USA and Asia Pacific multinational companies. Journal of Multinational Financial Management, $10(2), 185-211$.

Marton, F. (1981). Phenomenography - describing conceptions of the world around us. Instructional science, 10(2), 177-200.

Marton, F. (1986). Phenomenography-a research approach to investigating different understandings of reality. Journal of thought, 28-49.

Marton, F., \& Booth, S. A. (1997). Learning and awareness: Psychology Press.

Marton, F., \& Pong, W. Y. (2005). On the unit of description in phenomenography. Higher education research \& development, 24(4), 335-348.

Mathur, I. (1985). Managing Foreign Exchange Risks: Strategy Considerations. Managerial Finance, 11(2), 7-11. 
Maurel, C. (2009). Determinants of export performance in French wine SMEs. International Journal of Wine Business Research, 21(2), 118-142. doi: http://dx.doi.org/10.1108/17511060910967971

McGee, J. E., Dowling, M. J., \& Megginson, W. L. (1995). Cooperative strategy and new venture performance: The role of business strategy and management experience. Strategic Management Journal, 16(7), 565-580.

McNamee, D. (1997). Risk Management Today and Tomorrow. Managegment Control Concepts. California, USA.

McRae, T. W., \& Walker, D. P. (1980). Foreign exchange management: Prentice-Hall International.

MED. (July 2010). SMEs in New Zealand: Structure and Dynamics 2010: New Zealand Ministry of Economic Development.

Meyer, K. E., Estrin, S., Bhaumik, S. K., \& Peng, M. W. (2009). Institutions, resources, and entry strategies in emerging economies. Strategic Management Journal, $30(1), 61-80$.

Mian, S. L. (1996). Evidence on corporate hedging policy. Journal of Financial and quantitative Analysis, 31(03), 419-439.

Mikhailitchenko, A., \& Lundstrom, W. J. (2006). Inter-organizational relationship strategies and management styles in SMEs: The US-China-Russia study. Leadership \& Organization Development Journal, 27(6), 428-448.

Miles, M. B., \& Huberman, A. M. (1994). Qualitative data analysis: An expanded sourcebook: Sage Publications, Incorporated.

Miles, R. E., Snow, C. C., Meyer, A. D., \& Coleman Jr, H. J. (1978). Organizational strategy, structure, and process. Academy of Management Review, 546-562.

Miller, D. (1988). Relating Porter's business strategies to environment and structure: Analysis and performance implications. Academy of Management Journal, 31(2), 280-308.

Miller, K. D. (1992). A Framework for Integrated Risk Management in International Business. Journal of International Business Studies, 23(2), 311-331.

Mitchell, V.-W., \& Harris, G. (2005). The importance of consumers' perceived risk in retail strategy. European journal of marketing, 39(7/8), 821-837.

Molloy, J. C., Chadwick, C., Ployhart, R. E., \& Golden, S. J. (2011). Making Intangibles "Tangible" in Tests of Resource-Based Theory. Journal of Management, 37(5), 1496-1518. doi: 10.1177/0149206310394185

Moosa, I. A. (2004). Is there a need for hedging exposure to foreign exchange risk? Applied Financial Economics, 14(4), 279 - 283.

Mooslechner, P., \& Gnan, E. (2007). Survey Evidence on the Exchange Rate Exposure of Hungarian SMEs. Emerging Markets: Any Lessons for Southeastern Europe? , Vienna. 
Morey, M. R., \& Simpson, M. W. (2001). To hedge or not to hedge: the performance of simple strategies for hedging foreign exchange risk. Journal of Multinational Financial Management, 11(2), 213-223.

Moriarty, R. T., \& Bateson, J. E. G. (1982). Exploring Complex Decision Making Units: A New Approach. Journal of Marketing Research, 19(2), 182-191.

Morse, J. M. (2000). Determining sample size. Qualitative Health Research, 10(1), 3-5.

Muller, A., \& Verschoor, W. (2005). The impact of corporate derivative usage on foreign exchange risk exposure. Available at SSRN 676012.

Myers, J., \& Warner, W. (1968). Semantic Properties of Selected Evaluation Adjectives. Journal of Marketing Research,, 5(November), 409-412.

Myers, S. C. (1977). Determinants of corporate borrowing. Journal of Financial Economics, 5(2), 147-175.

Nachtigall, C., Kroehne, U., Funke, F., \& Steyer, R. (2003). should we use SEM? Pros and cons of structural equation modeling. Methods of Psychological Research Online, 8(2), 1-22.

Nakata, C., \& Sivakumar, K. (2001). Instituting the marketing concept in a multinational setting: the role of national culture. Journal of the Academy of Marketing Science, 29(3), 255-276.

Nakos, G., \& Brouthers, K. D. (2002). Entry Mode Choice of SMEs in Central and Eastern Europe. Entrepreneurship theory and practice, 27(1), 47-63. doi: $10.1111 / 1540-8520.271003$

Nance, D. R., Smith, C. W., Jr., \& Smithson, C. W. (1993). On the Determinants of Corporate Hedging. The Journal of Finance, 48(1), 267-284.

Naylor, M. J., \& Greenwood, R. C. (2008). The characteristics of foreign exchange hedging: A comparative analysis. Journal of Asia-Pacific Business, 9(2), 121152.

New Zealand Goverment. (2014). The Small Business Sector Report 2014.

Newbert, S. L. (2007). Empirical research on the resource-based view of the firm: an assessment and suggestions for future research. Strategic Management Journal, 28(2), 121-146. doi: 10.1002/smj.573

Nguyen, T. D. (2007). Factors affecting the utilization of the internet by internationalizing firms in transition markets. Marketing Intelligence \& Planning, 25(4), 360-376.

OECD. (1997). Globalization and Small and Medium Enterprises (SMEs), Paris: OECD.

OECD. (2002). Small and Medium Enterprise Outlook. OECD.

OECD. (2007a). Glossary Of Statistical Terms: Organisation for Economic Cooperation and Development.

OECD. (2007b). SMEs in Mexico: Issues and Policies.

OECD. (2012). Financing SMEs and Entrepreneurs 2012: An OECD Scoreboard. 
Okun, D. T., Lane, C. R., Pearson, D. R., Aranoff, S. L., Williamson, I. A., \& Pinkert, D. A. (2010). Small and Medium-Sized Enterprises: Characteristics and Performance. Washington, DC 20436: United States International Trade Commission.

Oswald, S. L., Mossholder, K. W., \& Harris, S. G. (1997). Relations between Strategic Involvement and Managers' Perceptions of Environment and Competitive Strengths The Effect of Vision Salience. Group \& Organization Management, 22(3), 343-365.

Oviatt, B. M., \& McDougall, P. P. (1994). Toward a theory of international new ventures. Journal of International Business Studies, 25(1), 45-64.

Oviatt, B. M., \& McDougall, P. P. (2005). Defining international entrepreneurship and modeling the speed of internationalization. Entrepreneurship theory and practice, 29(5), 537-554.

Oviatt, B. M., Shrader, R. C., \& McDougall, P. P. (2004). The internationalization of new ventures: A risk management model. Advances in international management, 16, 165-185.

Oxelheim, L. (2012). International financial integration. German: Springer Science \& Business Media.

Oxelheim, L., \& Wihlborg, C. G. (1987). Macroeconomic uncertainty: International risks and opportunities for the corporation. New York: John Wiley \& Sons.

Pantzalis, C., Simkins, B. J., \& Laux, P. A. (2001). Operational Hedges and the Foreign Exchange Exposure of U.S. Multinational Corporations. Journal of International Business Studies, 32(4), 793-812.

Papaioannou, M. G. (2006). Exchange Rate Risk Measurement and Management: Issues and Approaches for Firms. SSRN eLibrary.

Payne, J. W. (1975). Relation of perceived risk to preferences among gambles. Journal of Experimental Psychology: Human Perception and Performance, 1(1), 86.

Peng, M. W. (2001). The resource-based view and international business. Journal of Management, 27(6), 803(827).

Peng, M. W. (2006). Global strategy. Cincinnati: South-Western Thomson.

Pennings, J. M. E., \& Garcia, P. (2004). Hedging behavior in small and medium-sized enterprises: The role of unobserved heterogeneity. Journal of Banking \& Finance, 28(5), 951-978.

Penrose, E. T. (1995). The Theory of the Growth of the Firm: Oxford University Press.

Pla, R. L. (2008). Forex from the experts. NZ Business, 21(11), 46-48,50.

Podsakoff, P. M., MacKenzie, S. B., Lee, J.-Y., \& Podsakoff, N. P. (2003). Common method biases in behavioral research: A critical review of the literature and recommended remedies. Journal of Applied Psychology, 88(5), 879-903.

Podsakoff, P. M., MacKenzie, S. B., Moorman, R. H., \& Fetter, R. (1990).

Transformational leader behaviors and their effects on followers' trust in leader, 
satisfaction, and organizational citizenship behaviors. The Leadership Quarterly, $1(2), 107-142$.

Polkinghorne, D. E. (2005). Language and Meaning: Data Collection in Qualitative Research. Journal of Counseling Psychology, 52(2), 137-145.

Pollatsek, A., \& Tversky, A. (1970). A theory of risk. Journal of Mathematical Psychology, 7(3), 540-553.

Poon, P. S., Evangelista, F. U., \& Albaum, G. (2005). A comparative study of the management styles of marketing managers in Australia and the People's Republic of China. International Marketing Review, 22(1), 34-47.

Porter, M. E. (1981). The Contributions of Industrial Organization to Strategic Management. The Academy of Management Review, 6(4), 609-620.

Powell, T. C. (2001). Competitive Advantage: Logical and Philosophical Considerations. Strategic Management Journal, 22(9), 875-888.

Pramborg, B. (2005). Foreign exchange risk management by Swedish and Korean nonfinancial firms: A comparative survey. Pacific-Basin Finance Journal, 13(3), 343-366.

Prater, E., \& Ghosh, S. (2005). Current Operational Practices of U.S. Small and Medium-Sized Enterprises in Europe. Journal of Small Business Management, 43(2), 155-155-169.

Price Waterhouse and Confederation of British Industry. (Northern Ireland, 1995). Small Firms Export Survey. Price Waterhouse, Belfast.

Priem, R. L., \& Butler, J. E. (2001). Is the Resource-Based "View" a Useful Perspective for Strategic Management Research? The Academy of Management Review, 26(1), 22-40.

Qualtrics. (2014). About Qualtrics. Retrieved 19 February, 2014, from http://qualtrics.com/about/

Ramcharran, H. (2000). Foreign direct investments in Central and Eastern Europe: An analysis of regulatory and country risk factors. American Business Review, $18(2), 1-1-8$.

Reeb, D. M., Kwok, C. C., \& Baek, H. Y. (1998). Systematic risk of the multinational corporation. Journal of International Business Studies, 263-279.

Reid, S. D. (1981). The Decision-Maker and Export Entry and Expansion. Journal of International Business Studies, 12(2), 101-112.

Reynolds, P. D. (1997). New and Small Firms in Expanding Markets. Small Business Economics, 9(1), 79-84. doi: 10.1023/a:1007916217140

Reysen, S., Katzarska - Miller, I., Nesbit, S. M., \& Pierce, L. (2013). Further validation of a single - item measure of social identification. European Journal of Social Psychology, 43(6), 463-470.

Rialp, A., Rialp, J., \& Knight, G. A. (2005). The phenomenon of early internationalizing firms: what do we know after a decade (1993-2003) of scientific inquiry? International Business Review, 14(2), 147-166. 
Rouse, M. J., \& Daellenbach, U. S. (2002). More Thinking on Research Methods for the Resource-Based Perspective. Strategic Management Journal, 23(10), 963-967.

Rumelt, R. P., Schendel, D., \& Teece, D. J. (1991). Strategic management and economics. Strategic Management Journal, 12(S2), 5-29.

Saini, D. S., \& Budhwar, P. S. (2008). Managing the human resource in Indian SMEs: The role of indigenous realities. Journal of World Business, 43(4), 417-434.

Salanova, M., Agut, S., \& Peiró, J. M. (2005). Linking Organizational Resources and Work Engagement to Employee Performance and Customer Loyalty: The Mediation of Service Climate. Journal of Applied Psychology, 90(6), 12171227. doi: 10.1037/0021-9010.90.6.1217

Sandberg, J. (1994). Human competence at work: An interpretative approach: Företagsekonomi.

Sandberg, J. (2000). Understanding Human Competence at Work: An Interpretative Approach. The Academy of Management Journal, 43(1), 9-25. doi: $10.2307 / 1556383$

Sandberg, J., \& Pinnington, A. H. (2009). Professional competence as ways of being: An existential ontological perspective. Journal of Management Studies, 46(7), 1138-1170.

Sarasvathy, S. D. (2001). Causation and effectuation: Toward a theoretical shift from economic inevitability to entrepreneurial contingency. Academy of Management Review, 26(2), 243-263.

Sarin, R. K., \& Weber, M. (1993). Risk-value models. European Journal of Operational Research, 70(2), 135-149.

Schembri, S., \& Sandberg, J. (2002). Service quality and the consumer's experience: towards an interpretive approach. Marketing theory, 2(2), 189-205.

Schendel, D. E., \& Patton, G. R. (1978). A Simultaneous Equation Model of Corporate Strategy. Management Science, 24(15), 1611-1621.

Schiozer, R. F., \& Saito, R. (2009). The Determinants of Currency Risk Management in Latin American Nonfinancial Firms. Emerging Markets Finance and Trade, 45(1), 49-71. doi: http://www.mesharpe.com/mall/results1.asp?ACR=ree

Sekkat, K., \& Varoudakis, A. (2000). Exchange rate management and manufactured exports in Sub-Saharan Africa. Journal of Development Economics, 61(1), 237253.

Shaari, N. A., Hasan, N. A., Palanimally, Y. R., \& Mohamed, R. K. M. H. (2013). The Determinants of Derivative Usage: A study on Malaysian firms.

Interdisciplinary Journal of Contemporary Research In Business, 5(2), 300-316.

Shapiro, A. C. (2006). Multinational Financial Management (Eighth Edition ed.). Hoboken: John Wiley \& Sons, Inc.

Sharifi, O. (2014). Financial Risk Management for Small and Medium Sized Enterprises (SMES). International Journal of Information, Business and Management, 6(2), 82-94. 
Sharma, D. (1992). International business research: issues and trends. Scandinavian International Business Review, 1(3), 3-8.

Shih, T.-H., \& Fan, X. (2008). Comparing response rates from web and mail surveys: A meta-analysis. Field methods, 20(3), 249-271.

Shiu, Y.-M., Wang, C.-F., Adams, A., \& Shin, Y.-C. (2012). On the determinants of derivative hedging by insurance companies: Evidence from Taiwan. Asian Economic and Financial Review, 2(4), 538-552.

Shortell, S. M., \& Zajac, E. J. (1990). Perceptual and Archival Measures of Miles and Snow's Strategic Types: A Comprehensive Assessment of Reliability and Validity. The Academy of Management Journal, 33(4), 817-832.

Shuman, J. C., \& Seeger, J. A. (1986). The Theory and Practice of Strategic Management in Smaller Rapid Growth Companies. American Journal of Small Business, 11(1), 12.

Sim, A., \& Pandian, J. R. (2003). Emerging Asian MNEs and their internationalization strategies - Case study evidence on Taiwanese and Singaporean firms. Asia Pacific Journal of Management, 20(1), 27-50.

Simon, H. A. (1997). Administrative behavior: The Free Press, New York, NY.

Sinkovics, R. R., \& Ghauri, P. N. (2008). Enhancing the trustworthiness of qualitative research in international business. Management International Review, 48(6), 689-714.

Sirtaine, S. (2006). Access to finance by Chilean corporations: World Bank.

Sitkin, S. B., \& Pablo, A. L. (1992). Reconceptualizing the Determinants of Risk Behavior. The Academy of Management Review, 17(1), 9-38.

Sitkin, S. B., \& Weingart, L. R. (1995). Determinants of Risky Decision-Making Behavior: A Test of the Mediating Role of Risk Perceptions and Propensity. The Academy of Management Journal, 38(6), 1573-1592.

Slovic, P. (1987). Perception of risk. Science, 236(4799), 280-285. doi: 10.1126/science. 3563507

Slovic, P. (1992). Perception of risk: Reflections on the psychometric paradigm. Social theories of risk, 117-152.

Slovic, P., \& Peters, E. (2006). Risk Perception and Affect. Current Directions in Psychological Science, 15(6), 322-325. doi: 10.1111/j.1467-8721.2006.00461.x

Small Business Administration. (U.S. 1994). Handbook of Small Business Data: Washington, D.C: US Government Printing Office.

Smith, C. W., \& Stulz, R. M. (1985). The Determinants of Firms' Hedging Policies. The Journal of Financial and Quantitative Analysis, 20(4), 391-405.

Solakoglu, M. (2010). Exchange rate exposure and real exports. Applied Economics Letters, 17(5), 457.

Stake, R. E. (2005). Qualitative Case Study (Third Edition ed. Vol. III). London: Sage Publications Ltd. 
Steenkamp, J.-B. E., \& Van Trijp, H. (1991). The use of LISREL in validating marketing constructs. International Journal of Research in marketing, 8(4), 283299.

Stulz, R. M. (1996). Rethinking Risk Management. Journal of Applied Corporate Finance, 9(3), 8-25. doi: 10.1111/j.1745-6622.1996.tb00295.x

Sue, V. M., \& Ritter, L. A. (2012). Conducting online surveys: Sage.

Sui, S., Yu, Z., \& Baum, M. (2012). Prevalence and longitudinal trends of early internationalisation patterns among Canadian SMEs. International Marketing Review, 29(5), 519-535. doi: http://dx.doi.org/10.1108/02651331211260368

Sweeney, J. C., Soutar, G. N., \& Johnson, L. W. (1999). The role of perceived risk in the quality-value relationship: A study in a retail environment. Journal of Retailing, 75(1), 77-105. doi: http://dx.doi.org/10.1016/S0022-4359(99)80005-0

Tan, M. (2014, 2014 May 10). SMEs here more forex-sensitive than counterparts in the region, The Business Times. Retrieved from http://search.proquest.com/docview/1522944030?accountid=14782

Tenenhaus, M. (2008). Component-based structural equation modelling. Total quality management, 19(7-8), 871-886.

Thai, M. T. T., \& Chong, L. C. (2008). Born-global: The case of four Vietnamese SMEs. Journal of International Entrepreneurship, 6(2), 72-100.

Thampy, A. (2010). Financing of SME firms in India: Interview with Ranjana Kumar, Former CMD, Indian Bank; Vigilance Commissioner, Central Vigilance Commission. IIMB Management Review, 22(3), 93-101.

Tuppura, A., Saarenketo, S., Puumalainen, K., Jantunen, A., \& Kyläheiko, K. (2008). Linking knowledge, entry timing and internationalization strategy. International Business Review, 17(4), 473-487.

Turner, R. (1997). Management accounting and SMEs: a question of style? MANAGEMENT ACCOUNTING-LONDON-, 75, 24-26.

Uljens, M. (1992). Phenomenological features of phenomenography. Report no 1992:03. Goteborg: Department of Education and

Educational Research, University of Goteborg.

UNCTAD. (1993). Small and Medium-sized Transnational Corporations: Role, Impact and Policy Implications. Paper presented at the UNCTAD Programme on Transnationals Corporations.

Varintorn, S., Islam, N., \& Kulkarni, U. (2009). Influence of SME characteristics on knowledge management processes. Journal of Enterprise Information Management, 22(1/2), 63-80. doi: http://dx.doi.org/10.1108/17410390910922831

Vaughan, E. J., \& Vaughan, T. (2007). Fundamentals of risk and insurance: John Wiley $\&$ Sons. 
Venkatraman, N., \& Grant, J. H. (1986). Construct measurement in organizational strategy research: A critique and proposal. Academy of Management Review, 7187.

Wade, M., \& Hulland, J. (2004). Review: The Resource-Based View and Information Systems Research: Review, Extension, and Suggestions for Future Research. MIS Quarterly, 28(1), 107-142.

Wang, Y., \& Poutziouris, P. (2010). Leadership styles, management systems and growth: Empirical evidence from UK owner-managed SMEs. Journal of Enterprising Culture, 18(03), 331-354.

Ward, P. T., Leong, G. K., \& Boyer, K. K. (1994). Manufacturing Proactiveness and Performance*. Decision Sciences, 25(3), 337-358.

Ward, P. T., McCreery, J. K., Ritzman, L. P., \& Sharma, D. (1998). Competitive priorities in operations management. Decision Sciences, 29(4), 1035-1046.

Warner, J. B. (1977). Bankruptcy Costs: Some Evidence. The Journal of Finance, 32(2), 337-347.

Weber, E. U., Blais, A. R., \& Betz, N. E. (2002). A domain - specific risk - attitude scale: Measuring risk perceptions and risk behaviors. Journal of Behavioral Decision Making, 15(4), 263-290.

Weinrauch, J. D., Mann, O. K., Robinson, P. A., \& Pharr, J. (1991). Dealing with Limited Financial Resources: A Marketing Challenge for Small Business. Journal of Small Business Management, 29(4), 44-44.

Wernerfelt, B. (1984). A resource-based view of the firm. Strategic Management Journal, 5(2), 171-180. doi: 10.1002/smj.4250050207

Wernerfelt, B. (2011). The Use of Resources in Resource Acquisition. Journal of Management, 37(5), 1369-1373. doi: 10.1177/0149206310371693

Westhead, P., Wright, M., \& Ucbasaran, D. (2001). The internationalization of new and small firms: A resource-based view. Journal of Business Venturing, 16(4), 333358.

Westland, J. C. (2010). Lower bounds on sample size in structural equation modeling. Electronic Commerce Research and Applications, 9(6), 476-487.

Widäng, I., Fridlund, B., \& Mårtensson, J. (2008). Women patients’ conceptions of integrity within health care: a phenomenographic study. Journal of Advanced Nursing, 61(5), 540-548.

Woodcock, C. P., Beamish, P. W., \& Makino, S. (1994). Ownership-based entry mode strategies and international performance. Journal of International Business Studies, 25(2), 253-273.

Wright, A., Murray, J. P., \& Geale, P. (2007). A phenomenographic study of what it means to supervise doctoral students. Academy of Management Learning \& Education, 6(4), 458-474.

Yamakawa, Y., Peng, M. W., \& Deeds, D. L. (2008). What drives new ventures to internationalize from emerging to developed economies? Entrepreneurship theory and practice, 32(1), 59-82. 
Yeo, K. T., \& Lai, W. C. (2004, 18-21 Oct. 2004). Risk management strategies for SME investing in China - a Singaporean perspective. Paper presented at the Engineering Management Conference, 2004. Proceedings. 2004 IEEE International.

Yeoh, P.-L., \& Jeong, I. (1995). Contingency relationships between entrepreneurship, export channel structure and environment: a proposed conceptual model of export performance. European journal of marketing, 29(8), 95-115.

Yin, R. K. (2009). Case study research: Design and methods (Vol. 5): sage.

Zacharakis, A. (1997). Entrepreneurial entry into foreign markets: A transaction cost perspective. Entrepreneurship theory and practice, 21(3), 23.

Zafarullah, M., Ali, M., \& Young, S. (1997). The Internationalization of the Small Firm in Developing Countries-Exploratory Research from Pakistan. Journal of Global Marketing, 11(3), 21-40. doi: 10.1300/J042v11n03_03

Zahra, S. A., \& George, G. (2002). International entrepreneurship: the current status of the field and future research agenda. Strategic entrepreneurship: Creating a new mindset, 255-288.

Zhou, B. (1992). Forecasting foreign exchange rates subject to de-volatilization. Working paper, 3510.

Zikmund, W. (2003). Business research methods 7th ed., Thomson/South-Western: Appendices.

Zou, H., Chen, X., \& Ghauri, P. (2010). Antecedents and consequences of new venture growth strategy: An empirical study in China. Asia Pacific Journal of Management, 27(3), 393-421. doi: 10.1007/s10490-009-9157-0 


\section{APPENDIX}


Appendix A: Research on Forex Risk Management: The Choice of Hedging Strategies

\begin{tabular}{|c|c|c|c|c|c|c|}
\hline $\begin{array}{l}\text { Authors } \\
\text { (Date) }\end{array}$ & Firms & Countries & Factors & $\begin{array}{c}\text { Hedging } \\
\text { techniques/str } \\
\text { ategies }\end{array}$ & Methodology & Research findings \\
\hline $\begin{array}{l}\text { Smith \& Stulz } \\
\text { (1985) }\end{array}$ & Not given & Not given & $\begin{array}{l}\text { - Tax } \\
\text { - Cost of financial distress } \\
\text { - Managerial risk aversion }\end{array}$ & $\begin{array}{l}\text { - Financial } \\
\text { hedge } \\
\text { - Operational } \\
\text { hedge } \\
\end{array}$ & $\begin{array}{l}\text { Using } \\
\text { mathematical } \\
\text { functions }\end{array}$ & $\begin{array}{l}\text { - Providing three major reasons for firms } \\
\text { to hedge } \\
\text { - Offering a framework to understand the } \\
\text { wide diversity of hedging practices }\end{array}$ \\
\hline $\begin{array}{l}\text { Eaker \& Grant } \\
\text { (1987) }\end{array}$ & Not given & $\begin{array}{l}\text { Data collected } \\
\text { from the IMA } \\
\text { Yeurbook, the } \\
\text { International } \\
\text { Financial } \\
\text { Statistics } \\
\text { and the Wall } \\
\text { Street Jonrnal. }\end{array}$ & Not given & \begin{tabular}{|l} 
- Cross \\
hedging \\
- Single and \\
multiple \\
hedges \\
- Future \\
- Portfolio \\
hedging \\
- Naive, \\
simple and \\
copmlex \\
hedges
\end{tabular} & $\begin{array}{l}\text { - Compare the } \\
\text { effectiveness } \\
\text { of hedging } \\
\text { strategies } \\
\text { - Future market: } \\
\text { GBP, CAD, } \\
\text { DEM, JPY, } \\
\text { CHF } \\
\text { - No future } \\
\text { market: ITL, } \\
\text { GRD, ESP, } \\
\text { ZAR. } \\
\text { - Commodity: } \\
\text { gold. }\end{array}$ & $\begin{array}{l}\text { - Cross-hedging is likely to offer risk } \\
\text { reduction opportunities but not to be as } \\
\text { effective as same currency hedges. } \\
\text { - Portfolio hedge is effective. } \\
\text { - Naive hedging is as effective as more } \\
\text { sophisticated ones for portfolio hedge. } \\
\text { - Multiple hedges are likely to be an } \\
\text { improvement over single currency cross } \\
\text { hedges and to partially mitigate } \\
\text { problems of inter-temporal instability of } \\
\text { the coefficients } \\
\text { - Commodity cross-hedge using gold is } \\
\text { ineffective }\end{array}$ \\
\hline Joseph (2000) & MNEs & UK & $\begin{array}{l}\text { - Sources or types of } \\
\text { exposures } \\
\text { - Firm characteristics - The } \\
\text { degree of } \\
\text { internationalisation: } \\
\text { o The number of foreign } \\
\text { countries in which the } \\
\text { MNE operates } \\
\text { O The number of foreign }\end{array}$ & $\begin{array}{l}- \text { Internal } \\
\text { hedges } \\
\text { - External } \\
\text { hedges }\end{array}$ & Regression & $\begin{array}{l}\text { - UK industrial MNEs focus on a very } \\
\text { narrow set of hedging techniques, and } \\
\text { make greater use of derivatives than } \\
\text { internal hedging techniques } \\
\text { - The degree of utilisation of both internal } \\
\text { and external techniques depends on the } \\
\text { type of exposure } \\
\text { - Firm characteristics is likely to explain } \\
\text { the choice of hedging techniques but the }\end{array}$ \\
\hline
\end{tabular}




\begin{tabular}{|c|c|c|c|c|c|c|}
\hline $\begin{array}{c}\text { Authors } \\
\text { (Date) }\end{array}$ & Firms & Countries & Factors & $\begin{array}{c}\text { Hedging } \\
\text { techniques/str } \\
\text { ategies } \\
\end{array}$ & Methodology & Research findings \\
\hline & & & $\begin{array}{l}\text { subsidiaries within the } \\
\text { group } \\
\text { O The percentage of the } \\
\text { groups' total sales that is } \\
\text { generated overseas } \\
\text { O The percentage of the } \\
\text { groups' global exposure } \\
\text { that is hedged } \\
\text { - Cost of financial distress } \\
\text { o Gross cash flow to } \\
\text { market value } \\
\text { O Cash and marketable } \\
\text { securities to market value } \\
\text { Q Quick asset ratio } \\
\text { O Working capital ratio } \\
\text { O Interest charges to } \\
\text { operating and non- } \\
\text { operating income } \\
\text { O Preference capital and } \\
\text { total borrowing to total } \\
\text { capital employed } \\
\text { O Total borrowing to } \\
\text { ordinary shareholders' } \\
\text { equity plus reserves } \\
\text { O Long-term borrowing to } \\
\text { market value } \\
\text { Under-investment problem } \\
\text { o Sales to market value } \\
\text { O Book value to market }\end{array}$ & & & $\begin{array}{l}\text { use of certain hedging techniques } \\
\text { appears to be associated with increases } \\
\text { in the variability of some accounting } \\
\text { measures } \\
\text { - This adverse impact of hedging has not } \\
\text { been emphasized in the finance } \\
\text { literature. } \\
\text { - The results imply that firms need to } \\
\text { ensure that the appropriate techniques } \\
\text { are used to hedge exposures }\end{array}$ \\
\hline
\end{tabular}




\begin{tabular}{|c|c|c|c|c|c|c|}
\hline $\begin{array}{c}\text { Authors } \\
\text { (Date) }\end{array}$ & Firms & Countries & Factors & $\begin{array}{c}\text { Hedging } \\
\text { techniques/str } \\
\text { ategies }\end{array}$ & Methodology & Research findings \\
\hline & & & $\begin{array}{l}\text { value } \\
\text { ○ Dividend yield } \\
\text { - Tax liability } \\
\text { ○ Tax charge on profit/loss } \\
\text { to pre-tax profit/loss } \\
\text { ○ Tax charge on profit/loss } \\
\text { to market value } \\
\text { ○ Operating profit to sales } \\
\text { ○ Trading profit to sales } \\
\\
\text { - Compensation plans } \\
\text { ○ Managers' remuneration } \\
\text { to market value } \\
\text { ○ Employees' } \\
\text { remuneration to market } \\
\text { value } \\
\text { Book value to market } \\
\text { value }\end{array}$ & & & \\
\hline $\begin{array}{l}\text { Pramborg } \\
(2005)\end{array}$ & $\begin{array}{l}\text { Nonfinancial } \\
\text { firms }\end{array}$ & $\begin{array}{l}\text { Sweden and } \\
\text { Korea }\end{array}$ & $\begin{array}{l}\text { - FX exposure: the average } \\
\text { of the share of total } \\
\text { revenues and share of total } \\
\text { costs that are denominated } \\
\text { in foreign currency } \\
\text { - Size: the logarithm of total } \\
\text { revenues } \\
\text { - Growth opportunities: } \\
\text { book-to-market ratio } \\
\text { - Leverage: Debt-to-equity } \\
\text { ratio }\end{array}$ & $\begin{array}{l}\text { - } \text { Derivative } \\
\text { - Foreign debt } \\
\text { - Internal } \\
\text { methods }\end{array}$ & Regression & $\begin{array}{l}\text { - The aim of hedging differed between } \\
\text { firms in the two countries. } \\
\circ \text { Korean: reducing fluctuations in cash } \\
\text { flows } \\
\circ \text { Swedish: reducing fluctuations of } \\
\text { accounting numbers } \\
\text { - Significant less Korean firms used } \\
\text { derivatives than Swedish ones due to the } \\
\text { relative immaturity of the Korean } \\
\text { derivatives markets. } \\
\text { - Korean firms hedged as much as }\end{array}$ \\
\hline
\end{tabular}




\begin{tabular}{|c|c|c|c|c|c|c|}
\hline $\begin{array}{l}\text { Authors } \\
\text { (Date) }\end{array}$ & Firms & Countries & Factors & $\begin{array}{c}\text { Hedging } \\
\text { techniques/str } \\
\text { ategies } \\
\end{array}$ & Methodology & Research findings \\
\hline & & & $\begin{array}{l}\text { - Liquidity: the current ratio } \\
\text { - } 3 \text { prespecified objectives } \\
\text { for hedging } \\
\text { - Reasons for not using } \\
\text { derivatives } \\
\text { - Types of exposure } \\
\text { - Concerns about derivatives } \\
\text { use }\end{array}$ & & & $\begin{array}{l}\text { Swedish firms but substituted foreign } \\
\text { debt for derivatives. } \\
\text { - Korean firms were less rigorous than } \\
\text { Swedish firms in overseeing risk } \\
\text { management activity. } \\
\text { - A large proportion of firms in both } \\
\text { countries used a profit-based approach } \\
\text { to evaluating the risk management } \\
\text { function. }\end{array}$ \\
\hline Kula (2005) & SME & Turkey & $\begin{array}{l}\text { - Types of exposure } \\
\text { - Forex exposure groups: } \\
\text { Import, Export and Neutral. } \\
\text { - Forex exposure } \\
\text { measurement (the degree of } \\
\text { exposure) }\end{array}$ & $\begin{array}{l}\text { - Derivative } \\
\text { - Foreign debt } \\
\text { - Internal } \\
\text { hedges }\end{array}$ & $\begin{array}{l}\text { Questionaire, } \\
\text { Five-point } \\
\text { scales, and mean } \\
\text { comparison. }\end{array}$ & $\begin{array}{l}\text { - SMEs perceive forex exposure as } \\
\text { economic and transaction exposure } \\
\text { - SMEs focus on manage transaction } \\
\text { exposure rather tan economic exposure. } \\
\text { - SMEs healily rely on internal hedging } \\
\text { - SMEs are even unaware of external } \\
\text { hedging }\end{array}$ \\
\hline $\begin{array}{l}\text { Albuquerque } \\
(2007)\end{array}$ & Not given & US & $\begin{array}{l}\text { - Bankruptcy costs } \\
\text { - A convex tax schedule } \\
\text { - Manager's risk aversion }\end{array}$ & $\begin{array}{l}\text { - Forward } \\
\text { - Option }\end{array}$ & $\begin{array}{l}\text { Analysing } 3 \\
\text { heging models, } \\
\text { and an } \\
\text { illustration with } \\
\text { data on } \\
\text { transactions } \\
\text { costs for } \\
\text { American } \\
\text { options and } \\
\text { forwards for } 3 \\
\text { exchange rates: } \\
\text { JPY/USD, } \\
\text { EUR/USD, and }\end{array}$ & $\begin{array}{l}\text { - Forward contracts dominate options as } \\
\text { hedges of transactions exposure when } \\
\text { the firm is concerned with downside } \\
\text { risks } \\
\text { - Forwards are more widely used as } \\
\text { hedging derivatives than options }\end{array}$ \\
\hline
\end{tabular}




\begin{tabular}{|c|c|c|c|c|c|c|}
\hline $\begin{array}{l}\text { Authors } \\
\text { (Date) }\end{array}$ & Firms & Countries & Factors & $\begin{array}{c}\text { Hedging } \\
\text { techniques/str } \\
\text { ategies }\end{array}$ & Methodology & Research findings \\
\hline & & & & & GBP/USD. & \\
\hline $\begin{array}{l}\text { González, et } \\
\text { al. (2007) }\end{array}$ & Quoted firms & Spain & 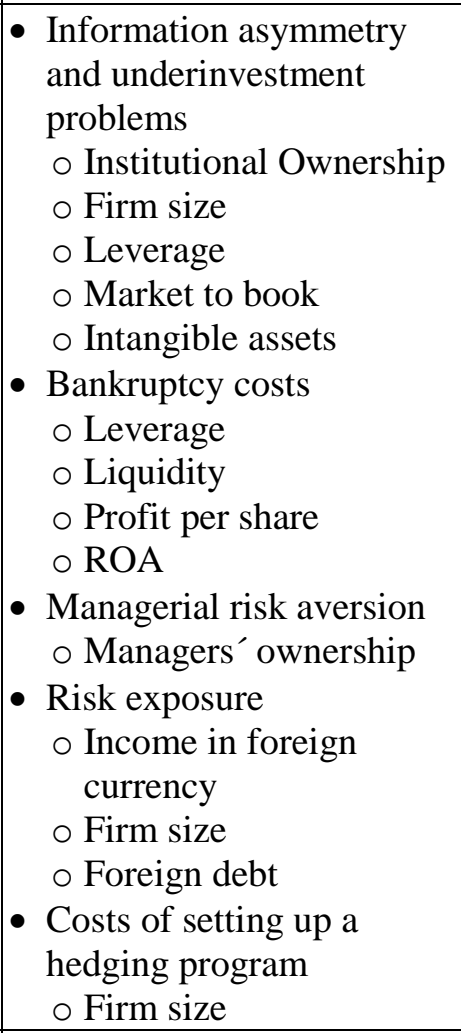 & $\begin{array}{l}\text { - Derivatives } \\
\text { - Foreign debt }\end{array}$ & a Tobit model & $\begin{array}{l}\text { - Among the variables related to the } \\
\text { creation of value and the existence of } \\
\text { scale economies, firm size, market to } \\
\text { book ratio, and liquidity are the main } \\
\text { factors for hedging } \\
\text { - The volume of hedging is mainly } \\
\text { determined by the level of exchange } \\
\text { exposition } \\
\text { - Foreign debt is probably used as a } \\
\text { complementary hedging instrument, } \\
\text { depending on the volume of foreign } \\
\text { sales only }\end{array}$ \\
\hline $\begin{array}{l}\text { Schiozer \& } \\
\text { Saito (2009) }\end{array}$ & $\begin{array}{l}\text { Nonfinancial } \\
\text { firms }\end{array}$ & $\begin{array}{l}\text { Argentina, } \\
\text { Brazil, Chile, } \\
\text { and Mexico }\end{array}$ & $\begin{array}{l}\text { - Financial Distress Costs } \\
\text { o Foreign to total debt } \\
\text { - Tax Benefits: } \\
\text { o Tax convexity }\end{array}$ & 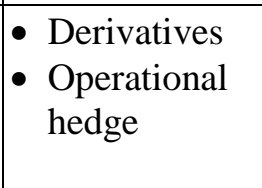 & TOBIT test & $\begin{array}{l}\text { - Derivative hedging can yield cash flows } \\
\text { of the same order of magnitude of } \\
\text { capital expenditures, operational } \\
\text { earnings, and financial expense }\end{array}$ \\
\hline
\end{tabular}




\begin{tabular}{|c|c|c|c|c|c|c|}
\hline $\begin{array}{c}\text { Authors } \\
\text { (Date) }\end{array}$ & Firms & Countries & Factors & $\begin{array}{c}\text { Hedging } \\
\text { techniques/str } \\
\text { ategies } \\
\end{array}$ & Methodology & Research findings \\
\hline & & & $\begin{array}{l}\text { - Costly External Financing, } \\
\text { Information Asymmetry, } \\
\text { and Underinvestment } \\
\text { o Coverage ratio } \\
\text { o Regulation } \\
\text { o Capex/depreciation } \\
\text { o Liquidity: Natural } \\
\text { logarithm of the ratio } \\
\text { current assets/current } \\
\text { liabilities } \\
\text { - Transaction Costs } \\
\text { o Firm size: Natural } \\
\text { logarithm of the total } \\
\text { assets }\end{array}$ & & & $\begin{array}{l}\text { Economies of scale, financial distress } \\
\text { costs, informational asymmetry, and } \\
\text { growth opportunities are important for } \\
\text { risk management decisions } \\
\text { - Firms do not hedge because of potential } \\
\text { tax benefits }\end{array}$ \\
\hline $\begin{array}{l}\text { Aabo, et al. } \\
(2010)\end{array}$ & $\begin{array}{l}\text { Medium- } \\
\text { sized } \\
\text { manufacturin } \\
\mathrm{g} \\
\text { firms }\end{array}$ & $\begin{array}{l}\text { Denmark (a } \\
\text { small, open } \\
\text { economy) }\end{array}$ & $\begin{array}{l}\text { - Export revenues in foreign } \\
\text { currency } \\
\text { - Import (of operating costs } \\
\text { in foreign currency. } \\
\text { - The number of currencies } \\
\text { to which the firm is } \\
\text { significantly exposed } \\
\text { - The most important } \\
\text { currency to the firm. } \\
\text { - Number of production } \\
\text { subsidiaries abroad } \\
\text { - Number of sales } \\
\text { subsidiaries abroad. }\end{array}$ & $\begin{array}{l}\text { - Derivatives } \\
\text { - Imports }\end{array}$ & Regression & $\begin{array}{l}\text { There is a strong, negative relation } \\
\text { between import and the use of foreign } \\
\text { exchange derivatives on the aggregate } \\
\text { level as firms might use import to match } \\
\text { the foreign exchange exposure created by } \\
\text { foreign sales activities }\end{array}$ \\
\hline
\end{tabular}




\begin{tabular}{|c|c|c|c|c|c|c|}
\hline $\begin{array}{c}\text { Authors } \\
\text { (Date) }\end{array}$ & Firms & Countries & Factors & $\begin{array}{c}\text { Hedging } \\
\text { techniques/str } \\
\text { ategies }\end{array}$ & Methodology & Research findings \\
\hline & & & $\begin{array}{l}\text { - The age of the firm. } \\
\text { - Total assets of the firm } \\
\text { measured in million DKK } \\
\text { - Logarithm of Total Assets. } \\
\text { - The gross profit of the firm } \\
\text { divided by the total assets } \\
\text { of the firm } \\
\text { - The equity of the firm } \\
\text { divided by the total assets } \\
\text { of the firm } \\
\text { - The R\&D expenses in } \\
\text { percent of the turnover of } \\
\text { the firm. }\end{array}$ & & & \\
\hline
\end{tabular}




\section{Appendix B: Cover Letter for Interview}

Dear...,

I am Vu Dang, currently a PhD candidate at Victoria University of Wellington, majoring in International Business. I am conducting a thesis, entitled "How Small and Medium-sized Enterprises (SMEs) manage foreign exchange (forex) risk: a study of New Zealand firms". This project has been reviewed and approved by the Victoria University of Wellington, Pipitea Human Ethics Committee.

I would be most grateful if you could spare the time for me to interview you about your exporting experience and approaches to managing foreign exchange risk in your business. The information that you provide will assist me with my understanding of the management of forex fluctuations by New Zealand firms.

The interview will take approximately an hour. Your interview material will be treated confidentially and considered alongside information from other interview in the analysis stage of the study. Both interview transcripts and a final copy of my research report, which you might find of interest for your firm, will be made available to you. Please see attached the information sheet for more information about this research project.

If you are willing to participate in an interview, please let me know and I will schedule a mutually agreeable time to meet.

Thank you for considering my request, and I hope that I am able to meet with you shortly. I look forward to hearing from you.

Yours sincerely,

\section{Vu Hung Dang}

PhD Candidate

School of Marketing and International Business

Victoria University of Wellington

Room 130, Rutherford House, 23 Lambton Quay

Wellington 6104, New Zealand

Tel: +64 - 4 - 4635233 ext. 8655

Mobile: +64 - 220.718317

Email: vu.dang@vuw.ac.nz; danghungvu@gmail.com 
Appendix C: Information Sheet for Interviewees

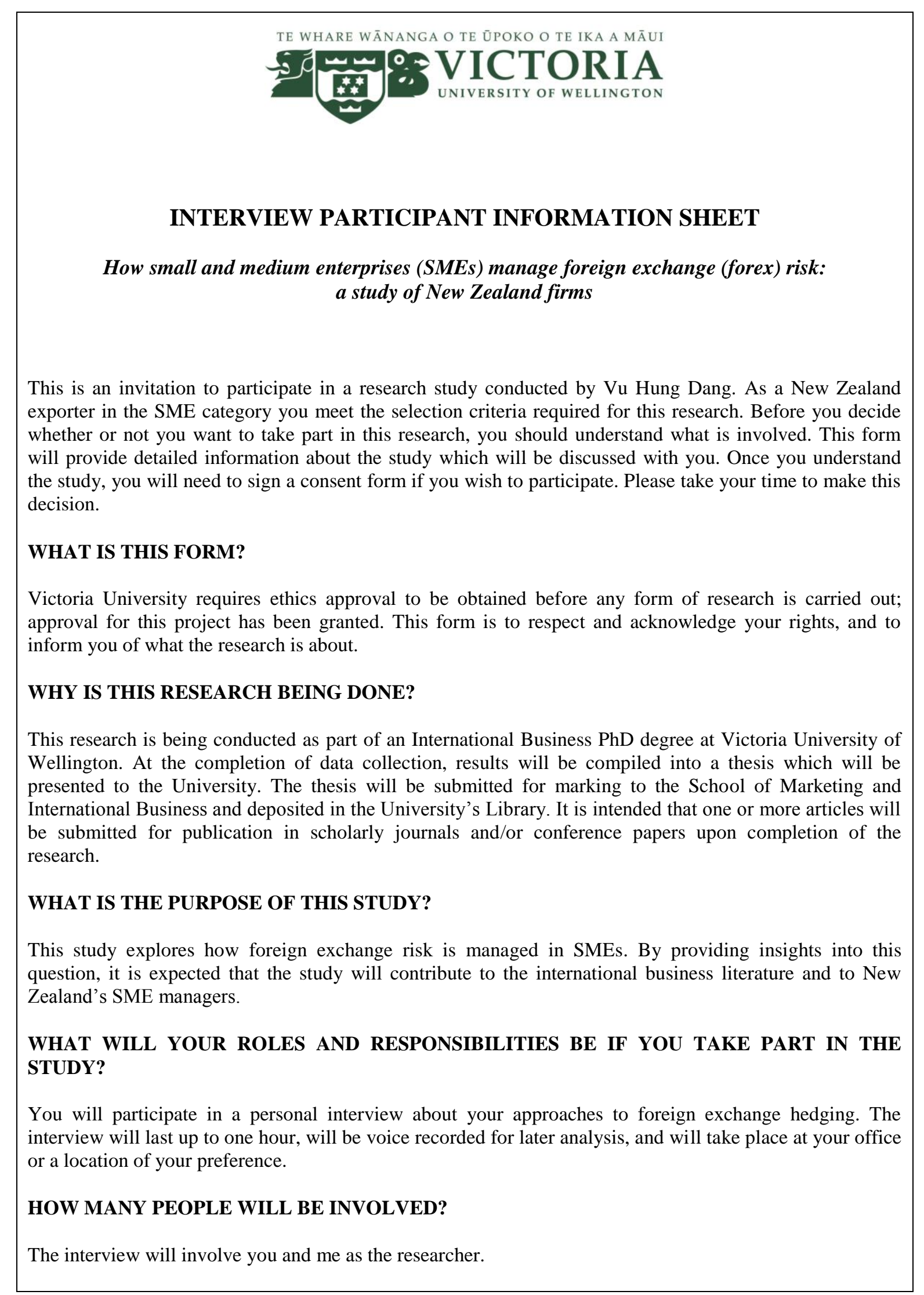




\section{WHAT WILL HAPPEN TO THE INFORMATION YOU GIVE?}

The research is completely confidential. Your name will not be used in the study and any information attributable to you will not be included in any analysis. The voice recordings will be reviewed by the researcher, supervisors, and transcribers for the sole purpose of this research and will be securely stored in a locked cabinet and password protected computer. In addition, the transcriber will sign a confidentiality agreement. You will have the opportunity to review the transcript of your interview for accuracy before it is analysis stage of the research.

The interview will only begin with your consent, which you will indicate by signing the consent form. Any information attributable to you will be destroyed or returned to you after three years, and confidentiality is assured at all times.

Any raw data will be securely stored for three years upon completion of the dissertation before it will be destroyed. The results may be published in academic journals or conference papers, however your name will have been changed and no information traceable to you or your company will be included.

\section{WHAT ARE THE POSSIBLE BENEFITS?}

By participating in this research, you will contribute to our knowledge of how SMEs manage foreign exchange risk. You will also have assisted me with my University studies. If you would like a written summary of the project at the end of the study, please provide your contact details on the consent form.

\section{WHEN CAN YOU WITHDRAW FROM THE RESEARCH?}

You can withdraw from the study at any time, up until four weeks of completing the interview, with no questions asked, and no disadvantage to yourself. If you choose to withdraw, any information you have provided will be destroyed or returned to you.

\section{ANY QUESTIONS OR PROBLEMS}

Should you have any questions or would like to receive further information about the project, please contact me at vu.dang@vuw.ac.nz or my supervisor, Associate Prof Val Lindsay at val.lindsay@vuw.ac.nz, Dr Hongzhi Gao at hongzhi.gao@vuw.ac.nz and Dr Leigh Roberts at leigh.roberts@ vuw.ac.nz.

Thank you for your time.

\section{Vu Hung Dang}

PhD Candidate

School of Marketing and International Business

Victoria University of Wellington

Room 130, Rutherford House, 23 Lambton Quay

Wellington 6104, New Zealand

Tel: +64 - 4 - 4638655

Mobile: +64 - 220.718317

Email: vu.dang@vuw.ac.nz 


\section{Appendix D: Interview Questions}

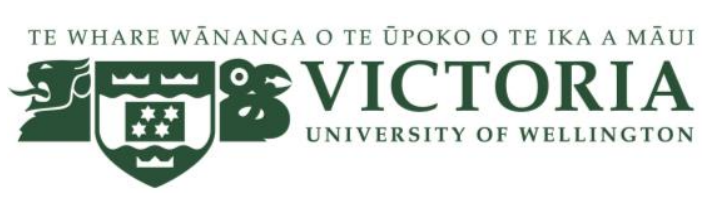

\section{INTERVIEW QUESTIONS}

\section{How small and medium enterprises (SMEs) manage foreign exchange risk: a study of New Zealand firms}

1. What types of entry modes have you chosen to go international? For example:

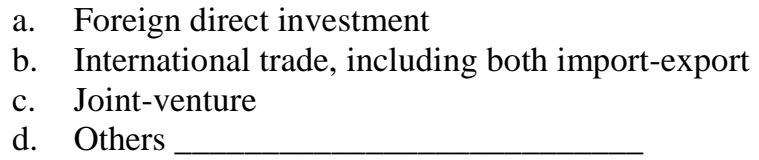

2. Could you tell us about the background of your internationalisation, and your involvement in current international markets?

3. How do you perceive forex risk as you become more involved in international markets?

4. How are your import-export activities going on as you become more involved in international markets? How about the import-export ratio?

5. What is your current hedging strategy?

a. Hedging techniques that you have used

b. The percentage of forex exposure being covered by all of the hedging techniques that you have used.

6. What could be impacts of forex exposure on your choices about hedging strategy, both hedging techniques and hedging tendency?

7. Do you think that forex exposure has any effects on resource allocation for hedging forex risk? Why do you think so? In what ways?

8. How have you used the firm's resources for hedging?
a. What resources have been used?
b. How have you used resources for hedging?
c. How have these resources influenced your hedging strategy?

9. Do you think that your perception of forex risk plays any role in resource allocation for hedging forex risk? Why do you think so?

10. Could you please tell me more about your hedging practice/experience? 
Appendix E: Consent Form for Interview

TE WHARE WĀNANGA O TE ÛPOKO O TE IKA A MĀUI if

\section{CONSENT TO PARTICIPATE IN INTERVIEW}

- I have been provided with adequate information relating to the nature and objectives of this research project;

- I have understood this information and have been given the opportunity to seek further clarification or explanations;

- I understand that I will be participating in a digitally recorded interview;

- I understand that I may withdraw from this study within the first four weeks of completing the interview,

- I understand that if I withdraw from the project, any data I have provided will be returned to me/destroyed;

- I understand that I may review the transcript of my interview for accuracy before it enters the analysis stage of the research;

- I understand that the researcher, the supervisor, and the transcribers will have access to the raw data;

- I understand that any information or opinions I provide will be kept confidential and reported only in an aggregated/non-attributable form;

- I understand that the results may be published in academic journals, and/or conference papers and that it will also be stored in the School of Marketing and International Business Library. If the results are used in this way, no identifiable information will be included;

- I understand that when this research is completed the raw data obtained will be destroyed after three years.

I would like a written summary of the results at the end of the project and my contact details are provided below.

Name of participant:

Signature of participant:

Date: 


\section{Appendix F: Nvivo Coding}

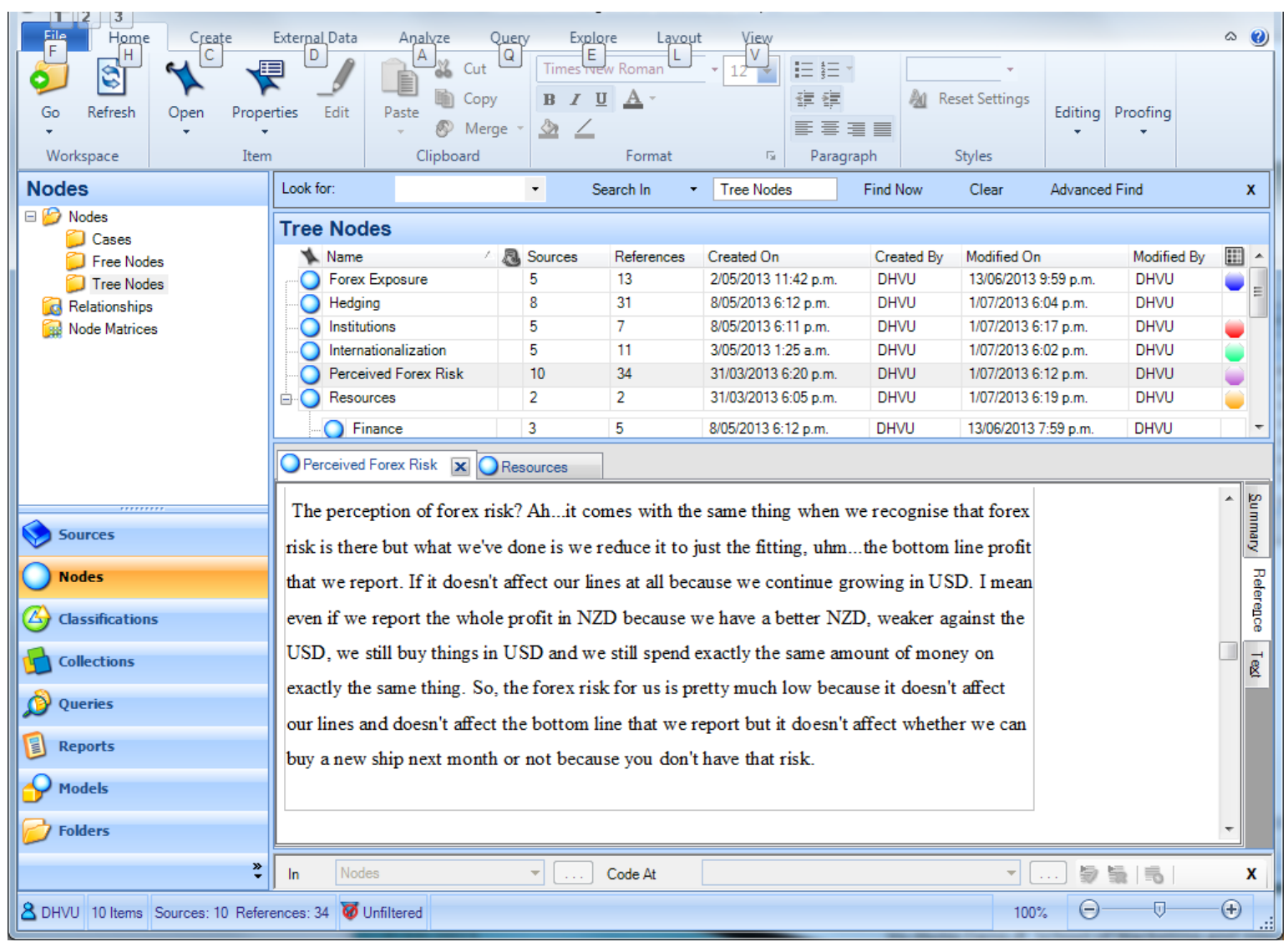


Appendix G: Cover Email for Survey Participants

\section{School of Marketing and International Business}
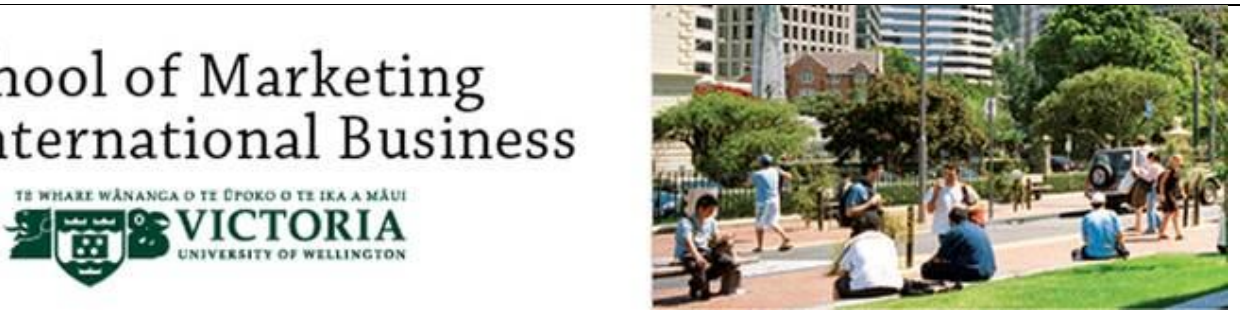

Dear...

I am a postgraduate student working towards my PhD at Victoria University of Wellington. As part of my PhD research I am investigating how exporting firms manage foreign currencies. Your experiences are important to my research and will help us identify critical factors that influence firms' choice of hedging behaviours. Understanding these factors could help firms to improve hedging activities.

The survey questions include your views on perceived foreign exchange risk, internationalisation and hedging techniques.

It would be appreciated if you would partake in this anonymous survey, which takes around 20 minutes. The survey software allows respondents to leave the survey and resume it later if necessary. If you exit the survey before completing it, then to resume it you must come back to the same computer and use the same browser in order to finish it. Please ensure that all questions are answered.

The survey will be available for you to complete until Monday $14^{\text {th }}$ October 2013. Please follow this link to take the survey

\section{Start Survey}

Or copy and paste the URL below into your internet browser: http://vuw.qualtrics.com/SE/?SID=SV 4N1uTCP9joovNn7

The research is approved by the Victoria University of Wellington, Pipitea Human Ethnics Committee. If you wish to confirm the authenticity of this survey you can contact me at vu.dang@vuw.ac.nz or any of my supervisors, Associate Prof Val Lindsay at ValerieLindsay@uowdubai.ac.ae, Dr Hongzhi Gao at hongzhi.gao@vuw.ac.nz or Dr Leigh Roberts at leigh.roberts@vuw.ac.nz.

Kindly let me know if you are not interested in participating in the survey. Many thanks

Yours sincerely,

\section{Vu Hung Dang}

PhD Candidate

School of Marketing and International Business

Victoria University of Wellington

Room 130, Rutherford House, 23 Lambton Quay

Wellington 6104, New Zealand

Tel: +64 - 4 - 4635233 ext. 8655

Mobile: $+64-220.718317$

Email: vu.dang@vuw.ac.nz; danghungvu@gmail.com 
Appendix H: Reminder Email for Survey Participants

\section{School of Marketing and International Business}
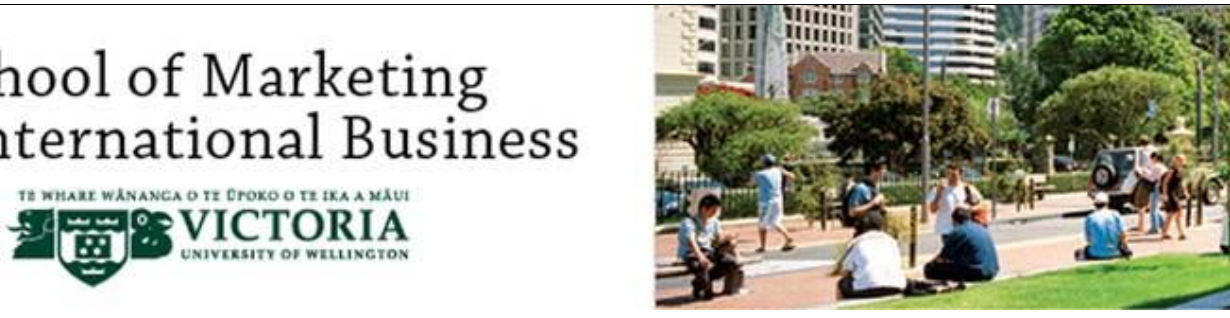

\section{Dear}

I recently sent you an email inviting you to respond to a survey for my PhD research. If you have already completed the survey, I would like to thank you very much for your contribution.

If you have not yet responded, it would be much appreciated if you could spend about 20 minutes to complete this survey, which for those who are in charge of foreign currency management.

The survey asks questions about factors that influence firms' choice of foreign currency management. Your response is very important in order for me to improve our understanding of critical success factors for managing foreign exchange risk.

The survey will be available for you to complete until Friday $18^{\text {th }}$ October 2013 . Please follow this link to take the Survey

\section{Start Survey}

Or copy and paste the URL below into your internet browser: http://vuw.qualtrics.com/SE/?SID=SV 4N1uTCP9joovNn7

I am happy to send you the results of this study if you would like to receive them. If you wish to confirm the authenticity of this survey you can contact me at vu.dang@vuw.ac.nz or any of my supervisors, Associate Prof Val Lindsay at ValerieLindsay@uowdubai.ac.ae, Dr Hongzhi Gao at hongzhi.gao@vuw.ac.nz or Dr Leigh Roberts at leigh.roberts@vuw.ac.nz.

Your name and email address were found on a business database. I sincerely apologise if it is incorrect. Please let me know if any details need to be changed. Kindly let me know if you are not interested in receiving this email. Many thanks.

Yours sincerely,

\section{Vu Hung Dang}

PhD Candidate

School of Marketing and International Business

Victoria University of Wellington

Room 130, Rutherford House, 23 Lambton Quay

Wellington 6104, New Zealand

Tel: +64 - 4 - 4635233 ext. 8655

Mobile: +64 - 220.718317

Email: vu.dang@vuw.ac.nz; danghungvu@gmail.com 


\section{Appendix I: Web-Based Survey Instrument}

School of Marketing and International Business

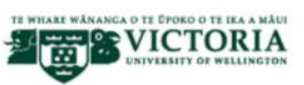

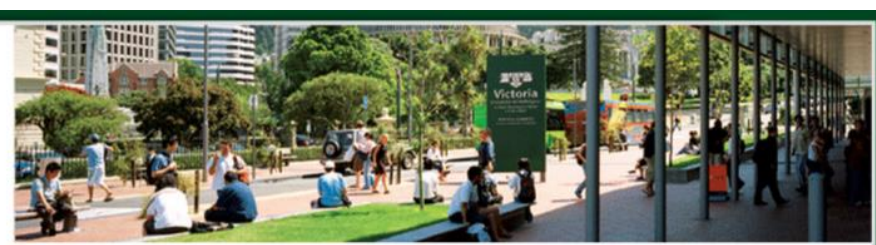

Welcome to the Survey on Foreign Exchange (Forex) Risk Management

In this questionnaire, the terms, "hedging" and "forex risk management" are used interchangeably. These refer to planning, organizing, directing, and controlling a firm's systems and resources for improving its ability to respond to forex rate changes.

The survey questions include your views on institutional factors, perceived foreign exchange risk, foreign exchange exposure, internationalization and hedging techniques. Please ensure that all questions are answered.

Victoria University ethics approval has been obtained for this research. Your answers are anonymous.

Please click NEXT to start the questionnaire.

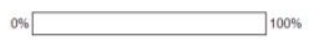

School of Marketing and International Business ㄴ.

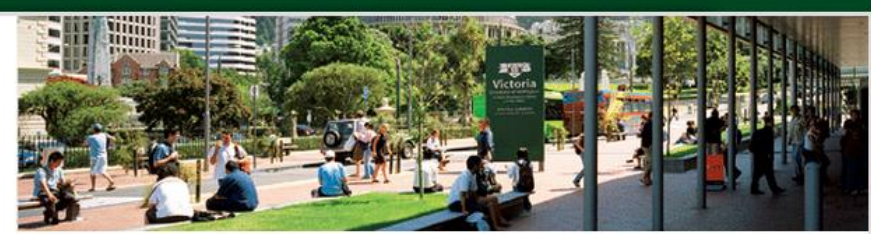

B. PERCEIVED FOREX RISK

Please indicate your response by choosing the appropriate answer that shows the extent to which you agree with following statements: $1=$ Strongly Disagree, $2=$ Disagree, $3=$ Neutral, $4=$ Agree, $5=$ Strongly Agree

We have a well-developed international strategic plan

We suffer losses due to changes in forex rates

Changes in forex rates affect the following aspects of our firm:

Firm's overall risk

Incomes, even if we do not have any foreign currency obligations or revenues:

Ability to specify export prices;

Ability to specify production volume

Decision to procure inputs domestically rather than from abroad:

Decision to either export or to sell our goods in the domestic market.

Please provide any additional information about these issues 
School of Marketing and International Business

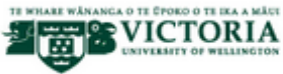

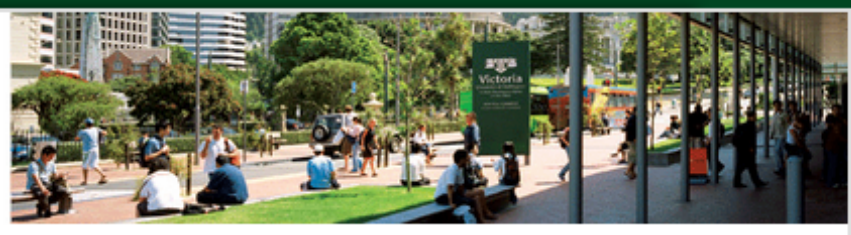

C. RESOURCES

Please indicate your response by choosing the appropriate answer that shows the extent to which you agree with following statements: 1 = Strongiy Disagree, 2 = Disagree, 3 = Neutral, 4 = Agree, 5 = Strongly Agree

We use imported items (e.g., products, services, materials, components

etc) for our business.

We have acoess to various sources of supply for our main inputs.

Our production capacity can meet market demands.

Techniques available to deal with forex risk are suitable for us.

There is sufficient information on how to find hedging solutions for exporting SMEs from the following sources:

Financial Consultants, e.g. bank representatives:

Educators

Business books;

Governmental bodies.

Our top management team has

Experience of exporting:

Experience of forex risk management;

Advanced degrees:

Attendance at specific training in forex risk management.

\begin{tabular}{|ccccc}
1 & 2 & 3 & 4 & 5 \\
\hline 0 & 0 & 0 & 0 & 0 \\
0 & 0 & 0 & 0 & 0 \\
0 & 0 & 0 & 0 & 0 \\
0 & 0 & 0 & 0 & 0
\end{tabular}

Managers ask employees for opinions about training for forex risk management.

Learning helps employees to overcome obstacles in their work on forex risk management.

Training for forex risk management is practical for employees.

We are provided with sufficient training for forex risk management.

Please provide any additional information about these issues 
School of Marketing and International Business

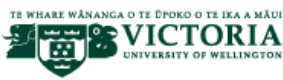

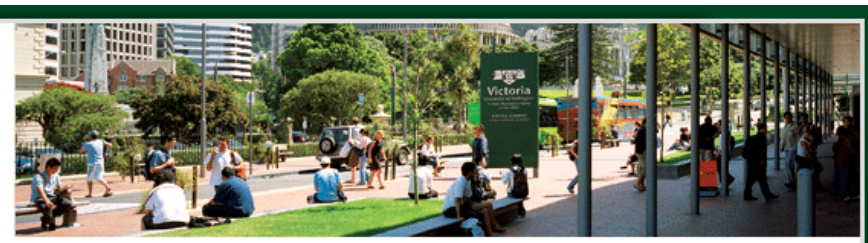

Please indicate your response by choosing the appropriate answer that shows the extent to which you agree with following statements: 1 = Strongly Disagree, 2 = Disagree, $3=$ Neutral, $4=$ Agree, 5 = Strongly Agree

In regard to forex risk management activities, employees have autonomy

to choose what hedging techniques to perform;

to decide the extent to which forex exposure is hedged;

to decide when to start hedging

Our firm has used the following support services:

Courses in forex risk management;

Training programmes of forex risk management,

Business advisory services (including bank services)

Forex market information.

Our expenditure on forex risk management is minor compared to other costs of doing business (e.g., production)

We have enough financial resources available to be devoted to forex risk management.

Please provide any additional information about these issues 
School of Marketing and International Business

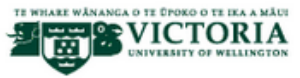

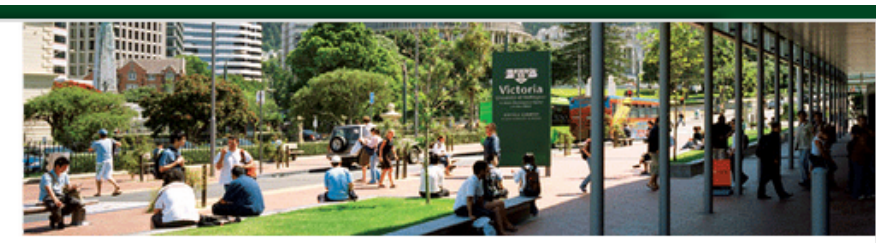

D. FOREX RISK MANAGEMENT

Please indicate your response by choosing the appropriate answer that shows how often you have used the following hedging techniques to manage forex risk:

$1=$ Never $; 2$ = Rarely; 3 = Occasionally; 4 = Frequently; 5 = Very Frequent $/ y$

Pricing goods that are exported in the following ways:

Domestic currency (NZD)

The currency in which the majority of the costs are incurred.

The domestic currency of the main competitors to eliminate the effect of exchange rate variations on comparative prices.

Hard and stable currencies (e.g., USD, EUR, and GBP) to avoid losses caused by

forex rate changes, no matter who or where the customers are.

Matching inflows (receivables denominated in foreign currency) and outflows
(payables denominated in foreign currency) with respect to timing of settlement

(payables denominated in foreign currency) with respect to timing of settlement.

Leading and lagging: expediting receipts or delaying payments of cash to gain an

advantage of forex rates.

Adjustment clause incorporated into a purchase and sale agreement to provide for an

adjustment to the transaction price in the event of changes in forex rates.

Currency derivatives (e.g., Forward, Futures, Options contracts)

Borrowing and lending foreign currencies to offset forex exposure caused by

receivables and payables in the same foreign currencies respectively.

Insurance policies

\begin{tabular}{|lllll}
1 & 2 & 3 & 4 & 5 \\
0 & 0 & 0 & 0 & 0 \\
0 & 0 & 0 & 0 & 0 \\
0 & 0 & 0 & 0 & 0 \\
0 & 0 & 0 & 0 & 0 \\
0 & 0 & 0 & 0 & 0
\end{tabular}

In total, approximately what percentage of forex exposure is covered by all the

Up to $20 \%$

Please provide any additional information about these issues 
School of Marketing and International Business

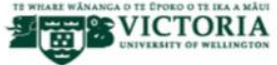

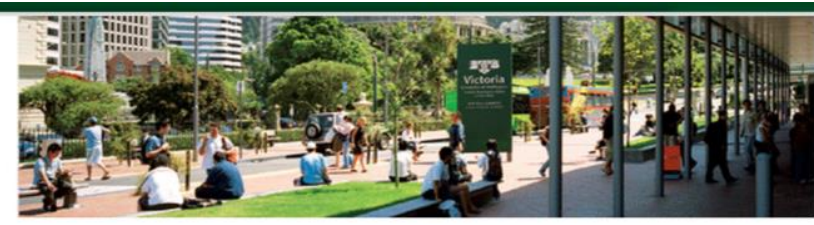

E. FOREX EXPOSURE

Please indicate your responses by choosing ONE appropriate box that shows the following ratios: The share of total revenue that is denominated in foreign currency The share of total cost that is denominated in foreign currency The share of total debt that is denominated in foreign currency Less than $21 \% \quad 21 \%-40 \%$ $41 \%-60 \%$ $61 \%-80 \%$ More than $80 \%$

Please indicate those who are responsible for managing forex risk for your business (Please tick ONE or MORE boxes)

$\square$ Our manager/s Bank or financial advisor/s $\square$ Accountant/s $\square$ Lawyer/s $\square$ others 
School of Marketing and International Business

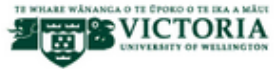

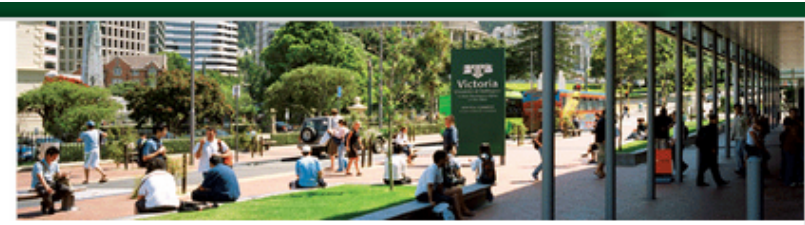

F. INTERNATIONALIZATION

Our main business is

-

We are

We are seen primarily as

\section{$\checkmark$}

Our firm imports products, services, materials, or components

Please indicate your responses by ticking ONE appropriate box that shows your export/ sales ratio

Please indicate all entry modes that your company has used since starting business

$\begin{array}{lll}\square \text { Export } & \square \text { Franchising } & \square \text { Turnkey projects } \\ \square \text { Licensing } & \square \text { Wholly owned subsidiaries } & \square \text { Strategic alliance }\end{array}$

Please indicate the number of countries in

which you are doing business (including

exporting, licensing, joint venture, and wholly

owned subsidiaries):

Please select the region(s) in which you are doing business.

$\square$ Europe $\square$ South/South East Asia

$\square$ North Asia

Middle East

Australia/ Pacifio

North America/ Caribbean

$\square$ Africa

$\square$ Latin America 
School of Marketing and International Business 蒌

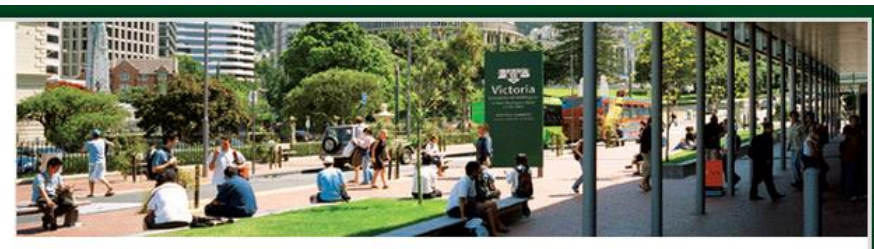

Among the selected region(s), please select the most important region.

$\checkmark$

Please describe the characteristics of your firm by providing the following information:

The foreign currency that is most frequently used in exporting

The foreign currency that is most frequently used

in importing

The number of your subsidiaries or branches in

New Zealand

The number of overseas subsidiaries

Years in business

Years in international business

The number of full-time equivalent (FTE) employees in New Zealand

The number of full-time equivalent (FTE)

employees outside New Zealand

The ratio of foreign assets to total assets

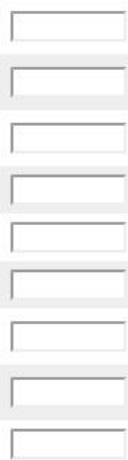

Do you have an international marketing department?

Yes

No 
School of Marketing and International Business :

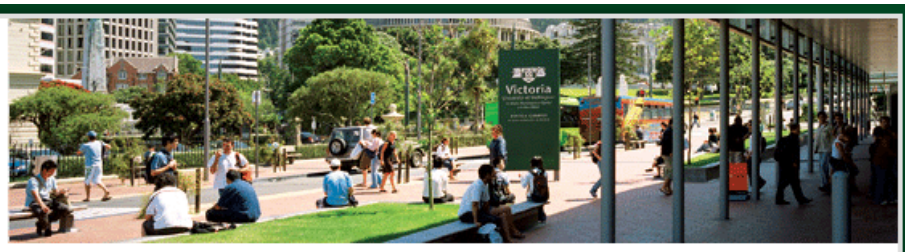

Please describe your financial features by providing the following information:

1. The ratio of current liabilities to current assets (as a percentage)

Current liabilities are obligations such as deferred dividends, trade credits, and unpaid taxes. Current assets include receivables, inventories, work in progress, or cash

(2.

2. The ratio of debts to total asset (as a percentage)

Debt includes all kind of liability/obligation such as bank loans, deferred dividends, trade credits, and unpaid taxes.

$+2$

3. Annual sales growth (as a percentage) - over the last twelve months

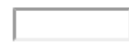

In regard to planning, accessing and utilizing financial capital for forex risk management, we use

$1=$ Never; 2 = Rarely; 3 = Occasionally; 4 = Frequently; $5=$ Very Frequently

Internally generated funds

Bank loans/ debts

Equity

Please provide any additional information about these issues

School of Marketing and International Business

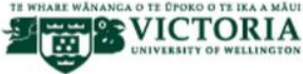

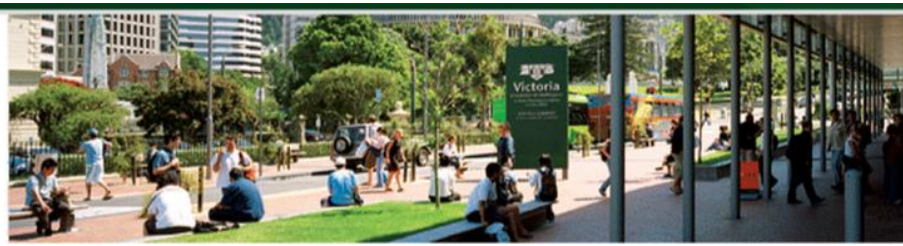

We thank you for your time spent taking this survey. Your response has been recorded.

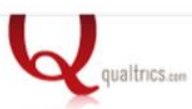

This survey was powered by Qualtrics

Would you like to use Qualtrics to conduct your own survey? Sign Up Free 


\section{Appendix J: Independent Samples Test}

\begin{tabular}{|c|c|c|c|c|c|c|c|c|}
\hline & \multicolumn{2}{|c|}{$\begin{array}{c}\text { Levene's } \\
\text { Test for } \\
\text { Equality of } \\
\text { Variances }\end{array}$} & \multicolumn{4}{|c|}{ t-test for Equality of Means } \\
\hline & & & $\mathrm{F}$ & Sig. & $\mathrm{t}$ & df & $\begin{array}{c}\text { Sig. } \\
\text { (2-tailed) }\end{array}$ & $\begin{array}{c}\text { Mean } \\
\text { Difference }\end{array}$ \\
\hline \multirow{2}{*}{1} & \multirow{2}{*}{$\begin{array}{l}\text { Loss due to forex } \\
\text { rate fluctuation }\end{array}$} & EVA & 0.323 & 0.57 & -0.6 & 175 & 0.547 & \\
\hline & & EVNA & & & -0.57 & 48.61 & 0.573 & \\
\hline \multirow{2}{*}{2} & \multirow[t]{2}{*}{ Overall risk } & EVA & 0.846 & 0.36 & -2.07 & 175 & 0.040 & Yes \\
\hline & & EVNA & & & -1.98 & 49.36 & 0.054 & \\
\hline \multirow{2}{*}{3} & \multirow[t]{2}{*}{ Incomes } & EVA & 0.283 & 0.6 & -0.77 & 175 & 0.442 & \\
\hline & & EVNA & & & -0.85 & 58.93 & 0.402 & \\
\hline \multirow{2}{*}{4} & \multirow[t]{2}{*}{ Export Prices } & EVA & 5.788 & 0.02 & 2.228 & 175 & 0.027 & \\
\hline & & EVNA & & & 2.566 & 63.7 & 0.013 & Yes \\
\hline \multirow{2}{*}{5} & \multirow[t]{2}{*}{ Production Volume } & EVA & 0.082 & 0.78 & 1.857 & 175 & 0.065 & \\
\hline & & EVNA & & & 1.869 & 52.48 & 0.067 & \\
\hline \multirow{2}{*}{6} & \multirow[t]{2}{*}{ Domestic Input } & EVA & 0.511 & 0.48 & 0.896 & 175 & 0.372 & \\
\hline & & EVNA & & & 0.961 & 57.07 & 0.341 & \\
\hline \multirow{2}{*}{7} & \multirow[t]{2}{*}{ Decision to Export } & EVA & 0.816 & 0.37 & 1.358 & 175 & 0.176 & \\
\hline & & EVNA & & & 1.267 & 48.21 & 0.211 & \\
\hline \multirow{2}{*}{8} & \multirow{2}{*}{ Imported Items } & EVA & 11.31 & 0 & 1.014 & 175 & 0.312 & \\
\hline & & EVNA & & & 1.216 & 68.38 & 0.228 & \\
\hline \multirow{2}{*}{9} & \multirow{2}{*}{ Sources of Supply } & EVA & 9.671 & 0 & 1.21 & 175 & 0.228 & \\
\hline & & EVNA & & & 1.431 & 66.68 & 0.157 & \\
\hline \multirow{2}{*}{10} & \multirow{2}{*}{ Production Capacity } & EVA & 5.61 & 0.02 & 0.218 & 175 & 0.828 & \\
\hline & & EVNA & & & 0.262 & 69.16 & 0.794 & \\
\hline \multirow{2}{*}{11} & \multirow{2}{*}{ Hedging Techniques } & EVA & 0.024 & 0.88 & -0.84 & 175 & 0.403 & \\
\hline & & EVNA & & & -0.84 & 52 & 0.406 & \\
\hline \multirow{2}{*}{12} & \multirow{2}{*}{$\begin{array}{l}\text { Financial } \\
\text { Consultants }\end{array}$} & EVA & 0.05 & 0.82 & -1.99 & 175 & 0.048 & Yes \\
\hline & & EVNA & & & -2.12 & 56.23 & 0.039 & \\
\hline \multirow{2}{*}{13} & Eduroton & EVA & 0.147 & 0.7 & -0.47 & 175 & 0.637 & \\
\hline & Equcators & EVNA & & & -0.48 & 53.17 & 0.633 & \\
\hline 14 & During Dolk & EVA & 2.681 & 0.1 & -1.49 & 175 & 0.137 & \\
\hline 14 & Busıness Books & EVNA & & & -1.72 & 63.38 & 0.091 & \\
\hline 15 & Governmental & EVA & 0.07 & 0.79 & -1.29 & 175 & 0.2 & \\
\hline 15 & Bodies & EVNA & & & -1.3 & 52.83 & 0.199 & \\
\hline 16 & Experience of & EVA & 1.787 & 0.18 & -2.1 & 175 & 0.037 & Yes \\
\hline 10 & Exporting & EVNA & & & -2.31 & 59.18 & 0.025 & \\
\hline
\end{tabular}




\begin{tabular}{|c|c|c|c|c|c|c|c|c|}
\hline \multirow{2}{*}{17} & \multirow{2}{*}{$\begin{array}{l}\text { Experience of Forex } \\
\text { Risk Management }\end{array}$} & EVA & 0.127 & 0.72 & -1.87 & 175 & 0.064 & \\
\hline & & EVNA & & & -1.98 & 56.31 & 0.052 & \\
\hline \multirow{2}{*}{18} & \multirow{2}{*}{ Advanced Degrees } & EVA & 0.748 & 0.39 & -0.53 & 175 & 0.598 & \\
\hline & & EVNA & & & -0.57 & 57.16 & 0.573 & \\
\hline \multirow{2}{*}{19} & \multirow{2}{*}{$\begin{array}{l}\text { Training in Forex } \\
\text { Risk Management }\end{array}$} & EVA & 3.192 & 0.08 & -1.37 & 175 & 0.174 & \\
\hline & & EVNA & & & -1.57 & 63.68 & 0.121 & \\
\hline \multirow{2}{*}{20} & \multirow{2}{*}{$\begin{array}{l}\text { Personnel for forex } \\
\text { risk management }\end{array}$} & EVA & 0.512 & 0.48 & -3.15 & 175 & 0.002 & Yes \\
\hline & & EVNA & & & -3.1 & 51.02 & 0.003 & \\
\hline \multirow[b]{2}{*}{21} & \multirow{2}{*}{$\begin{array}{l}\text { Easy to perform our } \\
\text { forex risk } \\
\text { management } \\
\text { activities }\end{array}$} & EVA & 0.008 & 0.93 & -1.41 & 175 & 0.159 & \\
\hline & & EVNA & & & -1.38 & 50.42 & 0.175 & \\
\hline \multirow{2}{*}{22} & \multirow{2}{*}{$\begin{array}{l}\text { Managers ask } \\
\text { employees about } \\
\text { training }\end{array}$} & EVA & 0.529 & 0.47 & 0.429 & 175 & 0.669 & \\
\hline & & EVNA & & & 0.43 & 52.2 & 0.669 & \\
\hline \multirow{2}{*}{23} & \multirow{2}{*}{$\begin{array}{l}\text { Learning helps } \\
\text { employees to } \\
\text { overcome obstacles }\end{array}$} & EVA & 0.002 & 0.97 & 0.449 & 175 & 0.654 & \\
\hline & & EVNA & & & 0.448 & 51.95 & 0.656 & \\
\hline \multirow{2}{*}{24} & \multirow{2}{*}{$\begin{array}{l}\text { Training is practical } \\
\text { for employees }\end{array}$} & EVA & 0.13 & 0.72 & -0.73 & 175 & 0.466 & \\
\hline & & EVNA & & & -0.71 & 50.4 & 0.481 & \\
\hline \multirow{2}{*}{25} & \multirow{2}{*}{$\begin{array}{l}\text { Sufficient training } \\
\text { for forex risk } \\
\text { management }\end{array}$} & EVA & 0.165 & 0.69 & -0.47 & 175 & 0.638 & \\
\hline & & EVNA & & & -0.47 & 51.73 & 0.641 & \\
\hline \multirow{2}{*}{26} & \multirow{2}{*}{$\begin{array}{l}\text { Autonomy to choose } \\
\text { what hedging } \\
\text { techniques to } \\
\text { perform }\end{array}$} & EVA & 13.21 & 0 & -1.64 & 175 & 0.103 & \\
\hline & & EVNA & & & -1.93 & 66.19 & 0.058 & \\
\hline \multirow[t]{2}{*}{27} & \multirow{2}{*}{$\begin{array}{l}\text { Autonomy to decide } \\
\text { the extent to which } \\
\text { forex exposure is } \\
\text { hedged }\end{array}$} & EVA & 4.566 & 0.03 & -1.34 & 175 & 0.181 & \\
\hline & & EVNA & & & -1.47 & 58.87 & 0.146 & \\
\hline \multirow{2}{*}{28} & \multirow{2}{*}{$\begin{array}{l}\text { Autonomy to decide } \\
\text { when to start } \\
\text { hedging }\end{array}$} & EVA & 3.166 & 0.08 & -0.66 & 175 & 0.512 & \\
\hline & & EVNA & & & -0.72 & 58.76 & 0.475 & \\
\hline \multirow{2}{*}{29} & \multirow{2}{*}{ Courses } & EVA & 0.01 & 0.92 & -0.16 & 175 & 0.871 & \\
\hline & & EVNA & & & -0.16 & 51.22 & 0.873 & \\
\hline \multirow{2}{*}{30} & \multirow{2}{*}{ Training programs } & EVA & 0.811 & 0.37 & -0.67 & 175 & 0.503 & \\
\hline & & EVNA & & & -0.68 & 53.27 & 0.497 & \\
\hline 21 & Business advisory & EVA & 0.019 & 0.89 & -0.56 & 175 & 0.579 & \\
\hline 31 & services & EVNA & & & -0.56 & 52.22 & 0.58 & \\
\hline & Forex market & EVA & 1.021 & 0.31 & 0.092 & 175 & 0.927 & \\
\hline 32 & information & EVNA & & & 0.098 & 56.38 & 0.922 & \\
\hline & Expenditure on forex & EVA & 2.748 & 0.1 & -0.55 & 175 & 0.584 & \\
\hline 33 & & EVNA & & & -0.51 & 47.56 & 0.615 & \\
\hline
\end{tabular}




\begin{tabular}{|c|c|c|c|c|c|c|c|c|}
\hline 34 & $\begin{array}{l}\text { Financial resources } \\
\text { available to forex } \\
\text { risk management }\end{array}$ & $\begin{array}{l}\text { EVA } \\
\text { EVNA }\end{array}$ & 3.575 & 0.06 & $\begin{array}{r}-1.81 \\
-1.68\end{array}$ & $\begin{array}{r}175 \\
47.96\end{array}$ & $\begin{array}{r}0.073 \\
0.1\end{array}$ & \\
\hline \multirow{2}{*}{35} & \multirow{2}{*}{$\begin{array}{l}\text { Internally generated } \\
\text { funds }\end{array}$} & EVA & 0.203 & 0.65 & -0.1 & 175 & 0.918 & \\
\hline & & EVNA & & & -0.1 & 49.97 & 0.921 & \\
\hline \multirow{2}{*}{36} & \multirow{2}{*}{ Bank loans/debts } & EVA & 0.04 & 0.84 & -0.44 & 175 & 0.658 & \\
\hline & & EVNA & & & -0.43 & 50.82 & 0.666 & \\
\hline \multirow{2}{*}{37} & \multirow{2}{*}{ Equity } & EVA & 1.828 & 0.18 & -1.13 & 175 & 0.258 & \\
\hline & & EVNA & & & -1.2 & 55.74 & 0.237 & \\
\hline \multirow{2}{*}{38} & \multirow{2}{*}{ Domestic currency } & EVA & 4.345 & 0.04 & 3.985 & 175 & 0 & \\
\hline & & EVNA & & & 4.319 & 57.94 & 0 & Yes \\
\hline \multirow{2}{*}{39} & \multirow{2}{*}{$\begin{array}{l}\text { Currency of incurred } \\
\text { cost }\end{array}$} & EVA & 7.299 & 0.01 & 0.799 & 175 & 0.425 & \\
\hline & & EVNA & & & 0.936 & 65.6 & 0.353 & \\
\hline \multirow{2}{*}{40} & \multirow{2}{*}{$\begin{array}{l}\text { Currency of the main } \\
\text { competitors }\end{array}$} & EVA & 21.5 & 0 & -2.08 & 175 & 0.039 & \\
\hline & & EVNA & & & -2.75 & 83.76 & 0.007 & Yes \\
\hline \multirow{2}{*}{41} & \multirow{2}{*}{$\begin{array}{l}\text { Hard and stable } \\
\text { currencies }\end{array}$} & EVA & 0.698 & 0.41 & -1.14 & 175 & 0.255 & \\
\hline & & EVNA & & & -1.23 & 57.32 & 0.224 & \\
\hline \multirow{2}{*}{42} & \multirow{2}{*}{$\begin{array}{l}\text { Matching inflows } \\
\text { and outflows }\end{array}$} & EVA & 0.018 & 0.89 & 0.376 & 175 & 0.708 & \\
\hline & & EVNA & & & 0.375 & 52.05 & 0.709 & \\
\hline \multirow{2}{*}{43} & \multirow{2}{*}{ Leading and lagging } & EVA & 1.599 & 0.21 & 1.445 & 175 & 0.15 & \\
\hline & & EVNA & & & 1.525 & 55.78 & 0.133 & \\
\hline \multirow{2}{*}{44} & \multirow{2}{*}{ Adjustment clause } & EVA & 0.777 & 0.38 & 2.56 & 175 & 0.011 & Yes \\
\hline & & EVNA & & & 2.544 & 51.67 & 0.014 & \\
\hline \multirow{2}{*}{45} & \multirow{2}{*}{ Currency derivatives } & EVA & 6.511 & 0.01 & -0.17 & 175 & 0.862 & \\
\hline & & EVNA & & & -0.2 & 63.26 & 0.842 & \\
\hline \multirow{2}{*}{46} & \multirow{2}{*}{$\begin{array}{l}\text { Borrowing and } \\
\text { lending FC }\end{array}$} & EVA & 0.895 & 0.35 & 1.67 & 175 & 0.097 & \\
\hline & & EVNA & & & 1.723 & 54.16 & 0.091 & \\
\hline \multirow{2}{*}{47} & \multirow{2}{*}{ Insurance policies } & EVA & 0.052 & 0.82 & 2.604 & 175 & 0.01 & Yes \\
\hline & & EVNA & & & 2.376 & 47.13 & 0.022 & \\
\hline 48 & Share of total foreign & EVA & 13.83 & 0 & -3.99 & 175 & 0 & \\
\hline 40 & currency revenue & EVNA & & & -4.84 & 69.84 & 0 & Yes \\
\hline 49 & Share of total foreign & EVA & 0.072 & 0.79 & -0.24 & 175 & 0.812 & \\
\hline 49 & currency cost & EVNA & & & -0.24 & 52.35 & 0.812 & \\
\hline 50 & Share of total foreign & EVA & 9.563 & 0 & -1.62 & 175 & 0.106 & \\
\hline 30 & currency debt & EVNA & & & -2.15 & 84.23 & 0.034 & Yes \\
\hline 51 & Fynort/Solec rotio & EVA & 0.388 & 0.53 & -3.48 & 175 & 0.001 & Yes \\
\hline 31 & Exportsates ratio & EVNA & & & -3.07 & 45.76 & 0.004 & \\
\hline & & EVA & 0.04 & 0.84 & 0.266 & 175 & 0.791 & \\
\hline 52 & $\begin{array}{l}\text { Number of Entry } \\
\text { Modes }\end{array}$ & EVNA & & & 0.26 & 50.79 & 0.796 & \\
\hline
\end{tabular}




\begin{tabular}{|c|c|c|c|c|c|c|c|}
\hline \multirow{2}{*}{53} & \multirow{2}{*}{$\begin{array}{l}\text { Number of countries } \\
\text { in which you are } \\
\text { doing business }\end{array}$} & EVA & 8.858 & 0 & 0.038 & 175 & 0.97 \\
\hline & & EVNA & & & 0.047 & 71.77 & 0.963 \\
\hline \multirow{2}{*}{54} & \multirow{2}{*}{$\begin{array}{l}\text { Number of exporting } \\
\text { regions }\end{array}$} & EVA & 6.349 & 0.01 & -0.08 & 175 & 0.935 \\
\hline & & EVNA & & & -0.09 & 64.87 & 0.925 \\
\hline \multirow{2}{*}{55} & \multirow{2}{*}{$\begin{array}{l}\text { Overseas } \\
\text { subsidiaries }\end{array}$} & EVA & 0.163 & 0.69 & -0.2 & 175 & 0.844 \\
\hline & & EVNA & & & -0.2 & 52.29 & 0.844 \\
\hline \multirow{2}{*}{56} & \multirow{2}{*}{$\begin{array}{l}\text { Years in } \\
\text { international } \\
\text { business }\end{array}$} & EVA & 0.065 & 0.8 & 1.655 & 175 & 0.1 \\
\hline & & EVNA & & & 1.609 & 50.38 & 0.114 \\
\hline \multirow{2}{*}{57} & \multirow{2}{*}{ Overseas Employees } & EVA & 2.711 & 0.1 & -0.71 & 175 & 0.48 \\
\hline & & EVNA & & & -0.72 & 53 & 0.476 \\
\hline \multirow{2}{*}{58} & \multirow{2}{*}{$\begin{array}{l}\text { International } \\
\text { Marketing Dept. }\end{array}$} & EVA & 0.847 & 0.36 & -0.43 & 175 & 0.665 \\
\hline & & EVNA & & & -0.44 & 53.02 & 0.662 \\
\hline \multirow{2}{*}{59} & \multirow{2}{*}{$\begin{array}{l}\text { International } \\
\text { strategic plan }\end{array}$} & EVA & 0.219 & 0.64 & -1.34 & 175 & 0.184 \\
\hline & & EVNA & & & -1.36 & 53.39 & 0.179 \\
\hline \multirow{2}{*}{60} & \multirow{2}{*}{$\begin{array}{l}\text { Foreign assets to } \\
\text { total assets }\end{array}$} & EVA & 11.39 & 0 & -1.32 & 175 & 0.19 \\
\hline & & EVNA & & & -1.36 & 54.3 & 0.179 \\
\hline \multirow{2}{*}{61} & \multirow{2}{*}{ Hedging Degree } & EVA & 0.17 & 0.68 & 1.802 & 175 & 0.073 \\
\hline & & EVNA & & & 1.875 & 54.74 & 0.066 \\
\hline \multirow{2}{*}{62} & \multirow{2}{*}{$\begin{array}{l}\text { Internal Hedging } \\
\text { Technique }\end{array}$} & EVA & 2.458 & 0.12 & -1.28 & 175 & 0.203 \\
\hline & & EVNA & & & -1.49 & 65.14 & 0.141 \\
\hline
\end{tabular}


Appendix K: Multi-Group Test

\begin{tabular}{|c|c|c|c|c|c|c|c|}
\hline & & & \multicolumn{2}{|c|}{$\begin{array}{c}\text { No Overseas } \\
\text { Subsidiary }\end{array}$} & \multicolumn{2}{|c|}{ Overseas Subsidiary } & \\
\hline & & & Estimate & $\mathrm{P}$ & Estimate & $\mathrm{P}$ & z-score \\
\hline PFR & $<--$ & DOI & 0.120 & 0.044 & -0.024 & 0.737 & -1.535 \\
\hline RES_OT & $<--$ & PFR & 0.597 & 0.000 & 0.453 & 0.124 & -0.441 \\
\hline FXE_1 & $<--$ & DOI & 1.022 & 0.000 & 1.469 & 0.000 & $2.275^{* *}$ \\
\hline RES_H & $<---$ & RES_OT & 0.092 & 0.088 & 0.558 & 0.089 & 1.402 \\
\hline RES_H & $<--$ & FXE_1 & 0.060 & 0.015 & 0.072 & 0.056 & 0.264 \\
\hline HGT & $<--$ & RES_H & 0.064 & 0.010 & -0.008 & 0.777 & $-1.921 *$ \\
\hline HGD & $<--$ & RES_OT & 0.287 & 0.006 & 0.574 & 0.170 & 0.667 \\
\hline HGD & $<--$ & PFR & 0.199 & 0.079 & 0.286 & 0.341 & 0.271 \\
\hline HGT & $<--$ & PFR & 0.016 & 0.229 & 0.093 & 0.067 & 1.470 \\
\hline RES_OT2 & $<--$ & RES_OT & 1.121 & 0.000 & 2.677 & 0.023 & 1.311 \\
\hline RES_H2 & $<--$ & RES_H & 2.564 & 0.000 & 1.932 & 0.000 & -1.039 \\
\hline RES_H5 & $<--$ & RES_H & 1.140 & 0.000 & 1.689 & 0.000 & 1.042 \\
\hline PFR_5 & $<---$ & PFR & 1.526 & 0.000 & 1.878 & 0.030 & 0.392 \\
\hline PFR_4 & $<--$ & PFR & 1.283 & 0.000 & 2.620 & 0.028 & 1.101 \\
\hline \multirow[t]{3}{*}{ RES_OT3 } & $<--$ & RES_OT & 1.198 & 0.000 & 3.010 & 0.023 & 1.359 \\
\hline & & & \multicolumn{2}{|c|}{$\begin{array}{l}\text { No Overseas } \\
\text { Employees }\end{array}$} & \multicolumn{2}{|c|}{ Overseas Employees } & \\
\hline & & & Estimate & $P$ & Estimate & $P$ & z-score \\
\hline PFR & <--- & DOI & 0.110 & 0.080 & 0.034 & 0.669 & -0.741 \\
\hline RES_OT & $<--$ & PFR & 0.621 & 0.000 & 0.388 & 0.054 & -0.908 \\
\hline FXE_1 & $<--$ & DOI & 0.940 & 0.000 & 1.543 & 0.000 & $3.19 * * *$ \\
\hline RES_H & $<--$ & RES_OT & 0.087 & 0.132 & 0.453 & 0.047 & 1.556 \\
\hline RES_H & $<--$ & FXE_1 & 0.052 & 0.054 & 0.076 & 0.018 & 0.560 \\
\hline HGT & $<--$ & RES_H & 0.063 & 0.025 & 0.009 & 0.690 & -1.453 \\
\hline HGD & $<--$ & RES_OT & 0.300 & 0.009 & 0.425 & 0.135 & 0.406 \\
\hline HGD & $<---$ & PFR & 0.204 & 0.111 & 0.225 & 0.262 & 0.087 \\
\hline HGT & $<--$ & PFR & 0.018 & 0.225 & 0.066 & 0.028 & 1.427 \\
\hline RES_OT2 & $<--$ & RES_OT & 1.202 & 0.000 & 2.019 & 0.006 & 1.092 \\
\hline RES_H2 & $<--$ & RES_H & 2.681 & 0.000 & 1.823 & 0.000 & -1.359 \\
\hline RES_H5 & $<--$ & RES_H & 1.217 & 0.000 & 1.439 & 0.000 & 0.469 \\
\hline PFR_5 & $<--$ & PFR & 1.558 & 0.000 & 1.649 & 0.003 & 0.148 \\
\hline PFR_4 & $<--$ & PFR & 1.399 & 0.000 & 1.815 & 0.003 & 0.636 \\
\hline \multirow[t]{3}{*}{ RES_OT3 } & $<--$ & RES_OT & 1.268 & 0.000 & 2.276 & 0.006 & 1.197 \\
\hline & & & \multicolumn{2}{|c|}{ No Foreign Assets } & \multicolumn{2}{|c|}{ Foreign Assets } & \\
\hline & & & Estimate & $\mathrm{P}$ & Estimate & $\mathrm{P}$ & z-score \\
\hline PFR & $<--$ & DOI & 0.151 & 0.023 & -0.023 & 0.747 & $-1.772 *$ \\
\hline RES_OT & $<--$ & PFR & 0.556 & 0.000 & 0.567 & 0.023 & 0.037 \\
\hline FXE_1 & $<--$ & $\mathrm{DOI}$ & 0.962 & 0.000 & 1.457 & 0.000 & $2.737 * * *$ \\
\hline RES_H & $<--$ & RES_OT & 0.085 & 0.155 & 0.298 & 0.047 & 1.320 \\
\hline
\end{tabular}




\begin{tabular}{|r|r|r|r|r|r|r|r|}
\hline RES_H & $<---$ & FXE_1 & 0.065 & 0.021 & 0.051 & 0.091 & -0.349 \\
\hline HGT & $<---$ & RES_H & 0.061 & 0.023 & 0.022 & 0.391 & -1.035 \\
\hline HGD & $<---$ & RES_OT & 0.304 & 0.007 & 0.316 & 0.190 & 0.048 \\
\hline HGD & $<---$ & PFR & 0.217 & 0.069 & 0.308 & 0.189 & 0.348 \\
\hline HGT & $<---$ & PFR & 0.007 & 0.630 & 0.080 & 0.015 & $2.028^{* *}$ \\
\hline RES_OT2 & $<---$ & RES_OT & 1.154 & 0.000 & 1.912 & 0.000 & 1.349 \\
\hline RES_H2 & $<---$ & RES_H & 2.558 & 0.000 & 2.119 & 0.000 & -0.675 \\
\hline RES_H5 & $<---$ & RES_H & 1.243 & 0.000 & 1.420 & 0.000 & 0.349 \\
\hline PFR_5 & $<---$ & PFR & 1.504 & 0.000 & 1.687 & 0.002 & 0.300 \\
\hline PFR_4 & $<---$ & PFR & 1.230 & 0.000 & 2.189 & 0.002 & 1.293 \\
\hline RES_OT3 & $<---$ & RES_OT & 1.265 & 0.000 & 1.928 & 0.000 & 1.155 \\
\hline
\end{tabular}

